\title{
Lanthanum Chromite Based Perovskites for Oxygen Transport Membrane
}

\author{
Sapna Gupta*, Manoj K. Mahapatra* and Prabhakar Singh ${ }^{\#}$ \\ Center for Clean Energy Engineering, Materials Science and Engineering, University of \\ Connecticut, 44 Weaver Road, Storrs, CT 06269, USA
}

\begin{abstract}
Judicious selection of mixed ionic-electronic conducting (MIEC) perovskite oxide as oxygen transport membrane (OTM) offers the potential to enhance overall process economics and systems performance for a wide variety of industrial applications ranging from clean and efficient energy conversion (oxy-combustion) to selective gas separation (high purity oxygen production) and value added chemicals (syngas and liquid fuel) production with near-zero greenhouse gas emissions. Doped lanthanum chromite perovskites have been considered as promising material of choice for oxygen transport membrane (OTM) due to their superior thermo-chemical stability in aggressive environment $\left(800-1000^{\circ} \mathrm{C}, 0.21-10^{-20} \mathrm{P}_{\mathrm{O}_{2}}\right)$ than the other mixed ionic- electronic conducting (MIEC) perovskites such as ferrites and cobaltite's. Thermo-physical properties of the lanthanum chromite, required for optimum oxygen transport can be tuned by modifying the crystal structure, chemical
\end{abstract}

*Equal contribution

\#Corresponding author at: Address: University of Connecticut, Center for Clean Energy Engineering, 44 Weaver Road, Storrs, CT 06269-5233, United States, Tel.: +1 860486 8379. Email address: $\underline{\text { singh@engr.uconn.edu }}$ 
bonding, and ionic and electronic transport properties through selection of dopant's type and level. A perspective on the development of lanthanum chromite-based oxygen transport membranes is presented with an insight based on the pertinent literature and data analysis. The role of various A- and B-site dopants on the crystal structure, densification, thermal expansion, electrical transport, oxygen permeation, mechanical properties, and thermochemical stability of lanthanum chromite is discussed to enlighten 'composition-structure-property' correlations. It has been found that; the preferred dopants are strontium at A-site and manganese, nickel, iron, and titanium at B-site to obtain the desired thermo-chemo-electro-mechano properties. Challenges for long term performance and structural stability of doped lanthanum chromite as an oxygen transport membrane are outlined for the applications under 'real system' exposure conditions.

Keywords: Lanthanum chromite, Oxygen transport membrane, Perovskites, Mixed ionicelectronic conductor, Stability, and 'Chemistry-Structure-Property' relationships. 


\section{Contents}

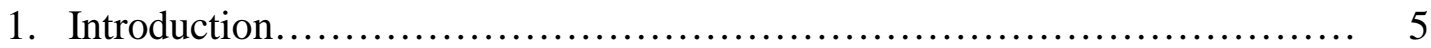

2. Materials for oxygen transport membrane $(\mathrm{OTM}) \ldots \ldots \ldots \ldots \ldots \ldots \ldots \ldots \ldots \ldots \ldots \ldots \ldots$

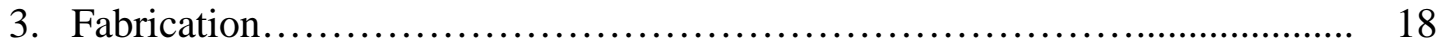

3.1 Fabrication Techniques......................................... 18

3.1.1 Wet chemical methods.............................. 20

3.1.2 Plasma spraying technique......................... 21

3.1.3 Physical vapor deposition (PVD) $\ldots \ldots \ldots \ldots \ldots \ldots \ldots \ldots \ldots, 22$

3.1.4 Chemical vapor deposition (CVD)................... 22

4. Lanthanum chromite $\left(\mathrm{LaCrO}_{3}\right)$ based perovskites for OTM................ 23

4.1 Crystal structure and phase transition.............................. 27

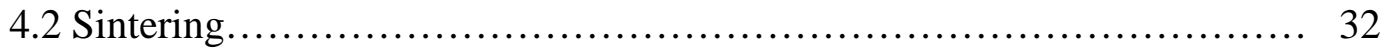

4.2.1 Role of dopants..................................... 33

4.2.1.1 A-site dopants............................... 34

4.2.1.2 A and B-site dopants...................... 36

4.3 Oxygen non-stoichiometry................................... 38

4.3.1 A-site dopants.................................. 39 
4.3.2 B-site dopants.................................. 40

4.3.3 A and B-site dopants............................. 41

4.4 Thermal expansion.......................................... 44

4.4.1 A-site dopants................................... 46

4.4.2 A and B-site dopants............................ 47

4.5 Electrical conductivity.................................... 50

4.5.1 A-site dopants.................................... 51

4.5.2 $\mathrm{A}$ and B-site dopants............................. 53

4.6 Mechanical behavior........................................ 56

4.7 Oxygen flux/permeation....................................... 61

4.8 Chemical stability......................................... 67

4.8.1 Bulk stability $\ldots \ldots \ldots \ldots \ldots \ldots \ldots \ldots \ldots \ldots \ldots \ldots \ldots \ldots \ldots .68$

4.8.1.1 A-site.................................... 68

4.8.1.2 $\mathrm{A}$ and B-site............................... 70

4.8.2 Surface segregation............................. 71

4.8 .3 Interface stability............................... 72 


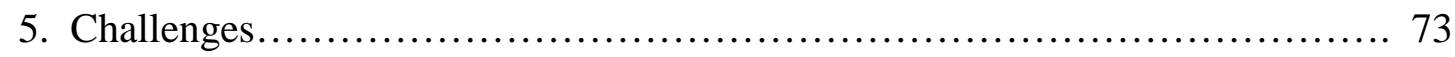

6. Summary..................................................... 76

Acknowledgements...................................................... 79

References..................................................... 80

\section{Introduction}

Oxygen transport membrane offers potential for applications in a wide variety of industrial processes ranging from high purity oxygen separation from air to oxycombustion of carbonaceous and hydrocarbon fuels as well as production of syngas for subsequent conversion to liquid fuels and hydrogen. Efficient and clean oxy-combustion of fossil fuels enable reduction of greenhouse gas emissions responsible for global climate change $[1,2]$. In the oxy-fuel combustion process, oxygen is separated from air 
and exclusively used for the fuel combustion unlike conventional combustion process where air is used as an oxidant. Use of oxygen results in significant increase in the process efficiency resulting in decrease in fuel consumption, heat loss, reduction in the size of the flue gas and $\mathrm{NO}_{\mathrm{x}}$ emissions treatment. The replacement of air to oxygen in the natural-gas fired furnaces, for example, reduced the fuel consumption and $\mathrm{NO}_{\mathrm{x}}$ emissions from $15 \%$ to $50 \%$ and from $50 \%$ to $90 \%$ respectively [1]. The flue gas after oxycombustion predominantly consists of $\mathrm{CO}_{2}$ and steam. After condensation of steam through cooling, the available $\mathrm{CO}_{2}$ gas is easily captured, stored, and/or used for chemical production by well-established industrial technologies. Higher flame stability, better heat transfer characteristics, reduced gas volume and lower particulate emissions are other advantages of the oxy-fuel combustion process [2].

For oxy-combustion, it is to be noted that high purity oxygen makes a difference not only by reducing the harmful gas emissions (e.g. $\mathrm{NO}_{\mathrm{x}}$ and $\mathrm{SO}_{\mathrm{x}}$ ) but also, it is important for $\mathrm{CO}_{2}$ capture from the flue gas $[3,4]$. This is because, the $\mathrm{CO}_{2}$ purity level in the flue gas decreases with decrease in $\mathrm{O}_{2}$ purity level. Lower purity oxygen containing impurities (e.g. nitrogen) are amenable to forming $\mathrm{NO}_{\mathrm{x}}$ as a combustion product, and be present with others $\left(\mathrm{SO}_{\mathrm{x}}, \mathrm{Ar}, \mathrm{N}_{2}\right.$ etc. $)$ in the flue gas. Lower purity oxygen used in oxycombustion process is also considered detrimental to compression and liquefaction processes commonly used for the transportation of $\mathrm{CO}_{2}$. Large scale conventional transportation process for transporting $\mathrm{CO}_{2}$ includes the use of gas pipelines, ships and vessels. For such processes, it is required to compress $\mathrm{CO}_{2}$ to supercritical state $(\sim 80-150$ bar) for pipeline transport. On the other hand, $\mathrm{CO}_{2}$ needs to be liquefied $(\sim 6.5$ bar and - 
$51^{\circ} \mathrm{C}$ ) for ship transport [4]. It is often found difficult to compress as well as liquefy the $\mathrm{CO}_{2}$ gas stream if the impurities level is high (approximately greater than 4\%) [4]. The impurities present in the post combustion $\mathrm{CO}_{2}$ gas stream as well as compressed gas stream can also cause corrosion when introduced into the pipeline [3,4]. The presence of inerts constituents (e.g. $\mathrm{N}_{2}$, Ar, He etc.) in the gas stream is also required to be removed and controlled as it can also increase the critical pressure of $\mathrm{CO}_{2}$ in the pipeline [3]. Gas conditioning (a sub-system to remove impurities from $\mathrm{CO}_{2}$ gas stream) step is conventionally incorporated to purify $\mathrm{CO}_{2}$ along with $\mathrm{CO}_{2}$ compression and drying. The specific energy requirement for gas conditioning is $100-200 \mathrm{kWh} / \mathrm{ton}(\mathrm{t})$ captured $\mathrm{CO}_{2}(\sim$ $360-720 \mathrm{~kJ} / \mathrm{kgCO}_{2}$ ). However, for approximately pure $\mathrm{CO}_{2}$ stream, the energy requirement for compression is significantly reduced to $90 \mathrm{kWh} / \mathrm{t}$ captured $\mathrm{CO}_{2}(\sim 324$ $\mathrm{kJ} / \mathrm{kgCO}_{2}$ ) [4].

An oxygen transport membrane (OTM) is required to separate high-purity oxygen from air for oxy-combustion of fuel [5-13]. The high-purity oxygen also finds application in metallurgical (iron and steel plants), chemical, petrochemical, medical and paper industries, welding and cutting [14]. Fig. 1 shows a simplified process flow diagram depicting the use of an oxygen transport membrane (air separation unit) in an integrated gasification combined cycle (IGCC) [15].

In the IGCC process, oxygen separated from air (air separation unit) reacts with coal particles or slurry to produce syngas at high temperature and pressure $\left(\sim 1000^{\circ} \mathrm{C}\right.$ and 394.8 atm) [16]. The syngas undergoes a water-gas shift reaction $\left(\mathrm{CO}+\mathrm{H}_{2} \mathrm{O} \leftrightarrow \mathrm{CO}_{2}+\right.$ 
$\mathrm{H}_{2}$ ) and further converts to hydrogen and carbon dioxide. In this process, after removal of the carbon dioxide, the hydrogen is used in a gas turbine to generate electricity. The hot exhaust gases are used to heat the water in the heat recovery steam generator (HRSG) for use in the steam turbine. Thus the IGCC process provides dual benefits: syngas production and power generation along with the carbon dioxide sequestration. In addition, the overall efficiency of the process is $45-50 \%$, which is significantly higher than the conventional gasification process (32-38\%) [16].

Table 1 summarizes the advantages and disadvantages of the conventional and advanced oxygen separation techniques currently being developed [1,14-21]. The two commercial methods currently used to separate oxygen from air are: 1) cryogenic and 2) pressure swing adsorption. In the cryogenic method, high purity oxygen $(\geq 99 \%)$ is produced on a large industrial scale by fractional distillation of air at low temperature and pressure [17]. First, air is compressed between 4-10 atm and cooled to ambient temperature $\left(30^{\circ} \mathrm{C}\right)$. It is then passed over the fixed bed of adsorbents (activated alumina/molecular sieve) to remove trace contaminants, i.e., water, carbon dioxide and hydrocarbons. The purified air is again cooled to its liquefaction temperature (approximately $-185^{\circ} \mathrm{C}$ ), after which distillation occurs and the products (nitrogen, oxygen, and argon) are obtained at low pressure column. Oxygen which has the highest boiling point $\left(-182.8^{\circ} \mathrm{C}\right)$ among the components is obtained from the bottom of the low pressure column. A simplified schematic of the cryogenic method is shown in Fig. 2 [18]. This method is energy intensive, less efficient, and more expensive than the pressure swing adsorption method. 
The pressure swing technique separates oxygen from air by selectively adsorbing nitrogen from compressed air at high pressure on active carbon or a zeolite [19]. The pressure is reduced after the separation to desorb the nitrogen. In Fig. 3, a schematic shows the pressure adsorption technique for air separation [19]. The process is discontinuous and suitable only for small-scale production when the oxygen purity (90$95 \%)$ is not an end-use concern.

High-purity oxygen ( $\geq 99 \%)$ separation from air using a dense ceramic material, an oxygen transport membrane, is a relatively new and developing technology. In this method, oxygen from air transports through the ion conducting ceramic material as oxygen ions by either an electrical or chemical driving force. In comparison to the cryogenic and pressure swing methods, oxygen production by dense ceramic membranes has distinct advantages (Table 1): (i) 40\% lower cost of oxygen generation than existing technologies, (ii) the process is more efficient, (iii) there is lower power usage, and (iv) the method enables heat recovery when integrated with the power generation, and combustion units [14]. In addition, when integrated into power or gasification combined cycle, the oxygen gas stream need not to be heated to high temperature and pressurized, as is needed for the cryogenic technique.

As mentioned above and table 1, the ceramic membranes are more advantageous than other existing technologies for oxygen separation especially when integrated with combustion and/or gasification cycle for oxy-combustion and/or syngas production. Pressure swing adsorption technique choice is eliminated for oxy-combustion and/or 
syngas production not only because it provides low purity oxygen, but also, the technique is only suitable for small to medium scale plant (20-100 tons/day) [22]. In addition, it is a batch (discontinuous) process. The process is not appropriate for integration into the combustion and/or gasification cycle. On the other hand, even though cryogenic technique provides high purity oxygen at large scale (beyond 100-300 tons/day), the process power consumption is high and the efficiency is low [22]. For oxy-combustion and syngas production, the cryogenic cycle integration into power plant requires large volume space, high installment capital cost $(\$ 310-500 / \mathrm{kWe})$, large energy consumption (245-670 $\left.\mathrm{kWh} / \mathrm{tO}_{2}\right)$, and drops down the total efficiency of the plant by 8-10\% [20]. When compared to cryogenic technique, ceramic membranes requires less installment cost $(\$ 260-295 / \mathrm{kWe})$, power consumption $\left(100-655 \mathrm{kWh} / \mathrm{tO}_{2}\right)$, and volume space on integration with power plants [20]. In addition, the process is single stage, and enables heat recovery. In other words, unlike cryogenic technique, it is a high temperature process and the permeated oxygen gas stream need not to be heated up and pressurized when integrated with gasification or power cycle. Overall, the ceramic membranes are beneficial (especially for oxy-combustion and syngas production) in terms of power consumption, volume space, heat recovery, installment cost, power production of the plant, and efficiency (Table 1).

Ceramic oxygen transport membranes can be divided into two groups based on the driving force used for the oxygen separation process: 1) electrically driven membrane also known as passive membrane and 2) chemical potential/oxygen partial pressuredriven membrane also known as active membrane. In passive membrane, the dense 
ceramic is predominantly an ionic conductor that transports oxygen ions under applied electrical potential. This process is economic and reliable for high purity oxygen production with precise control on produced oxygen volume [23]. An external electrical circuit and power source are required to transport electrons across the membrane to maintain charge neutrality and the membrane, therefore, is called electrically driven. The flux of electrons is required to maintain electro-neutrality according to Kröger-Vink notation:

$\mathrm{O}_{\mathrm{o}}^{\times} \leftrightarrow \frac{1}{2} \mathrm{O}_{2}(\mathrm{~g})+\mathrm{V}_{\mathrm{o}}+2 \mathrm{e}^{-}$

where $e^{-}$and $V_{0}$ refers to electron and oxygen vacancy respectively. The symbol $x$ and represents neutral and positive charge respectively.

In the oxygen partial pressure-driven active membrane, the dense ceramic, employed for the separation of oxygen, is a mixed ionic-electronic conductor (MIEC). An oxygen partial pressure differential between an oxidizing (air at $0.21 \mathrm{~atm}$ ) and reducing gas (fuel at $10^{-22} \mathrm{~atm}$ ) exists across the membrane as a driving force for the oxygen separation. It allows oxygen ions transport from the high oxygen partial pressure side to the low oxygen partial pressure side; meanwhile, electrons move in the opposite direction within the membrane and complete the internal electric circuit. Therefore, no external circuit or electrical power is required for the electron conduction [23]. For the pressuredriven MIEC based membrane, the driving force (electrochemical potential) for the transport of ion and electron species relates to the mass flux as shown in the general MIEC transport equation below [24]: 
$\int_{i}^{\operatorname{mass}}(x, t)=-\frac{\sigma_{i}(x, t)}{\left(z_{i}\right)^{2}} \frac{\partial \mu_{i}(x, t)}{\partial x}$

where $x$ is position, $t$ is time, $i$ is the species of charge carrier, $\mathrm{z}_{i}$ is the number of charges carried by species $i$, e is the electron charge, $J_{i}^{\operatorname{mags}}(x, t)$ is the carrier mass flux, $\sigma_{i}(x, t)$ is the electrical conductivity. The electrochemical potential, $\tilde{\mu}_{i}\left(x_{z} t\right)$ is given by

$\tilde{\mu}_{i}(x, t)=\mu_{i}(x, t)+z_{i} e \varphi(x, t)$

where $\mu_{i}(x, t)$ and $\varphi(x, t)$ are chemical and electrical potential respectively.

The electrochemical potential is dependent on oxygen chemical potential (Eq. (4)) across the membrane and electrical potential (Eq. (5)), leading to the migration of oxygen ions from the air side (higher $\mathrm{P}_{\mathrm{O}_{2}}$ ) to the fuel side (lower $\mathrm{P}_{\mathrm{O}_{2}}$ ), and electrons to the opposite side [24]. At time, $t=0$ under steady state condition:

$\mu_{O_{2}}=\mu_{O_{2}}^{2}+K_{\mathrm{E}} T \ln \frac{\mathrm{P}_{\mathrm{O}_{2}}}{\mathrm{P}_{\mathrm{O}_{2}}}$

$\frac{\mathrm{d} \varphi(\mathrm{x})}{\mathrm{dx}}=-\mathrm{E}=-\frac{\mathrm{k}_{\mathrm{B}} T}{\mathrm{e} L} \ln \frac{\sigma_{\text {ion }}+\sigma_{\mathrm{el}}(L)}{\sigma_{\mathrm{ion}}+\sigma_{\mathrm{el}}(0)}$

where $\mu_{O_{2}}$ is the chemical potential of the oxygen, $\mu_{O_{2}}^{2}$ is the chemical potential of pure oxygen, $\mathrm{K}_{\mathrm{B}}$ is the Boltzmann constant, $T$ is temperature, $E$ is the electrical field, $\mathrm{P}_{\mathrm{O}_{2}}$ and $\mathrm{P}_{\mathrm{O}_{2}}^{\prime}$ are oxygen partial pressure at the fuel side and air side, respectively, $\sigma_{\mathrm{ion}}$ represents ionic conductivity, and $\sigma_{\mathrm{el}}$ is electronic conductivity. The length of the membrane is $\mathrm{x}=0$ at the permeate side and $\mathrm{x}=\mathrm{L}$ at the feed side. 
Fig. $4 \mathrm{a}$ and $4 \mathrm{~b}$ show schematics of operation for the pressure and electrically driven oxygen transport membrane. The differences between the pressure-driven (active) and electrically driven (passive) membranes are tabulated in Table 2 [25-33]. Mixed ionic-electronic conductivity required for pressure-driven membrane can be found in either single phase mixed conducting perovskite oxide (cobaltite, ferrite) or dual phase composites consisting of ionic and electronic phase materials. In the case of dual phase membranes, the ionic phase transports oxygen while the electronic phase transports electron. However, oxygen ions cannot transport through the bulk membrane via purely electron conducting phase, resulting in decreased oxygen permeability and flux. For this reason, mixed ionic-electronic perovskite phase is preferred for oxygen ion migration through the bulk membrane [34]. It is challenging to obtain high electronic as well as ionic conductivity in a single perovskite phase. The ionic conductivity of MIEC perovskite is generally found to be less than fluorite phase. For example, the ionic conductivity of $\mathrm{LaCoO}_{3-\delta}$ and $\mathrm{La}_{0.7} \mathrm{Sr}_{0.3} \mathrm{Co}_{0.7} \mathrm{Cr}_{0.3} \mathrm{O}_{3-\delta}$ perovskites are $\sim 2 \times 10^{-4}$ and $\sim 10^{-3} \mathrm{~S}$ $\mathrm{cm}^{-1}$ at $1000^{\circ} \mathrm{C}$ in air, respectively, which is less than $\sim 0.1 \mathrm{~S} \mathrm{~cm}^{-1}$ for most commonly used fluorite phase $\left(\mathrm{Zr}_{0.8} \mathrm{Y}_{0.2} \mathrm{O}_{2-\delta}\right)$ [35-36]. Therefore, it is preferable that mixed conducting perovskite is combined with fluorite phase to form a composite with relatively high ionic conductivity. Subsequently, the combination of perovskite and fluorite phase provides higher performance/oxygen flux in OTM when compared to single phase. For instance, the oxygen flux $\left(/_{O_{z}}\right)$ of $\mathrm{Ce}_{0.8} \mathrm{Gd}_{0.2} \mathrm{O}_{2-\delta}$ fluorite phase is $\sim 9.9 \times 10^{-10} \mathrm{~mol} \mathrm{~cm}^{-2} \mathrm{sec}^{-1}$ under oxygen partial gradient maintained by air at the feed side and $\mathrm{Ar}$ at the permeate side (air/Ar). However, when combined with MIEC 
$\mathrm{La}_{0.8} \mathrm{Sr}_{0.2} \mathrm{Fe}_{0.8} \mathrm{Co}_{0.2} \mathrm{O}_{3-\delta}$ perovskite in the ratio of $48: 52$ (wt.\%), the $/ \mathrm{o}_{\mathbf{z}}$ increases to $\sim 6.3 \times 10^{-8} \mathrm{~mol} \mathrm{~cm}^{-2} \mathrm{sec}^{-1}$ (air/He) at $950^{\circ} \mathrm{C}$ [37]. Similarly, the $/_{\mathrm{o}_{2}}$ for single phase $\mathrm{La}_{0.8} \mathrm{Sr}_{0.2} \mathrm{Cr}_{0.5} \mathrm{Fe}_{0.5} \mathrm{O}_{3-\delta}$ perovskite is $\sim 2.5 \times 10^{-7} \mathrm{~mol} \mathrm{~cm}^{-2} \mathrm{sec}^{-1}$ and increases to $\sim 2.6 \times 10^{-6}$ mol cm ${ }^{-2} \sec ^{-1}$ (air/CO) for $\mathrm{La}_{0.8} \mathrm{Sr}_{0.2} \mathrm{Cr}_{0.5} \mathrm{Fe}_{0.5} \mathrm{O}_{3-8} / \mathrm{Zr}_{0.84} \mathrm{Y}_{0.16} \mathrm{O}_{1.92}$ composite at $950^{\circ} \mathrm{C}$ $[31,38]$. The oxygen flux performance of different single phase perovskite as well as dual phase with fluorite is summarized later in the oxygen flux section. For dual phase membranes, it is to be noted that there is a challenge of compatibility, structural and chemical stability (e.g. thermal expansion match, interfacial reaction) as discussed in subsequent sections.

The exchange of oxygen between the membrane surface and gas phase takes place in several steps for the reduction and transport of oxygen: adsorption and dissociation of oxygen molecules, oxygen transport via oxygen vacancies across the membrane, and desorption and association of oxygen ions [39-41]. This is explained in detail later in the oxygen flux section. MIEC's eliminate the necessity for an electrode. To enhance the oxygen surface exchange and improve the overall oxygen flux, however, a porous surface exchange (air side) and intermediate layer (fuel side) is integrated in the active membrane [39-40,42].

2.

Materials for

oxygen transport membrane 
MIEC's are considered for use as oxygen transport membranes (OTM) as well as the intermediate and surface exchange layer for separating oxygen from air [43-45]. A MIEC based OTM (Fig. 4a) device operates at $\sim 1000^{\circ} \mathrm{C}$ and oxygen partial pressure of $\sim 0.21-10^{-22}$ atm for oxy-combustion of fuel [46]. MIECs are also used as electrodes in other solid state devices (e.g. solid oxide fuel/electrolyzer cells) under exposure at 650$1000^{\circ} \mathrm{C}$ and $\sim 0.21-10^{-22}$ atm $\mathrm{P}_{\mathrm{O}_{2}}[47]$.

To obtain high purity oxygen through oxygen permeation, the OTM should be dense $(\geq 94 \%)$ to avoid contaminants and the mixing of air and fuel. OTM should be resilient to the aggressive operating environment $\left(\sim 1000^{\circ} \mathrm{C}\right.$ and $\left.\sim 0.21-10^{-22} \mathrm{~atm}\right)$ for more than 40,000 $\mathrm{h}$ and also cost effective [48]. The key requirements for oxygen transport membrane are summarized in Table 3 [43-48].

Generally, electronic and/or MIEC perovskite oxides are used as electronic and fluorite oxides as ionic phase constituents for OTM. Dual phase composites consisting of MIEC perovskites and fluorite phases are recognized to promote higher oxygen flux. Y/Sc doped $\mathrm{ZrO}_{2}$, and $\mathrm{Gd} / \mathrm{Sm}$ doped $\mathrm{CeO}_{2}$ or $\mathrm{ZrO}_{2}-\mathrm{CeO}_{2}$ system doped with $\mathrm{Y}$, Sc, $\mathrm{Gd}$, and/ or Sm are commonly used as ionic phase [34,49]. $\mathrm{ABO}_{3}$, Ruddlesden-Popper $\left(\mathrm{K}_{2} \mathrm{NiF}_{4} / \mathrm{A}_{\mathrm{n}+1} \mathrm{~B}_{\mathrm{n}} \mathrm{O}_{3 \mathrm{n}+1}\right.$ structure), and ordered double perovskites $\left(\mathrm{AA}^{\prime} \mathrm{Co}_{2} \mathrm{O}_{5+\mathrm{x}}, \mathrm{A}=\mathrm{RE}, \mathrm{Y}\right.$ and $\mathrm{A}^{\prime}=\mathrm{Ba}, \mathrm{Sr}$ ) have been investigated as MIEC phases [39-40]. The structural and thermo-chemical stability of the $\mathrm{A}^{3+} \mathrm{B}^{3+} \mathrm{O}_{3}$ are superior to the other types of perovskites and have been studied for OTM application [43,52-54].

\section{$\underline{A B O_{3}} \underline{\text { Perovskite }}$}


An ideal $\mathrm{ABO}_{3}$ perovskite is cubic, where $\mathrm{A}$ and $\mathrm{B}$ are two cations bonded with oxygen anions. The ionic radii of $B$ cation $\left(r_{B}\right)$ is smaller than A cation $\left(r_{A}\right)$. B cation has 6-fold coordination, whereas A cation has 12-fold coordination with oxygen ions as shown in Fig. 5. The stability of a perovskite structure is defined by the Goldschmidt tolerance factor, which is used to measure the degree of distortion of a perovskite from ideal cubic lattice, $\mathrm{t}$ as [55]:

$\mathrm{t}=\frac{r_{A}+r_{0}}{\sqrt{2}\left(r_{B}+r_{0}\right)}$

where $r_{A}, r_{B}$ and $r_{O}$ are ionic radii of the respective ions. The perovskite structure is stable for $0.77 \leq \mathrm{t} \leq 1.00[56]$.

The thermo-physical properties such as thermal expansion and electrical conductivity of $\mathrm{ABO}_{3}$ perovskites depend on the structure and the ionicity difference $\left(\Delta f_{\mathrm{i}}\right.$ ) between A-O and B-O bonds. Lattice distortion from the cubic symmetry ( $\mathrm{t}=1)$ is associated with a high degree of anisotropy in oxygen sites, and an increase in lattice distortion decreases the ionic conductivity. In other words, ionic conductivity improves with higher structural symmetry as observed for $\mathrm{LaCoO}_{3}$. The migration energy of oxygen ions depends on the critical radius of the saddle point for oxygen migration, electrostatic bonding energy, and Jahn-Teller effect, which represents a geometric distortion of a non-linear molecular system (e.g., octahedral complexes) to reduce its symmetry and energy. Higher the value of the saddle point radius, lower is the oxygen migration energy [57-59]. The ionic conductivity and thermal expansion coefficient increases with a lower ionicity difference $\left(\Delta f_{\mathrm{i}}\right)$ between A-O and B-O bonds [60-63]. For 
instance, thermal expansion and the oxygen ionic conductivity of $\mathrm{La}_{1-x} \mathrm{Sr}_{x} \mathrm{Fe}_{1-y} \mathrm{Co}_{y} \mathrm{O}_{3-\delta}$ perovskite increases with decrease in $\Delta f_{\mathrm{i}}[61]$. Because, the oxygen ion become unstable when the difference in the ionicity is small and results into the increase in the oxygen ion mobility. The ionic conductivity dependence on the Jahn-Teller effect has yet to be understood. The ionic and electronic conductivity of $\mathrm{ABO}_{3}$ can also be tuned by introduction of dopants at A and B-site. For example, when divalent acceptor ion is partially substituted at trivalent A-site, the charge compensation for electro-neutrality is occurred either by an increase in the valence state of the B-site ion (electronic compensation) and/or oxygen vacancies formation (ionic compensation) [56]. If doped with transition metals, the increase in the valence state of B-site cation results into an increase in $\mathrm{B}^{4+} / \mathrm{B}^{3+}$ redox couples which act as hopping sites for electronic conduction and increases the conductivity. On the other hand, the ionic conductivity increases if the charge balance is compensated by creation of oxygen vacancies.

Lanthanide series element (La) as A-site cation and transition metals $(\mathrm{Cr}, \mathrm{Fe}, \mathrm{Mn}$, $\mathrm{Ni}$ and $\mathrm{Co}$ ) as $\mathrm{B}$-site cation in $\mathrm{ABO}_{3}$ perovskite have been investigated [64-67]. These perovskite can be categorized as chromite, ferrite, manganite, nickelate, and cobaltite.

The stability of the undoped perovskite at $1000^{\circ} \mathrm{C}$ is in the increasing order of $\mathrm{LaCrO}_{3-\delta}$ 
$\left(10^{-22} \mathrm{~atm}\right)>\mathrm{LaFeO}_{3-\delta}\left(10^{-17} \mathrm{~atm}\right)>\mathrm{LaMnO}_{3-\delta}\left(10^{-15} \mathrm{~atm}\right)>\mathrm{LaCoO}_{3-\delta}\left(10^{-7} \mathrm{~atm}\right)>$

$\mathrm{LaNiO}_{3-\delta}\left(10^{-0.6} \mathrm{~atm}\right)$ [66], where $\delta$ represents oxygen deficiency.

Major advantages and disadvantages of the perovskites are outlined in Table 4 [69-76]. It is clear from the table that lanthanum ferrite, manganite and nickelate are not stable in a wide range of $\mathrm{P}_{\mathrm{O}_{z}}\left(0.21-10^{-22} \mathrm{~atm}\right)$ at $\sim 1000^{\circ} \mathrm{C}$, which is one of the key requirement for OTM. As mentioned in the Table 4, even though ferrites provide high mixed ionic $\left(\sim 0.05 \mathrm{~S} \mathrm{~cm}^{-1}\right.$ at $\left.900^{\circ} \mathrm{C}\right)$ - electronic $\left(\sim 100 \mathrm{~S} \mathrm{~cm}^{-1}\right.$ at $\left.1000^{\circ} \mathrm{C}\right)$ conductivity as well as higher activity for oxygen reduction, high thermal expansion coefficient $\left(23.8 \times 10^{-6} \mathrm{~K}^{-1}\right.$ for $\left.\mathrm{T}>600^{\circ} \mathrm{C}\right)$ and its decomposition into $\mathrm{La}_{2} \mathrm{O}_{3}$ and $\mathrm{Fe}$ metal in reducing atmosphere $\left(\leq 10^{-17} \mathrm{~atm}\right)$ at $1000^{\circ} \mathrm{C}$, eliminates this choice for OTM. Similarly, cobaltites are not suitable for OTM due to high thermal expansion coefficient $\left(20 \times 10^{-6} \mathrm{~K}^{-1}\right)$ and its decomposition into $\mathrm{La}_{2} \mathrm{CoO}_{4}$ and $\mathrm{CoO}$ at lower $\mathrm{P}_{\mathrm{O}_{2}}\left(<10^{-7}\right.$ atm) and OTM operating temperature $\left(\sim 1000^{\circ} \mathrm{C}\right)$. Likewise, manganites provide high electrical conductivity (83 S $\mathrm{cm}^{-1}$ at $\left.800^{\circ} \mathrm{C}\right)$ but also, decomposes into $\mathrm{La}_{2} \mathrm{O}_{3}$ and $\mathrm{MnO}$ in reducing atmosphere $\left(\leq 10^{-}\right.$ 
$\left.{ }^{15} \mathrm{~atm}\right)$ at $1000^{\circ} \mathrm{C}$. Furthermore, nickelates are not stable and decomposes into $\mathrm{La}_{2} \mathrm{NiO}_{4}$ and $\mathrm{NiO}$ below $10^{-0.6}$ atm at $1000^{\circ} \mathrm{C}$. Poor stability of various perovskites (ferrites, cobaltites, manganites) prohibit their application in the emerging power generation system and related device (OTM). On the other hand, chromites are stable under OTM operating conditions $\left(\sim 1000^{\circ} \mathrm{C}\right.$ and $\sim 0.21-10^{-22}$ atm. $)$, while the required thermo-physical properties can be achieved by using suitable dopants. Lanthanum chromite-based materials are also considered for solid oxide fuel cell interconnects because of superior stability and good electrical conductivity [77-83]. This suggests that chromite is the best choice of material for OTM from stability point of view, the subject of this review paper. In this review article, we have a) critically analyzed and examined the pertinent information on lanthanum chromite based perovskites in terms of chemistry, structure, and properties required for OTM systems, b) correlated the 'chemistry-structureproperty-stability' relationships, and c) suggested approaches for tuning the desired properties and reliability. Further, challenges and future research directions are discussed.

\section{Fabrication}

The fabrication techniques for the OTM, still an infant technology, are not widely published and remain mostly trade secret or industry specific information. As with other solid state electrochemical devices (solid oxide fuel cells and electrolyzers), there are planar and tubular configurations for OTM as shown in Fig. 8 [15,84-87]. Different fabrication technologies are discussed in brief based on the literature for SOFCs. 


\subsection{Fabrication Techniques}

For both planar and tubular configurations, the porous electrodes used in passive OTM, porous surface exchange and intermediate layers used in active OTM, and dense oxygen separation layers are coated on a $0.5-4.0 \mathrm{~mm}$ thick porous substrate. Porous substrates, which also provide mechanical strength and the gas flow path, are generally prepared by conventional ceramic routes such as pressing (planar type), slip casting (planar and tubular type), and extrusion (tubular type) followed by respective drying and sintering/co-firing [85]. Subsequent layers (5-50 $\mu \mathrm{m}$ thick) are coated on the porous substrate by various techniques: screen printing; tape casting; wet chemical methods such as slip casting, spraying, and sol-gel coating; plasma spraying; and gas phase deposition such as physical vapor deposition (PVD) and chemical vapor deposition (CVD) [85-95]. All of these techniques have inherent advantages and disadvantages. Screen printing and tape casting offer low cost, ease in controlling the coating thickness, and suitability for porous and dense microstructures through suitable thermal treatment (drying, binder removal, and sintering steps) [87,97]. These techniques are limited to simple planar configuration and cannot be applied for complex shaped substrates such as tubular configurations. Other techniques are applicable for both planar and tubular configurations. Wet chemical methods are economical but require critical thermal treatments to develop crack free microstructures, which are difficult to control. Plasma

spraying, PVD, and CVD techniques are not economical, but the desired microstructures 
can theoretically be achieved through control of the choice of solid targets (for PVD), solid or liquid precursors for plasma spray, and liquid precursor for CVD; plasma/gas phase deposition rate by instrumentation, chamber atmosphere, and substrate temperature without any sintering step. The distinct advantages of the plasma spraying, PVD, and CVD are threefold. Plasma spraying and PVD are in-sight controlled. For all three methods, in contrast with wet processing methods, multiple layers can be deposited in a few hours. The grain size and orientation can be tuned by optimization of instrumental parameters. It is known that smaller the grain size, higher is the catalytic activity for oxygen reduction and flux in OTM. Small grain size $(\mathrm{nm})$, the size and distribution of open pores, and the material's stability can be maintained during processing and fabrication due to the absence of the high temperature sintering step [81,88-91,93-94]. However, the grains grow and the microstructure changes due to active grain growth kinetics during long-term exposure at high temperature and reduced atmosphere. In reality, the deposited layers are co-fired at higher temperature $\left(1200-1500^{\circ} \mathrm{C}\right)$ to achieve strong interfacial bonding and to maintain material stability at the relatively low operating temperature $\left(\sim 1000^{\circ} \mathrm{C}\right)$.

A brief introduction on the deposition techniques that could be used for planar and tubular OTM and their principles are summarized below followed by the advantages and disadvantages outlined in Table 5 [87-92,98]. However, detailed information about the individual techniques and the corresponding figures are mentioned elsewhere in the cited references. 


\subsubsection{Wet chemical methods}

Slip casting: A slurry consisting of submicron sized powders, a liquid medium (ethanol, isopropanol etc.), organic binders, and additives are prepared to meet the prescribed flowability, suspension stability, and sedimentation requirements. When poured on a porous substrate, the slurry migrates through the porous support and a smooth and homogenous powder layer is formed on the surface. The layer is then dried, and subsequently sintered. A schematic of a vacuum slip casting method is shown in Fig. 9 [87].

Slurry spraying: A liquid suspension of powders is sprayed on a substrate using a spray gun. The coated layer is then dried and sintered. This technique can be used for complex shapes, but the thickness at the edges of a component is difficult to control. A schematic of the spraying method is illustrated in Fig. 10 [87].

Sol-gel deposition: In this method, a substrate is dipped into a stable suspension (sol) and then dried. The required coating thickness is generally obtained through multiple dipping and drying sequences. After obtaining the required thickness, the coating is sintered to develop the desired microstructure. This method is suitable for porous microstructures. A schematic is shown in Fig. 11 [87].

\subsubsection{Plasma spraying technique}


In plasma spray technique, plasma created by high voltage (DC power, $\mathrm{RF}$ induction) electrodes melt particles which travel (100-1200 m/s velocity) through the plasma jet and deposits on the substrate via rapid solidification [87-89,99]. Plasma jet temperatures vary between $6727-19727^{\circ} \mathrm{C}$. A schematic of a plasma spray apparatus is shown in Fig. 12 [88]. The powders can be deposited on the substrate at atmospheric pressure in the case of the atmospheric plasma spray (APS) method; under vacuum $\left(10^{-2}\right.$ $10^{-3} \mathrm{~atm}$ ) condition in the case of the vacuum plasma spray (VPS) method, and at low pressure $\left(<10^{-3} \mathrm{~atm}\right)$ in the case of the low pressure plasma spray method.

\subsubsection{Physical vapor deposition (PVD)}

In the physical vapor deposition (PVD) technique, atoms from a solid target are transported via gas phase and deposited on a substrate [87-88,91]. Three common methods are used for the evaporation of solid targets: electron beam evaporation (EBPVD), where electric energy is converted into heat at the sample surface; sputtering process, where material is removed from a target (cathode) using positively charged ions of a noble gas (argon); and pulsed laser ablation, in which high laser intensity is used to evaporate the material from the target surface. The schematics of the different PVD techniques are shown in Fig. 13 [91].

\subsubsection{Chemical vapor deposition (CVD)}


In chemical vapor deposition, a precursor (generally metal halides and metalorganic compounds with low vaporization temperature and high vapor pressure) is heated /decomposed to form active gas phase/species. The gaseous species transports into the reaction chamber and reacts to form the compounds on a substrate. Unlike PVD, chemical reactions and diffusion occur in CVD [98]. MOCVD refers to the CVD technique when metal- organic precursors are used for the deposition. Electrochemical vapor deposition (EVD) is another mode of CVD used to deposit dense ion or electronconducting oxide films on a porous substrate. EVD uses oxygen ion transport through an oxygen ion permeable membrane to enable the chemical reactions and subsequent deposition and growth of the oxides. The schematics of CVD and EVD techniques are shown in Fig. 14 [98].

\section{Lanthanum chromite $\left(\mathrm{LaCrO}_{3}\right)$ based perovskites for OTM}

Despite having good electrical conductivity $\left(0.6-1.0 \mathrm{~S} / \mathrm{cm}\right.$ at $\left.1000^{\circ} \mathrm{C}\right)$ and superior chemical stability in a wide $P_{O_{2}}$ range $\left(0.21-10^{-22}\right.$ atm) at high temperature $\left(\sim 1000^{\circ} \mathrm{C}\right)$, undoped $\mathrm{LaCrO}_{3}$ is not suitable for OTM due to lack of ionic conduction and densification. To densify and obtain the desired thermal and electrical properties, dopants are introduced at A-site as well as B-site of lanthanum chromite. $\mathrm{Sr}$ and $\mathrm{Ca}$ are used as Asite dopants while transition metals ( $\mathrm{Mn}, \mathrm{Co}, \mathrm{Fe}, \mathrm{Ni}, \mathrm{Ti}, \mathrm{Cu}$, and $\mathrm{Al}$ ) are considered for B-site dopants. A-site dopants are generally acceptor type and enhance densification as well as electrical conductivity. B-site dopants are introduced to maintain thermal and 
crystal structure stability, and to further increase the electrical conductivity (induce oxygen vacancy for ionic conduction). Below are some general defect reactions (KrögerVink notation) that can occur when $\mathrm{LaCrO}_{3}$ is doped at A-site with alkaline earth metals $(\mathrm{A}=\mathrm{Sr}, \mathrm{Ca})$ and/or transition metals $(\mathrm{M}=\mathrm{Mn}, \mathrm{Co}, \mathrm{Fe}, \mathrm{Ni}, \mathrm{Ti}, \mathrm{Cu}$, and $\mathrm{Al})$ at $\mathrm{B}$-site. These reactions modify the thermal-electrical-mechanical properties and stability of $\mathrm{LaCrO}_{3}$ based materials as explained later in the individual sections.

1) When alkaline earth metal $(\mathrm{A}=\mathrm{Sr}, \mathrm{Ca})$ is partially doped at A-site and/or Bsite, and the material is exposed to oxidizing atmosphere:

$$
\mathrm{La}_{\mathrm{La}}^{\mathrm{x}}+\mathrm{Cr}_{\mathrm{Cr}}^{\mathrm{x}} \stackrel{\mathrm{A}}{\rightarrow} \mathrm{A}_{\mathrm{La}}^{\prime}+\mathrm{Cr}_{\mathrm{Cr}}
$$

where $\mathrm{La}_{\mathrm{La}}^{\times}$refers to $\mathrm{La}^{3+}$ on $\mathrm{La}^{3+}$ sites, $\mathrm{Cr}_{\mathrm{Cr}}^{\times}$refers to $\mathrm{Cr}^{3+}$ on $\mathrm{Cr}^{3+}$ sites, $\mathrm{A}_{\mathrm{la}}^{\mathrm{a}}$ is single negatively (') charged; $\mathrm{A}^{2+}$ is substituted on the $\mathrm{La}^{3+}$ site and $\mathrm{Cr}_{\mathrm{Cr}}$ represent $\mathrm{Cr}^{4+}$ on $\mathrm{Cr}^{3+}$ site. The symbols $\times$ and $\cdot$ represents neutral and positive charges, respectively. When $\mathrm{A}^{2+}$ partially substitutes $\mathrm{La}^{3+}$ at A-site, a single negative charge is induced and compensated by the $\mathrm{Cr}^{3+} \rightarrow \mathrm{Cr}^{4+}$ transition.

2) When alkaline earth metal $(\mathrm{A}=\mathrm{Sr}, \mathrm{Ca})$ is partially doped at $\mathrm{A}$-site and/or Bsite, and the material is exposed to reducing atmosphere:

$$
\begin{aligned}
& 2 \mathrm{La}_{\mathrm{La}}^{\mathrm{X}}+\mathrm{O}_{\mathrm{O}}^{\mathrm{A}} \rightarrow 2 \mathrm{~A}_{\mathrm{La}}^{\mathrm{A}}+\mathrm{V}_{0}^{*}+\frac{1}{2} \mathrm{O}_{2} \\
& 2 \mathrm{Cr}_{\mathrm{Cr}}^{\circ}+\mathrm{O}_{0}^{\mathrm{X}} \rightarrow 2 \mathrm{Cr}_{\mathrm{Cr}}^{\mathrm{X}}+\mathrm{V}_{0}^{*}+\frac{1}{2} \mathrm{O}_{2}
\end{aligned}
$$


where $\mathrm{A}_{\mathrm{La}}^{\prime}$ is single negatively $\left({ }^{\prime}\right)$ charged; $\mathrm{A}^{2+}$ is substituted on the $\mathrm{La}^{3+}$ site, $\mathrm{La}_{\mathrm{La}}^{\times}$refers to $\mathrm{La}^{3+}$ on $\mathrm{La}^{3+}$ sites, $\mathrm{Cr}_{\mathrm{Cr}}^{\times}$refers to $\mathrm{Cr}^{3+}$ on $\mathrm{Cr}^{3+}$ sites, $\mathrm{Cr}_{\mathrm{Cr}}$ represent $\mathrm{Cr}^{4+}$ on $\mathrm{Cr}^{3+}$ site and $V_{o}^{*}$ represent oxygen vacancy. The symbols $\times$ and $\cdot$ represents neutral and positive charges, respectively. When $\mathrm{A}^{2+}$ is partially substituted at $\mathrm{A}$-site and an induced negative charge on $\mathrm{A}$ is then compensated by the formation of oxygen vacancies. On the other side, $\mathrm{Cr}^{4+}$ reduces to $\mathrm{Cr}^{3+}$ and oxygen vacancies formation occur for charge compensation.

3) When transition metal $(\mathrm{M}=\mathrm{Mn}, \mathrm{Co}, \mathrm{Fe}, \mathrm{Ni}, \mathrm{Ti}, \mathrm{Cu}$, and $\mathrm{Al})$ is partially doped at B-site and/or at A-site, and the material is exposed to oxidizing atmosphere:

$$
\frac{1}{2} \mathrm{O}_{2}+\mathrm{V}_{\mathrm{O}}^{*}+2 \mathrm{M}_{\mathrm{M}}^{\mathrm{X}}=\mathrm{O}_{0}^{\mathrm{x}}+2 \mathrm{M}_{\mathrm{M}}
$$

where $\mathrm{M}_{\mathrm{M}}^{\times}$refers to $\mathrm{M}^{3+}$ on $\mathrm{M}^{3+}$ sites, $\mathrm{M}_{\mathrm{M}}$ refers to $\mathrm{M}^{4+}$ on $\mathrm{M}^{3+}$ sites, and $V_{0}$ refers to oxygen vacancy with two positive charges. Transition metals (e.g. Mn and Co) can exist in $\mathrm{M}^{3+}$ and $\mathrm{M}^{4+}$ valence state in oxidizing atmosphere, and the charge compensation occurs by oxygen vacancy. In addition, when $\mathrm{A}^{2+}$ partially substitutes $\mathrm{La}^{3+}$ at $\mathrm{A}$-site, a single negative charge is induced and compensated by the $\mathrm{M}^{3+} \rightarrow \mathrm{M}^{4+}$ transition. The cation site vacancy formation can also occur for charge compensation of $\mathrm{M}^{4+}$ on $\mathrm{M}^{3+}$ site with an extra positive charge as shown below:

$$
3 \mathrm{M}_{\mathrm{M}}^{\mathrm{X}} \rightarrow 3 \mathrm{M}_{\mathrm{M}}+\mathrm{V}_{\mathrm{M}}^{\prime \prime \prime}
$$


where $\mathrm{M}_{\mathrm{M}}^{\times}, \mathrm{M}_{\mathrm{M}}$ and $\mathrm{V}_{\mathrm{M}}^{\prime \prime \prime}$ denotes $\mathrm{M}^{3+}$ on $\mathrm{M}^{3+}$ site leading to neutral $(\times)$ charge, $\mathrm{M}^{4+}$ on $\mathrm{M}^{3+}$ site with an extra positive (.) charge, and $\mathrm{Mn}^{3+}$ cation vacancy with three negative (') charges respectively.

4) When transition metal ( $\mathrm{M}=\mathrm{Mn}, \mathrm{Co}, \mathrm{Fe}, \mathrm{Ni}, \mathrm{Ti}, \mathrm{Cu}$, and $\mathrm{Al})$ is partially doped at B-site and/or alkaline earth metal (A) at A-site, and the material is exposed to oxidizing atmosphere:

$$
\begin{aligned}
& \frac{1}{2} \mathrm{O}_{2}+\mathrm{V}_{0}^{*}+2 \mathrm{M}_{\mathrm{M}}^{\times}=0_{0}^{\times}+2 \mathrm{M}_{\mathrm{M}} \\
& \frac{1}{2} \mathrm{O}_{2}+\mathrm{V}_{\mathrm{O}}^{\prime}+2 \mathrm{M}_{\mathrm{M}}^{\prime}=O_{0}^{\times}+2 \mathrm{M}_{\mathrm{M}}^{\times}
\end{aligned}
$$

where $\mathrm{M}_{\mathrm{M}}^{\times}$refers to $\mathrm{M}^{3+}$ on $\mathrm{M}^{3+}$ sites, $\mathrm{M}_{\mathrm{M}}$ refers to $\mathrm{M}^{4+}$ on $\mathrm{M}^{3+}$ sites, $\mathrm{M}_{\mathrm{M}}^{\prime}$ refers to $\mathrm{M}^{2+}$ on $\mathrm{M}^{3+}$ sites, and $\mathrm{V}_{0}^{*}$ refers to oxygen vacancy with two positive charges. In reducing atmosphere, the oxygen vacancies formation occur for charge compensation when $\mathrm{M}^{4+} \rightarrow \mathrm{M}^{3+}$ and $\mathrm{M}^{3+} \rightarrow \mathrm{M}^{2+}$

While introduction of dopants successfully tailor the desired thermal expansion and electrical conductivity behavior, the mechanical integrity and thermochemical stability are compromised due to oxygen non-stoichiometry and resultant defect chemistry. The lattice volume of lanthanum chromite based perovskite increases during heating and decreases during cooling due to generation of oxygen vacancies by dopants (Eq. (8), (10) and (13)) and reduced oxygen partial pressure $\left(\mathrm{P}_{\mathrm{O}_{2}}\right)$, resulting in, respectively, compressive and tensile stress during thermal cycling. The OTM is also 
exposed to a stress gradient due to variation in lattice volume originating from the $\left(\mathrm{P}_{\mathrm{O}_{2}}\right)$ gradient. The type and level of dopants and oxygen non-stoichiometry on the mechanical properties of lanthanum chromite have been correlated in this review article.

The thermochemical stability of lanthanum chromite based perovskite is discussed from three aspects: bulk chemical stability, interface stability, and surface segregation. The bulk stability mainly depends on the decomposition and/or formation of secondary phases in the doped lanthanum chromite. Interface stability depends on the interaction between lanthanum chromite and adjacent materials such as zirconia and ceria. Surface segregation is predominant for A-site dopants and dominated by defect chemistry.

It is to note that oxygen flux determines the performance of OTM materials. The oxygen flux in a single phase, dense lanthanum chromite perovskite depends on the tolerance factor, ionic conductivity, oxygen non-stoichiometry, and defect chemistry introduced by dopants.

The effect of type and level of different A-site and B-site dopants on lanthanum chromite densification and properties has been critically analyzed in this review article in the individual sections below. The discussed properties include thermal expansion, electrical conductivity, mechanical property, thermochemical stability (bulk, interface, and surface) and oxygen flux. Apart from chemistry and structure, the effect of dopant induced oxygen non-stoichiometry and defect chemistry on each properties have also been evaluated.

\subsection{Crystal structure and phase transition}


$\mathrm{LaCrO}_{3}$ is orthorhombic at room temperature and has three temperature dependent polymorphs: magnetic phase transition from an anti-ferromagnetic to a paramagnetic state at $\sim 15^{\circ} \mathrm{C}$ [99-101], orthorhombic to rhombohedral transformation at $\sim 260^{\circ} \mathrm{C}[100-$ 102], and rhombohedral to cubic structure at $\geq 1200^{\circ} \mathrm{C}$ [103-104]. The orthorhombic to rhombohedral phase transition $\left(\sim 260^{\circ} \mathrm{C}\right)$ leads to compression of the lattice with a volume contraction of $\sim 0.138 \%$ arising from the deformation and shrinkage of the $\left[\mathrm{CrO}_{6}\right]^{6-}$ octahedral [101]. The change in lattice volume can generate internal stress, contributing to mechanical failure during thermal cycling (start up and shut down).

Dopants in $\mathrm{LaCrO}_{3}$ shift the phase transition temperature. $\mathrm{Sr}$ and Ca- dopants decrease the magnetic transition temperature due to a reduction in magnetic ordering arising from the change in lattice structure corresponding to the $\mathrm{Cr}^{3+}\left(\mathrm{d}^{3}\right)$ to $\mathrm{Cr}^{4+}\left(\mathrm{d}^{2}\right)$ transition for charge compensation (Eq. (14)) [102-106]. For example, magnetic transition temperature decreases by $\sim 10^{\circ} \mathrm{C}$ for both $\mathrm{La}_{0.9} \mathrm{Sr}_{0.1} \mathrm{CrO}_{3}$ and $\mathrm{La}_{0.9} \mathrm{Ca}_{0.1} \mathrm{CrO}_{3}$ on doping [102-106]. When $\mathrm{Sr}^{2+}\left(\right.$ or $\left.\mathrm{Ca}^{2+}\right)$ partially substitutes $\mathrm{La}^{3+}$ at A-site, a single negative charge is induced and compensated by the $\mathrm{Cr}^{3+} \rightarrow \mathrm{Cr}^{4+}$ transition as shown below:

$\mathrm{La}_{\mathrm{La}}^{\times}+\mathrm{Cr}_{\mathrm{Cr}}^{\times} \stackrel{\mathrm{s}}{\rightarrow} \mathrm{Sr}_{\mathrm{La}}^{3}+\mathrm{Cr}_{\mathrm{Cr}}$

where $\mathrm{Sr}_{\mathrm{La}}^{\prime}$ is single negatively (') charged; $\mathrm{Sr}^{2+}$ is substituted on the $\mathrm{La}^{3+}$ site and $\mathrm{Cr}_{\mathrm{Cr}}$. represent $\mathrm{Cr}^{4+}$ on chromium site. The symbols $\times$ and $\cdot$ represent neutral and positive charges, respectively. 
The charge neutrality in $\mathrm{Sr}$ or Ca-doped $\mathrm{LaCrO}_{3}$ can also be maintained by the creation of oxygen vacancies (Eq. (15)) which are pronounced in reducing atmosphere. Oxygen vacancies are also considered to produce larger deformations in the lattice and lower the magnetic ordering of $\mathrm{Cr}^{3+}$ to a greater extent. The magnetic transition temperature of $\mathrm{La}_{1-x}(\mathrm{Sr} / \mathrm{Ca})_{x} \mathrm{CrO}_{3-\delta}$ with oxygen deficiencies further decreases by $\sim 10^{\circ} \mathrm{C}$ for $x=0.1[105-106]$.

$2 \mathrm{La}_{\mathrm{La}}^{\mathrm{x}}+\mathrm{O}_{\mathrm{o}}^{\mathrm{x}} \stackrel{5 \mathrm{~s}}{\rightarrow} 2 \mathrm{Sr}_{\mathrm{La}}^{\mathrm{z}}+\mathrm{V}_{\mathrm{O}}^{*}+\frac{1}{2} \mathrm{O}_{2}$

where $S r_{\mathrm{La}}^{?}$ is single negatively $\left(^{\prime}\right)$ charged; $\mathrm{Sr}^{2+}$ is substituted on the $\mathrm{La}^{3+}$ site and $\mathrm{V}_{0}$ represent oxygen vacancy. The symbols $x$ and $\cdot$ represents neutral and positive charges, respectively. Similar to Eq. (14), $\mathrm{Sr}^{2+}$ is partially substituted at A-site and an induced negative charge on $\mathrm{Sr}$ is compensated by the formation of oxygen vacancies in reducing gas atmosphere.

The orthorhombic to rhombohedral phase transition temperature $\left(\sim 260^{\circ} \mathrm{C}\right)$ of alkaline earth metal- doped $\mathrm{LaCrO}_{3}$ is found to be dependent on the average ionic radius $\left(\mathrm{r}_{\mathrm{A}}\right)$ of the A-site. The average ionic radius for $\mathrm{La}_{1-x}(\mathrm{Sr} / \mathrm{Ca})_{x} \mathrm{CrO}_{3}$ can be calculated by using Shannon's effective ionic radii in below equation [107]:

$r_{A}=(1-x) r_{\mathrm{Ia}^{3}+}+x r_{\mathrm{AE}} \mathrm{z}+$

where $r_{A E^{2}}$ is the ionic radius of alkaline earth metal ions $(\mathrm{Sr} / \mathrm{Ca})$.

The average ionic radius of $\mathrm{La}_{0.9} \mathrm{Sr}_{0.1} \mathrm{CrO}_{3}$ is $0.1368 \mathrm{~nm}$ and the rhombohedral phase transition temperature is $\sim 42^{\circ} \mathrm{C}$. For $\mathrm{La}_{0.9} \mathrm{Ca}_{0.1} \mathrm{CrO}_{3}$, the average ionic radii is 
$0.1342 \mathrm{~nm}$ and the transition temperature is $\sim 307^{\circ} \mathrm{C}$ due to the smaller ionic radii of $\mathrm{Ca}^{2+}$ $(0.134 \mathrm{~nm})$ compared to $\mathrm{Sr}^{2+}(0.144 \mathrm{~nm})$. The transition temperature shifts below room temperature $\left(-173^{\circ} \mathrm{C}\right)$ for $\mathrm{La}_{1-x} \mathrm{Sr}_{x} \mathrm{CrO}_{3}(x \geq 0.2)$ [105]. Smaller the average ionic radius, higher is the transition temperature of alkaline earth doped $\mathrm{LaCrO}_{3}$ as shown in Fig. 6 . Substitution of $\mathrm{La}^{3+}$ with $\mathrm{Ca}^{2+} / \mathrm{Sr}^{2+}$ alkaline earth ions changes oxidation state of chromium ion $\left(\mathrm{Cr}^{3+} \rightarrow \mathrm{Cr}^{4+}\right)$ to maintain charge neutrality, leading to rearrangement of constituent ions in the crystal structure of $\mathrm{La}_{1-x}(\mathrm{Ca} / \mathrm{Sr})_{x} \mathrm{CrO}_{3}$ with decreasing $\left(\mathrm{Cr}^{4+} / \mathrm{Cr}^{3+}\right)$ $\mathrm{O}^{2-}$ and $\mathrm{O}^{2-} \square \mathrm{O}^{2-}$ ionic distances [105-106]. The ionic distances decrease and $\left[\mathrm{CrO}_{6}\right]^{-6}$ octahedral units shrink with increase in the $\mathrm{Ca} / \mathrm{Sr}$-content; leading towards the orthorhombic to rhombohedral phase transformation [105].

In addition to A-site dopants, the B-site dopants can also effect the phase transformation of $\mathrm{LaCrO}_{3}$. However, the knowledge of $\mathrm{B}$-site dopants effects on the phase transformation and transition temperatures is limited in the literature as mentioned here. For $\mathrm{La}(\mathrm{Cr}, \mathrm{Ni}) \mathrm{O}_{3}$ or $\mathrm{LaCrO}_{3}-\mathrm{LaNiO}_{3}$ system, it is noticed that the $\mathrm{LaCrO}_{3}$ orthorhombic structure is maintained up to $60 \% \mathrm{Cr}$ is replaced by Ni. However, the structure changes to rhombohedral with further increase in Ni content [108]. This is probably due to the formation of oxygen vacancies into the lattice of $\mathrm{LaCrO}_{3}$ for the compensation of $\mathrm{Ni}^{2+}$. With increase in nickel content, oxygen vacancies increases and reaches a saturation point where the perovskite structure does not allow any more oxygen defects formation. This stage is reached at a 40 mole percent $(\mathrm{m} / \mathrm{o})$ of $\mathrm{LaNiO}_{3}$ content. On further doping, $\mathrm{Ni}^{3+}$ formation occurs for charge compensation with linear decrease in the lattice parameter and rhombohedral phase formation [108]. 
In case of $\mathrm{A}$ and $\mathrm{B}$-site simultaneously doped $\mathrm{La}_{0.75} \mathrm{Sr}_{0.25} \mathrm{Cr}_{0.5} \mathrm{Mn}_{0.5} \mathrm{O}_{3}$, the existence of cubic phase is observed like undoped $\mathrm{LaCrO}_{3}$ at high temperature $\left(\geq 1000^{\circ} \mathrm{C}\right)$. Using high-temperature neutron diffraction, it is identified that $\mathrm{La}_{0.75} \mathrm{Sr}_{0.25} \mathrm{Cr}_{0.5} \mathrm{Mn}_{0.5} \mathrm{O}_{3}$ exists in rhombohedral $(R \overline{3} c)$ phase up to $400^{\circ} \mathrm{C}$ [109]. However, the main peak splitting corresponding to rhombohedral phase decreases at $\geq 500^{\circ} \mathrm{C}$ and become insignificant when the temperature approaches $1000^{\circ} \mathrm{C}$. The peak splitting disappearance with increase in temperature corresponds to less distortion of the lattice and a higher symmetry phase i.e. cubic $\left(P_{m} \overline{3} m\right)$ formation. This indicates co-existence of cubic phase with rhombohedral. The fraction of cubic phase is calculated as $85.5 \%$ at $1000^{\circ} \mathrm{C}$ using Rietveld analysis and the transition of $R \overline{3} c \rightarrow P_{m} \overline{3} m$ is tend to complete at $1100^{\circ} \mathrm{C}[109]$. The reason for the phase transformation is not known. However, it could be due to the possible existence of different valence state of $\mathrm{Mn}(+2,+3$ and +4$)$. This leads to form oxygen vacancies for the charge compensation (Eq. (12) and (13)), and may result into less distortion of the lattice at higher temperature.

Distortion of the perovskite lattice and change in crystal structure from lower to higher symmetry or vice-versa can also be explained using tolerance factor. The tolerance factor of perovskite determines their symmetry and approaches one for ideal cubic symmetry. The tolerance factor of $\mathrm{LaCrO}_{3}$ is $<1(\mathrm{t}=0.968$, according to Eq. (6)). The use of alkaline earth metals as the A-site dopant tend to increase the tolerance factor and symmetry of $\mathrm{LaCrO}_{3}[57-58,82]$. The B-site dopant (transition metal) also tune the tolerance factor but are used mainly to tailor redox properties [110-111]. This 
corresponds to the change in average ionic radii of the A-site and B-site on doping. Initially, the average A-site ionic radius $\left(r_{\mathrm{A}}\right)$ for undoped $\mathrm{LaCrO}_{3}$ is $0.136 \mathrm{~nm}$. On substitution, it increases to $0.1368 \mathrm{~nm}$ for $\mathrm{La}_{0.9} \mathrm{Sr}_{0.1} \mathrm{CrO}_{3}$ based on Shannon's ionic radii formula. As the $r_{\mathrm{A}}$ increases, the tolerance factor will also increase according to the Eq. (6). For instance, tolerance factor of $\mathrm{La}_{0.9} \mathrm{Sr}_{0.1} \mathrm{CrO}_{3}$ increased to 0.981 from 0.968 on doping $\mathrm{LaCrO}_{3}$. Subsequently, the lower symmetry orthorhombic phase transforms to higher symmetry rhombohedral structure at lower temperature i.e. $\sim 42^{\circ} \mathrm{C}$ rather than $\sim 260^{\circ} \mathrm{C}[105]$. On the other hand, the phase transformation increases to $\sim 307^{\circ} \mathrm{C}$ from $\sim 260^{\circ} \mathrm{C}$ for $\mathrm{La}_{0.9} \mathrm{Ca}_{0.1} \mathrm{CrO}_{3}$ [105]. This is because, the tolerance factor of $\mathrm{LaCrO}_{3}$ decreases to 0.962 from 0.968 when partially substituted with $\mathrm{Ca}$. The tolerance factor of $\mathrm{LaCrO}_{3}$ can be further improved by doping with transition metals ( $\mathrm{M}=\mathrm{Mn}, \mathrm{Ni}, \mathrm{Al}$ etc. $)$ at the B-site of $\mathrm{La}_{0.9} \mathrm{Sr}_{0.1} \mathrm{Cr}_{0.9} \mathrm{M}_{0.1} \mathrm{O}_{3}$ as shown in Fig. 7 [112]. However, the symmetry is reduced when doping with $\mathrm{Mg}$, Ti and Fe. The reason is not well understood. This might be due to a large distortion of the $\left[\mathrm{CrO}_{6}\right]^{6-}$ octahedral in perovskite structure resulting in a lower tolerance factor, depending on their ionic radii and valence state of dopants.

\subsection{Sintering}

A dense, pore and crack free OTM is required for oxygen ion and electron transport through the bulk, prevention of air/fuel gas mixing, and leakage. Sintering is a process by which densification occurs at high temperature by atomic level mass transport. An OTM fabricated by any abovementioned techniques requires sintering step. 
The relative density of $\mathrm{LaCrO}_{3}$ sintered at $1450^{\circ} \mathrm{C}-1600^{\circ} \mathrm{C}$ in air is $\sim 50 \%$ with a porous microstructure (Fig. 15a) [113-115]. The poor sinterability of $\mathrm{LaCrO}_{3}$ is due to volatilization of chromium species $\left(\mathrm{CrO}_{3}, \mathrm{CrO}_{2}, \mathrm{CrO}\right)$ among which $\mathrm{CrO}_{3}$ is the predominant vapor species above $1000^{\circ} \mathrm{C}$ [116-118]. The chromium species evaporated from the bulk condenses at irregular contact points (grain boundaries) of higher surface energy and deposit as $\mathrm{Cr}_{2} \mathrm{O}_{3}$ at the inter-particle necks as shown in the SEM micrograph in Fig. 15b. As a result, further atomic diffusion (driving force for densification) impedes and the inter-particle neck grows leading to porous microstructure [113]. The mechanism of $\mathrm{CrO}_{3} \uparrow$ formation and $\mathrm{Cr}_{2} \mathrm{O}_{3}$ deposition is given in the following reaction [118]:

$\mathrm{Cr}_{2} \mathrm{O}_{3}+3 / 2 \mathrm{O}_{2} \leftrightarrow 2 \mathrm{CrO}_{3} \uparrow$

Few approaches have been considered to improve the densification of $\mathrm{LaCrO}_{3}$ : reduced sintering atmosphere, liquid phase sintering, and addition of various A-site and B-site dopants. In reducing atmosphere, the vapor pressure of $\mathrm{CrO}_{3}$ decreases significantly. For example, it decreases from $\sim 10^{-6}$ to $10^{-17}$ atm when $\mathrm{P}_{\mathrm{o}_{2}}$ decreases from $\sim 1$ to $10^{-15}$ atm (calculated using HSC Chemistry 6.0). Subsequently, $\mathrm{Cr}_{2} \mathrm{O}_{3}$ deposition at the inter-particle necks is inhibited resulting in higher densification [119].

In case of liquid phase sintering, a secondary phase of lower melting point assists in further densification of $\mathrm{LaCrO}_{3}$ [118]. The liquid phase wets the solid particles/grains, disintegrates and dissolves the particles due to capillary force, and enhances the mass transfer through the liquid phase; resulting in higher densification [121].

\subsubsection{Role of dopants}


Addition of A-site and B-site dopants are used to enhance densification. Most commonly used A-site dopants are calcium and strontium. Many researchers have investigated the densification mechanism of $\mathrm{LaCrO}_{3}$ by alkaline earth metals $(\mathrm{Ca}, \mathrm{Sr})$ substitution at A-site [114-115,122-125]. It is observed that A-site dopants enhances $\mathrm{LaCrO}_{3}$ sintering by the formation of liquid phase $\left(\mathrm{CaCrO}_{4} / \mathrm{SrCrO}_{4}\right)$ which dissolves back into the lattice with increase in temperature. Further enhancement on densification of $\mathrm{LaCrO}_{3}$ can be achieved by B-site doping with transition metals (Mn, Ni, Co and $\mathrm{Fe}$ ) [124-125]. Transition metals assist densification by cation vacancies formation which facilitates mass transport (Eq. (11)) or lowering the melting temperature of liquid phases facilitating liquid phase sintering. Detailed information is provided on the effect of A and B-site dopants on densification of $\mathrm{LaCrO}_{3}$ in individual sub-sections below.

\subsubsection{A-site dopants}

Mori et al. [114] have shown the effect of alkaline earth metals (Ca, Sr) substitution on $\mathrm{LaCrO}_{3}$ densification. It has been observed that the liquid phase $\mathrm{CaCrO}_{4}$ starts to form at $\sim 1000^{\circ} \mathrm{C}$ for Ca-doping in $\mathrm{La}_{1-\mathrm{x}} \mathrm{Ca}_{x} \mathrm{CrO}_{3}(0 \leq x \leq 0.3)$. The liquid phase wets the solid particles and enhances the densification. At high temperature (1230$1330^{\circ} \mathrm{C}$ ), the $\mathrm{CaCrO}_{4}$ phase re-dissolves into the chromite matrix according to the below reaction:

$0.9 \mathrm{LaCrO}_{3}+0.1 \mathrm{AECrO}_{4}$ (liquid) $\rightarrow \mathrm{La}_{0.9} \mathrm{AE}_{0.1} \mathrm{CrO}_{3}+0.05 \mathrm{O}_{2}$ (gas) 
where AE stands for alkaline earth metals i.e. Sr or Ca. The density increases with increase in dopant concentration $(0 \leq x \leq 0.3)$ at $1600^{\circ} \mathrm{C}$ in air. The highest density of $\sim 68 \%$ is achieved for $x=0.3$ in $\mathrm{La}_{1-x} \mathrm{Ca}_{x} \mathrm{CrO}_{3}$ sintered at $1600^{\circ} \mathrm{C}$ in air for $20 \mathrm{~h} \mathrm{[114].}$

To further improve the density, both A-site excess and A-site deficient $\mathrm{La}_{0.7} \mathrm{Ca}_{x} \mathrm{CrO}_{3}(0.25 \leq x \leq 0.35)$ are studied [124]. The A-site deficient $(x=0.28,0.29) \mathrm{Ca}$ doped lanthanum chromite provides $<60 \%$ density even at $1550^{\circ} \mathrm{C}$. Formation of transient liquid phase $\left(\mathrm{CaCrO}_{4}\right)$ leads to the partial densification $(<60 \%)$ of the material between 850 and $1100^{\circ} \mathrm{C}$ for A-site deficient $\mathrm{La}_{0.7} \mathrm{Ca}_{x} \mathrm{CrO}_{3}(0.25 \leq x \leq 0.30)$. The A-site excess $(x=0.31,0.32)$ Ca-doped $\mathrm{LaCrO}_{3}$ shows $>90 \%$ at $1400^{\circ} \mathrm{C}$. For A-site excess $\mathrm{La}_{0.7} \mathrm{Ca}_{x} \mathrm{CrO}_{3}(0.30<x<0.35)$, another phase namely $\mathrm{Ca}_{3}\left(\mathrm{CrO}_{4}\right)_{2}$ forms at $1090^{\circ} \mathrm{C}$ in addition to $\mathrm{CaCrO}_{4}$. Melting of $\mathrm{Ca}_{3}\left(\mathrm{CrO}_{4}\right)_{2}$ at $\leq 1253^{\circ} \mathrm{C}$ helps in further densification (>90\%) of the material by liquid phase sintering. Both the secondary phases re-dissolve into the chromite after densification as temperature increases. Fig. 16 shows the SEM micrograph for $\left(\mathrm{La}_{0.6} \mathrm{Ca}_{0.4}\right)_{1.02} \mathrm{CrO}_{3}\left(>95 \%\right.$ dense) heated to $1350^{\circ} \mathrm{C}$ (2h) and air quenched to room temperature (RT) [128]. A comparative plot of A-site deficient, stoichiometric and A-site excess Ca-doped $\mathrm{LaCrO}_{3}$ in Fig. 17 shows variation in density with calcium content $(x)$ at $\sim 1600^{\circ} \mathrm{C}[114-115,123]$. The variation in results is mostly due to the varying composition with different $\mathrm{Ca}$-content. The density increases with increase in $x$ due to the formation of lower melting phases: $\mathrm{CaCrO}_{4}$ for A-site deficient and both $\mathrm{CaCrO}_{4}$ and $\mathrm{Ca}_{3}\left(\mathrm{CrO}_{4}\right)_{2}$ for A-site excess $\mathrm{La}_{0.7} \mathrm{Ca}_{x} \mathrm{CrO}_{3}(0.25 \leq x \leq 0.35)$. Consequently, A-site excess doped $\mathrm{LaCrO}_{3}$ has higher density. 
Similarly, the partial substitution of $\mathrm{La}$ by $\mathrm{Sr}$ in the material $\left(\mathrm{La}_{1-x} \mathrm{Sr}_{x} \mathrm{CrO}_{3}\right)$ enhances densification due to the formation of $\mathrm{SrCrO}_{4}$ phase (melting point $\sim 1256^{\circ} \mathrm{C}$ ) $[114,122]$. For $x=0.3$ in $\mathrm{La}_{1-x} \mathrm{Sr}_{x} \mathrm{CrO}_{3}$, the density is $\sim 65 \%$ at $1600^{\circ} \mathrm{C}$ [114]. Simner et al. [122] have provided the sintering mechanism for $\left(\mathrm{La}_{0.7} \mathrm{Sr}_{0.3}\right)_{x} \mathrm{CrO}_{3}(0.95 \leq x \leq 1.05)$ in air between $1100-1700^{\circ} \mathrm{C}$. A-site deficient $(x<1)\left(\mathrm{La}_{0.7} \mathrm{Sr}_{0.3}\right)_{x} \mathrm{CrO}_{3}$ shows formation of only one lower melting phase i.e. $\mathrm{SrCrO}_{4}$ at $1250^{\circ} \mathrm{C}$ while both phase $\mathrm{SrCrO}_{4}$ and $\mathrm{Sr}_{2.67}\left(\mathrm{CrO}_{4}\right)_{2}$ phases form for A-site excess $(x>1)\left(\mathrm{La}_{0.7} \mathrm{Sr}_{0.3}\right)_{x} \mathrm{CrO}_{3}$. The highest density (>80\%) was observed by $\left(\mathrm{La}_{0.7} \mathrm{Sr}_{0.3}\right)_{x} \mathrm{CrO}_{3}(x=1.01)$ at $1400^{\circ} \mathrm{C}$. Fig. 17 shows the density increase in $\mathrm{LaCrO}_{3}$ with doped Sr-content at $1600^{\circ} \mathrm{C}$. Ding et al. [128] have also shown similar results for $\mathrm{La}_{0.85}(\mathrm{AE})_{0.15} \mathrm{CrO}_{3}(\mathrm{AE}=\mathrm{Ca}, \mathrm{Sr})$ densification.

The effect of simultaneous $\mathrm{Sr}$ and $\mathrm{Ca}$ doping on the $\mathrm{LaCrO}_{3}$ sintering further increases the density [130]. For example, the density of $\mathrm{La}_{0.75} \mathrm{Ca}_{0.25} \mathrm{CrO}_{3}$, $\mathrm{La}_{0.75} \mathrm{Sr}_{0.25} \mathrm{CrO}_{3}$, and $\mathrm{La}_{0.75} \mathrm{Ca}_{0.10} \mathrm{Sr}_{0.15} \mathrm{CrO}_{3}$ sintered at $1400^{\circ} \mathrm{C}$ for $24 \mathrm{~h}$ in air are $70 \%$, $73 \%$, and $84 \%$, respectively. The possible reason is the formation of different liquid phases $\left(\mathrm{SrCrO}_{4}, \mathrm{Sr}_{2.67}\left(\mathrm{CrO}_{4}\right)_{2}, \mathrm{CaCrO}_{4}, \mathrm{Ca}_{3}\left(\mathrm{CrO}_{4}\right)_{2}\right)$ at different temperatures enhancing the mass transport and subsequent densification.

\subsubsection{A and B-site dopants}

Another possibility of improving densification is the transition metals substitution at B-site of Sr-doped $\mathrm{LaCrO}_{3}[124,127,129]$. It has been suggested that the secondary phases with variable melting temperature form due to reaction of transition metals with $\mathrm{SrCrO}_{4}[126]$. These liquids have higher wettability and lower viscosity which facilitate 
liquid phase sintering. The B-site doping can also lead to the formation of cation vacancies (Eq. (11)) which can increase atomic diffusion and subsequent densification. In addition, the transition metal (B-site) dopants can increase the densification due to the higher diffusion coefficient of the transition metals.

Recently, it is notified that calcination temperature of $\mathrm{Sr}$ (A-site) and Fe (B-site) doped lanthanum chromite plays an important role on the densification of $\mathrm{La}_{0.8} \mathrm{Sr}_{0.2} \mathrm{Cr}_{1-}$ ${ }_{x} \mathrm{Fe}_{x} \mathrm{O}_{3-\delta}(x=0.1-0.5)$ [120]. The amount of $\mathrm{SrCrO}_{4}$ increases with decrease in calcination temperature. Higher amount of $\mathrm{SrCrO}_{4}$ was detected when the calcination temperature decreased from $1200^{\circ} \mathrm{C}$ to $900^{\circ} \mathrm{C}$. This is due to low solubility of $\mathrm{SrCrO}_{4}$ at lower temperatures. Therefore, higher densities $(84-97 \%)$ of sintered $\left(1400^{\circ} \mathrm{C}\right) \mathrm{La}_{0.8} \mathrm{Sr}_{0.2} \mathrm{Cr}_{1-}$ ${ }_{x} \mathrm{Fe}_{x} \mathrm{O}_{3-\delta}(x=0.1-0.5)$ were obtained when calcined below $1200^{\circ} \mathrm{C}$ due to the presence of higher amount of liquid phase. The density of $\mathrm{La}_{0.8} \mathrm{Sr}_{0.2} \mathrm{Cr}_{1-x} \mathrm{Fe}_{x} \mathrm{O}_{3-\delta}$ increases with increase in Fe-dopant level. For instance, the density increases from $\sim 84 \%(x=0.1)$ to $\sim 97(x=0.5)$. On the other hand, the amount of $\mathrm{SrCrO}_{4}$ decreased with increase in $\mathrm{Fe}-$ doping level from $5.8 \mathrm{~mol} \%(x=0.1)$ to $2.7 \mathrm{~mol} \%(x=0.5)$ in the calcined samples at $1000^{\circ} \mathrm{C}[120]$. The reason for the variation in the amount of $\mathrm{SrCrO}_{4}$ with increase in $\mathrm{Fe}-$ doping level is not provided. However, it could be due to the higher amount of Fe doping stabilizes the perovskite phase at lower temperature and therefore, suppresses the exsolution of $\mathrm{SrCrO}_{4}$.

Simner [126] and Ding et al. [129] have provided detailed experimental analysis on sinterability of transition metal doped $\mathrm{La}_{0.85} \mathrm{Sr}_{0.15} \mathrm{Cr}_{1-x} \mathrm{M}_{x} \mathrm{O}_{3}(\mathrm{M}=$ transition metal). 
The density comparison of various transition metal doped $\mathrm{La}_{0.85} \mathrm{Sr}_{0.15} \mathrm{Cr}_{1-x} \mathrm{M}_{x} \mathrm{O}_{3}(\mathrm{M}=\mathrm{Ni}$, $\mathrm{Co}$ and $\mathrm{Cu}$ ) is shown in Fig. 18 [126,129]. The density increases with increase in temperature $\left(1300-1650^{\circ} \mathrm{C}\right)$. Nickel, cobalt, and copper have significant effect on the densification $[126,129,131]$. The trend shows nickel substitution provides the highest density. It is postulated that the transition metal decreases the formation melting temperature of liquid phases in $\mathrm{La}_{0.85} \mathrm{Sr}_{0.15} \mathrm{Cr}_{1-x} \mathrm{M}_{x} \mathrm{O}_{3}$ and enhance densification although no evidence is available [132].

Koc et al. [133] have shown the increased densification of $\mathrm{La}_{0.9} \mathrm{Sr}_{0.1} \mathrm{Cr}_{1-x} \mathrm{Mn}_{x} \mathrm{O}_{3}$ when $\mathrm{Cr}$ is partially substituted with $\mathrm{Mn}$ as shown in the micrograph (Fig. 19). The increase in density from $\sim 78 \%$ for $x=0.5$ to $\sim 95 \%$ for $x=0.7$ at $1475^{\circ} \mathrm{C}$ is suggested due to the presence of higher $\mathrm{Mn}^{4+}$ ions resulting in more cation site vacancies facilitating mass transport [133]. The defect reaction for the formation of cation site vacancies on $\mathrm{Mn}^{3+}$ to $\mathrm{Mn}^{4+}$ transition can be written as:

$3 \mathrm{Mn}_{\mathrm{Mn}}^{\mathrm{X}} \rightarrow 3 \mathrm{Mn}_{\mathrm{Mn}}+\mathrm{V}_{\mathrm{Mn}}^{\prime \prime \prime}$

where $\mathrm{Mn}_{\mathrm{Mn}}^{\mathrm{x}}, \mathrm{Mn}_{\mathrm{Mn}}$ and $\mathrm{V}_{\mathrm{Mn}}^{\prime \prime \prime}$ denotes $\mathrm{Mn}^{3+}$ on $\mathrm{Mn}^{3+}$ site leading to neutral $(\mathrm{x})$ charge, $\mathrm{Mn}^{4+}$ on $\mathrm{Mn}^{3+}$ site with an extra positive $(\cdot)$ charge, and $\mathrm{Mn}^{3+}$ cation vacancy with three negative (') charges respectively.

4.3. Oxygen non-stoichiometry 
Undoped lanthanum chromite is a stoichiometric oxide at least upto $1000^{\circ} \mathrm{C}$ and 0.21-10 ${ }^{-20}$ atm $\mathrm{P}_{\mathrm{O}_{2}}$ range [134-135]. On tailoring $\mathrm{LaCrO}_{3}$ composition by dopants, deviation of oxygen content is often observed to maintain the charge neutrality in the crystal structure and thermodynamic equilibrium [47,136-137]. The deviation of oxygen content, $\delta$, is known as oxygen non-stoichiometry. For example, $20 \mathrm{~mol} \% \mathrm{Ca}$ doping creates 1.2 mol\% oxygen vacancies (Eq. (8)) [99]. Increment in oxygen deficiency with reducing $\mathrm{P}_{\mathrm{O}_{\mathrm{x}}}$ is due to generation of higher oxygen vacancies. However, only reducing atmosphere is not responsible to induce detectable oxygen vacancies in doped $\mathrm{LaCrO}_{3}$ $[111,134]$. This may be attributed to the bonding and packing structure of doped $\mathrm{LaCrO}_{3}$ [137].

The stability of the material tends to decrease with increase in $\delta$ due to the lattice expansion and stress generation in presence of the oxygen vacancies. This may lead to failure of the membrane when the vacancies are present in excess. Dissociation of the chromite based materials is also possible due to large variance in $\delta$ [138].

\subsubsection{A-site dopants}

Fig. 20a shows the effect of type and amount of dopants, and $\mathrm{P}_{\mathrm{O}_{2}}$ on oxygen nonstoichiometry while Fig. 20b shows the temperature effect [138-142]. A general trend is followed. The amount of oxygen non-stoichiometry increases with dopant concentration, temperature and $\mathrm{P}_{\mathrm{O}_{2}}$. On partial substitution of lanthanum $\left(\mathrm{La}^{3+}\right)$ with alkaline earth metals $\left(\mathrm{Sr}^{2+} / \mathrm{Ca}^{2+}\right)$ to form $\mathrm{La}_{1-x} \mathrm{Sr}_{x} \mathrm{CrO}_{3-\delta}$, a loss of positive charge is compensated by $\mathrm{Cr}^{3+} \rightarrow \mathrm{Cr}^{4+}$ (Eq. (14)) in oxidizing atmosphere. However, the $\mathrm{Cr}^{4+}$ reduces to $\mathrm{Cr}^{3+}$ in 
reducing atmosphere and the charge compensation is occurred by the formation of oxygen vacancy (Eq. (9)).

With increase in dopant ( $\mathrm{Sr}$ and $\mathrm{Ca}$ ) concentration, oxygen vacancies concentration also increase to maintain the charge electro-neutrality in reducing atmosphere. The oxygen non-stoichiometry $(\delta)$ deviation increases further with increase in temperature and decrease in $\mathrm{P}_{\mathrm{O}_{2}}$ as shown in Fig. 20b [140]. Oxygen vacancies (oxygen non-stoichiometry) promote oxygen ion conduction. Therefore, the increase in oxygen vacancies corresponds to increase in oxygen ion conductivity of $\mathrm{Ca} / \mathrm{Sr}$ doped $\mathrm{LaCrO}_{3}$ with decrease in $\mathrm{P}_{\mathrm{O}_{2}}$. For instance, the ionic conductivity of $\mathrm{La}_{0.9} \mathrm{Ca}_{0.1} \mathrm{Cr}_{1.03} \mathrm{O}_{3-\delta}$ increases from $1.59 \times 10^{-6}$ to $3.53 \times 10^{-5} \mathrm{~S} \mathrm{~cm}^{-1}$ when $\mathrm{P}_{\mathrm{o}_{z}}$ decrease from 0.21 to $10^{-15}$ atm at $1015^{\circ} \mathrm{C}$, respectively. Similarly, $\mathrm{Sr}$-doped $\mathrm{La}_{0.87} \mathrm{Sr}_{0.13} \mathrm{Cr}_{1.03} \mathrm{O}_{3-\delta}$ oxygen ion conductivity increases from $4.01 \times 10^{-6} \mathrm{~S} \mathrm{~cm}^{-1}$ at $\mathrm{P}_{\mathrm{O}_{z}} \sim 0.21$ atm to $1.95 \times 10^{-5} \mathrm{~S} \mathrm{~cm}^{-1}$ at $\mathrm{P}_{\mathrm{O}_{z}} \sim 10^{-15}$ atm and $1015^{\circ} \mathrm{C}$.

It is to note that the type of commonly used A-site dopants i.e. $\mathrm{Sr}$ and $\mathrm{Ca}$ has no distinct effect on oxygen non-stoichiometry (Fig. 20a) and a saturation value in oxygen stoichiometry is observed at half of the substituents, i.e., $x / 2$. Also, there is no significant difference in the oxygen ionic conductivity of $\mathrm{Sr} / \mathrm{Ca}$ doped $\mathrm{LaCrO}_{3}$ at different $\mathrm{P}_{\mathrm{O}_{2}}$. This means the defect reaction kinetics is same for both the dopants [140].

\subsection{2. $\quad$ B-site dopants}


For B site dopants, no specific relation between oxygen non-stoichiometry with type and concentration can be drawn because of limited information [138]. Unlike A-site dopants, the oxygen non-stoichiometry varies differently depending on the type of Bdopants. At $800^{\circ} \mathrm{C}$ and $\mathrm{P}_{\mathrm{O}_{2}}<10^{-10}$ atm, the amount of oxygen nonstoichiometry increases in the order of $\mathrm{Ni}>\mathrm{Co}>\mathrm{Mg}>\mathrm{Fe}>\mathrm{Ti}$ for $10 \mathrm{~mol} \%$ B-site doping [138]. No significant variation in oxygen non-stoichiometry is observed for $\mathrm{LaCr}_{0.9} \mathrm{Ti}_{0.1} \mathrm{O}_{3-\delta}$ perovskite at $800^{\circ} \mathrm{C}$ in the wide range of $\mathrm{P}_{\mathrm{O}_{2}}\left(\sim 10^{-5}-10^{-20}\right.$ atm) [138]. This is associated with no change in the valence state of titanium in the perovskite. Fig. 20c shows the deviation in $\delta$ for Bsite doped $\mathrm{LaCr}_{0.9} \mathrm{M}_{0.1} \mathrm{O}_{3-\delta}(\mathrm{M}=\mathrm{Fe}, \mathrm{Ni}$ and $\mathrm{Co})$ at $1000^{\circ} \mathrm{C}$ in the $\mathrm{P}_{\mathrm{O}_{2}}$, range of $\sim 10^{-5}-10^{-20}$ atm. Comparatively, less deviation in $\delta$ is observed for Fe than $\mathrm{Ni}$ and Co-doping. However, the oxygen stoichiometry for $\mathrm{Ni}$ and Co dopants is comparable as shown in Fig. 20c. The possible reason is the existence of different oxidation state of B-site dopants. For instance, cobalt exists in mixed valence state i.e. $\mathrm{Co}^{2+} / \mathrm{Co}^{3+}[138]$. On the other hand, the reduction of $\mathrm{Co}^{3+} \rightarrow \mathrm{Co}^{2+}$ also leads to the formation of oxygen vacancies for the charge balance in reducing gas atmosphere.

Point defects including oxygen vacancies in oxides may interact with lattice ions and other defects by columbic attraction with negative ions/cation vacancy resulting in the formation of localized defect cluster, repulsion between similarly charged ions/defects, and localized change in energy bandwidth [136,137,143,144]. Interaction of oxygen vacancy with lattice is proven for doped $\mathrm{LaCrO}_{3}$ but the type and extent of interaction has not been understood [139]. The interaction of defects among themselves and lattice depends on dopant type and level. The interaction is stronger for B-site 
dopants than A-site dopants [138-139,141]. This suggests that the defect reaction kinetics for B-site doping is more complex than A-site doping.

\subsubsection{A-site and B-site dopants}

No specific trend is observed for type and concentration for simultaneous A and B-site doped $\mathrm{LaCrO}_{3}[141,145,146-148]$. For example, oxygen non-stoichiometry increases with increase in $\mathrm{Al}$ doping for $10 \mathrm{~mol} \% \mathrm{Ca}$-doped $\mathrm{LaCrO}_{3}$ but decreases with increasing Ti doping in 30 mol\% $\mathrm{Sr}$ doped $\mathrm{LaCrO}_{3}[141,145]$. Al exists only in $\mathrm{Al}^{3+}$ state. Subsequently, Al will create oxygen vacancies by substituting $\mathrm{Cr}^{4+}$ ions in doped $\mathrm{LaCrO}_{3}$, resulting in increasing oxygen non-stoichiometry with $\mathrm{Al}$ content for $\mathrm{La}_{0.9} \mathrm{Ca}_{0.1} \mathrm{Cr}_{1-y} \mathrm{Al}_{y} \mathrm{O}_{3-\delta}[145]$. On the other hand, Ti may exist in $\mathrm{Ti}^{3+}$ and $\mathrm{Ti}^{4+}$ valance states [148]. Depending on $\mathrm{Cr}^{4+}$ amount in $\mathrm{LaCrO}_{3}$, there will be a redox reaction involving $\mathrm{Ti}$ and $\mathrm{Cr}$ valance change compensating the charge balance associated with partial molar free energy, sufficient to reduce significant oxygen vacancies $[137,148]$. Fig. 20d shows the change in oxygen non-stoichiometry for simultaneously doped $\mathrm{La}_{0.7} \mathrm{Sr}_{0.3} \mathrm{Cr}_{1-x} \mathrm{Ti}_{x} \mathrm{O}_{3-\delta}(x=0.1-0.3)$ and compared with only A-site doped $\mathrm{La}_{0.7} \mathrm{Sr}_{0.3} \mathrm{CrO}_{3-\delta}$ at $1000^{\circ} \mathrm{C}$ in the $\mathrm{P}_{\mathrm{O}_{2}}$ range of $0.21-10^{-20}$ atm. It is observed that the simultaneously $\mathrm{Sr}$ (A-site) and Ti (B-site) doped $\mathrm{La}_{0.7} \mathrm{Sr}_{0.3} \mathrm{Cr}_{1-x} \mathrm{Ti}_{x} \mathrm{O}_{3-\delta}(x=0.1-0.3)$ shows less deviation from oxygen stoichiometry when compared to $\mathrm{Sr}$-doped $\mathrm{La}_{0.7} \mathrm{Sr}_{0.3} \mathrm{CrO}_{3-\delta}$. This is associated with the existence of $\mathrm{Ti}^{4+}$ acting as donor dopant which can compensates for the loss of the positive charge for $\mathrm{Sr}^{2+}$ rather than oxygen vacancy formation in reducing 
gas atmosphere [143]. With increase in Ti doping, the deviation goes further down (Fig. 20d) due to increase in $\mathrm{Ti}^{4+}$ and donor dopant.

Fig. 20e shows the comparison of oxygen non-stoichiometry of $\mathrm{La}_{0.75} \mathrm{Sr}_{0.3} \mathrm{Cr}_{0.7} \mathrm{Ti}_{0.3} \mathrm{O}_{3-\delta}, \mathrm{La}_{0.75} \mathrm{Sr}_{0.25} \mathrm{Cr}_{0.5} \mathrm{Mn}_{0.5} \mathrm{O}_{3-\delta}$, and $\mathrm{La}_{0.75} \mathrm{Sr}_{0.25} \mathrm{Cr}_{0.5} \mathrm{Fe}_{0.5} \mathrm{O}_{3-\delta}$ as a function of $\mathrm{P}_{\mathrm{O}_{2}}\left(\sim 1-10^{-25}\right.$ atm $)$ at $1000^{\circ} \mathrm{C}$ [141]. It is observed that $\mathrm{Sr}$ and $\mathrm{Ti}$ simultaneously doped $\mathrm{La}_{0.75} \mathrm{Sr}_{0.3} \mathrm{Cr}_{0.7} \mathrm{Ti}_{0.3} \mathrm{O}_{3-\delta}$ does not show any significant deviation from oxygen stoichiometry when compared to $\mathrm{La}_{0.75} \mathrm{Sr}_{0.25} \mathrm{Cr}_{0.5} \mathrm{Mn}_{0.5} \mathrm{O}_{3-\delta}$ and $\mathrm{La}_{0.75} \mathrm{Sr}_{0.25} \mathrm{Cr}_{0.5} \mathrm{Fe}_{0.5} \mathrm{O}_{3-\delta}$. This is because $\mathrm{Mn}$ and $\mathrm{Fe}$ can exist in different valence state of $4+, 3+$ and $2+$. Due to the change in valence state of $\mathrm{Mn} / \mathrm{Fe}$, the charge compensation occurs by oxygen vacancies formation in the LSCM/LSCF perovskite lattice, resulting in larger deviation from oxygen stoichiometry. For instance, this is shown in Eq. (20) and (21) for LSCF perovskite [141].

$$
\begin{aligned}
& \frac{1}{2} \mathrm{O}_{2}+\mathrm{V}_{\mathrm{o}}^{*}+2 \mathrm{Fe}_{\mathrm{Fe}}^{\times}=\mathrm{O}_{\mathrm{o}}^{\times}+2 \mathrm{Fe}_{\mathrm{Fe}} \\
& \frac{1}{2} \mathrm{O}_{2}+\mathrm{V}_{\mathrm{o}}^{*}+2 \mathrm{Fe}_{\mathrm{Fe}}^{\mathrm{x}}=\mathrm{O}_{\mathrm{o}}^{\mathrm{x}}+2 \mathrm{Fe}_{\mathrm{Fe}}^{\mathrm{x}}
\end{aligned}
$$

where $\mathrm{Fe}_{\mathrm{Fe}}^{\times}$refers to $\mathrm{Fe}^{3+}$ on $\mathrm{Fe}^{3+}$ sites, $\mathrm{Fe}_{\mathrm{Fe}}^{-}$refers to $\mathrm{Fe}^{4+}$ on $\mathrm{Fe}^{3+}$ sites, $\mathrm{Fe}_{\mathrm{Fe}}^{8}$ refers to $\mathrm{Fe}^{2+}$ on $\mathrm{Fe}^{3+}$ sites, and $\mathrm{v}_{0}^{\cdot}$ refers to oxygen vacancy with two positive charges.

According to the above oxygen non-stoichiometry discussion, it would be beneficial to dope lanthanum chromite based material with $\mathrm{Sr}$ and $\mathrm{Ti}$ dopants at A-site and B-site respectively for higher redox stability of OTM. On the other hand, it is known that oxygen ion conductivity increases with increase in oxygen vacancies or decrease in 
$\mathrm{P}_{\mathrm{O}_{z}}$. For example, $\left(\mathrm{La}_{0.75} \mathrm{Sr}_{0.25}\right)_{0.95} \mathrm{Cr}_{0.5} \mathrm{Mn}_{0.5} \mathrm{O}_{3-\delta}$ ionic conductivity increases from

$3.1 \times 10^{-5}$ to $2.2 \times 10^{-4}$ when $\mathrm{P}_{\mathrm{O}_{z}}$ decrease from 0.21 to $10^{-15}$ atm at $950^{\circ} \mathrm{C}$, respectively.

[149] The corresponding transference number (the fraction of the total current carried by

a given ion $\left(\mathrm{O}^{2-}\right)$ in OTM, $\left.t_{\text {ion }}=\frac{\sigma_{\text {ion }}}{\sigma_{\text {ion }}+\sigma_{g l}}\right)$ also increases from $8.9 \times 10^{-7}$ to $5.6 \times 10^{-5} \mathrm{~S} \mathrm{~cm}^{-1}$

with increase in oxygen ion conductivity, respectively. The oxygen vacancies also increase with increase in dopant level. For instance, the ionic conductivity of $\left(\mathrm{La}_{0.75} \mathrm{Sr}_{0.25}\right)_{0.95} \mathrm{Cr}_{1-x} \mathrm{Fe}_{x} \mathrm{O}_{3-\delta}$ is $0.056 \mathrm{~S} \mathrm{~cm}^{-1}(x=0.3, \delta=0.16)$ and $0.079 \mathrm{~S} \mathrm{~cm}^{-1}(x=0.4, \delta$ $=0.19)$ at $950^{\circ} \mathrm{C}$ and $\mathrm{P}_{\mathrm{O}_{z}} \sim 10^{-17}$ atm [33]. Similarly, the transference number increases from 0.04 to 0.15 , respectively. With increase in Fe-doping level, the ionic conductivity increases due to increase in oxygen vacancy concentration. It is noted that higher ionic conductivity and transference number is obtained for Fe-doping. This could be due to the variation in the disproportion of valence state of $\mathrm{Mn} / \mathrm{Fe}$ and oxygen vacancies formation. This suggests that Fe doping at B-site would be more beneficial over Mn-doping to induce mixed ionic-electronic conductivity in lanthanum chromite based materials. However, Ti-doping would be suitable from redox stability point of view. From author's perspective, it is suggested to use co-doping of transition metal (e.g. Fe) at B-site with $\mathrm{Ti}$ to obtain mixed conductivity and redox stability at the same time. However, an in-depth study is required to understand the co-doping effect and optimize doping level.

Microscopic level change in crystal lattice due to oxygen non-stoichiometry significantly affects $\mathrm{LaCrO}_{3}$ properties such as thermal expansion, electronic and ionic conductivity, catalytic property for oxygen reduction, and thermo-mechanical and 
thermochemical stability $[33,111,134,136-137,142,146-152]$. The effect of oxygen nonstoichiometry on $\mathrm{LaCrO}_{3}$ properties will be discussed in subsequent sections.

\subsection{Thermal expansion}

$\mathrm{LaCrO}_{3}$-based perovskites are in contact with fluorite phases such as YSZ (yttriastabilized zirconia), ScSZ (scandia stabilized zirconia) or GDC (gadolinium doped cerium oxide) in dual phase composite OTM and adjacent component layers (intermediate and surface exchange layers) consisting of perovskite-fluorite composites [153-154]. Thermal expansion mismatch between $\mathrm{LaCrO}_{3}$-based perovskites and the adjacent materials can lead to thermal stress $(\sigma)$ according to the equation [155] below: $\sigma=\frac{\mathrm{E}}{1-\theta} \Delta \alpha\left(T-\mathrm{T}_{0}\right)$

where, $\mathrm{E}$ is the Young modulus and $\theta$ is the Poisson ratio of the $\mathrm{LaCrO}_{3}$ based perovskites, $\Delta \alpha$ is the difference in thermal expansion coefficient (TEC) between $\mathrm{LaCrO}_{3}$ based perovskite and the adjacent material, $T$ is the operating temperature and $T_{0}$ is the stress free temperature. The fabrication temperature is generally considered as $T_{0}$ which can be the operating temperature if the stress is relaxed due to material deformation. If $T$ $<\mathrm{T}_{0}$, compressive and tensile stress will be developed, respectively, for positive and negative value of $\Delta \alpha$. Cracks and warpage may develop at the interfaces of adjacent materials and components due to thermal stress, leading to gas leakage and mechanical failure during operation and thermal cycling during start up and shut down. The tolerable TEC difference is $\sim 1.0 \times 10^{-6}{ }^{\circ} \mathrm{C}^{-1}$ [156-157]. The fluorite phase considered for OTM is 
either YSZ or GDC or ScSZ. The thermal expansion coefficient (TEC) of 8YSZ (8 mol $\%$ yttria doped zirconia) is $\sim 10.3 \times 10^{-6}{ }^{\circ} \mathrm{C}^{-1}$ up to $1000^{\circ} \mathrm{C}$ under both oxidizing and reducing atmosphere $[112,158]$. The TEC of GDC20 (20 mol \% gadolinium doped ceria) and $8 \mathrm{ScSZ}\left(8 \mathrm{~mol} \%\right.$ scandia doped zirconia) are $\sim 12.9 \times 10^{-6}{ }^{\circ} \mathrm{C}^{-1}$ and $11.9 \times 10^{-6}{ }^{\circ} \mathrm{C}^{-1}$ in the temperature range of $50-900^{\circ} \mathrm{C}$ and $370-1000^{\circ} \mathrm{C}$, respectively [159-160]. However, in GDC, $\mathrm{Ce}^{4+}$ reduces to $\mathrm{Ce}^{3+}$, and the charge compensation occurs by the formation of oxygen vacancies as shown in the below redox reaction:

$2 \mathrm{Ce}_{\mathrm{Ce}}^{\mathrm{x}}+\mathrm{O}_{\mathrm{O}}^{\mathrm{X}} \rightarrow \frac{1}{2} \mathrm{O}_{2}(\mathrm{~g})+\mathrm{V}_{\mathrm{O}}^{\prime}+2 \mathrm{Ce}_{\mathrm{Ce}}^{\prime}$

where $\mathrm{Ce}_{\mathrm{Ce}}^{\mathrm{x}}$ refers to $\mathrm{Ce}^{4+}$ on $\mathrm{Ce}^{4+}$ site, $\mathrm{Ce}_{\mathrm{Ce}}^{\prime}$ refers to $\mathrm{Ce}^{3+}$ on $\mathrm{Ce}^{4+}$ site, and $\mathrm{V}_{\mathrm{o}}^{*}$ refers to oxygen vacancy with two positive charges.

It indicates that GDC is not very stable in reducing atmosphere due to the oxygen vacancies formation leading to significant increase in lattice expansion. This generates micro-cracks as well as pin holes on the surface and at the fracture of GDC electrolyte. [161] Yttria-stabilized zirconia (YSZ) is one of the most common oxygen ion conductive and stable material which can be used as a fluorite phase in oxygen separation membrane and the other layers $[42,162-163]$.

For the above reason, the lanthanum chromite based membranes are expected to have similar thermal expansion coefficient (TEC) as fluorite phase (YSZ). However, the average TEC of $\mathrm{LaCrO}_{3}$ was measured in the range of $8.1-8.6 \times 10^{-6}{ }^{\circ} \mathrm{C}^{-1}$ in both air and $\mathrm{H}_{2}$ atmosphere in the temperature range of $50-1000^{\circ} \mathrm{C}[99,112,134,162]$. The thermal expansion coefficient of $\mathrm{LaCrO}_{3}$ is $4.6 \times 10^{-6}{ }^{\circ} \mathrm{C}^{-1}$ and $9.4 \times 10^{-6}{ }^{\circ} \mathrm{C}^{-1}$ in the temperature range of $\sim 40-275^{\circ} \mathrm{C}$ and $\sim 290-1050^{\circ} \mathrm{C}$ respectively [165]. Recently, the change in TEC 
due to high temperature cubic phase formation at $\sim 1300^{\circ} \mathrm{C}$ is reported as $9.8 \times 10^{-6}{ }^{\circ} \mathrm{C}^{-1}$ in the temperature range of $1100-1395^{\circ} \mathrm{C}$ [113].

Under OTM operating conditions, the TEC of lanthanum chromite based material can be influenced by three factors: change in valence state and ionic radius of dopant, oxygen nonstoichiometry or oxygen loss, and decrease in elastic modulus or interatomic bond strength [112]. The variation in valence state of cation-dopant changes the ionic radii of the cation and increases/decreases the lattice dimension [166]. Oxygen nonstoichiometry or oxygen loss introduces oxygen vacancies into the lattice, resulting in the lattice expansion [166]. Dopants in $\mathrm{LaCrO}_{3}$ can result into deformation of chromiumoxygen polyhedral and weakens the $\mathrm{Cr}-\mathrm{O}$ covalent bond linkages. The decrease in interatomic bond strength or elastic modulus could increase the probability of the lattice to expand more on increasing the temperature and lead to higher thermal expansion. The TEC of doped- $\mathrm{LaCrO}_{3}$ depends on the type and level of dopants. Therefore, dopant type and their concentration are needed to control the TEC and stability of the membrane material under the OTM operation conditions.

\subsubsection{A-site dopants}

Alkaline earth metals, $\mathrm{Ca}(0.134 \mathrm{~nm})$ and $\mathrm{Sr}(0.144 \mathrm{~nm})$ have comparable ionic radii to $\mathrm{La}^{3+}$ ion $(0.136 \mathrm{~nm})$ [167]. When $\mathrm{LaCrO}_{3}$ is doped at A-site by divalent alkaline earth metals $(\mathrm{Ca}, \mathrm{Sr})$, the $\mathrm{La}^{3+}$ ions are substituted by $\mathrm{Ca}^{2+} / \mathrm{Sr}^{2+}$. To maintain the electroneutrality, the decrease in positive charge is compensated by a change in valence state of chromium from $\mathrm{Cr}^{3+}$ to $\mathrm{Cr}^{4+}$ (Eq. (14)), resulting in the lattice contraction due to 
change in ionic radii $\left(\mathrm{r}_{\mathrm{Cr}}^{4+}<\mathrm{rrr}^{\mathrm{z}+}\right)$. In reducing atmosphere, the charge is compensated by the formation of oxygen vacancies (Eq. (15)) resulting into an increase in thermal expansion. This can also be due to increase in cation-cation repulsion as in-between bridging oxygen ion is removed (oxygen vacancy formation) [168]. Fig. 21 shows the TEC of $\mathrm{La}_{1-x}(\mathrm{Sr} / \mathrm{Ca})_{x} \mathrm{CrO}_{3}$ with various dopant concentrations $(x=0.1-0.3)$ and $\mathrm{YSZ}$ in air and $\mathrm{H}_{2}$ atmosphere in the temperature range of $50-1000^{\circ} \mathrm{C}[112,129,134,169]$. The TEC of both $\mathrm{Sr}$ and $\mathrm{Ca}$ doped $\mathrm{LaCrO}_{3}$ increases with increase in dopant concentration. This is explained by the increase of the thermal expansion coefficient of $\mathrm{O}^{2-}-\mathrm{O}^{2-}$ and $\mathrm{Cr}^{3-}$ $-\mathrm{O}^{2-}$ distances using molecular dynamics calculation [103]. However, the TEC variation for $\mathrm{La}_{1-x} \mathrm{Ca}_{x} \mathrm{CrO}_{3}$ is significantly larger than $\mathrm{La}_{1-x} \mathrm{Sr}_{x} \mathrm{CrO}_{3}$. According to Fig. 21, $\mathrm{La}_{1-x} \mathrm{Sr}_{x} \mathrm{CrO}_{3}(x \sim 0.1)$ appears to be a promising candidate with comparable TEC as YSZ $\left(\sim 10.3 \times 10^{-6}{ }^{\circ} \mathrm{C}^{-1}\right)$ in both air and $\mathrm{H}_{2}$ atmosphere. It is noted that there is a variation in the thermal expansion coefficient of same composition reported by different authors. The reason for the variation is not known. Sr-doped $\mathrm{LaCrO}_{3}$ is more preferred than $\mathrm{Ca}$ due to comparable TEC with YSZ [132].

\subsubsection{A and B-site dopants}

Transition metals (Mn, Ni, Fe, Co, $\mathrm{Al}$ and Ti) as B-site dopant also tune the TEC of $\mathrm{LaCrO}_{3}$ based perovskites [112,169-171]. The mechanism for change in the thermal expansion of $\mathrm{La}_{1-x} \mathrm{Sr}_{x} \mathrm{CrO}_{3}$ doped with transition metal can be explained by varying average ionic radius of B-site dopants [112,132]. Mori et al. [112] have illustrated the same by plotting the subtracted TEC of $\mathrm{La}_{0.9} \mathrm{Sr}_{0.1} \mathrm{Cr}_{1-x} \mathrm{M}_{x} \mathrm{O}_{3}(x=0.05 ; \mathrm{M}=\mathrm{Mg}, \mathrm{Al}$, Ti, 
$\mathrm{Mn}, \mathrm{Fe}, \mathrm{Co}, \mathrm{Ni}$ ) from $\mathrm{La}_{0.9} \mathrm{Sr}_{0.1} \mathrm{CrO}_{3}$ in the temperature range of $50-1000^{\circ} \mathrm{C}$ versus ionic radii of B-site dopant in air and $\mathrm{H}_{2}$ atmosphere as shown in Fig. 22a and 22b, respectively. The increment in TEC is the most for cobalt dopant. At low temperature, cobalt ions exist in $3+$ valence state with low spin and ionic radius of $0.068 \mathrm{~nm}$. With increasing temperature (up to $-73^{\circ} \mathrm{C}$ ), it transforms from low to high spin state with ionic radii of $0.075 \mathrm{~nm}$. Further increase in temperature transforms the pair of low and high spin cobalt with $3+$ valance state to low spin cobalt with $2+(r=0.079 \mathrm{~nm})$ and $4+(\mathrm{r}=$ $0.067 \mathrm{~nm})$ valence state $[112,172-173]$. This shows that the increase in the TEC is related to the change in valence state of B-site dopant, ionic radii and/or spin [172]. Similarly, the higher TEC of Mn-doped $\mathrm{La}_{0.9} \mathrm{Sr}_{0.1} \mathrm{Cr}_{1-x} \mathrm{Mn}_{x} \mathrm{O}_{3}$ is due to the change in valence state between $\mathrm{Mn}^{4+}(0.067 \mathrm{~nm}), \mathrm{Mn}^{3+}$ (high-spin, $0.078 \mathrm{~nm}$ ), and $\mathrm{Mn}^{2+}$ ions (low-spin, 0.081 $\mathrm{nm})$ leading to the increase in average ionic radii of B-site cation at high temperature [112]. Lower thermal expansion of $\mathrm{La}_{0.85} \mathrm{Sr}_{0.15} \mathrm{Cr}_{0.95} \mathrm{Ni}_{0.05} \mathrm{O}_{3}$ is observed when $\mathrm{Cr}$ is substituted by Ni due to increase in inter-atomic bond strength [132,172]. Fig. 23 shows the deviation in thermal expansion coefficient of $\mathrm{La}_{1-y} \mathrm{Sr}_{y} \mathrm{Cr}_{1-x} \mathrm{M}_{x} \mathrm{O}_{3}(y=0.05$ or 0.1 and $x$ $=0.05 ; \mathrm{M}=\mathrm{Mg}, \mathrm{Al}, \mathrm{Ti}, \mathrm{Mn}, \mathrm{Fe}, \mathrm{Co}, \mathrm{Ni})$ with $8 \mathrm{YSZ}$ in air and $\mathrm{H}_{2}$ gas $[112,129,171]$. It has been observed that the A-site deficiency can significantly reduce the volume expansion [149]. Tao et al. [149] have measured the average thermal expansion coefficient (TEC) of $\left(\mathrm{La}_{0.75} \mathrm{Sr}_{0.25}\right)_{0.95} \mathrm{Cr}_{0.5} \mathrm{Mn}_{0.5} \mathrm{O}_{3-\delta}(\mathrm{LSCM})$ to be $9.3 \times 10^{-6}{ }^{\circ} \mathrm{C}^{-1}$ in air, close to YSZ $\left(10.3 \times 10^{-6}{ }^{\circ} \mathrm{C}^{-1}\right)$ in the temperature range of $60-950^{\circ} \mathrm{C}$. Another study on $\left(\mathrm{La}_{0.75} \mathrm{Sr}_{0.25}\right)_{0.95} \mathrm{Cr}_{0.5} \mathrm{Mn}_{0.5} \mathrm{O}_{3-\delta}$ composition has shown linear TEC of $\sim 12.7 \times 10^{-6}{ }^{\circ} \mathrm{C}^{-1}$ and $\sim 11.7 \times 10^{-6}{ }^{\circ} \mathrm{C}^{-1}$ in oxidizing $\left(\mathrm{P}_{\mathrm{O}_{2}}=0.21 \mathrm{~atm}\right)$ and reducing 
atmosphere $\left(\mathrm{P}_{\mathrm{O}_{2}}=5 \times 10^{-21}-3 \times 10^{-14} \mathrm{~atm}\right)$ respectively in the temperature range of 650-950 ${ }^{\circ} \mathrm{C}$ [32]. The average thermal expansion coefficient of $\mathrm{La}_{0.75} \mathrm{Sr}_{0.25} \mathrm{Cr}_{0.5} \mathrm{Mn}_{0.5} \mathrm{O}_{3}$ is reported to be $11.4 \times 10^{-6}{ }^{\circ} \mathrm{C}^{-1}$ in air between 30 and $900^{\circ} \mathrm{C}$ [174], which is higher than the TEC $\left(9.3 \times 10^{-6}{ }^{\circ} \mathrm{C}^{-1}\right)$ reported by Tao et al. [149]. The TEC of $\mathrm{La}_{0.75} \mathrm{Sr}_{0.25} \mathrm{Cr}_{0.5} \mathrm{Mn}_{0.5} \mathrm{O}_{3}$ is reduced to $10.3 \times 10^{-6}{ }^{\circ} \mathrm{C}^{-1}$ with the addition of YSZ phase forming LSCM (50\%)/YSZ (50\%) composite. This results into TEC match of the composite with YSZ [174]. However, an addition of Sm-doped ceria $\left(\mathrm{Ce}_{0.8} \mathrm{Sm}_{0.2} \mathrm{O}_{1.9^{-}}\right.$ SDC) fluorite phase to LSCM does not significantly change the TEC when compared to LSCM. The TEC's of LSCM $-x \operatorname{SDC}(x=10-50$ wt. $\%)$ range from $11.7 \times 10^{-6}{ }^{\circ} \mathrm{C}^{-1}$ $11.5 \times 10^{-6}{ }^{\circ} \mathrm{C}^{-1}$ and similar to $\operatorname{LSCM}\left(11.6 \times 10^{-6}{ }^{\circ} \mathrm{C}^{-1}\right)$ in the temperature range of RT$800^{\circ} \mathrm{C}[175]$.

$\left(\mathrm{La}_{0.75} \mathrm{Sr}_{0.25}\right)_{0.95} \mathrm{Cr}_{1-x} \mathrm{Fe}_{x} \mathrm{O}_{3-\delta}(x=0.3-0.4)$ has been considered to be one of the promising material for fuel side electrode $[33,120]$, and can be used as OTM. This is because, it provides the combination of high electrochemical activity and good chemical compatibility with electrolyte. It is reported that the average TEC's of $\left(\mathrm{La}_{0.75} \mathrm{Sr}_{0.25}\right)_{0.95} \mathrm{Cr}_{1-}$ ${ }_{x} \mathrm{Fe}_{x} \mathrm{O}_{3-\delta}(0.3-0.4)$ are almost independent of $x$, and lies in between $11.1-11.3 \times 10^{-6}{ }^{\circ} \mathrm{C}^{-1}$ in air and $10.3-10.5 \times 10^{-6}{ }^{\circ} \mathrm{C}^{-1}$ in $\mathrm{CO}-\mathrm{CO}_{2}\left(\mathrm{P}_{\mathrm{O}_{2}} \sim 10^{-12}\right.$ atm at $\left.1097^{\circ} \mathrm{C}\right)$ gas atmosphere in the temperature range of $27^{\circ} \mathrm{C}-1097^{\circ} \mathrm{C}$. The TEC is slightly lower in the reducing gas atmosphere. However, it is still thermally compatible with the most commonly used solid electrolyte i.e. YSZ [33]. Under similar conditions, it is observed that the chemical strain (due to oxygen partial pressure gradient) of $\left(\mathrm{La}_{0.75} \mathrm{Sr}_{0.25}\right)_{0.95} \mathrm{Cr}_{0.5} \mathrm{Mn}_{0.5} \mathrm{O}_{3-\delta}$ is 3-5 times lower than $\left(\mathrm{La}_{0.75} \mathrm{Sr}_{0.25}\right)_{0.95} \mathrm{Cr}_{1-x} \mathrm{Fe}_{x} \mathrm{O}_{3-\delta}[33,174]$. This corresponds to higher thermo- 
mechanical stability of LSCM as needed for oxygen transport membrane and its intermediate layer (fuel oxidation layer).

\subsection{Electrical conductivity}

Oxygen transport membrane (OTM) simultaneously requires electronic and ionic conductive species in the material in case of active OTM where voltage or flow of electron is not externally supplied. $\mathrm{LaCrO}_{3}$ is a p-type electronic conductor and conducts holes by small polaron hopping mechanism [176-177] and has a conductivity of 0.6-1.0 $\mathrm{Scm}^{-1}$ at $1000^{\circ} \mathrm{C}$ in air $[134,176-177]$. The absence of long range order due to the distorted structure of a material leads to localization of charge carrier (hole). The strong interaction between the carrier and phonon results into small polaron formation which move further by activated hopping $[134,178]$. Introduction of dopants increases electronic conductivity and induces ionic conductivity in the $\mathrm{LaCrO}_{3}$ by tailoring the defect chemistry as well as crystal structure and chemical bonding [135,179-180]. In addition to the dopants, oxygen partial pressure $\left(\mathrm{P}_{\mathrm{O}_{2}}\right)$ also varies the electrical conductivity of

$\mathrm{LaCrO}_{3}$ based materials. At lower $\mathrm{P}_{\mathrm{O}_{2}}$, the electrical conductivity decreases due to the reduction in the charge carriers responsible for $\mathrm{p}$-type conduction as the charge compensation on doping occurs by the formation of oxygen vacancies. However, the formation of oxygen vacancies will enhance the oxygen transport and ionic conductivity.

\subsubsection{A-site dopants}


When $\mathrm{La}^{3+}(0.136 \mathrm{~nm})$ ions in $\mathrm{LaCrO}_{3}$ is substituted by $\mathrm{Sr}^{2+}(0.144 \mathrm{~nm})$ and $\mathrm{Ca}^{2+}$ $(0.134 \mathrm{~nm})$ at A-site, the single negative charge on $\mathrm{Sr}\left(\mathrm{Sr}_{\mathrm{La}}^{\prime}\right)$ is compensated by a $\mathrm{Cr}^{3+} \rightarrow \mathrm{Cr}^{4+}$ transition (Eq. (14)) giving rise to the formation of small polaron. As a result, the conductivity of $\mathrm{LaCrO}_{3}$ increases $(\leq 35 \% \mathrm{Sr})$ due to the polaron hopping between $\mathrm{Cr}^{3+}$ and $\mathrm{Cr}^{4+}$ ions [177,181-182]. The expression for electrical conductivity of alkaline earth metal doped $\mathrm{LaCrO}_{3}$ can be written as [134,183]:

$\sigma=\frac{1}{T} \frac{\mathrm{e}^{2} \mathrm{a}^{2}}{6 \mathrm{~K}_{\mathrm{B}} \mathrm{r}_{0}}\left[\mathrm{Cr}^{3+}\right]\left[\mathrm{Cr}^{4+}\right] \exp \left(-\frac{E}{\mathrm{~kg}_{\mathrm{B}} \mathrm{T}}\right)$

where $\sigma, T, \mathrm{e}, \mathrm{k}_{\mathrm{B}}, \mathrm{a}, \tau_{\mathrm{o}},\left[\mathrm{Cr}^{3+}\right],\left[\mathrm{Cr}^{4+}\right]$ and $\mathrm{E}$ are the electrical conductivity, absolute temperature, elementary electric charge, Boltzmann constant, distance traversed in a hop, average free time, $\mathrm{Cr}^{3+}$ mole fraction, $\mathrm{Cr}^{4+}$ mole fraction and activation energy/hopping energy of small polaron respectively.

There is another postulation for the increase in conductivity of $\mathrm{LaCrO}_{3}$ when doped with $\mathrm{Ca} / \mathrm{Sr}$ at A-site. According to the electronic band structure of $\mathrm{La}_{1-x} \mathrm{M}_{x} \mathrm{CrO}_{3-x / 2}$ $(\mathrm{M}=\mathrm{Ba}, \mathrm{Sr}$ and $\mathrm{Ca})$ based on $a b$ initio calculations, the charge carriers adjacent to the top of valence band increases with decrease in band gap for Ba, Sr and Ca doping [167]. The A-site dopants $\left(\mathrm{Ba}, \mathrm{Sr}\right.$ and $\mathrm{Ca}$ ) shift the conduction band of $\mathrm{LaCrO}_{3}$ down by $0.08,0.13$, and $0.14 \mathrm{eV}$, respectively. Accordingly, the energy band gap between top of the valence band and bottom of the conduction band of $\mathrm{LaCrO}_{3}$ decreases from 0.95 to $0.87,0.82$, and $0.81 \mathrm{eV}$ respectively (Fig. 24) [167]. The difference in the electronic band structure and electrical conductivity of $\mathrm{A}$-site doped $\mathrm{LaCrO}_{3}$ is due to the difference in the ionic 
radii of $\mathrm{La}^{3+}$ and $\mathrm{Ca}^{2+} / \mathrm{Sr}^{2+} / \mathrm{Ba}^{2+}$. A larger ionic radius of A-site dopant distorts the perovskite lattice, and results into scattering of the charge carriers [167]. This is why Ba $\left(\mathrm{r}_{\mathrm{Ea}^{\mathrm{I}}}=0.161 \mathrm{~nm}\right)$ is not an appropriate dopant for $\mathrm{LaCrO}_{3}$ because it has larger radii $(18.4 \%)$ than $\mathrm{La}\left(\mathrm{r}_{\mathrm{La}^{\mathrm{I}+}}=0.136 \mathrm{~nm}\right)$. In addition, $\mathrm{BaCr}_{2} \mathrm{O}_{4}$ secondary phase formation in case of $\left(\mathrm{La}_{0.70} \mathrm{Ba}_{0.30}\right) \mathrm{CrO}_{3}$ eliminates $\mathrm{Ba}$ as the choice of dopant [181].

The electrical conductivity variation with temperature and concentration of alkaline earth metal dopants (Sr, Ca) are shown in Fig. 25a (air) and Fig. 25b $\left(\mathrm{H}_{2}\right.$ atmosphere) $[134,167,182-184]$. The conductivity increases with increase in temperature and dopant concentration. Predominantly, $\mathrm{LaCrO}_{3}$ shows lower conductivity on $\mathrm{Sr}$ doping than $\mathrm{Ca}$ in air. This might be due to the smaller lattice parameter of $\mathrm{LaCrO}_{3}$ on Ca-doping than $\mathrm{Sr}$ [177]. However, $\mathrm{La}_{1-x} \mathrm{Sr}_{x} \mathrm{CrO}_{3}$ results into higher conductivity in reducing atmosphere $\left(\mathrm{H}_{2}\right.$ gas $)$ depending on the dopant concentration. It has been observed that the conductivity of $\mathrm{La}_{1-x} \mathrm{Sr}_{x} \mathrm{CrO}_{3}$ increases up to $x \leq 0.35$ and then starts to decrease in air. This may be due to the formation of oxygen vacancies for charge compensation of $\mathrm{Sr}^{2+}$ rather than $\mathrm{Cr}^{3+} \rightarrow \mathrm{Cr}^{4+}$ transition when $x \geq 0.35$ [182]. The conductivity of $\mathrm{La}_{1-x} \mathrm{Ca}_{x} \mathrm{CrO}_{3}(x=0.2,0.5)$ also decreases with higher dopant concentration [183].

In addition to dopants, oxygen vacancies also form in reducing atmosphere (low $\mathrm{P}_{\mathrm{O}_{2}}$ ) to maintain charge neutrality due to change in $\mathrm{Cr}^{4+}$ to $\mathrm{Cr}^{3+}$ valance state (Eq. (9)). The ionic conductivity increases due to the formation of oxygen vacancies. Apart from dopant level, the oxygen defect concentration depends on oxygen partial pressure $\left(\mathrm{P}_{\mathrm{O}_{\mathrm{z}}}\right)$ and temperature (Fig. 20), resulting into change in conductivity [184]. 


\subsubsection{A and B-site dopants}

$\mathrm{La}_{1-x} \mathrm{Sr}_{x} \mathrm{CrO}_{3}$ is doped with transition metals (e.g., Ni, $\mathrm{Co}, \mathrm{Cu}, \mathrm{Mn}, \mathrm{Ti}$ ) to enhance the conductivity along with other properties. Nickel is most stable in its +2 valence state and increases the number of $\mathrm{Cr}^{4+}$ ions when doped in $\mathrm{La}_{1-x} \mathrm{Sr}_{x} \mathrm{CrO}_{3}$ to maintain electroneutrality, contributing to p-type conduction $[129,172]$. Similarly, cobalt doped $\mathrm{La}_{1-x} \mathrm{Sr}_{x} \mathrm{CrO}_{3}$ shows higher conductivity due to the increase in $\mathrm{Co}^{2+}$ ions with temperature and conversion of $\mathrm{Cr}^{3+}$ to $\mathrm{Cr}^{4+}$ for the charge compensation. Copper can exist simultaneously in +2 and +3 valence state. However, $\mathrm{Cu}^{2+}$ contributes towards the increase in charge carriers and electrical conductivity [172].

$\mathrm{La}_{1-x} \mathrm{Ca}_{x} \mathrm{CrO}_{3}$ doped with transition metals (Ni, Fe, and $\mathrm{Mn}$ ) has also been investigated [185]. Iron exists in +3 valence state in $\mathrm{La}_{1-x} \mathrm{Ca}_{x} \mathrm{Cr}_{1-x} \mathrm{Fe}_{x} \mathrm{O}_{3}(x=1 / 4,1 / 3)$ [186]. Therefore, the increase in the valence state of chromium ions and the generation of holes for the conduction is mostly due to Ca substitution on La-site. Similarly, the electrical conductivity varies with $\mathrm{Cr}^{4+}$ ions on manganese doping [172,185,187-188]. However, the charge compensation for Ca-doping in $\mathrm{La}_{0.9} \mathrm{Ca}_{0.1} \mathrm{Cr}_{0.5} \mathrm{Mn}_{0.5} \mathrm{O}_{3}$ is done by $\mathrm{Cr}^{3+} \rightarrow \mathrm{Cr}^{4+}$ and partly by $\mathrm{Mn}^{3+} \rightarrow \mathrm{Mn}^{4+}[185]$. This is due to slightly less ionization energy of the $3 \mathrm{~d}$ electron of the $\mathrm{Cr}^{3+}\left(48.6 \mathrm{eV}\right.$ for $\left.3 \mathrm{~d}^{3}\right)$ than $\mathrm{Mn}^{3+}\left(50.6 \mathrm{eV}\right.$ for $\left.3 \mathrm{~d}^{4}\right)$ unlike $\mathrm{Fe}^{3+}$ $\left(53.7 \mathrm{eV}\right.$ for $\left.3 \mathrm{~d}^{5}\right)$ [185]. In case of $\mathrm{Fe}$ and $\mathrm{Mn}$ doped $\mathrm{La}_{1-x} \mathrm{Ca}_{x} \mathrm{CrO}_{3}$, it is considered that the further change in conductivity is due to the dopants effect on band structure [172].The higher valence $\mathrm{Cr}^{4+}$ ions and the electrical conductivity of the compound $\mathrm{La}_{0.9} \mathrm{Ca}_{0.1} \mathrm{Cr}_{0.5} \mathrm{M}_{0.5} \mathrm{O}_{3}(\mathrm{M}=\mathrm{Ni}, \mathrm{Fe}$ and $\mathrm{Mn})$ increases in the order of $\mathrm{La}_{0.9} \mathrm{Ca}_{0.1} \mathrm{Cr}_{0.5} \mathrm{Ni}_{0.5} \mathrm{O}_{3}$ 
$\left(23.3 \mathrm{~S} \mathrm{~cm}^{-1}\right)>\mathrm{La}_{0.9} \mathrm{Ca}_{0.1} \mathrm{Cr}_{0.5} \mathrm{Fe}_{0.5} \mathrm{O}_{3}\left(3.0 \mathrm{~S} \mathrm{~cm}^{-1}\right)>\mathrm{La}_{0.9} \mathrm{Ca}_{0.1} \mathrm{Cr}_{0.5} \mathrm{Mn}_{0.5} \mathrm{O}_{3}\left(2.2 \mathrm{~S} \mathrm{~cm}^{-1}\right)$ at $727^{\circ} \mathrm{C}$ [185]. Fig. 26 also shows the change in electrical conductivity of different compositions with varying dopant level and increase in temperature in air (and $\mathrm{La}_{0.75} \mathrm{Ca}_{0.25} \mathrm{Cr}_{0.5} \mathrm{Mn}_{0.5} \mathrm{O}_{3}$ in $5 \% \mathrm{H}_{2}$-Ar atmosphere) $[33,129,131,134,189]$. In case of nickel dopant, the conductivity increases with concentration from $x=0.1$ to $x=0.5$. The highest conductivity $\left(72.8 \mathrm{~S} \mathrm{~cm}^{-1}\right)$ is observed for $\mathrm{La}_{0.9} \mathrm{Sr}_{0.1} \mathrm{Cr}_{0.5} \mathrm{Ni}_{0.5} \mathrm{O}_{3}$ at $800^{\circ} \mathrm{C}$. Above $x=0.5$, the conductivity starts to decrease from $72.8(x=0.5)$ to $69.2(x=0.6) \mathrm{S} \mathrm{cm}^{-1}$ due to the formation of secondary phases $\left(\mathrm{Sr}_{2} \mathrm{CrO}_{4},\left(\mathrm{La}_{01.4} \mathrm{Sr}_{0.6}\right) \mathrm{NiO}_{4},\left(\mathrm{La}_{01.6} \mathrm{Sr}_{0.4}\right) \mathrm{NiO}_{4}\right)$ [131].

Composition with $\sim 50 \% \mathrm{Co}, \mathrm{Ni}$ and $\mathrm{Cu}$ doping are not stable under fuel atmosphere since the dopants tend to reduce into metal [188]. It is known that the $\mathrm{FeO}$ and $\mathrm{MnO}$ are stable in fuel atmosphere. However, $\mathrm{FeO}$ reduces to metal at $1000^{\circ} \mathrm{C}$ and $\mathrm{P}_{\mathrm{O}_{2}} \sim 10^{-15}$ atm (calculated using HSC Chemistry 6.0). $\mathrm{MnO}$ is more stable when compared to $\mathrm{FeO}$ [188]. In addition, the possibility of the presence of lower coordination $\mathrm{Mn}^{3+}$ (five-fold) unlike $\mathrm{Cr}^{3+}$ (six-fold) may improve the oxygen-ion migration by inducing oxygen vacancies for oxygen transport. Thus, manganese doping can provide the mixed ionic-electronic conductivity in $\mathrm{La}_{0.9} \mathrm{Sr}_{0.1} \mathrm{Cr}_{1-x} \mathrm{Mn}_{x} \mathrm{O}_{3}$ depending on its concentration [188]. The conductivity of $\mathrm{La}_{0.9} \mathrm{Sr}_{0.1} \mathrm{Cr}_{1-x} \mathrm{Mn}_{x} \mathrm{O}_{3}$ increases with increase in temperature and Mn content up to $x \leq 0.5$ as shown in Fig. 26.

$(\mathrm{La}, \mathrm{Sr})(\mathrm{Cr}, \mathrm{Mn}) \mathrm{O}_{3-\delta}$ and $(\mathrm{La}, \mathrm{Sr})(\mathrm{Cr}, \mathrm{Fe}) \mathrm{O}_{3-\delta}$ perovskite based materials are promising candidates for OTM [32,33,120,149-150,175,188-192]. Because, these materials can provide the mixed ionic-electronic conductivity, high electrochemical activity, in both reducing and oxidizing conditions. In addition, these materials are 
compatible with other components of the electrochemical system. Tao et al. [149] have measured the total conductivity of $\mathrm{La}_{0.75} \mathrm{Sr}_{0.25} \mathrm{Cr}_{0.5} \mathrm{Mn}_{0.5} \mathrm{O}_{3-\delta}$ as 38.6 and $1.49 \mathrm{~S} \mathrm{~cm}^{-1}$ at $900^{\circ} \mathrm{C}$ in air and $5 \% \mathrm{H}_{2}$-Ar respectively. Recently, Kharton et al. [32] have reported a similar perovskite oxide, $\left(\mathrm{La}_{0.75} \mathrm{Sr}_{0.25}\right)_{0.95} \mathrm{Cr}_{0.5} \mathrm{Mn}_{0.5} \mathrm{O}_{3-\delta}$ a promising material for SOFC anode which can also be used for OTM. The material exhibits the p-type electronic conductivity of $20-35 \mathrm{~S} \mathrm{~cm}^{-1}$ in oxidizing and moderately reducing atmosphere $\left(>10^{-12}\right.$ atm) in the temperature range of $750-1000^{\circ} \mathrm{C}$. The ionic conductivity of $\left(\mathrm{La}_{0.75} \mathrm{Sr}_{0.25}\right)_{0.95} \mathrm{Cr}_{0.5} \mathrm{Mn}_{0.5} \mathrm{O}_{3-\delta}$ is $~ 3 \times 10^{-5} \mathrm{~S} \mathrm{~cm}^{-1}$ at $950^{\circ} \mathrm{C}$ and $\sim 0.01$ atm. There is no significant change in the electronic and ionic conductivity of $\left(\mathrm{La}_{0.75} \mathrm{Sr}_{0.25}\right)_{0.95} \mathrm{Cr}_{0.5} \mathrm{Mn}_{0.5} \mathrm{O}_{3-}$ ${ }_{\delta}$ in the $\mathrm{P}_{\mathrm{O}_{2}}$ ranging from $0.01-10^{-12}$ atm. However, the ionic conductivity increases $\left(\sim 3.5 \times 10^{-4} \mathrm{~S} \mathrm{~cm}^{-1}\right.$ at $\sim 10^{-14}$ atm $)$ significantly with further decrease in $P_{\mathrm{O}_{2}}\left(<10^{-12} \mathrm{~atm}\right)$ [32]. On the other hand, the electronic conductivity decreases down to $1.3 \mathrm{~S} \mathrm{~cm}^{-1}$. This is due to significant oxygen release and increase in the oxygen vacancy concentration below oxygen partial pressure of $\sim 10^{-12}$ atm [32].

Electrical conductivity of $\mathrm{La}_{0.8} \mathrm{Sr}_{0.2} \mathrm{Cr}_{0.5} \mathrm{Fe}_{0.5} \mathrm{O}_{3-\delta}$ is $21.9 \mathrm{~S} \mathrm{~cm}^{-1}$ in oxidizing (air) and $6.4 \mathrm{~S} \mathrm{~cm}^{-1}$ in reducing $\left(5 \% \mathrm{H}_{2}-\mathrm{Ar}\right)$ gas atmosphere at $800^{\circ} \mathrm{C}[120]$. The conductivity decreases in reducing gas atmosphere due to reduction in the valence state of $\mathrm{Cr}^{4+}$ to $\mathrm{Cr}^{3+}$ (Eq. (9)) and $\mathrm{Fe}^{4+} / \mathrm{Fe}^{3+}$ to $\mathrm{Fe}^{2+}$ (Eq. (12) and Eq. (13)), resulting in charge carrier reduction by oxygen vacancies formation for charge compensation. For instance, the conductivity of $\left(\mathrm{La}_{0.75} \mathrm{Sr}_{0.25}\right)_{0.95} \mathrm{Cr}_{0.7} \mathrm{Fe}_{0.3} \mathrm{O}_{3-\delta}$ decreases from $\sim 31.6 \mathrm{~S} \mathrm{~cm}^{-1}$ to $\sim 2 \mathrm{Scm}^{-1}$ when $\mathrm{P}_{\mathrm{O}_{2}}$ decreases from 0.21 to $\sim 10^{-18}$ atm at $900^{\circ} \mathrm{C}$ [33]. Under similar conditions 


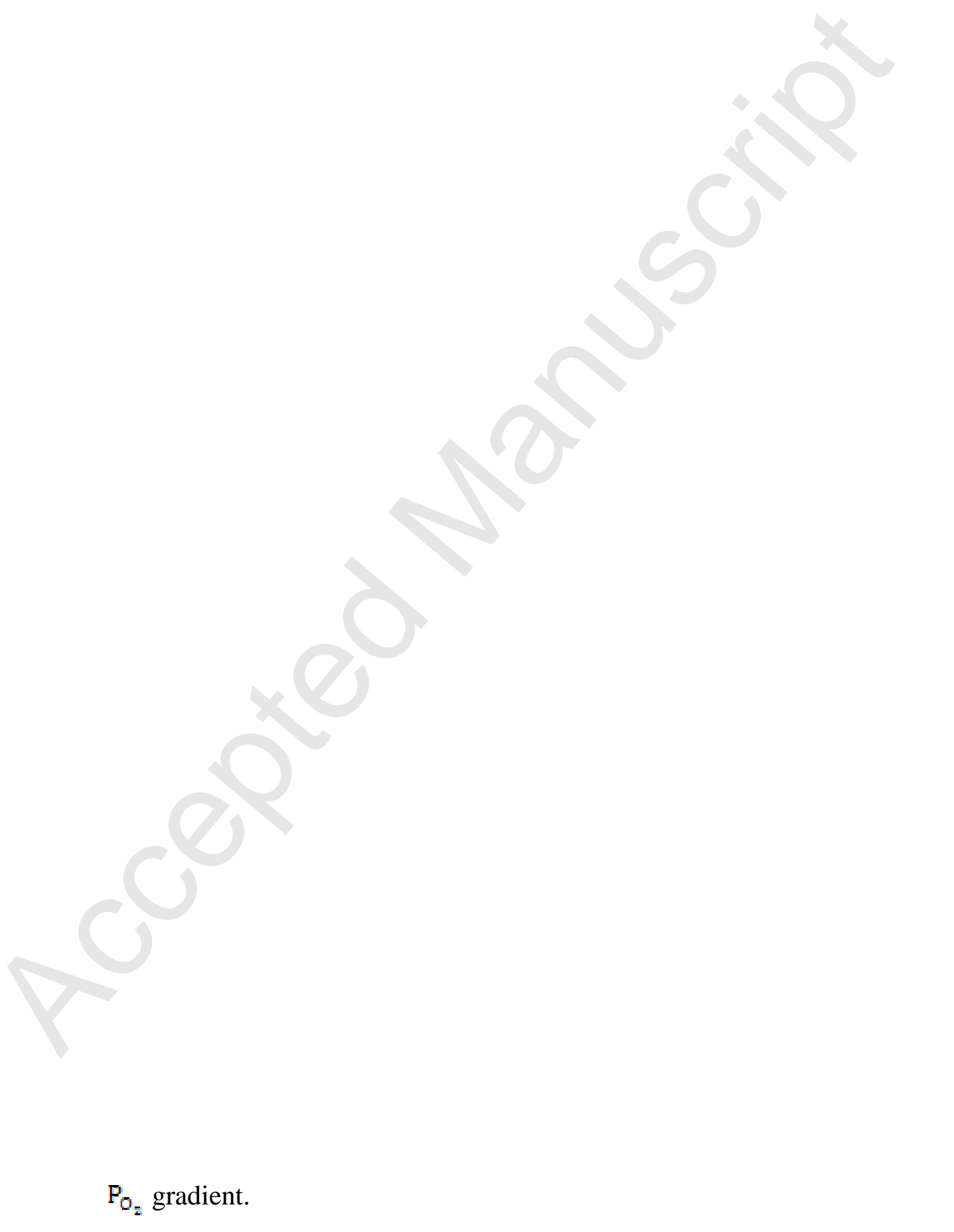

Page 58 of 172 
The mechanical properties (elastic modulus, fracture toughness, fracture strength, and Weibull modulus) of doped lanthanum chromite tend to vary with different dopant type and level at OTM operating conditions $\left(1000^{\circ} \mathrm{C}\right.$ and $\left.0.21-10^{-22} \mathrm{~atm}\right)$ as shown in Table $6[110,155,193-197]$. It is observed that the flexure strength of the material increases with increase in the level of A-site dopants ( $\mathrm{Sr}$ and $\mathrm{Ca}$ ) due to enhanced densification $[110,193]$. For example, $\mathrm{La}_{0.85} \mathrm{Ca}_{0.15} \mathrm{CrO}_{3}\left(\sim 87 \%\right.$ dense) and $\mathrm{La}_{0.8} \mathrm{Ca}_{0.2} \mathrm{CrO}_{3}$ ( 95\%) have flexural strength of $61 \pm 11.5$ and $96 \pm 14.4 \mathrm{MPa}$ respectively at $25^{\circ} \mathrm{C}$ and $0.21 \mathrm{~atm}$ [193]. Also, the flexure strength of $\mathrm{La}_{0.9} \mathrm{Sr}_{0.1} \mathrm{CrO}_{3}(\sim 80 \mathrm{MPa})$ is lower than $\mathrm{La}_{0.8} \mathrm{Sr}_{0.2} \mathrm{CrO}_{3}(\sim 105 \mathrm{MPa})$ at $600^{\circ} \mathrm{C}$ in air $(0.21 \mathrm{~atm})$ [110].

$\mathrm{Sr} / \mathrm{Ca}$ doped $\mathrm{LaCrO}_{3}$ are further doped with transition metals ( $\mathrm{Al}, \mathrm{Cu}, \mathrm{Co}$ and $\mathrm{Fe}$ ) at B-site to improve the flexure strength, mean fracture strength, and fracture toughness by minimizing the internal stresses due to the existing oxygen deficiency [194]. For $\mathrm{La}_{0.8} \mathrm{Ca}_{0.2} \mathrm{Cr}_{0.9} \mathrm{M}_{0.1} \mathrm{O}_{3-\delta}(\mathrm{M}=\mathrm{Al}, \mathrm{Cu}, \mathrm{Co}, \mathrm{Fe})$ system, the mechanical properties are found to be affected with the type of B-site dopants. The flexure and mean fracture strength of $\mathrm{La}_{0.8} \mathrm{Ca}_{0.2} \mathrm{Cr}_{0.9} \mathrm{M}_{0.1} \mathrm{O}_{3-\delta}$ increases in the order of $\mathrm{La}_{0.8} \mathrm{Ca}_{0.2} \mathrm{Cr}_{0.9} \mathrm{Cu}_{0.1} \mathrm{O}_{3-}$ ${ }_{\delta}>\mathrm{La}_{0.8} \mathrm{Ca}_{0.2} \mathrm{Cr}_{0.9} \mathrm{Co}_{0.1} \mathrm{O}_{3-\delta}>\mathrm{La}_{0.8} \mathrm{Ca}_{0.2} \mathrm{Cr}_{0.9} \mathrm{Fe}_{0.1} \mathrm{O}_{3-\delta}>\mathrm{La}_{0.8} \mathrm{Ca}_{0.2} \mathrm{Cr}_{0.9} \mathrm{Al}_{0.1} \mathrm{O}_{3-\delta}$. The reliability of a material is determined by Weibull modulus. Fu et al. [194] have found that the Weibull modulus and reliability of $\mathrm{La}_{0.8} \mathrm{Ca}_{0.2} \mathrm{Cr}_{0.9} \mathrm{M}_{0.1} \mathrm{O}_{3-\delta}(\mathrm{M}=\mathrm{Al}, \mathrm{Cu}, \mathrm{Co}, \mathrm{Fe})$ increases in the order of $\mathrm{Cu}>\mathrm{Fe}>\mathrm{Al}>\mathrm{Co}$. Most of the mechanical properties mentioned in the Table 6 cannot be compared either due to the varying dopant level or different set of conditions applied while measuring the properties. It suggests the need of consistent data on mechanical properties of lanthanum chromite based materials under identical conditions. Although the reasons for the 
change in mechanical properties with different dopants and their level are not clear, the possible reasons could be the difference in structure and microstructure (grain, pore size and their distribution, inter-atomic bond strength, lattice distortion, and oxygen nonstoichiometry) of the investigated doped $\mathrm{LaCrO}_{3}$. The partial substitution of A-site dopant changes the valence state of $\mathrm{Cr}^{3+}$ to $\mathrm{Cr}^{4+}$ (Eq. (14)) which has smaller ionic radii. In addition, the transition metals $(\mathrm{M}=\mathrm{Fe}, \mathrm{Co}$ and $\mathrm{Mn})$ can exist in more than one valence state $\left(\mathrm{M}^{2+}, \mathrm{M}^{3+}\right.$ and $\mathrm{M}^{4+}$ ) depending on temperature and oxygen partial pressure. This may lead to change in lattice structure which might induce stress/strain in the membrane due to change in the interatomic bond length. It has been studied that the strength and hardness of these materials varies with the amount of porosity $[102,108,198]$. The relation between porosity (p), elastic modulus $(E)$, shear modulus $(\mathrm{G})$ and Poisson's ratio $(\vartheta)$ is given below [195]:

$E=E_{o} \frac{\left(1-p^{2}\right)}{\left(1+b_{g} p\right)}, G=G_{o} \frac{\left(1-p^{2}\right)}{\left(1+b_{G} p\right)}$ and $\vartheta=0.25 \frac{4 \theta_{0}+3 p-7 \theta_{0} p}{1+2 p-3 \theta_{0} p}$

where $b_{E}=2-3 \vartheta_{o}$ and $b_{G}=\frac{11-19 g_{0}}{4+4 \vartheta_{0}} . E_{0}, \vartheta_{o}$ and $G_{o}$ are elastic modulus, Poisson's ratio and shear modulus at zero porosity respectively.

According to the above relation, the elastic and shear modulus decreases with increase in porosity. This corresponds to the decrease in strength of the material. For example, a dense $\mathrm{La}_{0.8} \mathrm{Ca}_{0.2} \mathrm{CoO}_{3}(99 \%$ dense) has a bending strength of $150 \mathrm{MPa}$ whereas $\mathrm{LaCoO}_{3}\left(83 \%\right.$ dense) and $\mathrm{La}_{0.8} \mathrm{Sr}_{02} \mathrm{CoO}_{3}$ (90\% dense) have lower strength of 53 MPa and $76 \mathrm{MPa}$, respectively [198]. 
The existence of partial pressure gradient across the membrane is another major factor affecting the mechanical properties of doped $\mathrm{LaCrO}_{3}$ material. At constant temperature, formation of oxygen vacancy increases with reducing atmosphere (Fig. 20) and cause the lattice expansion. Reducing atmosphere also changes valence state of Bsite cations (Eq. (12) and (13)) resulting in the relaxation of the lattice by cation repulsion around oxygen vacancy and change in lattice volume [150]. The strain due to the change in lattice volume is known as chemically induced strain, $\varepsilon_{\mathrm{c}}$ [195].

Exposure to high oxygen partial pressure gradient further induces residual stress due to $\varepsilon_{\mathrm{c}}$ gradient across the OTM. For doped lanthanum chromite, the typical strain was observed to be $0.2-0.4 \%$ when oxygen partial pressure was reduced from 0.21 atm to $10^{-}$ ${ }^{18} \mathrm{~atm}$ at $1000^{\circ} \mathrm{C}[111]$. In reducing gas atmosphere, the $\mathrm{Sr} / \mathrm{Ca}$ doping at A-site of $\mathrm{LaCrO}_{3}$ leads to the formation of oxygen vacancies for charge compensation as shown in Eq. (15). However, in oxidizing atmosphere, the $\mathrm{Cr}^{3+}$ converts to $\mathrm{Cr}^{4+}$ (Eq. (14)). For instance, $\mathrm{La}_{0.7} \mathrm{Ca}_{0.3} \mathrm{CrO}_{3-\delta}$ exhibits the $\delta=0.019$ and 0.26 mole fraction of $\mathrm{Cr}^{4+}$ at $25^{\circ} \mathrm{C}$ in air while in reducing atmosphere $\left(\mathrm{P}_{\mathrm{O}_{2}}=10^{-18} \mathrm{~atm}\right)$ at $1000^{\circ} \mathrm{C}$, the $\delta$ increases to 0.12 and $\mathrm{Cr}^{4+}$ mole fraction reduces to 0.06 [111]. For $\mathrm{La}_{0.7} \mathrm{Ca}_{0.3} \mathrm{Cr}_{0.9} \mathrm{Ti}_{0.1} \mathrm{O}_{3-\delta}$ system, $\Delta \delta$, the difference in oxygen stoichiometry in air and reducing atmosphere $\left(\mathrm{P}_{2}=10^{-18} \mathrm{~atm}\right)$ is 0.073, the minimal among the available reports [111]. Therefore, Ti doping can be considered to minimize the strain induced due to the oxygen partial pressure gradient [111]. The variation in the oxygen vacancy formation or non-stoichiometry with the 
change in $\mathrm{P}_{\mathrm{O}_{2}}$ can generate strain in the membrane due to expansion and contraction of lattice volume, respectively, in low and high $\mathrm{P}_{\mathrm{O}_{2}}$ can contribute to the mechanical failure.

The expression below shows the relation between biaxial strain, elastic modulus, Poisson's ratio, deviation in oxygen non-stoichiometry and thickness of the membrane for a stack of $N$ layers [199].

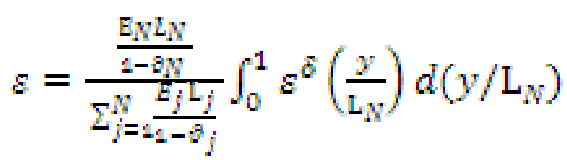

where $\varepsilon, E_{j}, \vartheta_{j}$ and $L_{j}$ are the biaxial strain, Young's modulus, Poisson's ratio and thickness of a component $\mathrm{j}$ in the stack. $\varepsilon^{\delta}\left(\frac{y}{\mathrm{I}_{w}}\right)$ is the function which refers to the linear expansion of a volume element at position y resulting from local deviation in stoichiometry $(\delta)$. In case $j=N$, it is only one component i.e. membrane. In case of composite or dual phase membrane, $j \neq N$ and can be referred to the second phase, the equation provides that the difference in elastic modulus and Poisson's ratio of two phases or component can generate bi-axial strain at the interface. This can affect interfacial strength of the membrane.

In a dual phase OTM and/or an OTM in contact with intermediate and surface exchange layers, the difference in sintering behavior of different phases and layers during fabrication can lead to the formation of pores and cracks at the interface. This is due to difference in the linear shrinkage of two phases or layers during sintering. The differential shrinkage between the two different phases or components can generate 
stress, and form micro-cracks at the interface. For example, difference in sintering behavior causes formation of crack at the interface between $\mathrm{YSZ}$ and $\mathrm{Ca}$-doped $\mathrm{LaCrO}_{3}$ during co-firing at $1200-1500^{\circ} \mathrm{C}$ in air [200]. The cracks at the interface can grow and propagate through the interface and the porous adjacent layers, leading to mechanical failure during operation [201-202]. As discussed in section 4.4, thermal stress (Eq. (22) can be developed at the interfaces between the membrane and the adjacent layers (intermediate and surface exchange) as well as between the perovskite and fluorite phases due to difference in their TEC. In addition, the temperature gradient due to inhomogeneous temperature distribution as well as thermal cycling during start-up and shut-down of the device can also generate stress according to Eq. (22). The thermal stress can also lead to pore and crack formation, origin of mechanical failure [144]. Therefore, an optimization of level and type of A and B-site dopants is needed to match shrinkage/TEC of one phase/layer to the other. This will minimize the stress in the bulk/interface, and increase the lifetime of OTM system. However, the available literature does not provide an in-depth study on mechanical behavior of bulk as well as interface of A and/or B-site doped lanthanum chromite based materials.

\subsection{Oxygen flux/permeation}

Oxygen permeation through a mixed ionic-electronic conductor involves three steps as shown in Fig. 28: surface exchange reaction at gas-solid interface I (higher $\mathrm{P}_{\mathrm{O}_{2}}$ 
side), diffusion through membrane, and surface exchange reaction at solid-gas interface II (lower $\mathrm{P}_{\mathrm{O}_{2}}$ side) [203-204].

The following steps are involved at the different region as shown in Fig. 29:

Interface I: a) Oxygen adsorption $\left(\mathrm{O}_{\mathrm{ads}}\right): \mathrm{O}_{2}(\mathrm{~g}) \rightarrow \mathrm{O}_{\mathrm{ads}}$

b) Oxygen incorporation $\left(\mathrm{O}_{\text {inc }}\right): \frac{1}{2} \mathrm{O}_{2}+\mathrm{V}_{\mathrm{o}}^{*}+2 \mathrm{e}^{-} \rightarrow \mathrm{O}_{0}^{\mathrm{x}}$

(c) Charge transfer/ionization: $\mathrm{O}_{\mathrm{inc}}+2 \mathrm{e}^{-} \rightarrow \mathrm{O}^{2-}$

Membrane: d) Lattice and grain boundary diffusion of $\mathrm{O}_{\mathrm{inc}}$ due to chemical potential gradient of oxygen $\left(\mathrm{P}_{\mathrm{O}}^{\prime} \gg \mathrm{P}_{\mathrm{O}_{2}}^{\prime \prime}\right)$

e) Oxygen transport through oxygen vacancy $\left(v_{0}\right)$

Interface II: f) Desorption of oxygen: $\mathrm{O}^{2-} \rightarrow \mathrm{O}_{\mathrm{des}}+2 \mathrm{e}^{-}$

g) Association of oxygen: $O_{d e s}+o_{d e s} \rightarrow o_{2 n s}$

h) Gas diffusion of associated oxygen molecules

Oxygen permeation through membrane is mainly dependent on surface/interfacial exchange on either side of the membrane and bulk diffusion within the membrane as shown in Fig. 28 and 29. $L_{c}$ is a characteristic thickness value at which the oxygen flux is controlled by surface exchange kinetics as well as bulk diffusion [41]. The thickness of 
the membrane can be reduced to enhance the oxygen flux until it becomes less than $\mathrm{L}_{\mathrm{c}}$. The value for $\mathrm{L}_{\mathrm{c}}$ can be determined by the ratio of the oxygen self-diffusivity and surface exchange coefficient. The oxygen flux of the membrane cannot be further improved by decreasing the thickness below $\mathrm{L}_{\mathrm{c}}$. However, the oxygen flux can significantly be increased by depositing a porous MIEC layer (surface exchange and intermediate) on the membrane which would enhance the surface kinetics and oxygen exchange at the interface $[40-41,43,205]$.

The oxygen flux across the membrane can be written as (Wagner equation) [41]:

$$
j_{O_{2}}=-\frac{\mathrm{RT}}{4^{2} F^{2} \mathrm{~L}} \int_{\ln P_{O_{2}}}^{\ln P_{2}} \frac{\sigma_{81} \sigma_{\mathrm{ion}}}{\sigma_{\mathrm{Q}}+\sigma_{\text {ion }}} \mathrm{d} \ln P_{O_{2}}
$$

where $l_{0_{z}}$ corresponds to oxygen flux through unit area, $\sigma_{\mathrm{el}}$ and $\sigma_{\mathrm{ion}}$ are materials electronic and ionic conductivity respectively, $\mathrm{R}$ refers to ideal gas constant, $\mathrm{T}$ is absolute temperature, $\mathrm{L}$ is the membrane thickness, $\mathrm{F}$ refers to Faraday's constant, $\mathrm{P}_{\mathrm{O}_{2}}$ is feed oxygen partial pressure and $\mathrm{P}_{2}^{\prime \prime}$ is permeate side oxygen partial pressure. Depending on membrane thickness, operating temperature and oxygen partial pressure gradient, the limiting step is determined. Surface exchange reaction is dominant for oxygen transport for thin membrane but diffusion dominates for thicker membrane $[41,203]$. Oxygen ions transports through the bulk of the perovskite lattice via oxygen vacancies once it is adsorbed on the surface (Fig. 29). Oxygen permeation flux increases with increase in differential $\mathrm{P}_{\mathrm{O}_{2}}$ (oxygen chemical potential gradient) and temperature because of decrease in oxygen ion migration energy [41,203-204]. It is to note that, closed pores may be 
present in a dense membrane as a processing defect and the bulk diffusion path involves two more steps: distorted pathway and molecular gas diffusion through the pores as shown in Fig. 30 [206].

As described in introduction section, undoped lanthanum chromite is predominantly electronic conductor and requires ionic conductivity or oxygen flux for the transport of oxygen ion in OTM. Doping of A-site (alkaline earth metals) and B-site (transition metals) is proposed to be useful for improving oxygen ionic conductivity via formation of oxygen vacancies. However, limited information is available for doped lanthanum chromites. Calcium doped lanthanum chromite has been investigated to a considerable extent [207-212]. Oxygen transport occurs predominately through diffusion of oxygen vacancies. Although cationic defects and anti-Frenkel defects are present in calcium doped lanthanum chromite, their role on oxygen transport is negligible but yet to be confirmed [211]. At high $\mathrm{P}_{\mathrm{O}_{2}}(\geq 1 \mathrm{~atm})$ oxygen diffusion through grain boundaries affects oxygen permeation because of calcium enriched phase at grain boundaries [212]. The effect of calcium content on normalized oxygen flux for $\mathrm{La}_{1-x} \mathrm{Ca}_{x} \mathrm{CrO}_{3-\delta}$ at $1000^{\circ} \mathrm{C}$ in the $\mathrm{P}_{\mathrm{O}_{2}}$ range of $0.21-10^{-11}$ atm is shown in Fig. 31. Oxygen permeation increases with increase in oxygen vacancy concentration either by increase in calcium concentration or lowering $\mathrm{P}_{\mathrm{O}_{2}}$ (Fig. 31) [211-212]. $\mathrm{La}_{0.8} \mathrm{Sr}_{0.2} \mathrm{CrO}_{3}$ (1.3 mm thick) provides oxygen flux of $2 \times 10^{-7} \mathrm{~mol} \mathrm{~s}^{-1} \mathrm{~cm}^{-2}$ at $850^{\circ} \mathrm{C}$ and $\Delta \mathrm{P}_{\mathrm{O}_{\mathrm{z}}}=0.2 \mathrm{~atm}$. Oxygen permeation is also dominated by oxygen vacancy diffusion in $\left(\mathrm{La}_{0.75} \mathrm{Sr}_{0.25}\right)_{0.95} \mathrm{Cr}_{0.5} \mathrm{Mn}_{0.5} \mathrm{O}_{3-\delta}$ [32]. The oxygen flux for $\left(\mathrm{La}_{0.75} \mathrm{Sr}_{0.25}\right)_{0.95} \mathrm{Cr}_{0.5} \mathrm{Mn}_{0.5} \mathrm{O}_{3-\delta}$ is determined as $1.3 \times 10^{-9} \mathrm{~mol} \mathrm{~s}^{-1} \mathrm{~cm}^{-2}$ at $1000^{\circ} \mathrm{C}$ and $10^{-14}$ 
atm with the membrane thickness of $1 \mathrm{~mm}$. However, the oxygen permeation flux for $\left(\mathrm{La}_{0.75} \mathrm{Sr}_{0.25}\right)_{0.95} \mathrm{Cr}_{1-x} \mathrm{Fe}_{x} \mathrm{O}_{3-\delta}(x=0.3-0.4)$ is higher than $\left(\mathrm{La}_{0.75} \mathrm{Sr}_{0.25}\right)_{0.95} \mathrm{Cr}_{0.5} \mathrm{Mn}_{0.5} \mathrm{O}_{3-\delta}$ due to higher oxygen vacancy concentration [33]. At $950^{\circ} \mathrm{C}$ and $\sim 10^{-18} \mathrm{~atm}$, the oxygen flux for $\left(\mathrm{La}_{0.75} \mathrm{Sr}_{0.25}\right)_{0.95} \mathrm{Cr}_{0.7} \mathrm{Fe}_{0.3} \mathrm{O}_{3-\delta}$ and $\left(\mathrm{La}_{0.75} \mathrm{Sr}_{0.25}\right)_{0.95} \mathrm{Cr}_{0.6} \mathrm{Fe}_{0.4} \mathrm{O}_{3-\delta}\left(1 \mathrm{~mm}\right.$ thick) are $\sim 10^{-7.4}$ and $\sim 10^{-6.8} \mathrm{~mol} \mathrm{~s}^{-1} \mathrm{~cm}^{-2}$ respectively. The reason for increase in oxygen flux with increase in Fe doping level is due to higher oxygen vacancy concentration resulting into weakening of the metal-oxygen bonds [33] and higher mobility of oxygen ions.

Fig. 32 shows the performance (oxygen permeation flux) of different single phase perovskites (chromites, cobaltites, manganites, and ferrites) based oxygen transport membrane as a function of temperature $\left(700-1000^{\circ} \mathrm{C}\right)[32-33,38,213-219]$. Predominantly, the compositions are doped with alkaline earth metals at A-site ( $\mathrm{Sr}, \mathrm{Ca}$ ) and transition metals at $\mathrm{B}$-site $(\mathrm{Cr}, \mathrm{Fe}, \mathrm{Co}, \mathrm{Mn}, \mathrm{Al})$, which induces oxygen vacancies on partial substitution (Eq. (8), (12) and (13)). As shown in Fig. 32, it is difficult to compare the oxygen flux reported in literature due to the following reasons: a) the doping level varies from composition to composition, b) the oxygen flux measurements have been carried out under varying oxygen partial gradient; air is used as feed gas and different reducing gases $\left(\mathrm{He} / \mathrm{N}_{2} / \mathrm{H}_{2} / \mathrm{CO} / \mathrm{CH}_{4}\right)$ are used at the permeate side, $\left.\mathrm{c}\right)$ the membrane design (e.g. shape, thickness), and d) the fabrication conditions (e.g. sintering temperature and $\mathrm{P}_{\mathrm{O}_{2}}$ ) of the membrane varies from literature to literature for the same composition. Considering the above mentioned varying parameters, it is hard to visualize a specific trend. However, there are few general conclusions that can be made based on the available performance data as shown in Fig. 32 . 
The oxygen flux increases with increase in temperature due to increase in oxygen vacancies and faster kinetics. Also, as expected from Eq. 32, the flux increases with decrease in thickness for the same composition and operation conditions. For instance, the oxygen flux of $\left(\mathrm{La}_{0.75} \mathrm{Sr}_{0.25}\right)_{0.95} \mathrm{Cr}_{0.6} \mathrm{Fe}_{0.4} \mathrm{O}_{3-\delta}$ ( $\left.\mathrm{LSCrF64}\right)$ membrane increases from $\sim 2.1 \times 10^{-7} \mathrm{~mol} \mathrm{~cm}^{-2} \mathrm{sec}^{-1}(\mathrm{~d}=1 \mathrm{~mm})$ to $\sim 3.4 \times 10^{-7} \mathrm{~mol} \mathrm{~cm}^{-2} \mathrm{sec}^{-1}(\mathrm{~d}=0.5 \mathrm{~mm})$ at $950^{\circ} \mathrm{C}$ under air/ $\mathrm{H}_{2}-\mathrm{N}_{2}$ gradient [33]. Furthermore, the flux increases with increase in dopant level due to increase in oxygen vacancies. For $\left(\mathrm{La}_{0.75} \mathrm{Sr}_{0.25}\right)_{0.95} \mathrm{Cr}_{1-x} \mathrm{Fe}_{x} \mathrm{O}_{3-\delta}$, the flux raised from $\sim 9.9 \times 10^{-8} \mathrm{~mol} \mathrm{~cm}^{-2} \sec ^{-1}(x=0.3)$ to $2.1 \times 10^{-7} \mathrm{~mol} \mathrm{~cm}^{-2} \mathrm{sec}^{-1}(x=0.4)$ at $950^{\circ} \mathrm{C}$ [33]. The flux also varies depending on the shape of the membrane. Generally, it is indicated from Fig. 32 that the compositions heavily doped with $\mathrm{Co}$ and $\mathrm{Fe}$ (cobaltites and ferrites) provides higher flux than $\mathrm{Cr}$ (chromites). This is because, Co and Fe exists in different valence state $(+2 /+3 /+4)$, and induces higher oxygen vacancies (Eq. (12) and (13)) when oxygen partial pressure gradient is applied. However, as discussed before (in the introduction section, Table 4), the structural stability of the perovskite decreases when heavily doped with $\mathrm{Co}$ and $\mathrm{Fe}$ transition metals due to the change in valence state. Therefore, chromites are preferred.

To further enhance the performance/oxygen flux of lanthanum chromite as well as other materials based OTM, fluorite phase (ionic conductor) is added to the perovskite. Fig. 33 shows the performance of different dual phase (perovskite-fluorite) membrane in the temperature range of $600-1000^{\circ} \mathrm{C}[31,37,220-225]$. Similar to single phase membranes, it is difficult to compare and observe a specific trend in the available performance data of dual phase membranes. In addition, there are two more varying 
parameter in case of dual phase membrane i.e. fluorite phase composition and the perovskite to fluorite ratio. The ionic conductivity, stability as well as the interaction of the perovskite phase varies depending on the fluorite phase composition and the ratio of perovskite to fluorite phase. On the other hand, in general, similar to single phase perovskites (Fig. 32), the oxygen flux of dual phase membranes increase with increase in the temperature as well as doping level, and decrease in the membrane thickness as shown in the Fig. 33. Overall, lanthanum chromite based dual phase membrane (e.g. $\mathrm{Ce}_{0.8} \mathrm{Sm}_{0.2} \mathrm{O}_{2-\delta} / \mathrm{La}_{0.7} \mathrm{Ca}_{0.3} \mathrm{Cr}_{0.4} \mathrm{O}_{3-\delta} \quad$ and $\left.\quad \mathrm{Zr}_{0.84} \mathrm{Y}_{0.16} \mathrm{O}_{1.92} / \mathrm{La}_{0.8} \mathrm{Sr}_{0.2} \mathrm{Cr}_{0.5} \mathrm{Fe}_{0.5} \mathrm{O}_{3-\delta}\right)$ shows higher performance than cobaltites, ferrites and manganites based membrane. This is probably due to less interaction of the chromites with fluorite phase, otherwise which can result into insulating secondary phase formation (e.g. $\mathrm{SrZrO}_{3}$ ) and lower oxygen flux/performance. For instance, $\mathrm{La}_{0.6} \mathrm{Sr}_{0.4} \mathrm{Co}_{0.2} \mathrm{Fe}_{0.8} \mathrm{O}_{3-\delta}$ interacts with $8 \mathrm{YSZ}$ to form $\mathrm{SrZrO}_{3}$ at the interface in addition to $\mathrm{CoFe}_{2} \mathrm{O}_{4}$ and $\mathrm{Co}_{3} \mathrm{O}_{4}$ [226]. From Fig. 32 and 33, it is also observed that the hollow fiber membrane (e.g. LSF and YSZ/LSCrM55) provides higher flux than disk shaped (planar) membrane because of higher surface area/volume ratios [221]. This is also due to the achieved lower wall thickness $(0.1-0.4 \mathrm{~mm})$ in the hollow membrane design.

\subsection{Chemical Stability}

$\mathrm{LaCrO}_{3}$-based perovskites should be stable in OTM operating conditions $\left(\mathrm{P}_{\mathrm{O}_{2}} \sim 1\right.$ $10^{-20}$ atm, $\mathrm{T}=850-1000^{\circ} \mathrm{C}$ ) for $\geq 40,000 \mathrm{~h}$ [227]. The stability of these oxides can be 
classified into three types namely bulk stability, surface/interface segregation, and interfacial stability.

\subsubsection{Bulk stability}

Although undoped $\mathrm{LaCrO}_{3}$ is stable at OTM fabrication and operation temperature, it decomposes into vapor species depending on temperature and atmosphere [228-231]. Computational evaluation shows that $\mathrm{LaCrO}_{3}$ vaporization starts in the temperature range of $1200-1400^{\circ} \mathrm{C}$ depending on the atmosphere: $1300^{\circ} \mathrm{C}$ in $\mathrm{H}_{2}$ atmosphere and $1400^{\circ} \mathrm{C}$ in $\mathrm{O}_{2}$ as well as $\mathrm{CO}$ atmosphere [229]. The weight loss due to vaporization increases from $8.0 \times 10^{-4} \%$ in $\mathrm{O}_{2}$ to $0.03 \%$ in $\mathrm{CO}$, and $0.09 \%$ in $\mathrm{H}_{2}$ atmospheres at $1800^{\circ} \mathrm{C}$ [229]. The evolved vapor species are $\mathrm{CrO}_{3}, \mathrm{CrO}_{2}, \mathrm{CrO}, \mathrm{LaO}$, and $\mathrm{O}$ in $\mathrm{O}_{2} ; \mathrm{Cr}, \mathrm{CrO}_{2}, \mathrm{CrO}$, and $\mathrm{LaO}$ in $\mathrm{CO}$; and $\mathrm{Cr}, \mathrm{CrO}_{2}, \mathrm{CrOH}$, and $\mathrm{LaO}$ in $\mathrm{H}_{2}$ atmosphere [229]. Among these species, $\mathrm{CrO}_{3}$ is predominant in air and $\mathrm{O}_{2}$ atmospheres whereas $\mathrm{Cr}$ is predominant in $\mathrm{CO}$ and $\mathrm{H}_{2}$ atmospheres. The computational evaluation for $\mathrm{LaCrO}_{3}$ vaporization is also in agreement with that of experimental results [230]. Doped $\mathrm{LaCrO}_{3}$,

in reality, is used as OTM which is exposed to gas atmospheres $\left(\mathrm{P}_{\mathrm{O}_{2}} \sim 0.21-10^{-22} \mathrm{~atm}\right)$

containing $\mathrm{H}_{2}, \mathrm{CO}_{2}, \mathrm{CO}, \mathrm{N}_{2}, \mathrm{H}_{2} \mathrm{O}, \mathrm{S}$, and $\mathrm{O}_{2}$. Bulk stability of the doped materials varies depending on type and level of dopants as well as temperature and oxygen partial pressure as discussed below.

\subsubsection{A-site dopants}


Lanthanum chromite is doped at A-site with alkaline earth metals ( $\mathrm{Sr}$ and $\mathrm{Ca}$ ). The stability of A-site doped $\mathrm{LaCrO}_{3}$ depends on the solid solubility limit of the dopants [116,232-235]. The solid solubility of dopants $(\mathrm{Sr}$ and $\mathrm{Ca})$ in $\mathrm{La}_{1-x}(\mathrm{Sr} / \mathrm{Ca})_{x} \mathrm{CrO}_{3}$ depends on temperature and atmosphere as shown in Fig. 27 along with dotted phase boundaries obtained from thermodynamic calculations. For example, the solid solubility limit for $\mathrm{Sr}$ is $\sim 10 \mathrm{~mol} \%$ at $1000^{\circ} \mathrm{C}$ in air and increases with reducing $\mathrm{P}_{\mathrm{O}_{2}}$ (Fig. 27a). Above the solid solution limit, $\mathrm{SrCrO}_{4}$ along with several unknown phases appear as shown in Fig. 27a [232]. While $\mathrm{SrCrO}_{4}$ is common secondary phase, the remaining depends on the composition of the doped $\mathrm{LaCrO}_{3}$ [122]. For example, $\mathrm{Cr}_{2} \mathrm{O}_{3}$ is found for A-site deficient, and $\mathrm{Sr}_{2.67}\left(\mathrm{CrO}_{4}\right)_{2}$ and $\mathrm{La}_{2} \mathrm{O}_{3}$ are found for A-site excess $\left(\mathrm{La}_{0.7} \mathrm{Sr}_{0.3}\right)_{x} \mathrm{CrO}_{3}(0.95 \leq x \leq 1.05)$ at $1000^{\circ} \mathrm{C}$ in air [122]. $\mathrm{La}_{2} \mathrm{CrO}_{6}$ phase is also found at $<1000^{\circ} \mathrm{C}$ [122]. Thermodynamic assessment suggests the possible evolution of $\mathrm{La}_{16} \mathrm{Cr}_{7} \mathrm{O}_{44}$ phase in air [232].

The solid solubility limit for $\mathrm{Ca}$ is $\sim 30 \mathrm{~mol} \%$ at $1000^{\circ} \mathrm{C}$ in air and increases with reducing $P_{\mathrm{O}_{\mathrm{z}}}$ as shown in Fig. 27b [201]. Although, the figure shows that the solubility of Ca increases in lower $\mathrm{P}_{\mathrm{O}_{2}}$, one report in contrast shows that it decreases to $\sim 20 \mathrm{~mol} \%$ in $10^{-9} \mathrm{~atm} \mathrm{P}_{\mathrm{O}_{2}}$ at $1600^{\circ} \mathrm{C}[234]$. The secondary phases in Ca-doped $\mathrm{LaCrO}_{3}$ are $\mathrm{CaCrO}_{4}$, $\mathrm{La}_{2} \mathrm{CrO}_{6}, \mathrm{Ca}_{3}\left(\mathrm{CrO}_{4}\right)_{2}$ and $\mathrm{Ca}_{10}\left(\mathrm{CrO}_{4}\right)_{7}$ [235]. It is to be noted that solid solubility limit of $\mathrm{La}_{1-x} \mathrm{Ca}_{x} \mathrm{CrO}_{3}(30 \mathrm{~mol} \%)$ is higher than $\mathrm{La}_{1-x} \mathrm{Sr}_{x} \mathrm{CrO}_{3}(10 \mathrm{~mol} \%)$ at $1000^{\circ} \mathrm{C}$ in air. However, $\mathrm{CaCrO}_{4}$ decomposes into $\mathrm{Ca}_{3}\left(\mathrm{CrO}_{4}\right)_{2}$ and liquid phase at $\sim 1070^{\circ} \mathrm{C}$. On the other hand, $\mathrm{SrCrO}_{4}$ is more refractory than $\mathrm{CaCrO}_{4}$ and decomposes at $\sim 1250^{\circ} \mathrm{C}$. Therefore, if $\mathrm{La}_{1-x}(\mathrm{Sr} / \mathrm{Ca})_{x} \mathrm{CrO}_{3}$ is placed outside the single phase conditions (Fig. 27a 
and 27b), the second phase will precipitate faster in case of Ca-doped when compared to Sr-doped $\mathrm{LaCrO}_{3}$ at the operating temperature of OTM $\left(1000^{\circ} \mathrm{C}\right)[232,235]$.

Apart from solid solubility limit, the reducing gas atmospheres also affect the chemical stability. In humidified $\mathrm{H}_{2}$ atmosphere, the $\mathrm{Sr}(\mathrm{OH})_{2}, \mathrm{Ca}(\mathrm{OH})_{2}, \mathrm{Cr}(\mathrm{OH})_{2}$, and $\mathrm{LaH}_{2}$ may form while $\mathrm{SrCO}_{3}, \mathrm{CaCO}_{3}$, and $\mathrm{Cr}_{2} \mathrm{O}_{3}$ phases can form in $\mathrm{CO}$ and $\mathrm{CO}_{2}$ containing atmospheres even at $800^{\circ} \mathrm{C}[116,236]$. Among these, hydroxyl compounds are volatile in the order of $\mathrm{Cr}(\mathrm{OH})_{2}>\mathrm{Ca}(\mathrm{OH})_{2}>\mathrm{Sr}(\mathrm{OH})_{2}$ [116]. This means Sr-doped $\mathrm{LaCrO}_{3}$ is more chemically stable than that of Ca-doped $\mathrm{LaCrO}_{3}$. The melting point of the $\mathrm{CaCrO}_{4}$ secondary phase decreases from $\sim 1000^{\circ} \mathrm{C}$ in air to $850^{\circ} \mathrm{C}$ in $\mathrm{CO}_{2}$ atmosphere to $640^{\circ} \mathrm{C}$ in $\sim 3 \% \mathrm{H}_{2} \mathrm{O}$ containing $10 \% \mathrm{H}_{2}$ in $\mathrm{N}_{2}$ atmosphere [122,237]. Similarly, it is expected that the melting point of $\mathrm{SrCrO}_{4}$ secondary phase also reduces to lower temperatures in reducing atmospheres. The appearance of liquid phase at lower temperature accelerates the precipitation of secondary phases.

\subsubsection{A and B-site dopants}

The information on the chemical stability of $\mathrm{B}$-site doped $\mathrm{LaCrO}_{3}$ is limited. Thermodynamic calculation shows that metallic phases appear as secondary phase due to the decomposition of the $\mathrm{B}$-site doped $\mathrm{LaCrO}_{3}[116]$. For instance, Fe-doped lanthanum chromites decompose to $\mathrm{Fe}$ metal and the $\mathrm{LaCrO}_{3}$ phase at $850^{\circ} \mathrm{C}$ and an oxygen partial pressure of $1.3 \times 10^{-23} \mathrm{~atm}$. At $850^{\circ} \mathrm{C}$, the $\mathrm{P}_{\mathrm{O}_{2}}$ for $\mathrm{B}$-site doped $\mathrm{LaCrO}_{3}$ decomposition to metal oxide and $\mathrm{LaCrO}_{3}$ phase is calculated as $1.6 \times 10^{-14}$ atm for $\mathrm{Mg}, 1.9 \times 10^{-14}$ atm for Co, and $6.3 \times 10^{-24}$ atm for Mn doping [113]. $\mathrm{La}_{0.25} \mathrm{Sr}_{0.75} \mathrm{Cr}_{0.5} \mathrm{Mn}_{0.5} \mathrm{O}_{3-\delta}$ decomposes to 
$(\mathrm{LaSr})_{2} \mathrm{MnO}_{4}$ and $\mathrm{MnO}$ in reducing atmosphere $\left(\sim 10^{-20}\right.$ atm $)$ at $900^{\circ} \mathrm{C}[141]$. This is due to higher amount of oxygen vacancies formation for the charge balance of $\mathrm{Mn}^{4+} \rightarrow \mathrm{Mn}^{3+}$ and $\mathrm{Mn}^{3+} \rightarrow \mathrm{Mn}^{2+}$ in reducing gas atmosphere. Similarly, $\mathrm{La}_{0.25} \mathrm{Sr}_{0.75} \mathrm{Cr}_{0.5} \mathrm{Fe}_{0.5} \mathrm{O}_{3-\delta}$ decomposes to $(\mathrm{LaSr})_{2} \mathrm{FeO}_{4}$ and $\mathrm{Fe}$ due to the reduction of $\mathrm{Fe}^{4+} \rightarrow \mathrm{Fe}^{3+}$ and $\mathrm{Fe}^{3+} \rightarrow \mathrm{Fe}^{2+}$ under same conditions [141]. Precipitation of Ni has been observed in the grain boundaries of $\mathrm{La}_{0.8} \mathrm{Ca}_{0.2} \mathrm{Cr}_{0.9} \mathrm{Ni}_{0.1} \mathrm{O}_{3}$ composition after annealing at $900{ }^{\circ} \mathrm{C}$ in $\sim 3 \% \mathrm{H}_{2} \mathrm{O}$

containing $10 \% \mathrm{H}_{2}\left(\mathrm{P}_{\mathrm{O}_{2}} \sim 5.0 \times 10^{-16} \mathrm{~atm}\right)$ [237]. Carbon deposition in the form of 5-20 nm film or soot has been observed for $\mathrm{A}_{0.15} \mathrm{La}_{0.85} \mathrm{Cr}_{0.9} \mathrm{~B}_{0.1} \mathrm{O}_{3}(\mathrm{~A}=\mathrm{Sr}, \mathrm{Ca}$ and $\mathrm{B}=\mathrm{Mn}, \mathrm{Fe}, \mathrm{Co}$, and Ni) samples treated in $\mathrm{CH}_{4}$ containing gas atmosphere at $900^{\circ} \mathrm{C}$ [238].

\subsubsection{Surface Segregation}

Despite $\mathrm{LaCrO}_{3}$ is stable in reducing atmosphere at $\leq 1000^{\circ} \mathrm{C}$ [228-229], surface segregation is often observed for doped $\mathrm{LaCrO}_{3}$ [239-242]. The segregated phases are generally $\mathrm{Sr}$ or Ca enriched for A-site doped as well as simultaneous A- and B-site doped $\mathrm{LaCrO}_{3}$, and transition metal enriched for B-site dopants. For example, Sr-enriched segregation has been observed at the surface of $\mathrm{La}_{0.75} \mathrm{Sr}_{0.25} \mathrm{Cr}_{0.5} \mathrm{Mn}_{0.5} \mathrm{O}_{3-\delta}$ annealed at $\mathrm{P}_{\mathrm{O}_{2}} \sim 10^{-3}$ atm for $10 \mathrm{~h}$ even at $600^{\circ} \mathrm{C}$ [241]. Sr-segregation concentration at the surface decreases with lowering $P_{\mathrm{O}_{2}}$ as evident by its absence in cathodic polarization of $-2.5 \mathrm{~V}$ and reappearance after subsequent anodic polarization of $+2.0 \mathrm{~V}$ in an in-situ XPS study during electrochemical investigation [241]. However, $\mathrm{Sr}$ and Ca segregation at surface is also observed in reducing atmospheres containing $\mathrm{H}_{2}, \mathrm{CH}_{4}$, and $\mathrm{CO} / \mathrm{CO}_{2}$. Co segregation 
has been reported for $\mathrm{LaCr}_{0.9} \mathrm{Co}_{0.1} \mathrm{O}_{3}$ annealed at $1000^{\circ} \mathrm{C}$ and $\sim 10^{-16}$ atm for one night [241].

One of the driving forces for surface segregation is electric potential gradient induced kinetic de-mixing of cations as evident from the electrochemical studies $[239,241]$. The driving forces for surface segregation without electrical potential gradient [241-242] may be the difference between the enthalpies of defect formation at the surface and in the bulk, and the chemisorption of gaseous species from the gas atmospheres, as observed in $\mathrm{SrTiO}_{3}$ and $\mathrm{La}_{0.7} \mathrm{Sr}_{0.3} \mathrm{MnO}_{3}$ [243-244]. This is supported by the observations of surface segregation in the doped $\mathrm{LaCrO}_{3}$ even though the dopants concentrations are within solubility limits [242].

\subsubsection{Interface Stability}

Interface stability may be defined as the compatibility of $\mathrm{LaCrO}_{3}$ perovskites with adjacent materials such as YSZ in dual phase composite OTM and perovskites/fluorites at surface exchange and intermediate layers. Undoped $\mathrm{LaCrO}_{3}$ is compatible with YSZ but doped $\mathrm{LaCrO}_{3}$ reacts with YSZ during OTM fabrication and operation, resulting in electrically insulating zirconate phase's formation (e.g. $\mathrm{SrZrO}_{3}, \mathrm{CrZrO}_{3}$ ) [245]. It is shown that $\mathrm{CaCrO}_{4}$ or other $\mathrm{Ca}$-containing secondary phase needs to be precipitated from Ca-doped $\mathrm{LaCrO}_{3}$ to form calcium zirconate $\left(\mathrm{CaZrO}_{3}\right)$. Ca from the secondary phase such as $\mathrm{CaCrO}_{4}$ diffuses and reacts with YSZ resulting in $\mathrm{CaZrO}_{3}$ phase at the interface [245]. $\mathrm{CaZrO}_{3}$ phase formation will be favored in reducing atmosphere because the 
melting point of $\mathrm{CaCrO}_{4}$ decreases in reducing atmosphere and the liquid phase enhances the Ca diffusion into the YSZ [245]. In corollary, the $\mathrm{SrCrO}_{4}$ may need to be precipitated from $\mathrm{Sr}$-doped $\mathrm{LaCrO}_{3}$ prior to the formation of $\mathrm{SrZrO}_{3}$. Since the melting point of $\mathrm{SrCrO}_{4}$ is higher than that of $\mathrm{CaCrO}_{4}, \mathrm{Sr}$-doped $\mathrm{LaCrO}_{3}$ is preferred for interface stability. Also, the formation of zirconate phases can be avoided by limiting the level of dopants to the lower end of solubility limit to inhibit $\mathrm{CaCrO}_{4}$ or $\mathrm{SrCrO}_{4}$ phase formation. It is noted that the lanthanum zirconate $\left(\mathrm{La}_{2} \mathrm{Zr}_{2} \mathrm{O}_{7}\right)$ phase formation, like in lanthanum manganite/YSZ interaction [246-248], is not favorable because the existence of $\mathrm{La}_{2} \mathrm{O}_{3}$ precipitates to interact with $\mathrm{YSZ}$ to form $\mathrm{La}_{2} \mathrm{Zr}_{2} \mathrm{O}_{7}$ is unlikely, consistent with the experimental observation $[116,245]$.

5.

\section{Challenges}

The challenges for the OTM development and commercial deployment are predominantly associated with fabrication, long term reliable operation and robust systems integration. Materials degradation arising from gas-solid and solid-solid interactions needs to be minimized. Basic scientific understanding of transport kinetics and standardized method for oxygen flux/permeation evaluation also remain largely unknown. Above challenges are discussed below: 
Fabrication: Fabrication of a flaw (crack and pore) free dense membrane is difficult due to poor sinterability of $\mathrm{LaCrO}_{3}$ based perovskites (section 4.2). A-site excess and simultaneous A and B-site doping increases the density of $\mathrm{LaCrO}_{3}$ if sintered at high temperature $\left(1350-1600^{\circ} \mathrm{C}\right.$, Fig. 17 and 18$)$. The fabrication temperature can be reduced to certain extent if sintered in controlled reducing $\mathrm{P}_{\mathrm{O}_{2}}$ and/or high dopant level $(x \geq 0.3)$. With increased dopant level and reduced $\mathrm{P}_{\mathrm{O}_{\mathrm{z}}}$, the structural and chemical stability may be compromised as discussed in section 4.8. Difference in sintering behavior of the perovskite and fluorite phases can generate cracks at the interface of these phases. The flaws in the microstructure (bulk and interfaces) propagate and result into mechanical failure. Film deposition techniques have been applied (plasma spray, physical vapor deposition (sputtering and laser ablation), and electrochemical chemical vapor deposition) to avoid the high temperature sintering for obtaining dense $\mathrm{LaCrO}_{3}$ based perovskites. Even though density can be achieved with controlled microstructure for the bulk membrane, high temperature $\left(\geq 1300^{\circ} \mathrm{C}\right)$ annealing is required for strong interface. The installation, operation, and maintenance costs are very high for these deposition techniques compared to the conventional ceramic processing techniques such as wet chemical method. However, the parameters for the conventional techniques (wet chemical method) to deposit $\mathrm{LaCrO}_{3}$ based perovskite are yet to be optimized.

Materials degradation: The OTM operating conditions (temperature, time, and atmosphere) also degrade the stability of materials due to reaction kinetics and solid-gas 
interaction as discussed in section 4.8. The perovskite phases can also react with the fluorite phase in dual phase membrane and form new compounds. The electrical conductivities of the secondary compounds are different than the bulk and affect the electrochemical activity for oxygen flux. Further, the bulk membrane may form interfacial compounds due to interaction between the membrane and the intermediate and surface exchange layers. The difference between the thermal expansion behavior of the primary and secondary compounds can lead to crack and pore formation. In addition, the porous microstructure of the intermediate and surface exchange layer can change due to atomic diffusion and grain growth. The gradient in $\mathrm{P}_{\mathrm{O}_{2}}$ across the OTM as well as thermal cycling can also lead to mechanical failure. The lattice volume change can be mitigated by suitable B-site dopants to decrease the amount of oxygen vacancy.

The components of OTM devices are connected to other components (ceramic, metallic or alloy) in a balance of plant by sealants. The sealants for high temperature application are alumino-silicate based materials (glass and ceramic pastes). Silica evaporation from glass based sealants during operation can degrade not only sealant performance for preventing gas leakage but also the catalytic activity of the device due to deposition of silica vapor species at the electrochemically active areas (triple phase boundary) [156,249].

Lack of fundamental understanding of transport kinetics and standardized method for oxygen flux/permeation evaluation: Electronic and ionic transport as well as the surface 
exchange kinetics depend on the defect chemistry and defect interactions. The transport and surface exchange kinetics are not much investigated despite the total electrical conductivity for lanthanum chromite based perovskites have been studied. The transference number for the doped lanthanum chromites need to be determined to effectively model defect chemistry and its correlation with the electrochemical activity. The desirable transference number is not known.

Different research groups use different methods to determine the oxygen flux and report as normalized value without detailing the experimental procedure and sample dimensions. As a result, the literature report cannot be compared for same composition for further improvement in materials development. Also, the information about oxygen flux is limited in literature. In most cases, the oxygen flux is determined by maintaining $\mathrm{P}_{\mathrm{O}_{2}}$ gradient. In practice, the OTM will be exposed to the reducing atmospheres containing $\mathrm{CO}, \mathrm{CH}_{4}, \mathrm{H}_{2}, \mathrm{~S}, \mathrm{~N}$, and other elements depending on the gas composition. The electrochemical behavior and oxygen flux not necessarily be same for all the gas compositions. It will depend on the redox behavior and microstructure of the OTM materials - a subject of further research.

Integration with a gasification or power generation system: To integrate in a gasification or power generation system, the OTM needs to be joined with the corresponding (ceramics and/or metal) components in the system. High temperature ceramic/glass/brazing seals are used at the joints with or without applied pressure. The 
joining points are generally prone to mechanical failure because of high pressure (as high as $\sim 400 \mathrm{~atm}$ ), interfacial compounds due to interaction between the components, and generation of pores and cracks at the joining. The material development for joining the components as well the compatibility with the adjacent components needs to be studied.

6.

\section{Summary}

The status of the lanthanum chromite based perovskites as mixed and ionic electronic conductor, for application in the active oxygen transport membrane, to separate oxygen from air has been reviewed. The tailoring of the required properties such as density, thermal expansion behavior, electrical conductivity, oxygen permeation, and thermo-chemo-mechano stability by tailoring the composition using dopants has been reviewed and discussed. Table 7 summarizes the properties of A and/or B-site doped lanthanum chromites.

The density of undoped lanthanum chromite is less than $60 \%$. The poor sinterability is attributed to the evaporation of $\mathrm{CrO}_{3}$ specie and its deposition as $\mathrm{Cr}_{2} \mathrm{O}_{3}$ at the inter-particle necks of $\mathrm{LaCrO}_{3}$ during sintering process. A-site ( $\mathrm{Sr}, \mathrm{Ca}$ ) and B-site dopants ( $\mathrm{Ni}, \mathrm{Co}, \mathrm{Cu}, \mathrm{Mn}, \mathrm{Fe}$ ) enhance densification of lanthanum chromite. More than 94\% density can be obtained in Ca doped A-site excess as well in simultaneous A and Bsite doped lanthanum chromite as shown in Table 7. Iron and nickel as the B-site dopant shows highest densification. However, it is dependent on dopant level and sintering temperature. Density increases with increasing doping level and sintering temperature. 
$\mathrm{La}_{0.8} \mathrm{Sr}_{0.2} \mathrm{Cr}_{0.5} \mathrm{Fe}_{0.5} \mathrm{O}_{3-\delta}$ and $\mathrm{La}_{0.85} \mathrm{Sr}_{0.15} \mathrm{Cr}_{0.95} \mathrm{Ni}_{0.05} \mathrm{O}_{3}$ are the best two compositions (Table 7) among doped $\mathrm{LaCrO}_{3}$. But, the required sintering temperature is above $1350^{\circ} \mathrm{C}$.

Undoped lanthanum chromite changes room temperature orthorhombic to rhombohedral structure at $\sim 260^{\circ} \mathrm{C}$ with a volume change. Strontium dopant (10 mol\%) decreases the polymorphic transition temperature to $\sim 42^{\circ} \mathrm{C}$, eliminating the stress due to the change in lattice during thermal cycling. Calcium dopant $(10 \mathrm{~mol} \%)$ increases the polymorphic transition temperature to $307^{\circ} \mathrm{C}$.

The thermal expansion coefficient (TEC) of the lanthanum chromite can be tuned virtually by maintaining the level of any dopant. For example, $<20 \mathrm{~mol} \% \mathrm{Sr} / \mathrm{Ca}$ doping and $5 \mathrm{~mol} \% \mathrm{Ni} / \mathrm{Mn} / \mathrm{Fe}$ doping is suitable to obtain TEC similar to $8 \mathrm{YSZ}\left(\sim 10.3 \times 10^{-6}{ }^{\circ} \mathrm{C}^{-}\right.$ ${ }^{1}$ ). The dopants also induce chemical expansion because of the presence of oxygen vacancy and different valance states of B-site cations. From Table 7, $\mathrm{La}_{0.9} \mathrm{Sr}_{0.1} \mathrm{Cr}_{0.95} \mathrm{M}_{0.05} \mathrm{O}_{3}(\mathrm{Ni}, \mathrm{Fe}, \mathrm{Mn})$ composition shows TEC within the tolerable difference limit $\left( \pm 1.0 \times 10^{-6}{ }^{\circ} \mathrm{C}^{-1}\right)$ of fluorite phase (e.g. 8YSZ) in air and $\mathrm{H}_{2}$ atmosphere $\left(50-1000^{\circ} \mathrm{C}\right)$.

Undoped lanthanum chromite shows only electronic conduction. Ionic conductivity is induced in doped lanthanum chromites due to creation of oxygen vacancies. The dopants also increase the total (ionic and electronic) conductivity due to polaron hopping. The electrical conductivity value is varied for A-site dopants (strontium and calcium) depending on the dopant type and level. However, there is no significant variation. Nickel doping in the B-site shows the highest conductivity among others. 
However, $\mathrm{Mn}$ and $\mathrm{Fe}$ doping can induce mixed ionic-electronic conductivity. The role of dopants on the electrochemical activity for oxygen permeation cannot be concluded due to limited knowledge. It is identified that $\mathrm{La}_{0.9} \mathrm{Sr}_{0.1} \mathrm{Cr}_{0.5} \mathrm{Ni}_{0.5} \mathrm{O}_{3}$ composition shows the highest electrical conductivity as shown in Table 7.

Undoped lanthanum chromite is the most stable at the extreme OTM operating conditions. For the doped lanthanum chromite, strontium doping is more stable than calcium doping. Surface segregation is generally observed for $\geq 20 \mathrm{~mol} \%$ dopant levels. Therefore, strontium is preferred A-site dopant at less than $20 \mathrm{~mol} \%$ level. The stability for the B-site doping is not studied well. The solubility of the B-site dopants in the lanthanum chromite decreases in reducing atmosphere and tend to reduce to metallic form. Considering the positive role on the thermo-physical properties of the lanthanum chromite, B-site dopants can be used at lower level ( $\leq 30 \mathrm{~mol} \%)$. However, cobalt doping should be avoided because it undesirably increases the TEC attributed to the change in valance state.

From the above discussions, it can be suggested that strontium as A-site dopant and transition metals ( $\mathrm{Mn}, \mathrm{Ni}$ and $\mathrm{Fe}$ ) as B-site dopants can be considered for compositional design to achieve all the required properties simultaneously. From the thermo-mechanical stability point of view, titanium as B-site dopant can be considered because of reduced chemical expansion. In addition, Ti-based $\mathrm{La}_{0.7} \mathrm{Sr}_{0.3} \mathrm{Cr}_{0.7} \mathrm{Ti}_{0.3} \mathrm{O}_{3-\delta}$ composition provides least oxygen-nonstoichiometry $(\delta)$ at $1000^{\circ} \mathrm{C}$ and $\mathrm{P}_{\mathrm{O}_{2}} \sim 1-10^{-15}$ atm (Table 7). Overall, $\mathrm{La}_{1-x} \mathrm{Sr}_{x} \mathrm{Cr}_{1-y-z} \mathrm{M}_{y} \mathrm{Ti}_{z} \mathrm{O}_{3}(\mathrm{M}=\mathrm{Ni}, \mathrm{Fe}, \mathrm{Mn} ; x<0.2, y, z \leq 0.3)$ composition 
would be the best perovskite composition for OTM. For higher oxygen flux and performance, it is suggested to combine perovskite phase with fluorite phase (e.g. 8YSZ) to obtain higher ionic conductivity. More fundamental research needs to be conducted in the areas of transport behavior and electrochemical activity, in particular, for doped lanthanum chromites, to fully exploit the material for active OTM application.

\section{Acknowledgements:}

Authors sincerely acknowledge the financial support from the US Department of Energy under contract DE-FC26-07NT43088. One of the author (PS) also acknowledges financial support through UTC endowment from University of Connecticut Foundation. S. Gupta and M.K. Mahapatra contributed equally to this work. Helpful technical discussions with Drs. Michael Keane, $\mathrm{Na} \mathrm{Li,} \mathrm{Mahesh} \mathrm{Venkataraman,} \mathrm{Boxun} \mathrm{Hu} \mathrm{and}$ Gavin Le is gratefully acknowledged. 


\section{References:}

[1] A. Frassoldati, A. Cuoci, T. Faravelli, E. Ranzi, C. Candusso, D. Tolazzi, 1st International Conference on Sustainable Fossil Fuels for Future Energy - S4FE, 2009.

[2] H. Stadler, F. Beggel, M. Habermehl, B. Persigehl, R. Kneer, M. Modigell, P.

Jeschke. Int. J. Greenhouse Gas Control 5 (2011) 7-15.

[3] V. White, R. Allam, E. Miller. 8th International Conference on Greenhouse Gas Emissions, Trondheim, Norway, 2006, 1-6.

[4] S. Walspurger, H.A.J. van Dijk. ECN-E-12-054 (2012) 28-34.

[5] D. Kang, R.S. Srinivasan, R.T. Thorogood, E.P. Foster EP. US Patent 5516359, 1996.

[6] M.F. Carolan, P. N. Dyer, US Patent 5712220, 1998.

[7] M.F. Carolan, P. N. Dyer. US Patent 5599383, 1997.

[8] A.G. Dixon, W.R. Moser, Y.H. Ma. Ind. Eng. Chem. Res. 33 (1994) 3015-24.

[9] H. Stadler, F. Beggel, M. Habermehl, B. Persigehl, R. Kneer, M. Modigell, P. Jeschke. Int J Greenhouse Gas Control 5 (2011) 7-15.

[10] S.S. Hashim, A.R. Mohamed, S. Bhatia. Ren. Sustain Energy Rev. 15 (2011) 128493.

[11] E.H. Shreiber, B. A.V. Hassel, R. Prasad. US Patent 7118612B2, 2006.

[12] Y. Zeng, Y. S. Lin, S.L. Swartz. J. Mem. Sci. 150 (1998) 87-98.

[13] B.C.H. Steele. Solid State Mater. Sci. 1 (1996) 684-91.

[14] S.P.S. Badwal, F.T. Ciacchi. Adv. Mater. 13 (2001) 993-96.

[15] L.L. Anderson, P.A. Armstrong, J.M. Repasky, V.E. Stein. International Pittsburgh Coal Conference, Pittsburgh, USA, 2011. 
[16] S. Cooper, N. Frazier, P. Urane. Calvin College Department of Engineering 339/340 (2011) 1-63.

[17] W.P. Schmidt, K.W. Kovak, W.R. Licht, S.L. Feldman. Air Products and Chemicals Inc., 2000.

[18] Use of process analytics in cryogenic air separation plants, Chemical Industry case study, Siemens, p. 2

[19] R. Jafari. Iran International Zeolite Conference (IIZC), 2008.

[20] J. Da. Costa, S. Smart, J. Motuzas, S. Liu, D. Zhang. Project Number: 3-0510-0034. Report (2013) 1-13.

[21] P.N. Dyer, R. E. Richards , S.L. Russek , D.M. Taylor. Solid State Ionics 134 (2000) 21-33.

[22] B. Belaissaoui, Y.L. Moullec, H. Hagi, E. Favre. Sep. Purif. Tech. 125 (2014) 142150.

[23] N.D. Paul, E.R. Robin, L.R. Steven, M.T. Dale. Solid State Ionics 134 (2000) 21-33.

[24] W. Lai, S.M. Haile. Phys. Chem. Chem. Phys. 10 (2008) 865-83.

[25] J.W. Stevenson, T.R. Armstrong, R.D. Carmeim, L.R. Pederson, L.R. Weber. J. Electrochem. Soc. 143 (1996) 2722-29.

[26] V.V. Kharton, A.A. Yaremchenko, A.V. Kovalevsky, A.P. Viskup, E.N. Naumovich, P.F. Kerko. J. Mem. Sci. 163 (1999) 307-17.

[27] X. Zhu and W. Yang, AIChE Journal 54 (2008) 665-672.

[28] J. Han, Y. Zeng, G. Xomeritakis, Y.S. Lin. Solid State Ionics 98 (1997) 63-72.

[29] J. Kim, Y.S. Lin. J. Mem. Sci. 167 (2000) 123-33. 
[30] D.P. Fagg, I.P. Marozau, A.L. Shaula, V.V. Kharton, J.R. Frade. J. Solid State Chem. 179 (2006) 3347-56.

[31] J.J. Liu, T. Liu, W.D. Wang, J.F. Gao, C.S. Chen, J. Mem. Sci. 389 (2012) 435-440.

[32] V.V. Kharton, E.V. Tsipis, I.P. Marozau, A.P. Viskup, J.R. Frade, J.T.S. Irvine. Solid State Ionics 178 (2007) 101-13.

[33] M.F. Lü, E.V. Tsipis, J.C. Waerenborgh, A.A. Yaremchenko, V.A. Kolotygin, S. Bredikhin, V.V. Kharton. J. Power Sources 206 (2012) 59-69.

[34] X. Zhu, W. Yang. Mem. Sci. Tech. 14 (2011) 275-93.

[35] A. Yu. Zuev, A.I. Vylkov, D.S. Tsvetkov. Solid State Ionics 192 (2011) 220-224.

[36] T.A. Ramanarayanan, S.C. Singhal, and E.D. Wachsman. The Electrochemical Society Interface. Summer (2001) 1-27.

[37] J. Samson, M. Søgaard, P.V. Hendriksen. J. Mem. Sci. 470 (2014) 178-188.

[38] W. He, H. Huang, M. Chen, J.F. Gao, C.S. Chen. Solid State Ionics 260 (2014) 8689.

[39] A. Julbe, D. Farrusseng, C. Guizard. Catal. Today 104 (2005) 102-113.

[40] H.J.M Bouwmeester, A.J. Burggraaf, in: A.J. Burggraaf, L. Cot (Eds.), Membrane Sci. Technol. Series, Amsterdam, Elsevier; 1996, pp. 435-510.

[41] J. Hong, P. Kirchen, A.F. Ghoniem. J. Mem Sci. 407 (2012) 407.

[42] N. Nagabhushana, J.A. Lane, G.M Christie, B.A. Van Hassel. US Patent 7556676, 2009.

[43] G.M. Christie, J.R. Wilson, B.A. Van Hassel. US Patent 090645 A2, 2011. [44] M.F. Carolan, P.N. Dyer. US Patent 553447, 1996. 
[45] M. Liu, A.V. Joshi, Y. Shen. US Patent 5240480, 1993.

[46] T. Nakamura, G. Petzow, L.J. Gauckler. Mater. Res. Bull. 14 (1979) 649-59.

[47] P. Dalach, D.E. Ellis, A.V. Walle. Phys. Rev. B 85 (2012) 014108.

[48] S.K. Mazumder, K. Acharya, C.L. Haynes, R. Williams, M.R.V. Spakovsky, D.J. Nelson, D.F. Rancruel, J. Hartvigsen, R.S. Gemmen. IEEE transactions on power electronics 19 (2004) 1263-78.

[49] D.J.L. Brett, A. Atkinson, N.P. Brandon, S.J. Skinner. Chem. Soc. Rev. 37 (2008) $1568-78$.

[50] A.J Jacobson. Chem. Mater. 22 (2010) 660-74.

[51] A. Aguadero, L. Fawcett, S. Taub, R. Woolley, K.T. Wu, N. Xu, J.A. Kilner, S.J. Skinner. J. Mater. Sci. 47 (2012) 3925-48.

[52] J. Sunarso, S. Baumann, J.M. Serra, W.A. Meulenberg, S. Liu, Y.S. Lin, J.C. Diniz da Costa. J. Mem. Sci. 320 (2008) 13-41.

[53] Q. Jiang, S. Faraji, D.A. Slade, S.M.S. Williams. Mem. Sci. Tech. 14 (2011) 235-73. [54] A.S. Mukasyan, C. Costello, K.P. Sherlock, D. Lafarga, A. Varma. Sep. Purif. Tech. 25 (2001) 117-26.

[55] V. V. M. Goldschmidt. Geochemische Verteilungsgesetze der Elemente. Tl. VIII (Skrifter utgitt av Det Norske Videnskaps - Akademi i Oslo, I. Matem.-Naturvid.Klasse. 1926): Untersuchungen über Bau und Eigenschaften von Krystallen.Dybwad Oslo, 1927. [56] J. Richter, P. Holtappels, T. Graule, T. Nakamura, L.J. Gauckler. Monatsh Chem. 140 (2009) 985-99.

[57] R.A. De Souza, M. Martin. Monatsh Chem. 140 (2009) 1011-15. 
[58] M. Cherry, M.S. Islam, C.R.A. Catlow. J. Solid State Chem. 118 (1995) 125-32.

[59] J.A. Kilner, R.J. Brook. Solid State Ionics 6 (1982) 237-52.

[60] Y.T. Suru, M. Shimazu, M. Shiono, M. Morinaga. Jap. J. Appl. Phys. 49 (2010)

045701.

[61] S. Taniguchi, M. Aniya. Int. Ferroelectrics 115 (2010) 18-24.

[62] H. Hayashi, H. Inaba, M. Matsuyama, N.G. Lan, M. Dokiya, H. Tagawa. Solid State Ionics $122(1999)$ 1-15.

[63] M. Mogensen, D. Lybye, N. Bonanos, P.V. Hendriksen, F.W. Poulsen. Solid State Ionics 174 (2004) 279-86.

[64] H.U. Anderson. Solid State lonics 52 (1992) 33-41.

[65] H.U. Anderson, in: F.W. Poulsen, J.J. Bentzen, T. Jacobsen, E. Skou, M.J.L.

Ostergard (Eds.), Proceedings of the $14^{\text {th }}$ Riso International Symposium on Materials

Science, Riso National Laboratory, Roskilde, 1993.

[66] J. Mizusaki. Solid State Ionics 52 (1992) 79-91.

[67] H. Yokokawa, N. Sakai, T. Kawada, M. Dokiya. Solid State Ionics. 52 (1992) 43-56.

[68] T. Nakamura, G. Petzow, L.J. Gauckler, Mat. Res. Bull. 14 (1979) 649.

[69] S. Gangopadhayay, T. Inerbaev, A.E. Masunov, D. Altilio, N. Orlovskaya. ACS

Appl. Mater. Interfaces 7 (2009) 1512-19.

[70] C.H. Chen, H. Kruidhof, H.J.M. Bouwmeester, A.J. Burggraaf. J. Appl. Electrochem. 27 (1997) 71-75.

[71] M. Søgaard, P.V. Hendriksen, M. Mogensen. J. Solid State Chem. 180 (2007) 14891503. 
Page 88 of 172 
[87] N.H. Menzler, F. Tietz, S. Uhlenbruck, H.P. Buchkremer, D. Stöver. J. Mater. Sci. 45 (2010) 3109-35.

[88] L.R. Pederson, P. Singh, X.D. Zhou. Vacuum 80 (2006) 1066-83.

[89] R. Hui, Z. Wang, O. Kesler, L. Rose, J. Jankovic, S. Yick, R. Maric, D. Ghosh. J. Power Sources 170 (2007) 308-23.

[90] R. Maric, J. Roller, R. Neagu. J. Thermal Spray Tech. 20 (2011) 696-718.

[91] D. Beckel, A. Bieberle-Hütter, A. Harvey, A. Infortuna, U.P. Muecke, M. Prestat, J.L.M. Rupp, L.J. Gauckler. J. Power Sources 173 (2007) 325-45.

[92] G.Y. Meng, H.Z. Song, H.B. Wang, C.R. Xia, D.K. Peng. Thin Solid Films 409 (2002) 105-11.

[93] J.C. Boeker, P. Singh. US patent 4861345, 1989.

[94] P. Singh, R.J. Ruka. US Patent 5389456, 1995.

[95] A.J. Burggraaf, Y.S. Lin. US Patent 5, 1993.

[96] C. Keegan. Wincewicz, J.S. Cooper. J. Power Sources 140 (2005) 280-96.

[97] H. Itoh, M. Mori, N. Mori, T. Abe. J. Power Sources 49 (1994) 315-32.

[98] K.L. Choy. Prog. Mater. Sci. 48 (2003) 57-170.

[99] N. Sakai, S. Stùlen. J. Chem. Thermodyn. 27 (1995) 493-506.

[100] H. Hayashi, M. Watanabe, H. Inaba. Thermochimica Acta 359 (2000) 77-85.

[101] K. Oikawa, T. Kamiyama, T. Hashimoto, Y. Shimojyo, Y. Morii. J. Solid State Chem. 154 (2000) 524-29. 
[102] T. Hashimotoa, N. Tsuzukia, A. Kishib, K. Takagic, K. Tsudac, M. Tanaka, K. Oikawa, K. Kamiyama, K. Yoshida, H. Tagawa, M. Dokiya. Solid State Ionics 132 (2000) 183-90.

[103] Y.S. Malghe, S.R. Dharwadkar, K. Krishnan, K.D.S Mudher. J. Thermal Anal. Calorimetry 95 (2009) 49-52.

[104] N.M. Sammes, R. Ratanaraj. J. Mater. Sci. 29 (1994) 4319-24.

[105] H. Hayashi, M. Watanabe, M. Ohuchida, H. Inaba, Y. Hiei, T. Yamamoto, M. Mori. Solid State Ionics 144 (2001) 301-13.

[106] N. Sakai, H. Fjellvâg, B.C. Hauback. J. Solid State Chem. 121 (1996) 202-13.

[107] R.D. Shannon. Acta Crystallogr. 32 A (1976) 751-767.

[108] H. E. Hoefer, W. F. Kock, J. Electrochem. Soc. 140 (1993) 2889.

[109] S. Tao and J. T. S. Irvine, Chem. Mater. 18 (2006) 5453-5460.

[110] N.M. Sammes, R. Ratnaraj. J. Mater. Sci. 30 (1995) 4523-26.

[111] T.R. Armstrong, J.W. Stevenson, L.R. Pederson, P.E. Raney. J. Electrochem. Soc. 143 (1996) 2919-25.

[112] M. Mori, Y. Hiei, T. Yamamoto. J. Am. Ceram. Soc. 84 (2001) 781-86.

[113] S. Gupta, M.K. Mahapatra, P. Singh. Mat. Res. Bull. 48 (2013) 3262-67.

[114] M. Mori, Y. Hiei, N.M. Sammes. Solid State Ionics 135 (2000) 743-48.

[115] M. Mori, Y. Hieia, N.M. Sammes. Solid State Ionics 123 (1999) 103-11.

[116] J. Sfeir. J. Power Sources 118 (2003) 276-85.

[117] H.C. Grahm, H.H. Davis. J. Am. Ceram. Soc. 54 (1971) 89-93.

[118] D.B. Meadowcroft, J.M. Wimmer. Am. Ceram. Soc. Bull. 58 (1979) 610. 
[119] H. Yokokawa, N. Sakai, T. Kawada, M. Dokiya. J. Electrochem. Soc. 138 (1991) 1018-27.

[120] T. Wei, X. Liu, C. Yuan, Q. Gao, X. Xin, S. Wang. J. Power Sources 250 (2014) 152-159.

[121] R.M. German, P. Suri, S.J. Park. J. Mater. Sci. 44 (2009) 1-39.

[122] S. Simner, J. Hardy, J. Stevenson, T. Armstrong. J. Mater. Sci. 34 (1999) 5721-32.

[123] S. Simner, J. Hardy, J. Stevenson, T. Armstrong. J. Mater. Sci. 19 (2000) 863-865. [124] L.A. Chick, J. Liu, J.W. Stevenson, T.R. Armstrong, D.E McCready. J. Am. Ceram. Soc. 80 (1997) 2109-20.

[125] B.F. Flandermeyer, M.M. Nasrallah, D.M. Sparlin, H.U. Anderson. High Temp. Sci. 20 (1985) 265.

[126] S.P. Simner, J.S. Hardy, J.W. Stevenson. J. Electrochem. Soc. 148 (2001) A351-60. [127] S.P. Simner, J.S. Hardy, J.W. Stevenson, T.R. Armstrong, in: S.C. Singhal and M. Dokiya (Eds.), The Electrochemical Society Proceedings Series - SOFC-VI, Pennington, NJ, 1999.

[128] J.D. Carter, M.M. Nasrallah, H.U. Anderson. J. Mater. Sci. 31 (1996) 157-163.

[129] X. Ding, Y. Liu, L. Gao, L. Guo. J. Alloys Comp. 425 (2006) 318-322.

[130] K. Homma, F. Nakamura, N. Ohba, A.M. Sui, T. Hashimoto. J. Ceram. Soc. Japan 115 (2007) 81-84.

[131] A. Ruangvittayanon, S. Kuharuangrong. Suranaree J. Sci. Tech. 16 (2009) 319-323. [132] G.M. Christie, P.H. Middleton, BCH Steele. J. Euro. Ceram. Soc. 14 (1994) 16375. 
Page 92 of 172 
[147] K. Hilpert, R.W. Steinbrech, F. Boroomand, E. Wessel, F. Meschke, A. Zuev, O.

Teller, H. Nickel, L. Singheiser. J. Euro. Ceram. Soc. 23 (2003) 3009-20.

[148] V. Vashooka, L. Vasylechkob, J. Zoselc, W. Grunerd, H. Ullmanna, U. Gutha. J. Solid State Chem. 177 (2004) 3784-94.

[149] S. Tao, J.T.S. Irvine. J. Electrochem. Soc. 151 (2004) A252-59.

[150] A. Atkinson, T.M.G.M Ramos. Solid State Ionics 129 (2000) 259-69.

[151] L. Deleebeeck, J.L. Fournier, V. Birss. Solid State Ionics 181 (2010) 1229-37.

[152] S. Miyoshi, J.O. Hong, K. Yashiro, A. Kaimai, Y. Nigara, K. Kawamura, T.

Kawada, J. Mizusaki. Solid State Ionics 161 (2003) 209-217.

[153] SM Kelly. Recovery Act: oxy-combustion: oxygen transport membrane development DOE Presentation, http://www.netl.doe.gov/publications/proceedings/11/co2capture/presentations/3Wednesday/24Aug11-Kelly-Praxair-OTM\%20Development.pdf.

[154] N. Nagabhushana, J.A. Lane, G.M. Christie, B.A.V. Hassel. US Patent 7556676B2, 2009.

[155] A. Atkinson, B. Sun. Mater. Sci. Tech. 23 (2007) 1135-43.

[156] M.K. Mahapatra, K. Lu. Mater. Sci. Eng. R 67 (2010) 65-85.

[157] M.K. Mahapatra, K. Lu. J. Power Sources 195 (2010) 7129-39.

[158] M. Mori, T. Yamamoto, H. Itoh, H. Inaba, H. Tagawa. J. Electrochem. Soc. 145 (1998) 1374-81.

[159] A. Bieberle, L.J. Gauckler, in: H. Tuller, J. Schoonman, I. Riess (Eds.), Kluwer Academic Publishers, Dordrecht, 2000. 
[160] D. Leea, I. Leea I, Y. Jeona, R. Songb. Solid State Ionics 176 (2005) 1021-25.

[161] H.J. Ko, J.J. Lee, S.H. Hyun. Solid State Lett. 13 (2010) B113-15.

[162] M. Filal, C. Petot, M. Mokchah, C. Chateau, J.L. Carpentier. Solid State Ionics 80 (1995) 27-35.

[163] V.V. Srdić, R.P. Omorjan. Ceram. Int. 27 (2001) 859-63.

[164] M.D. Mathews, B.R. Ambekar, A.K. Tyagi. Thermochimica Acta 309 (2002) 61-6.

[165] M.E. Hofer, W.F. Kock. J. Electrochem. Soc. 140 (1993) 2889-94.

[166] D.M. Bastidas, S. Tao, J.T.S. Irvine. J. Mater. Chem. 16 (2006) 1603.

[167] K.P. Ong, P. Wua. Appl. Phys. Lett. 90 (2007) 044109.

[168] W.Z. Zhu, S.C. Deevi. Mater. Sci. Eng. A 348 (2003) 227-43.

[169] S. Srilomsak, D.P. Schilling, H.U. Anderson. Ed. S.C. Singhal. Electrochemical Society, Pennington, NJ, 1989.

[170] K. Mori, H. Miyamoto, K. Takenobu, T. Matsudaira, in: B. Thorstensen, U. Bossel (Eds.), Proceedings of 2nd European Solid Oxide Fuel Cell Forum, Oslo, Norway, 1996. [171] I. Yasuda, M. Hishinuma. Electrochem. 68 (2000) 526-30.

[172] K.J. Yoon, C.N. Cramer, J.W. Stevenson, O.A. Marina. Electrochem. Solid State Lett. 13 (2010) B101-05.

[173] K. Hilpert, R.W. Steinbrech, F. Boroomand, E. Wessel, F. Meschke, A. Zuev, O. Teller. J. Euro. Ceram. Soc. 23 (2003) 3009-20.

[174] S.P. Jiang, X.J. Chen, S.H. Chan, J.T. Kwok, K.A. Khor. Solid State Ionics 177 (2006) 149-57.

[175] S. He, H. Chen, R. Li, L. Ge, L. Guo, J. Power Sources 253 (2014) 187-192. 
[176] J. Mizusaki, Y. Mima, S. Yamauchi, K. Fueki, H. Tagawa. J. Solid State Chem. 80 (1989) 102.

[178] D.P. Karim, A.T. Aldred. Phys. Rev. B 20 (1979) 2255-63.

[179] G.P. Triberis, M. Dimakogianni. J. Phys. Condens. Matter 21 (2009) 385406.

[180] W.Y. Howng, R.J. Thorn. J. Phys. Chem. Solids 41 (1980) 75-81.

[181] D.B. Meadowcroft. Brit. J. Appl. Phys. 2 (1969) 1225-33.

[182] S.P. Jiang, L. Liua, K.P. Ong, P. Wu, J. Li, J. Puc. J. Power Sources 176 (2008) 8289.

[183] P.S. Devi, S.M. Rao. J. Solid State Chem. 98 (1992) 237-44.

[184] S. Mukherjee, M.R. Gonal, M.K. Patel, M. Roy, A. Patra, A.K. Tyagi. J. Am. Ceram. Soc. 95 (2012) 290-95.

[185] J. Mizusaki, M. Yoshihiro, S. Yamauchi, K. Fueki. J. Solid State Chem. 58 (1985) 257.

[186] H. Xiong, G.J. Zhang, J.Y. Zheng, Y.Q. Jia. Mater. Lett. 51 (2001) 61-67.

[187] G.J. Zhang, Y.R. Chen, R. Li, Y.Q. Jia, M.L. Liu, M.J. Jin. Mater. Chem. Phys. 63 (2000) 178-82.

[188] K.R. Poeppelmeier, M.E. Leonowicz, J.M. Longo. J. Solid State Chem. 44 (1982) 89-98.

[189] S. Tao, J.T.S. Irvine. Nature Mater. 2 (2003) 320-23.

[190] S. Zha, P. Tsang, Z. Cheng, M. Liu. J. Solid State Chem. 178 (2005) 1844-50.

[191] S. Tao, J.T.S. Irvine, J.A. Kilner. Adv. Mater. 17 (2005) 1734. 
[181] S.P. Jiang, X.J. Chen, S.H. Chan, J.T. Kwok, K.A. Khor. Solid State Ionics 177 (2006) 177-149.

[192] K. Sasaki, J.P. Wurtz, R. Gschwend, M. Gödickemeier, L.J. Gauckler. J.

Electrochem. Soc. 143 (1996) 143-530.

[193] S.W. Paulik, S. Baskaran, T.R. Armstrong. J. Mater. Sci. 33 (1998) 2397-404.

[194] Y.P. Fu, H.C. Wang. Int. J. Hydrogen Energy 36 (2011) 747-54.

[195] A. Atkinson, A. Selc. Solid State Ionics 134 (2000) 59-66.

[196] W. Acchar, C.R.C. Sousa, S.R.H. Mello-Castanho. Mater. Sci. Eng. A 550 (2012)

76-79.

[197] N. Nagendra, S. Bandopadhyay. J. Euro. Ceram. Soc. 23 (2003) 1361-68.

[198] N. Orlovskava, K. Kleveland, T. Grande, M.A. Einarsrud. J. Euro. Ceram. Soc. 20 (2000) 51-56.

[199] J.D. Carter, P.V. Hendriksen, M. Mogensen, Materials Department, Riso National Laboratory, Denmark, 1995.

[200] D.S. Smith, A. Smith. J. Mater. Sci. Lett. 5 (1986) 349-52.

[201] B.N. Sørensen, A. Horsewell. J. Am. Ceram. Soc. 84 (2001) 2051-59.

[202] B.N. Nguyen, B.J. Koeppel, S. Ahzi, M.A. Khaleel, P. Singh. J. Am. Ceram. Soc. 89 (2006) 1358-68.

[203] J. Sunarso, S. Baumann, J.M. Serra, W.A. Meulenberg, S. Liu, Y.S. Lind, J.C.D.

Costa. J. Mem. Sci. 320 (2008) 13-41.

[204] Y.S. Lin, W. Wand, J. Han. AlChE J. 40 (1994) 786-98.

[205] D. Huiming, Z. Minyau, A. Benjamin. Solid State Ionics 74 (1994) 75-84. 
[206] K. Zhang, J. Sunarso, Z. Shao, W. Zhou, C. Sun, S. Wanga, S. Liu. RSC Adv. 1 (2011) 1661-76.

[207] N. Sakai, T. Horita, H. Yokokawa, M. Dokiya, T. Kawada. Solid State Ionics 86-88 (1996) 1273-78.

[208] B.A. Van Hassel, T. Kawada, N. Sakai, H. Yokokawa, M. Dokiya. Solid State Ionics 66 (1993) 41-47.

[209] B.A. Van Hassel, T. Kawada, N. Sakai, H. Yokokawa, M. Dokiya. Solid State Ionics 66 (1993) 295-305.

[210] T. Kawada, T. Horita, N. Sakai, N. Yokokawa, M. Dokiya. Solid State Ionics 79 (1995) 201-7.

[211] D.K. Lee, H.I. Yoo. J. Electrochem. Soc. 147 (2000) 2835-43.

[212] N. Sakai, K. Yamaji, T. Horita, H. Yokokawa, T. Kawada, M. Dokiya, K.I.

Hiwatashi, A. Ueno, M. Aizawad. J. Electrochem. Soc. 146 (1999) 1341-45.

[213] A.A. Yaremchenko, V.V. Kharton, V.A. Kolotygin, M.V. Patrakeev, E.V. Tsipis, J.C. Waerenborgh. J. Power Sources 249 (2014) 483-496.

[214] X. Tan, Y. Liu, K. Li. Ind. Eng. Chem. Res. 44 (2005) 61-66.

[215] Z. Taheri, K. Nazari, N. Seyed-Matin, A.A. Safekordi, B. Ghanbari, S.

Zarrinpashne, R. Ahmadi. Reac. Kinet. Mech. Cat. 100 (2010) 459-469.

[216] A.A. Yaremchenko, V.V. Kharton, A.L. Shaula, M.V. Patrakeev, F.M.B. Marques.

J. European Ceramic Society 25 (2005) 2603-2607.

[217] F.S. Küppers, S. Baumann, F. Tietz, H.J.M. Bouwmeester, W.A. Meulenberg. J. European Ceramic Society 34 (2014) 3741-3748. 
Page 98 of 172 
[235] S. Onuma, S. Miyoshi, K. Yashiro, A. Kaimai, K. Kawamura, Y. Nigara, T.

Kawada, J. Mizusaki, N. Sakai, H. Yokokawa. J. Solid State Chem. 170 (2003) 68-74.

[236] H. Yokokawah, T. Horitaa, N. Sakaia, T. Kawadaa, M. Dokiyaa, Y. Takaib, M.

Todokib. Thermochim. Acta 267 (1995) 129-138.

[237] G.M. Christie, P.H. Middleton, B.C.H. Steele. J. Euro. Ceram. Soc. 14 (1994) 16375.

[238] J. Sfeir, P.A. Buffat, P.M. Ckli, N. Xanthopoulos, R. Vasquez, H.J. Mathieu, J.V. Herle, K.R. Thampi. J. Catal. 202 (2001) 229-44.

[239] J. Sfeir, J.V. Herle, A.J. McEvoy. J. Euro. Ceram. Soc. 19 (1999) 897-902.

[240] K. Rida, A. Benabbas, F. Bouremmad, M.A. Peńa, A. Martínez-Arias. Catal. Commun. 7 (2006) 963-68.

[241] A.K. Huber, M. Falk, M. Rohnke, B.G.L. Luerben, M. Amatib, J. Janek. Phys. Chem. Chem. Phys. 14 (2012) 751-58.

[242] M. Oishi, K. Yashiro, J.O. Hong, Y. Nigara, T. Kawada, J. Mizusaki. Solid State Ionics 178 (2007) 307-12.

[243] G. Horvath, J. Gerblinger, H. Meixner, J. Giber. Sensors Actuators B 32 (1996) 9399.

[244] T.T. Fister, D.D. Fong, J.A. Eastman, P.M. Baldo, M.J. Highland, P.H. Fuoss, K.R. Balasubramaniam, J.C. Meador, P.A. Salvador. Appl. Phys. Lett. 93 (2008) 151904. [245] J.D. Carter, C.C. Appel, M. Mogensen. J. Solid State Chem. 122 (1996) 407-15. [246] M.K. Mahapatra, S. Bhowmick, N. Li, P. Singh. J. Euro. Ceram. Soc. 32 (2012) 2341-49. 
[247] M. Keane, M.K. Mahapatra, A. Verma, P. Singh. Int. J. Hyd. Energy 37 (2012) $16776-85$.

[248] N. Li, M.K. Mahapatra, P. Singh. J. Power Sources 221 (2013) 57-63.

[249] P. Singh, S.D. Vora. Ceram. Eng. Sci. Proc. 26 (2005) 99-110. 


\section{Captions}

\section{Tables}

Table 1 Advantages and disadvantages of various oxygen separation techniques $[1,14-$ 21].

Table 2 Differences between active and passive oxygen transport membrane [25-33].

Table 3 Materials' key requirement for OTM [43-48].

Table 4 Advantages and disadvantages of various perovskite oxides [69-76].

Table 5 Advantages and disadvantages of various fabrication techniques [87-92,98].

Table 6 Mechanical properties of various doped Lanthanum chromite materials [110,155,193-197].

Table 7. Summary - Properties of A and/or B-site doped lanthanum chromite materials [32-33,38,110,112-115,120,123,126,128-131,134,139-142,149,183-185,193-194]. 


\section{Figure Captions}

Fig. 1. Simplified process flow diagram of an oxygen transport membrane integrated in IGCC (BFW: Boiler Feed Water) [15].

Fig. 2. Flow diagram of cryogenic distillation process [18].

Fig. 3. Flow diagram of pressure adsorption technique for air separation.

Fig. 4. Schematic of the working principle of oxygen transport membrane (OTM): (a) Partial pressure driven/Active (Mixed ionic electronic conductor), (b) Electrically driven/Passive (Ionic conductor).

Fig. 5. Ideal perovskite structure of $\mathrm{ABO}_{3}$.

Fig. 6. Orthorhombic to rhombohedral phase transition temperature versus A-site average ionic radii $\left(\mathrm{r}_{\mathrm{A}}\right)$ for $\mathrm{La}_{1-x}(\mathrm{Sr} / \mathrm{Ca})_{x} \mathrm{CrO}_{3}$ (Reproduced from ref. 105 with permission).

Fig. 7. Tolerance factor of $\mathrm{La}_{0.9} \mathrm{Sr}_{0.1} \mathrm{Cr}_{0.9} \mathrm{M}_{0.1} \mathrm{O}_{3}(\mathrm{M}=\mathrm{Mg}, \mathrm{Al}, \mathrm{Ti}, \mathrm{Mn}, \mathrm{Fe}, \mathrm{Co}, \mathrm{Ni})$. The broken line corresponds to $\mathrm{La}_{0.9} \mathrm{Sr}_{0.1} \mathrm{CrO}_{3}$ tolerance factor [Reprinted from reference [112 with permission].

Fig. 8. Oxygen transport membrane configuration: (a) Planar [84], (b) Tubular.

Fig. 9. Schematic of vacuum slip casting for tubular configuration [Reprinted from reference 87 with permission].

Fig. 10. Positions of spray gun and components to be coated: a) horizontal/horizontal, b) horizontal/vertical, both with tubular design and c) vertical/horizontal with planar Design [Reprinted from reference 87 with permission].

Fig. 11. Sol-gel dip coating technique [Reprinted from reference 87 with permission]. 
Fig. 12. Schematics of DC and RF plasma spraying apparatus [Reprinted from reference 88 with permission].

Fig. 13. Schematics of physical vapor deposition techniques: (a) Electron beam (EB) PVD, (b) Sputtering, and (c) Laser ablation [Reprinted from reference 91 with permission].

Fig. 14. Schematics of (a) CVD, and (b) EVD techniques [Reprinted from reference 98 with permission].

Fig. 15. Microstructures of $\mathrm{LaCrO}_{3}$ sintered at $1450^{\circ} \mathrm{C}$ in air for $10 \mathrm{~h}$ : (a) lower magnification to show the porosity, (b) higher magnification with $\mathrm{Cr}_{2} \mathrm{O}_{3}$ deposition at inter-particle neck [113].

Fig. 16. SE- micrograph for $\left(\mathrm{La}_{0.6} \mathrm{Ca}_{0.4}\right)_{1.02} \mathrm{CrO}_{3}$ heated to $1350^{\circ} \mathrm{C}(2 \mathrm{~h})$ and air quenched to RT [Reprinted from reference 128 with permission].

Fig. 17. Relative density of A-site (Sr,Ca) doped $\mathrm{LaCrO}_{3}$ vs $x$ in $\mathrm{La}_{1-x}(\mathrm{Sr} / \mathrm{Ca})_{x} \mathrm{CrO}_{3}$ at $1600^{\circ} \mathrm{C}[114-115,123]$.

Fig. 18. Relative density of A-site ( $\mathrm{Sr}$ ) and B-site (Ni, Co and $\mathrm{Ni}$ ) doped $\mathrm{LaCrO}_{3}$ vs Temperature and $x$ in $\mathrm{La}_{0.85} \mathrm{Sr}_{0.15} \mathrm{Cr}_{1-x} \mathrm{M}_{x} \mathrm{O}_{3}(\mathrm{M}=\mathrm{Co}, \mathrm{Cu}, \mathrm{Ni})[126,129]$.

Fig. 19. SE-micrograph of $\mathrm{La}_{0.9} \mathrm{Sr}_{0.1} \mathrm{Cr}_{0.3} \mathrm{Mn}_{0.7} \mathrm{O}_{3}$ sintered at $1475^{\circ} \mathrm{C}$ for $48 \mathrm{~h}$ [Reprinted from reference 133 with permission].

Fig. 20. Oxygen non-stoichiometry of $\mathrm{La}_{1-x} \mathrm{~A}_{x} \mathrm{Cr}_{1-y} \mathrm{~B}_{y} \mathrm{O}_{3-\delta}$ : a) A-site doping; b) variation with temperature, c) B-site doping, and d) Simultaneous A and B-site doping at $1000^{\circ} \mathrm{C}$, e) Simultaneous A (Sr) and B-site $(\mathrm{Ti} / \mathrm{Mn} / \mathrm{Fe})$ at $1000^{\circ} \mathrm{C}$ [138-142]. 
Fig. 21. Thermal expansion coefficient of A-site ( $\mathrm{Sr}, \mathrm{Ca})$ doped $\mathrm{LaCrO}_{3}$ vs $x$ in $\mathrm{La}_{1 \text { - }}$ ${ }_{x}(\mathrm{Sr} / \mathrm{Ca})_{x} \mathrm{CrO}_{3}$ in air and $\mathrm{H}_{2}$ with $8 \mathrm{YSZ}[112,129,134,169]$.

Fig. 22. Subtracted TEC of $\mathrm{La}_{0.9} \mathrm{Sr}_{0.1} \mathrm{Cr}_{1-x} \mathrm{M}_{x} \mathrm{O}_{3}(x=0.05 ; \mathrm{M}=\mathrm{Mg}, \mathrm{Al}, \mathrm{Ti}, \mathrm{Mn}, \mathrm{Fe}, \mathrm{Co}$, Ni) with $\mathrm{La}_{0.9} \mathrm{Sr}_{0.1} \mathrm{CrO}_{3}$ versus ionic radii of B-site dopant in: (a) air and b) $\mathrm{H}_{2}$ atmosphere. The subtracted zero TEC values correspond to the broken line [Reprinted from reference 112 with permission].

Fig. 23. Comparison of thermal expansion coefficient of A-site ( $\mathrm{Sr})$ and B-site $(\mathrm{M}=\mathrm{Mg}$, $\mathrm{Al}, \mathrm{Ti}, \mathrm{Mn}, \mathrm{Fe}, \mathrm{Co}, \mathrm{Ni}, \mathrm{Cu})$ doped $\mathrm{LaCrO}_{3}$ with (----) 8YSZ in air and $\mathrm{H}_{2}\left(\sim 50-1000^{\circ} \mathrm{C}\right)$ $[112,129,171]$.

Fig. 24. Electronic band structure of $\mathrm{LaCrO}_{3}$ and $\mathrm{La}_{1-x} \mathrm{M}_{x} \mathrm{CrO}_{3-x / 2}(\mathrm{M}=\mathrm{Ba}, \mathrm{Ca}$ and $\mathrm{Sr})$.

Fig. 25. Electrical conductivity of A-site ( $\mathrm{Sr}, \mathrm{Ca})$ doped $\mathrm{LaCrO}_{3}$ as a function of temperature with various dopant levels: (a) air, (b) $\mathrm{H}_{2}$ atmosphere [134,167,182-184].

Fig. 26. Electrical conductivity of A-site ( $\mathrm{Sr}$ ) and B-site (Ni, $\mathrm{Mn}, \mathrm{Co}, \mathrm{Fe})$ doped $\mathrm{LaCrO}_{3}$ as a function of temperature with various dopant levels $[33,129,131,134,189]$.

Fig. 27. Solid solubility limit of A-site ( $\mathrm{Sr}, \mathrm{Ca}$ ) dopants in $\mathrm{LaCrO}_{3}$ with $\mathrm{PO}_{2}$ and temperature: Sr-dopant level, (b) and (c) comparison between $\mathrm{Sr}$ and $\mathrm{Ca}$-dopants [Reproduced from references 231,234 with permission].

Fig. 28. Oxygen transport steps during oxygen permeation through a dense MIEC [204].

Fig. 29. Schematic of different steps involved in surface exchange for oxygen reduction and its diffusion in OTM.

Fig. 30. Schematic of bulk diffusion path of oxygen in an OTM with closed pores [206]. Fig. 31. Effect of calcium content on normalized permeation flux (JL), (, 
$\Delta$ ) $\mathrm{La}_{0.75} \mathrm{Ca}_{0.25} \mathrm{CrO}_{3-\delta},(\square) \mathrm{La}_{0.9} \mathrm{Ca}_{0.1} \mathrm{CrO}_{3-\delta}$ at $\mathrm{T}=1000^{\circ} \mathrm{C}$ (Reproduced from reference 212 with permission).

Fig. 32. Oxygen flux of various perovskite phases (lanthanum

chromites/manganites/ferrites/cobaltites) as a function of temperature $\left(700-1000^{\circ} \mathrm{C}\right)$ [32-

$33,38,213-219]$.

Fig. 33. Oxygen flux of various dual phase (perovskite-fluorite) OTM (lanthanum chromites/manganites/ferrites/cobaltites and YSZ/CGO/CSO) as a function of temperature $\left(600-1000^{\circ} \mathrm{C}\right)[31,37,220-225]$. 
Table 1

Advantages and disadvantages of various oxygen separation techniques [1,14-21].

\begin{tabular}{|c|c|c|c|c|}
\hline $\begin{array}{c}\text { Types/ } \\
\text { Methods }\end{array}$ & $\begin{array}{c}\text { Principle/ } \\
\text { Driving force }\end{array}$ & Advantages & Disadvantages & Applications \\
\hline \begin{tabular}{|l|} 
Pressure \\
swing \\
adsorption
\end{tabular} & Adsorption/desorption & $\begin{array}{l}\text { - Less expensive } \\
\text { - More efficient }\end{array}$ & $\begin{array}{l}\text { - Low purity oxygen (90-95\%) } \\
\text { - Batch process (does not provide continuous } \\
\text { oxygen gas flow) } \\
\text { - Not suitable for large scale applications } \\
\text { (integration with power or IGCC) } \\
\text { - Multiple stage air separation technique } \\
\text { - Large volume space required for the } \\
\text { plant/equipment set up }\end{array}$ & $\begin{array}{l}\text { - Waste water } \\
\text { treatment - wet } \\
\text { oxidation } \\
\text { - Chemical } \\
\text { leaching for } \\
\text { minerals } \\
\text { extraction }\end{array}$ \\
\hline
\end{tabular}




\begin{tabular}{|c|c|c|c|c|}
\hline $\begin{array}{l}\text { Cryogenic } \\
\text { distillation }\end{array}$ & $\begin{array}{l}\text { Fractional } \\
\text { distillation }\end{array}$ & - High purity oxygen $(\geq 99 \%)$ & 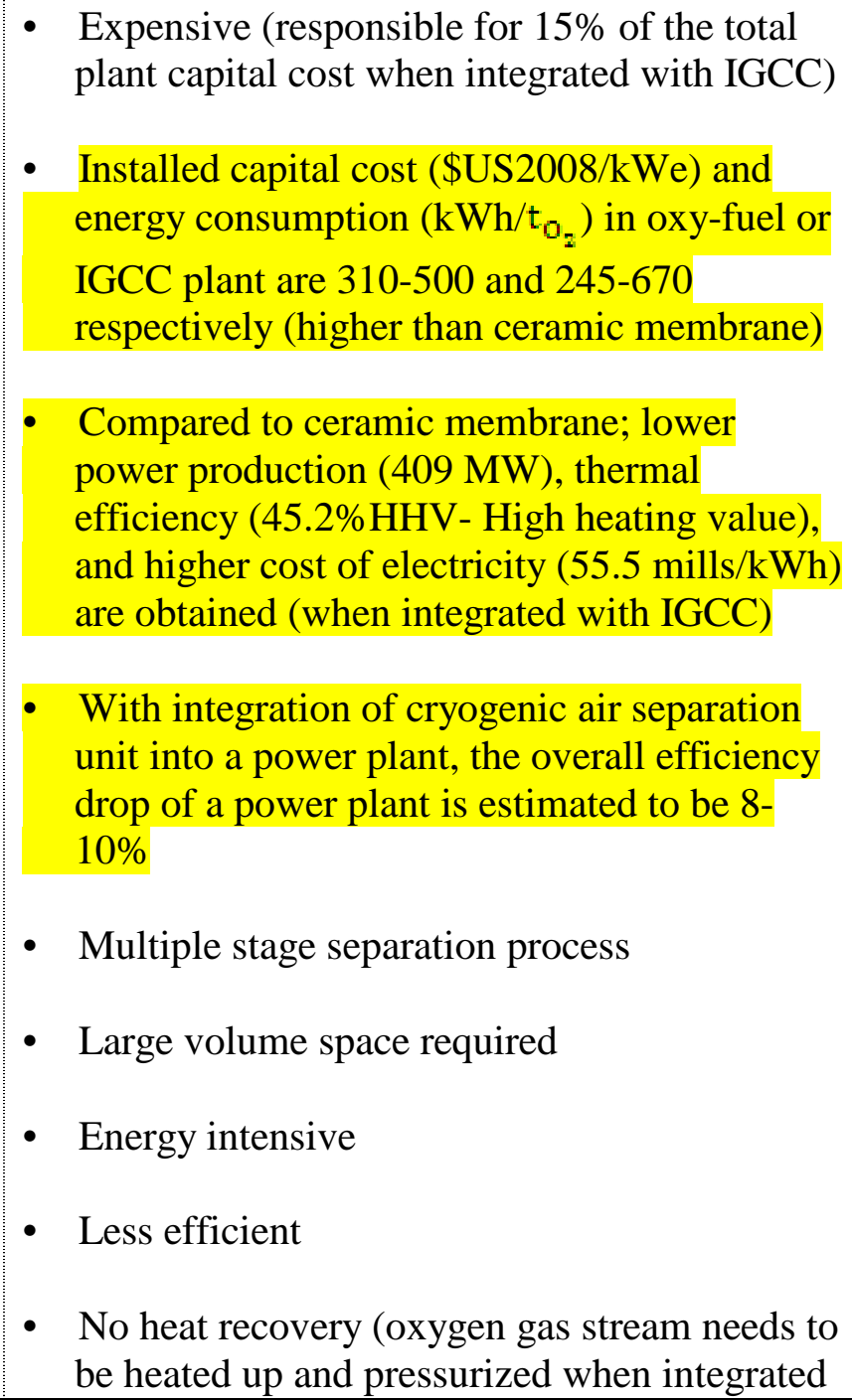 & $\begin{array}{l}\text { - Welding, } \\
\text { medical, } \\
\text { and petrochemical } \\
\text { industries } \\
\text { - Syngas } \\
\text { production and } \\
\text { oxy-combustion }\end{array}$ \\
\hline
\end{tabular}




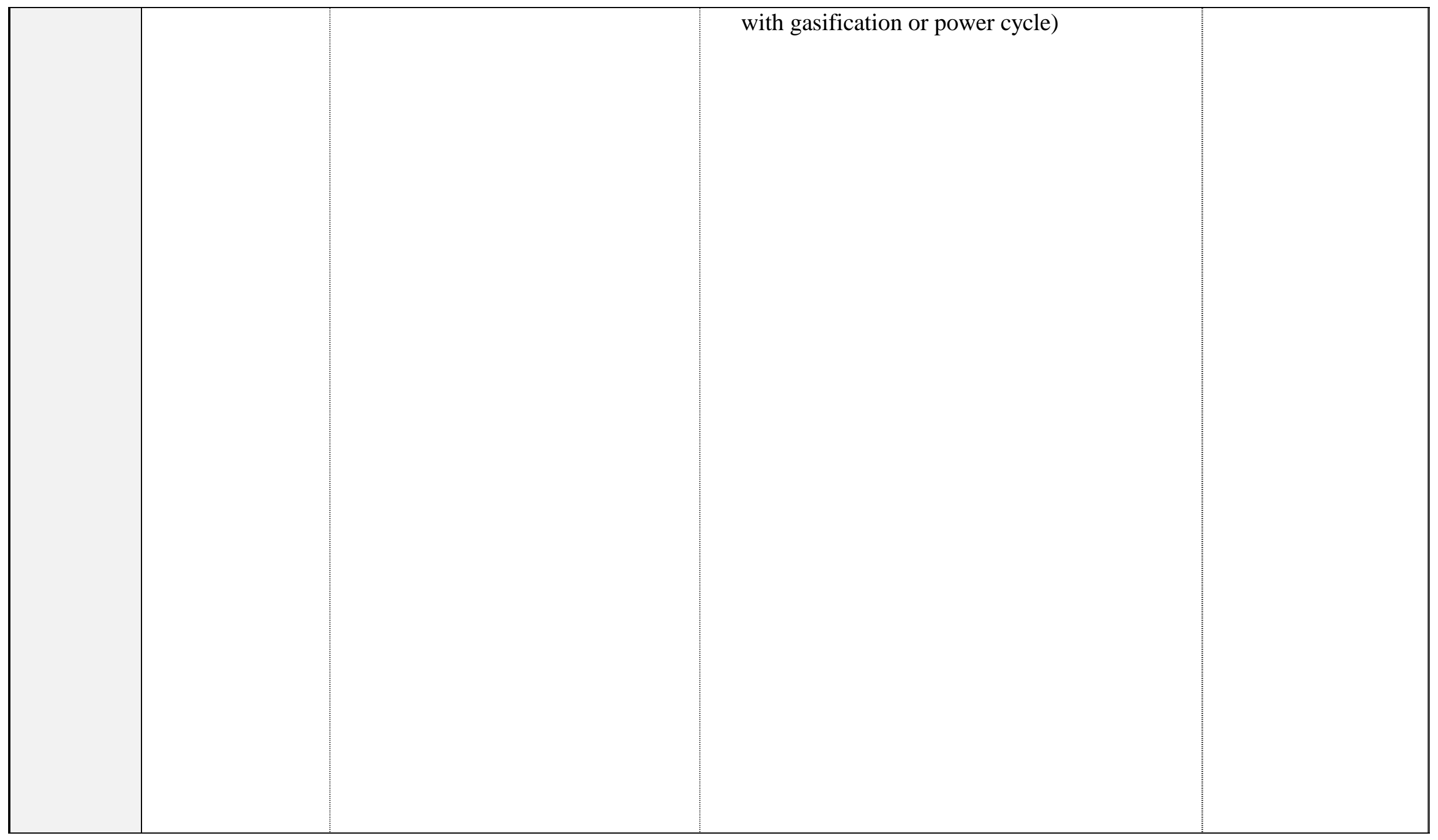




\begin{tabular}{|c|c|c|c|c|}
\hline $\begin{array}{l}\text { Ceramic } \\
\text { oxygen } \\
\text { transport } \\
\text { membrane }\end{array}$ & $\begin{array}{l}\text { Electric } \\
\text { potential/Partial } \\
\text { pressure } \\
\text { gradient }\end{array}$ & $\begin{array}{l}\text { - High purity oxygen }(\geq 99 \%) \\
\text { - Installed capital cost } \\
\text { (\$US2008/kWe) and energy } \\
\text { consumption }\left(\mathrm{kWh} / \mathrm{t}_{\mathrm{O}_{2}} \text { ) in oxy- }\right. \\
\text { fuel or IGCC plant are } 260-295 \\
\text { and } 100-655 \text { respectively (lower } \\
\text { than cryogenic air separation) } \\
\text { - Compact (do not require large } \\
\text { space) } \\
\text { - Single stage air separation } \\
\text { process } \\
\text { - Heat recovery (high temperature } \\
\text { process and more suitable to be } \\
\text { combined with power generation } \\
\text { cycle) } \\
\text { - Cost savings (35-40\% over a } \\
\text { cryogenic process with IGCC ) } \\
\text { - Less power consumption } \\
\text { (comparatively } 37 \% \text { less with } \\
\text { IGCC) } \\
\text { - With OTM integration into a } \\
\text { power plant, the effective energy } \\
\text { demand is estimated to be reduced }\end{array}$ & $\begin{array}{l}\text { - Long term sustainability } \\
\text { - High oxygen flux }\end{array}$ & $\begin{array}{l}\text { - Syngas } \\
\text { production and } \\
\text { oxy-combustion } \\
\text { - Welding, } \\
\text { medical, and } \\
\text { petrochemical } \\
\text { industries } \\
\end{array}$ \\
\hline
\end{tabular}




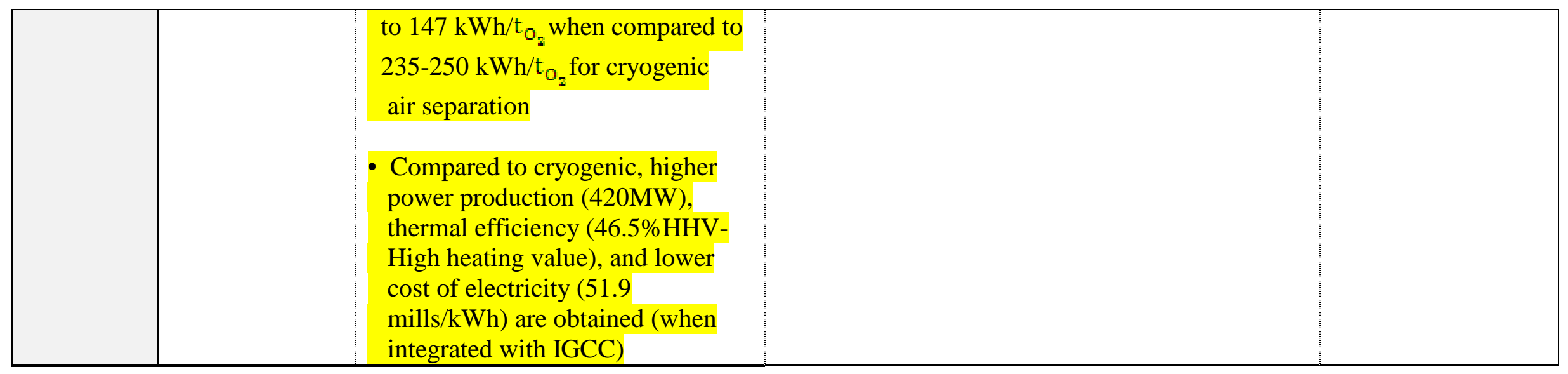


Table 2

Differences between active and passive oxygen transport membrane [25-33].

\begin{tabular}{|c|c|c|}
\hline & Active & Passive \\
\hline Advantages & $\begin{array}{l}\text { - No external voltage/power source and } \\
\text { electrodes required } \\
\text { - Need mixed ionic-electronic conductor } \\
\text { materials }\end{array}$ & $\begin{array}{l}\text { - Control on amount of oxygen produced } \\
\text { via supply of external voltage } \\
\text { - External voltage/power source and } \\
\text { electrodes required }\end{array}$ \\
\hline $\begin{array}{l}\text { Materials } \\
\text { example }\end{array}$ & $\begin{array}{l}\left(\mathrm{La}_{0.75} \mathrm{Sr}_{0.25}\right)_{0.95} \mathrm{Cr}_{0.6} \mathrm{Fe}_{0.4} \mathrm{O}_{3-\delta}, \\
\left(\mathrm{La}_{0.75} \mathrm{Sr}_{0.25}\right)_{0.95} \mathrm{Cr}_{0.5} \mathrm{Mn}_{0.5} \mathrm{O}_{3-\delta}, \\
\mathrm{La}_{0.4} \mathrm{Ca}_{0.6} \mathrm{Co}_{0.2} \mathrm{Fe}_{0.8} \mathrm{O}_{3-\delta}, \mathrm{LaFe}_{0.8} \mathrm{Ni}_{0.2} \mathrm{O}_{3-\delta}, \\
\mathrm{Zr}_{0.84} \mathrm{Y}_{0.16} \mathrm{O}_{1.92}+\mathrm{La}_{0.8} \mathrm{Sr}_{0.2} \mathrm{Cr}_{0.5} \mathrm{Fe}_{0.5} \mathrm{O}_{3-\delta} \text {, and } \\
\mathrm{Gd}_{0.2} \mathrm{Sr}_{0.8} \mathrm{FeO}_{3-\delta}+\mathrm{Ce}_{0.8} \mathrm{Gd}_{0.2} \mathrm{O}_{1.9}\end{array}$ & $\begin{array}{l}\left(\mathrm{ZrO}_{2}\right)_{0.8}\left(\mathrm{Y}_{2} \mathrm{O}_{3}\right)_{0.20}, \mathrm{Bi}_{1.5} \mathrm{Y}_{0.3} \mathrm{Sm}_{0.2} \mathrm{O}_{3} \text { and } \\
\mathrm{Gd}_{0.2} \mathrm{Ce}_{0.6} \mathrm{Pr}_{0.2} \mathrm{O}_{2-\delta}\end{array}$ \\
\hline Phase & Mixed ionic-electronic phase & Ionic phase \\
\hline Driving force & Oxygen partial pressure gradient & Electric potential \\
\hline
\end{tabular}


Table 3

Materials' key requirement for active OTM [43-48].

- $\quad$ Dense $(\geq 94 \%)$ membrane

- High mixed ionic-electronic conductivity

- High stability in a wide range of $\mathrm{P}_{\mathrm{O}_{2}} \sim 0.21-10^{-22}$ atm at the OTM operating temperature $\left(\sim 1000^{\circ} \mathrm{C}\right)$

- High electro-catalytic activity (low polarization resistance)

- High oxygen flux $\left(\geq 10^{-6} \mathrm{~mol} \mathrm{~s}^{-1} \mathrm{~cm}^{-2}\right)$

- Thermal expansion coefficient of 9.5-12.0 $\times 10^{-6}{ }^{\circ} \mathrm{C}^{-1}$ similar to those of the adjacent materials

- High mechanical strength including interfacial strength to withstand the differential partial pressure, handling, vibration during transportation and operation

- Excellent thermal cycling resistance

- Excellent chemical resistance to withstand both oxidizing and reducing atmosphere at $\sim 1000^{\circ} \mathrm{C}$

- Resistance to aging of materials (long-term $(\geq 40,000 \mathrm{~h})$ materials stability in aggressive operating condition)

Structure: no change in crystal symmetry and minimal chemical expansion to minimize change in lattice volume

Microstructure: no change in microstructure (grain growth, secondary phase formation, surface segregation; pore growth and densification for adjacent intermediate and surface exchange layers and electrodes) Chemical: no solid-solid and solid-gas interaction to change the chemical formula by formation of new compounds, precipitation of oxides, reduction of oxides into metallic form, evaporation of materials Mechanical: Acceptable creep rate: $\sim 10^{-10} \mathrm{~s}^{-1}$ yielding a tolerable strain of $\sim 1 \%$ per year) 
Table 4

Advantages and disadvantages of various perovskite oxides [56-63].

\begin{tabular}{|c|c|c|c|}
\hline Perovskites & Ionic/electronic/mixed & Advantages & Disadvantages \\
\hline Chromites & Predominantly electronic & $\begin{array}{l}\text { - Higher stability }\left(0.21-10^{-22} \text { atm at }\right. \\
\left.\sim 1000^{\circ} \mathrm{C}\right) \\
\text { - Good electrical conductivity }(0.6-1.0 \\
\left.\mathrm{S} \mathrm{cm}^{-1} \text { at } 1000^{\circ} \mathrm{C}\right)\end{array}$ & - Low density $(<60 \%)$ and ionic conductivity \\
\hline
\end{tabular}




\begin{tabular}{|c|c|c|c|}
\hline Ferrites & Mixed ionic-electronic & $\begin{array}{l}\text { - Exhibits high ionic }\left(0.05 \mathrm{~S} \mathrm{~cm}^{-1} \text { at }\right. \\
\left.900^{\circ} \mathrm{C}\right) \text { and electronic conductivity } \\
\left(\sim 100 \mathrm{~S} \mathrm{~cm}^{-1} \text { at } 1000^{\circ} \mathrm{C}\right) \\
\text { - Higher activity for oxygen reduction } \\
\text { with oxygen flux }\left(1.8 \times 10^{-6} \mathrm{~mol} \mathrm{~cm}^{-2}\right. \\
\left.\mathrm{s}^{-1}\right)\end{array}$ & $\begin{array}{l}\text { - High thermal expansion coefficient }\left(23.8 \times 10^{-6}\right. \\
\left.\mathrm{K}^{-1} \text { for } \mathrm{T}>600{ }^{\circ} \mathrm{C}\right) \\
\text { - Decomposes into } \mathrm{La}_{2} \mathrm{O}_{3} \text { and } \mathrm{Fe} \text { in reducing } \\
\text { atmosphere }\left(\leq 10^{-17} \mathrm{~atm}\right) \text { at } 1000^{\circ} \mathrm{C} \\
\text { - Ferrites are more prone to lattice structure } \\
\text { distortion due to the possibility of } \mathrm{Fe} \\
\text { disproportionation occurring from change in } \\
\text { valence state }\left(\mathrm{Fe}^{3+} / \mathrm{Fe}^{2+} / \mathrm{Fe}^{4+}\right)\end{array}$ \\
\hline Manganites & Predominantly electronic & $\begin{array}{l}\text { - High electrical conductivity (83 S } \\
\left.\mathrm{cm}^{-1} \text { at } 800^{\circ} \mathrm{C}\right)\end{array}$ & $\begin{array}{l}\text { - Decomposes into } \mathrm{La}_{2} \mathrm{O}_{3} \text { and } \mathrm{MnO} \text { in reducing } \\
\text { atmosphere }\left(\leq 10^{-15} \mathrm{~atm}\right) \text { at } 1000^{\circ} \mathrm{C} \\
\text { - Low ionic conductivity }\left(1.10 \times 10^{-7} \mathrm{~S} \mathrm{~cm}^{-1} \text { at }\right. \\
\left.900^{\circ} \mathrm{C}\right)\end{array}$ \\
\hline
\end{tabular}




\begin{tabular}{|c|c|c|c|}
\hline Nickelates & Predominantly electronic & $\begin{array}{l}\text { - Good electrical conductivity }(\sim 10 \mathrm{~S} \\
\left.\mathrm{cm}^{-1} \text { at } 800^{\circ} \mathrm{C}\right) \\
\text { - Higher activity for oxygen reduction } \\
\text { with oxygen flux }\left(\sim 1.6 \times 10^{-8} \mathrm{~mol}\right. \\
\left.\mathrm{cm}^{-2} \mathrm{~s}^{-1}\right)\end{array}$ & $\begin{array}{l}\text { - Not stable and decomposes into } \mathrm{La}_{2} \mathrm{NiO}_{4} \text { and } \\
\mathrm{NiO} \text { in reducing atmosphere }\left(<10^{-0.6} \mathrm{~atm}\right) \text { at } \\
1000^{\circ} \mathrm{C} \\
\text { - Exolution of } \mathrm{Ni} \text { metal when heavily doped } \\
(\sim 50 \%)\end{array}$ \\
\hline Cobaltites & Mixed ionic-electronic & $\begin{array}{l}\text { - Higher activity for oxygen reduction } \\
\text { with oxygen flux }\left(0.3-3 \times 10^{-7} \mathrm{~mol}\right. \\
\left.\mathrm{cm}^{-2} \mathrm{~s}^{-1}\right) \\
\text { - High electronic conductivity }(103 \mathrm{~S} \\
\left.\mathrm{cm}^{-1} \text { at } 1000^{\circ} \mathrm{C}\right) \text { and ionic } \\
\text { conductivity }\left(10^{-3} \mathrm{~S} \mathrm{~cm}^{-1} \text { at } 900^{\circ} \mathrm{C}\right) \\
\text { and density }(\geq 90 \%)\end{array}$ & $\begin{array}{l}\text { - High thermal expansion coefficient }\left(20 \times 10^{-6}\right. \\
\left.\mathrm{K}^{-1}\right) \\
\text { - Decomposes into } \mathrm{La}_{2} \mathrm{CoO}_{4} \text { and } \mathrm{CoO} \text { in } \\
\text { reducing atmosphere }\left(<10^{-7} \mathrm{~atm}\right) \text { in reducing } \\
\text { atmosphere at } 1000^{\circ} \mathrm{C} \\
\text { - Similar to ferrites, cobaltites are also more } \\
\text { prone to lattice structure distortion due to the } \\
\text { possibility of Co disproportionation occurring } \\
\text { from change in valence state }\left(\mathrm{Co}^{3+} / \mathrm{Co}^{2+} / \mathrm{Co}^{4+}\right)\end{array}$ \\
\hline
\end{tabular}


Table 5

Advantages and disadvantages of various fabrication techniques [87-92,98].

\begin{tabular}{|l|c|c|c|c|}
\hline $\begin{array}{c}\text { Fabrication } \\
\text { Techniques }\end{array}$ & $\begin{array}{c}\text { Deposition } \\
\text { rate/thickness }\end{array}$ & Advantages & $\begin{array}{c}\text { Examples of } \\
\text { related } \\
\text { materials }\end{array}$ \\
\hline Wet chemical & \multirow{2}{*}{$\begin{array}{l}\text { Disadvantages } \\
\text { Slip casting }\end{array}$} & $\begin{array}{c}\text { Economical/low cost } \\
\text { Dense/porous } \\
\text { microstructure }\end{array}$ & $\begin{array}{l}\text { Required drying and sintering steps } \\
\text { Defect (cracks) in microstructure } \\
\text { due to uncontrolled drying and } \\
\text { sintering } \\
\text { High temperature sintering can lead } \\
\text { to interaction between different } \\
\text { materials in composites resulting in } \\
\text { materials instability }\end{array}$ \\
\hline
\end{tabular}




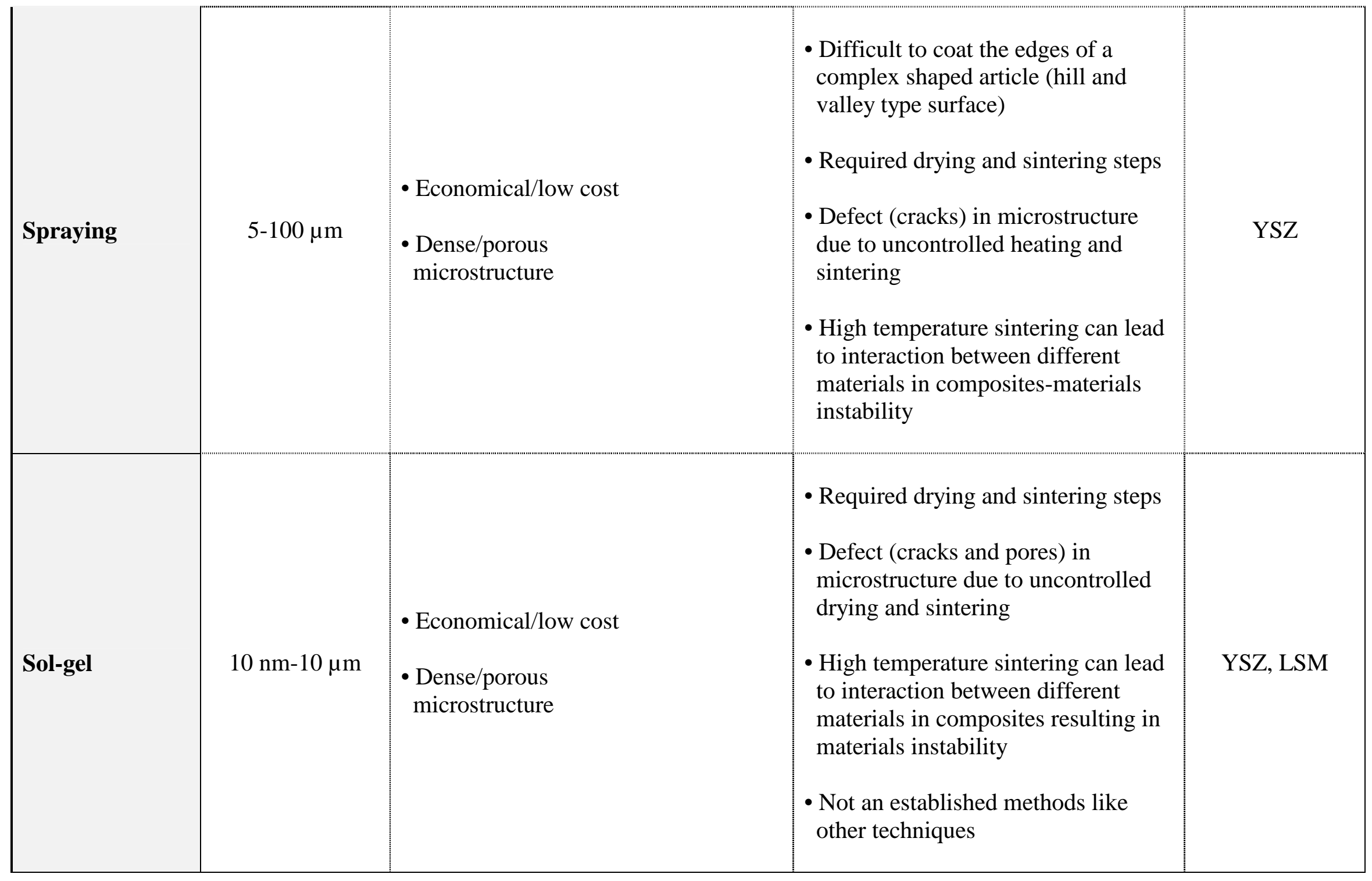




\begin{tabular}{|c|c|c|c|c|}
\hline $\begin{array}{l}\text { Plasma } \\
\text { snraving }\end{array}$ & \multicolumn{4}{|c|}{ In-sight technique } \\
\hline Atmospheric & $50-300 \mu \mathrm{m}$ & $\begin{array}{l}\text { - In-principle, no sintering step is } \\
\text { required } \\
\text { - Faster than wet chemical technique } \\
\text { - Controlled stoichiometry and high } \\
\text { purity } \\
\text { - Dense microstructure }\end{array}$ & $\begin{array}{l}\text { - High cost } \\
\text { - Micro-cracks and pores in } \\
\text { microstructure } \\
\text { - Thermal stress } \\
\text { - Difficult to deposit 2-10 } \mu \mathrm{m} \text { thick } \\
\text { layer }\end{array}$ & YSZ \\
\hline Vacuum & $30-150 \mu \mathrm{m}$ & $\begin{array}{l}\text { - In-principle, no sintering step is } \\
\text { required } \\
\text { - High deposition rate - less } \\
\text { fabrication time } \\
\text { - Faster than wet chemical technique } \\
\text { - Thinner layers }\end{array}$ & $\begin{array}{l}\text { - High cost } \\
\text { - High temperature process } \\
\text { - Decomposition of perovskites due } \\
\text { to use of inert/reducing gas (argon, } \\
\text { hydrogen) } \\
\text { - Non-uniform thickness and lower } \\
\text { densification }\end{array}$ & YSZ, LSM \\
\hline
\end{tabular}




\begin{tabular}{|c|c|c|c|c|}
\hline Low pressure & $20-100 \mu \mathrm{m}$ & $\begin{array}{l}\text { - In-principle, no sintering step is } \\
\text { required } \\
\text { - Faster than wet chemical technique } \\
\text { - Less thermal gradient } \\
\text { - Thinner layers } \\
\text { - Faster deposition }\end{array}$ & $\begin{array}{l}\text { - High cost } \\
\text { - Decomposition of perovskites due } \\
\text { to use of inert/reducing gas (argon, } \\
\text { hydrogen) }\end{array}$ & YSZ \\
\hline \multicolumn{2}{|c|}{ Physical vapor deposition } & \multicolumn{3}{|c|}{ In-sight technique } \\
\hline Sputtering & $\sim 1 \mu \mathrm{m}$ & $\begin{array}{l}\text { - Control on varying grain size with } \\
\text { columnar structure } \\
\text { - Easy attainment of nano-sized grain }\end{array}$ & - Expensive & $\begin{array}{c}\text { YSZ, LSM, } \\
\mathrm{La}_{0.50} \mathrm{Sr}_{0.50} \mathrm{CoO}_{3}\end{array}$ \\
\hline
\end{tabular}




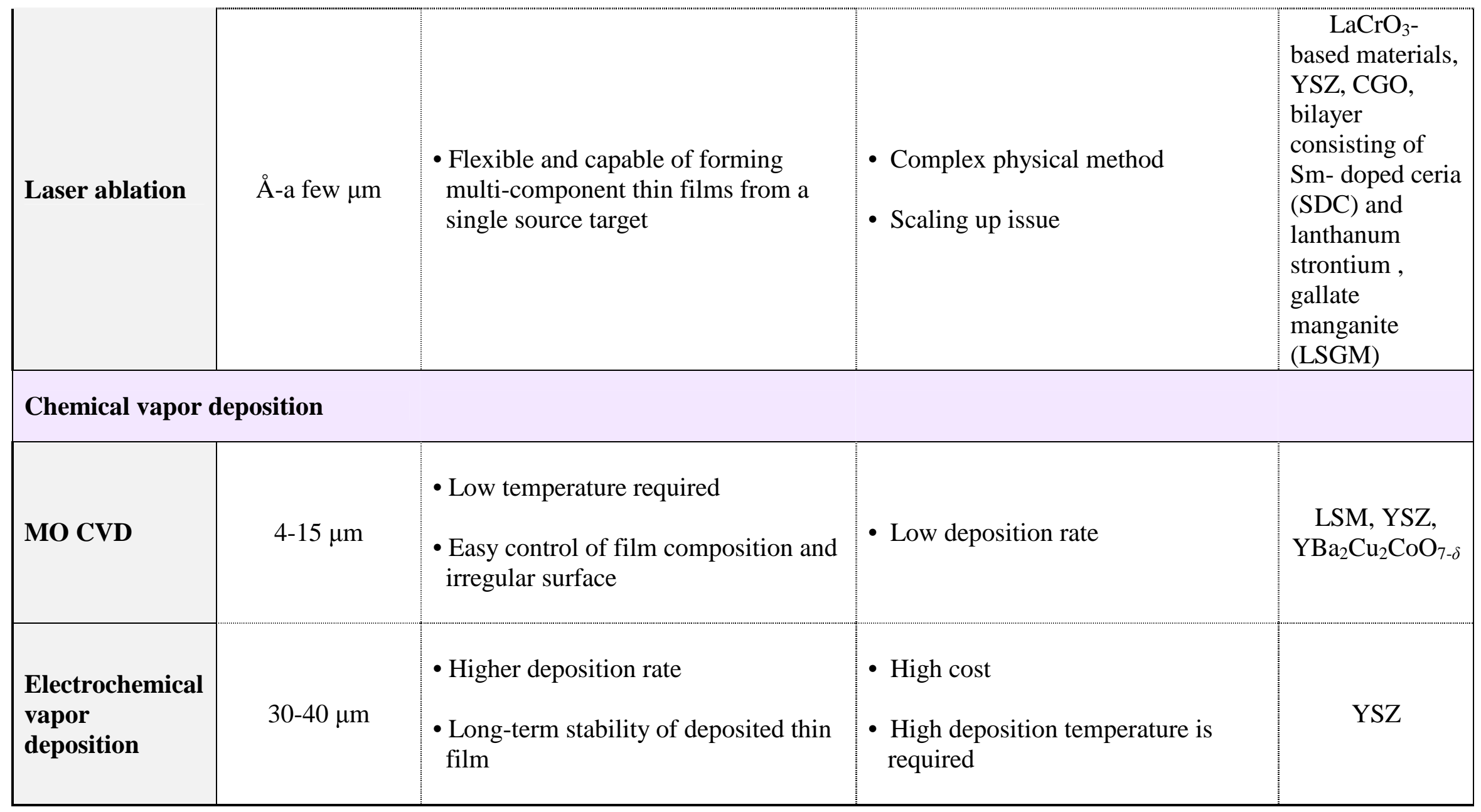


Table 6

Mechanical properties of various doped lanthanum chromite materials [110,155,193-197].

\begin{tabular}{|c|c|c|c|c|c|c|c|c|c|}
\hline Composition & $\begin{array}{c}\text { Tempe } \\
\text { rature } \\
\left({ }^{\circ} \mathbf{C}\right)\end{array}$ & $\begin{array}{c}\text { Oxygen partial } \\
\text { pressure } \\
\text { (atm) }\end{array}$ & $\begin{array}{c}\text { Elastic } \\
\text { Modulus } \\
\text { (GPa) }\end{array}$ & $\begin{array}{l}\text { Poisson's } \\
\text { ratio }\end{array}$ & $\begin{array}{c}\text { Fracture } \\
\text { toughness } \\
\left(\mathbf{K}_{\mathrm{IC}}-\mathbf{M P a} \mathbf{~ m}^{1 / 2}\right)\end{array}$ & $\begin{array}{c}\text { Flexure } \\
\text { strength } \\
\text { (MPa) }\end{array}$ & $\begin{array}{c}\text { Mean } \\
\text { fracture } \\
\text { Strength } \\
\text { (MPa) }\end{array}$ & $\begin{array}{c}\text { Micro } \\
\text { hardness } \\
\text { (GPa) }\end{array}$ & $\begin{array}{l}\text { Weibull } \\
\text { Modulus }\end{array}$ \\
\hline \multirow{3}{*}{$8 \mathrm{YSZ}$} & $\mathrm{RT}$ & 0.21 & 190 & 0.308 & 1.61 & 416 & 214 & - & 5.7 \\
\hline & 800 & 0.21 & 157 & 0.313 & - & - & 146 & - & 8.6 \\
\hline & 900 & 0.21 & - & - & 1.02 & - & - & - & \\
\hline \multirow{2}{*}{10 CGO } & RT & 0.21 & 200 & 0.328 & - & - & 120 & - & 3.8 \\
\hline & 800 & 0.21 & 200 & - & - & - & 169 & - & 5.7 \\
\hline $\mathrm{La}_{0.9} \mathrm{Sr}_{0.1} \mathrm{CrO}_{3}$ & 600 & 0.21 & - & - & - & $\sim 80$ & - & - & - \\
\hline $\mathrm{La}_{0.7} \mathrm{Sr}_{0.3} \mathrm{CrO}_{3-\delta}$ & 1400 & 0.21 & - & - & - & $\sim 98$ & - & - & 10 \\
\hline $\mathrm{La}_{0.85} \mathrm{Ca}_{0.15} \mathrm{CrO}_{3}$ & RT & 0.21 & - & - & - & $61 \pm 11.5$ & - & - & - \\
\hline
\end{tabular}




\begin{tabular}{|c|c|c|c|c|c|c|c|c|c|}
\hline $\mathrm{La}_{0.8} \mathrm{Ca}_{0.2} \mathrm{CrO}_{3}$ & $\mathrm{RT}$ & 0.21 & - & - & - & $96 \pm 14.4$ & - & - & - \\
\hline $\mathrm{La}_{0.8} \mathrm{Ca}_{0.2} \mathrm{CrO}_{3-\delta}$ & $\mathrm{RT}$ & 0.21 & $73.5 \pm 7.9$ & - & $3.52 \pm 0.11$ & 131.3 & $91.2 \pm 11$ & $4.33 \pm 0.24$ & 8.7 \\
\hline \multirow{3}{*}{$\mathrm{La}_{0.75} \mathrm{Ca}_{0.25} \mathrm{CrO}_{3}$} & $\mathrm{RT}$ & 0.21 & $\sim 180$ & - & $\sim 2.1$ & $122.7 \pm 26$ & - & - & - \\
\hline & RT & $10^{-10}$ & $\sim 180$ & - & $\sim 2$ & 145 & - & - & - \\
\hline & $\mathrm{RT}$ & $10^{-16}$ & $\sim 175$ & - & $\sim 1.4$ & $\sim 15$ & - & - & - \\
\hline \multirow{3}{*}{$\mathrm{La}_{0.7} \mathrm{Ca}_{0.3} \mathrm{CrO}_{3}$} & RT & 0.21 & $\sim 181$ & - & - & $107.4 \pm 5.9$ & - & - & - \\
\hline & RT & $10^{-10}$ & $\sim 178$ & - & - & $107.4 \pm 5.9$ & - & - & - \\
\hline & RT & $10^{-16}$ & $\sim 175$ & - & - & $\sim 15$ & - & - & - \\
\hline $\mathrm{La}_{0.7} \mathrm{Ca}_{0.3} \mathrm{CrO}_{3-\delta}$ & 1400 & 0.21 & - & - & - & $\sim 220$ & - & - & 11.3 \\
\hline $\begin{array}{l}\mathrm{La}_{0.8} \mathrm{Sr}_{0.2} \mathrm{Cr}_{0.92} \mathrm{C} \\
\mathrm{O}_{0.08} \mathrm{O}_{3}\end{array}$ & $\mathrm{RT}$ & 0.21 & - & - & - & 62 & - & 5.98 & - \\
\hline $\begin{array}{l}\mathrm{La}_{0.7} \mathrm{Sr}_{0.3} \mathrm{Cr}_{0.9} \mathrm{Co} \\
0.1 \mathrm{O}_{3}\end{array}$ & 1000 & 0.21 & - & - & - & 103 & - & - & 9.7 \\
\hline \multirow{2}{*}{$\begin{array}{l}\mathbf{L a}_{0.2} \mathrm{Sr}_{0.8} \mathrm{Fe}_{0.8} \mathrm{Cr}_{\mathbf{0}} \\
{ }_{.2} \mathrm{O}_{3-\delta}\end{array}$} & $\mathrm{RT}$ & 0.21 & - & - & $0.5-0.8$ & - & 167 & 5.2 & 5.2 \\
\hline & 1000 & 0.21 & - & - & - & - & 108 & - & - \\
\hline $\begin{array}{l}\mathrm{La}_{0.8} \mathrm{Ca}_{0.2} \mathrm{Cr}_{0.9} \mathrm{Al} \\
0.1 \mathrm{O}_{3-\delta}\end{array}$ & RT & 0.21 & $91.5 \pm 10.3$ & - & $4.02 \pm 0.12$ & 98.9 & $80.8 \pm 8.7$ & $7.35 \pm 0.42$ & 9.4 \\
\hline $\begin{array}{l}\mathbf{L a}_{0.8} \mathrm{Ca}_{0.2} \mathrm{Cr}_{0.9} \mathrm{Co} \\
{ }_{0.1} \mathrm{O}_{3-\delta}\end{array}$ & RT & 0.21 & $143.6 \pm 17.6$ & - & $4.23 \pm 0.14$ & 170.5 & $148.9 \pm 14.6$ & $9.04 \pm 0.54$ & 9.3 \\
\hline
\end{tabular}




\begin{tabular}{|c|c|c|c|c|c|c|c|c|c|}
\hline $\begin{array}{l}\mathbf{L a}_{0.8} \mathbf{C a}_{0.2} \mathrm{Cr}_{0.9} \mathrm{C} \\
\mathbf{u}_{0.1} \mathbf{O}_{3-\delta}\end{array}$ & $\mathrm{RT}$ & 0.21 & $371.2 \pm 36.2$ & - & $4.33 \pm 0.15$ & 356.9 & $339.2 \pm 16.2$ & $9.85 \pm 0.34$ & 36.9 \\
\hline $\begin{array}{l}\mathrm{La}_{0.8} \mathrm{Ca}_{0.2} \mathrm{Cr}_{0.9} \mathrm{Fe} \\
0.1 \mathrm{O}_{3-\delta}\end{array}$ & $\mathrm{RT}$ & 0.21 & $99.8 \pm 10.3$ & - & $4.02 \pm 0.12$ & 154.3 & $133.6 \pm 12.3$ & $7.35 \pm 0.42$ & 12.9 \\
\hline
\end{tabular}


Table 7

Summary - Properties of A and/or B-site doped lanthanum chromite materials [32-33,38,110,112-115,120,123,126,128-

131,134,139-142,149,183-185,193-194].

\begin{tabular}{|c|c|c|c|c|c|c|}
\hline Composition & $\begin{array}{l}\text { Relative } \\
\text { Density } \\
\quad(\%)\end{array}$ & $\begin{array}{c}\text { Oxygen- } \\
\text { Nonstoichiometry } \\
(\Delta \delta) \\
\left(\mathrm{T}=1000{ }^{\circ} \mathrm{C}\right. \\
\mathrm{PO}_{2} \sim \mathbf{0 . 2 1 - 1 0 ^ { - 1 5 }} \\
\text { atm })\end{array}$ & $\begin{array}{c}\text { Thermal } \\
\text { Expansion } \\
\left(\times 10^{-6}{ }^{\circ} C^{-1}\right)\end{array}$ & $\begin{array}{l}\text { Electrical } \\
\text { Conductivity } \\
\left(\mathrm{S} \mathrm{cm}^{-1}\right)\end{array}$ & $\begin{array}{l}\text { Mechanical } \\
\text { Property } \\
\text { (Flexure } \\
\text { Strength - } \\
\text { MPa) }\end{array}$ & $\begin{array}{l}\text { Oxygen } \\
\text {-Flux } \\
(\mathrm{mol} \\
\mathrm{cm}^{-2} \\
\left.\text { sec }^{-1}\right)\end{array}$ \\
\hline $\mathrm{LaCrO}_{3}$ & $\begin{array}{c}\sim 50 \\
\left(\mathrm{~T} \sim 1450^{\circ} \mathrm{C}\right)\end{array}$ & - & $\begin{array}{c}9.4(\text { air }) \\
\left(\mathrm{T}=290-1050^{\circ} \mathrm{C}\right)\end{array}$ & $\begin{array}{c}0.2-0.35 \text { (air), } 0.003- \\
0.05\left(\mathrm{H}_{2}\right) \\
\left(\mathrm{T} \sim 500-800^{\circ} \mathrm{C}\right)\end{array}$ & - & - \\
\hline \multicolumn{7}{|l|}{ A-site ( $\mathrm{Ca}$ ) doped $\mathrm{LaCrO}_{3}$} \\
\hline $\mathrm{La}_{0.9} \mathrm{Ca}_{0.1} \mathrm{CrO}_{3-\delta}$ & - & $\sim 0.0112$ & $\begin{array}{c}9(\text { air }) \\
\left(\mathrm{T}=50-1000^{\circ} \mathrm{C}\right)\end{array}$ & $\begin{array}{c}9.4-12.0 \text { (air), 0.7-2.7 } \\
\left(\mathrm{H}_{2}\right) \\
\left(\mathrm{T} \sim 500-1000^{\circ} \mathrm{C}\right)\end{array}$ & - & - \\
\hline $\mathrm{La}_{0.7} \mathrm{Ca}_{0.28} \mathrm{CrO}_{3}$ & $\begin{array}{c}<60 \\
\left(\mathrm{~T} \sim 1550^{\circ} \mathrm{C}\right)\end{array}$ & - & & & - & - \\
\hline $\mathrm{La}_{0.7} \mathrm{Ca}_{0.3} \mathrm{CrO}_{3-\delta}$ & $\begin{array}{c}\sim 68 \\
\left(\mathrm{~T}=1600^{\circ} \mathrm{C}\right)\end{array}$ & $\sim 0.07$ & $\begin{array}{c}9.7 \text { (air) } \\
\left(\mathrm{T}=50-1000^{\circ} \mathrm{C}\right)\end{array}$ & $\begin{array}{c}30.2-37.1 \text { (air), } 2.2-4.3 \\
\left(\mathrm{H}_{2}\right) \\
\left(\mathrm{T} \sim 500-850^{\circ} \mathrm{C}\right)\end{array}$ & $\begin{array}{c}\sim 220(\mathrm{~T}= \\
\left.1400^{\circ} \mathrm{C}\right)\end{array}$ & - \\
\hline
\end{tabular}




\begin{tabular}{|c|c|c|c|c|c|c|}
\hline $\mathrm{La}_{0.7} \mathrm{Ca}_{0.32} \mathrm{CrO}_{3}$ & $\begin{array}{c}>90 \\
\left(\mathrm{~T}=1400^{\circ} \mathrm{C}\right)\end{array}$ & - & - & - & - & - \\
\hline$\left(\mathrm{La}_{0.6} \mathrm{Ca}_{0.4}\right)_{1.02} \mathrm{CrO}_{3}$ & $\begin{array}{c}>95 \\
\left(\mathrm{~T}=1350^{\circ} \mathrm{C}\right)\end{array}$ & - & - & - & - & - \\
\hline \multicolumn{7}{|l|}{ A-site $(\mathrm{Sr})$ doped $\mathrm{LaCrO}_{3}$} \\
\hline $\mathrm{La}_{0.9} \mathrm{Sr}_{0.1} \mathrm{CrO}_{3-\delta}$ & - & $\sim 0.0114$ & $\begin{array}{c}10.7 \text { (air) } \\
\left(\mathrm{T}=50-1000^{\circ} \mathrm{C}\right)\end{array}$ & $\begin{array}{c}7.3-8.5 \text { (air), } 0.4-2.1 \\
\left(\mathrm{H}_{2}\right) \\
\left(\mathrm{T} \sim 500-800^{\circ} \mathrm{C}\right)\end{array}$ & $\begin{array}{c}\sim 80(\mathrm{~T}= \\
\left.600^{\circ} \mathrm{C}\right)\end{array}$ & - \\
\hline$\left(\mathrm{La}_{0.85} \mathrm{Sr}_{0.15}\right)_{0.95} \mathrm{CrO}_{3}$ & $\begin{array}{c}\sim 58 \\
\left(\mathrm{~T}=1600^{\circ} \mathrm{C}\right.\end{array}$ & - & - & - & - & - \\
\hline $\mathrm{La}_{0.7} \mathrm{Sr}_{0.3} \mathrm{CrO}_{3-\delta}$ & $\begin{array}{c}\sim 65 \\
\left(\mathrm{~T}=1400^{\circ} \mathrm{C}\right)\end{array}$ & $\sim 0.082$ & $\begin{array}{c}11.1 \text { (air) } \\
\left(\mathrm{T}=50-1000^{\circ} \mathrm{C}\right)\end{array}$ & $\begin{array}{c}37.2-39.8 \text { (air), } 3.9-4.8 \\
\left(\mathrm{H}_{2}\right) \\
\left(\mathrm{T} \sim 500-800^{\circ} \mathrm{C}\right)\end{array}$ & $\begin{array}{l}\sim 98(\mathrm{~T}= \\
\left.1400^{\circ} \mathrm{C}\right)\end{array}$ & - \\
\hline$\left(\mathrm{La}_{0.85} \mathrm{Sr}_{0.15}\right)_{1.02} \mathrm{CrO}_{3}$ & $\begin{array}{c}>90 \\
\left(\mathrm{~T}=1600^{\circ} \mathrm{C}\right)\end{array}$ & - & - & - & - & - \\
\hline \multicolumn{7}{|c|}{ A-site $(\mathrm{Sr}, \mathrm{Ca})$ doped $\mathrm{LaCrO}_{3}$} \\
\hline $\mathrm{La}_{0.75} \mathrm{Ca}_{0.10} \mathrm{Sr}_{0.15} \mathrm{CrO}_{3}$ & $\begin{array}{c}\sim 84 \\
\left(\mathrm{~T}=1400^{\circ} \mathrm{C}\right)\end{array}$ & - & - & - & - & - \\
\hline \multicolumn{7}{|c|}{$\begin{array}{l}\text { A-site }(\mathrm{Ca} / \mathrm{Sr}) \text { and } \mathrm{B} \text {-site }(\mathrm{Fe}) \\
\text { doped } \mathrm{LaCrO}_{3}\end{array}$} \\
\hline $\mathrm{La}_{0.9} \mathrm{Ca}_{0.1} \mathrm{Cr}_{0.5} \mathrm{Fe}_{0.5} \mathrm{O}_{3}$ & $\begin{array}{c}57.6 \\
\left(\mathrm{~T}=1250^{\circ} \mathrm{C}\right)\end{array}$ & - & - & $\begin{array}{c}3.0 \text { (air) } \\
\left(\mathrm{T} \sim 727^{\circ} \mathrm{C}\right)\end{array}$ & - & - \\
\hline $\mathrm{La}_{0.8} \mathrm{Ca}_{0.2} \mathrm{Cr}_{0.9} \mathrm{Fe}_{0.1} \mathrm{O}_{3-\delta}$ & - & - & - & - & $\begin{array}{l}\sim 154.3(\mathrm{~T}= \\
\left.25^{\circ} \mathrm{C}\right)\end{array}$ & - \\
\hline $\mathrm{La}_{0.9} \mathrm{Sr}_{0.1} \mathrm{Cr}_{0.95} \mathrm{Fe}_{0.05} \mathrm{O}_{3}$ & - & - & $\begin{array}{c}9.2(\mathrm{air}), 10.2\left(\mathrm{H}_{2}\right) \\
\left(\mathrm{T}=50-1000^{\circ} \mathrm{C}\right)\end{array}$ & - & - & - \\
\hline
\end{tabular}




\begin{tabular}{|c|c|c|c|c|c|c|}
\hline $\mathrm{La}_{0.8} \mathrm{Sr}_{0.2} \mathrm{Cr}_{0.9} \mathrm{Fe}_{0.1} \mathrm{O}_{3-\delta}$ & $\begin{array}{c}\sim 84 \\
\left(\mathrm{~T}=1400^{\circ} \mathrm{C}\right)\end{array}$ & - & - & - & - & - \\
\hline $\mathrm{La}_{0.75} \mathrm{Sr}_{0.25} \mathrm{Cr}_{0.7} \mathrm{Fe}_{0.3} \mathrm{O}_{3-\delta}$ & - & $\sim 0.1266$ & & & - & - \\
\hline$\left(\mathrm{La}_{0.75} \mathrm{Sr}_{0.25}\right)_{0.95} \mathrm{Cr}_{0.7} \mathrm{Fe}_{0.3} \mathrm{O}_{3-\delta}$ & $\begin{array}{c}95.2 \\
\left(\mathrm{~T}=1700^{\circ} \mathrm{C}\right)\end{array}$ & - & $\begin{array}{c}11.3 \text { (air), } 10.3 \\
\left(\mathrm{CO} / \mathrm{CO}_{2}\right) \\
\left(\mathrm{T}=27-1097^{\circ} \mathrm{C}\right)\end{array}$ & $\begin{array}{c}\sim 31.6 \text { (air), } \sim 2.0\left(10^{-18}\right. \\
\text { atm) } \\
\left(\mathrm{T} \sim 900^{\circ} \mathrm{C}\right)\end{array}$ & - & $\begin{array}{c}\sim 1.0 \mathrm{E}-7 \\
\left(\mathrm{~T}=950^{\circ} \mathrm{C},\right. \\
\text { disk, } \mathrm{d}= \\
1 \mathrm{~mm}, \\
\left.\text { air } / \mathrm{H}_{2}-\mathrm{N}_{2}\right)\end{array}$ \\
\hline$\left(\mathrm{La}_{0.75} \mathrm{Sr}_{0.25}\right)_{0.95} \mathrm{Cr}_{0.6} \mathrm{Fe}_{0.4} \mathrm{O}_{3-\delta}$ & - & - & $\begin{array}{c}11.1 \text { (air), } 10.5 \\
\left(\mathrm{CO} / \mathrm{CO}_{2}\right) \\
\left(\mathrm{T}=27-1097^{\circ} \mathrm{C}\right)-\end{array}$ & - & - & $\begin{array}{c}\sim 1.5 \mathrm{E}-7 \\
\left(\mathrm{~T}=900^{\circ} \mathrm{C},\right. \\
\text { disk, } \\
\mathrm{d}=1 \mathrm{~mm}, \\
\left.\text { air } / \mathrm{H}_{2}-\mathrm{N}_{2}\right)\end{array}$ \\
\hline $\mathrm{La}_{0.8} \mathrm{Sr}_{0.2} \mathrm{Cr}_{0.5} \mathrm{Fe}_{0.5} \mathrm{O}_{3-\delta}$ & $\begin{array}{c}\sim 97 \\
\left(\mathrm{~T}=1400^{\circ} \mathrm{C}\right)\end{array}$ & - & - & $\begin{array}{c}\sim 21.9 \text { (air), } \sim 6.4\left(5 \% \mathrm{H}_{2^{-}}\right. \\
\mathrm{Ar}) \\
\left(\mathrm{T}=800^{\circ} \mathrm{C}\right)\end{array}$ & - & $\begin{array}{c}\sim 1.2 \mathrm{E}-7 \\
\left(\mathrm{~T}=950^{\circ} \mathrm{C}\right. \\
\text { disk, } \\
\mathrm{d}=1 \mathrm{~mm} \\
\text { air } / \mathrm{CO})\end{array}$ \\
\hline \multicolumn{7}{|l|}{$\begin{array}{l}\text { A -site }(\mathrm{Ca} / \mathrm{Sr}) \text { and } \mathrm{B} \text {-site } \\
(\mathrm{Mn}) \text { doped } \mathrm{LaCrO}_{3}\end{array}$} \\
\hline $\mathrm{La}_{0.9} \mathrm{Ca}_{0.1} \mathrm{Cr}_{0.5} \mathrm{Mn}_{0.5} \mathrm{O}_{3}$ & $\begin{array}{c}54.4 \\
\left(\mathrm{~T}=1250^{\circ} \mathrm{C}\right)\end{array}$ & - & - & $\begin{array}{l}2.2 \text { (air) } \\
\left(\mathrm{T} \sim 727^{\circ} \mathrm{C}\right)\end{array}$ & - & - \\
\hline $\mathrm{La}_{0.9} \mathrm{Sr}_{0.1} \mathrm{Cr}_{0.95} \mathrm{Mn}_{0.05} \mathrm{O}_{3}$ & - & - & $\begin{array}{c}10.2 \text { (air), } 11.2\left(\mathrm{H}_{2}\right) \\
\left(\mathrm{T}=50-1000^{\circ} \mathrm{C}\right)\end{array}$ & - & - & - \\
\hline $\mathrm{La}_{0.9} \mathrm{Sr}_{0.1} \mathrm{Cr}_{0.5} \mathrm{Mn}_{0.5} \mathrm{O}_{3}$ & $\begin{array}{c}\sim 78 \\
\left(\mathrm{~T}=1475^{\circ} \mathrm{C}\right)\end{array}$ & - & - & - & - & - \\
\hline
\end{tabular}




\begin{tabular}{|c|c|c|c|c|c|c|}
\hline $\mathbf{L a}_{0.75} \mathrm{Sr}_{0.25} \mathrm{Cr}_{0.5} \mathrm{Mn}_{0.5} \mathrm{O}_{3-\delta}$ & $\begin{array}{c}>94 \\
\left(\mathrm{~T}=1600^{\circ} \mathrm{C}\right)\end{array}$ & $\sim 0.1468$ & - & $\begin{array}{c}\sim 38.6 \text { (air), } \sim 1.49 \\
\quad\left(5 \% \mathrm{H}_{2}-\mathrm{Ar}\right) \\
\left(\mathrm{T}=900^{\circ} \mathrm{C}\right)\end{array}$ & - & - \\
\hline$\left(\mathrm{La}_{0.75} \mathrm{Sr}_{0.25}\right)_{0.95} \mathrm{Cr}_{0.5} \mathrm{Mn}_{0.5} \mathrm{O}_{3-\delta}$ & $\begin{array}{c}\sim 94 \\
\left(\mathrm{~T}=1600^{\circ} \mathrm{C}\right)\end{array}$ & - & $\begin{array}{c}12.7 \text { (air), } 11.7 \\
\left(\mathrm{CO} / \mathrm{CO}_{2}\right) \\
\left(\mathrm{T}=650-950^{\circ} \mathrm{C}\right)\end{array}$ & $\begin{array}{c}20-35\left(0.21-10^{-12} \mathrm{~atm}\right) \\
\quad\left(\mathrm{T} \sim 750-1000^{\circ} \mathrm{C}\right)\end{array}$ & - & $\begin{array}{c}\sim 8.9 \mathrm{E}-10 \\
\left(\mathrm{~T}=950^{\circ} \mathrm{C}\right. \\
\text { disk, } \\
\mathrm{d}=1 \mathrm{~mm}, \\
\sim 0.2 / \mathrm{E}- \\
15)\end{array}$ \\
\hline $\mathrm{La}_{0.9} \mathrm{Sr}_{0.1} \mathrm{Cr}_{0.3} \mathrm{Mn}_{0.7} \mathrm{O}_{3}$ & $\begin{array}{c}\sim 95 \\
\left(\mathrm{~T}=1475^{\circ} \mathrm{C}\right)\end{array}$ & - & - & - & - & - \\
\hline \multicolumn{7}{|l|}{$\begin{array}{l}\text { A -site }(\mathrm{Ca} / \mathrm{Sr} r) \text { and } \mathrm{B} \text {-site }(\mathrm{Ni}) \\
\text { doped } \mathrm{LaCrO}_{3}\end{array}$} \\
\hline $\mathrm{La}_{0.9} \mathrm{Ca}_{0.1} \mathrm{Cr}_{0.5} \mathrm{Ni}_{0.5} \mathrm{O}_{3}$ & $\begin{array}{c}53.6 \\
\left(\mathrm{~T}=1250^{\circ} \mathrm{C}\right)\end{array}$ & - & - & $\begin{array}{l}23.3 \text { (air) } \\
\left(\mathrm{T} \sim 727^{\circ} \mathrm{C}\right)\end{array}$ & - & - \\
\hline $\mathrm{La}_{0.9} \mathrm{Sr}_{0.1} \mathrm{Cr}_{0.95} \mathrm{Ni}_{0.05} \mathrm{O}_{3}$ & - & - & $\begin{array}{l}9.4(\text { air }), 10.1\left(\mathrm{H}_{2}\right) \\
\left(\mathrm{T}=50-1000^{\circ} \mathrm{C}\right)\end{array}$ & - & - & - \\
\hline $\mathrm{La}_{0.9} \mathrm{Sr}_{0.1} \mathrm{Cr}_{0.5} \mathrm{Ni}_{0.5} \mathrm{O}_{3}$ & - & - & - & $\begin{array}{l}72.8 \text { (air) } \\
\left(\mathrm{T} \sim 800^{\circ} \mathrm{C}\right)\end{array}$ & - & - \\
\hline $\mathrm{La}_{0.85} \mathrm{Sr}_{0.15} \mathrm{Cr}_{0.95} \mathrm{Ni}_{0.05} \mathrm{O}_{3}$ & $\begin{array}{c}\sim 96.4 \\
\left(\mathrm{~T}=1450^{\circ} \mathrm{C}\right)\end{array}$ & - & $\begin{array}{c}10.3 \text { (air) } \\
\left(\mathrm{T} \sim 50-1000^{\circ} \mathrm{C}\right)\end{array}$ & - & - & - \\
\hline \multicolumn{7}{|l|}{$\begin{array}{l}\text {-site }(\mathrm{Ca} / \mathrm{Sr}) \text { and } \mathrm{B} \text {-site }(\mathrm{Co}) \\
\text { doped } \mathrm{LaCrO} \mathrm{O}_{3}\end{array}$} \\
\hline $\mathrm{La}_{0.8} \mathrm{Ca}_{0.2} \mathrm{Cr}_{0.9} \mathrm{Co}_{0.1} \mathrm{O}_{3-\delta}$ & - & - & - & & $\begin{array}{c}\sim 170.5(\mathrm{~T}= \\
\left.25^{\circ} \mathrm{C}\right)\end{array}$ & - \\
\hline $\mathrm{La}_{0.85} \mathrm{Sr}_{0.15} \mathrm{Cr}_{0.95} \mathrm{Co}_{0.05} \mathrm{O}_{3}$ & $\begin{array}{c}\sim 91 \\
\left(\mathrm{~T}=1450^{\circ} \mathrm{C}\right)\end{array}$ & - & $\begin{array}{c}11.4 \text { (air) } \\
\left(\mathrm{T} \sim 50-1000^{\circ} \mathrm{C}\right)\end{array}$ & $\begin{array}{c}0.1-0.7 \text { (air) } \\
\left(\mathrm{T} \sim 100-860^{\circ} \mathrm{C}\right)\end{array}$ & - & - \\
\hline
\end{tabular}




\begin{tabular}{|c|c|c|c|c|c|c|}
\hline $\mathrm{La}_{0.9} \mathrm{Sr}_{0.1} \mathrm{Cr}_{0.95} \mathrm{Co}_{0.05} \mathrm{O}_{3}$ & - & - & $\begin{array}{c}10.4 \text { (air), } 11.5\left(\mathrm{H}_{2}\right) \\
\left(\mathrm{T}=50-1000^{\circ} \mathrm{C}\right)\end{array}$ & - & - & - \\
\hline \multicolumn{7}{|c|}{$\begin{array}{l}\text { A -site }(\mathrm{Ca} / \mathrm{Sr}) \text { and } \mathrm{B} \text {-site }(\mathrm{Cu}) \\
\text { doped } \mathrm{LaCrO}_{3}\end{array}$} \\
\hline $\mathrm{La}_{0.8} \mathrm{Ca}_{0.2} \mathrm{Cr}_{0.9} \mathrm{Cu}_{0.1} \mathrm{O}_{3-\delta}$ & - & - & - & - & $\begin{array}{c}\sim 356.9(\mathrm{~T}= \\
\left.25^{\circ} \mathrm{C}\right)\end{array}$ & - \\
\hline $\mathrm{La}_{0.85} \mathrm{Sr}_{0.15} \mathrm{Cr}_{0.95} \mathrm{Cu}_{0.05} \mathrm{O}_{3}$ & $\begin{array}{c}\sim 94.5 \\
\left(\mathrm{~T}=1450^{\circ} \mathrm{C}\right)\end{array}$ & - & $\begin{array}{c}10.6 \text { (air) } \\
\left(\mathrm{T} \sim 50-1000^{\circ} \mathrm{C}\right)\end{array}$ & - & - & - \\
\hline \multicolumn{7}{|c|}{$\begin{array}{l}\text { A -site }(\mathrm{Ca} / \mathrm{Sr}) \text { and } \mathrm{B} \text {-site }(\mathrm{Ti}) \\
\text { doped } \mathrm{LaCrO}_{3}\end{array}$} \\
\hline $\mathrm{La}_{0.9} \mathrm{Sr}_{0.1} \mathrm{Cr}_{0.95} \mathrm{Ti}_{0.05} \mathrm{O}_{3}$ & - & - & $\begin{array}{l}9.0(\text { air }), 9.3\left(\mathrm{H}_{2}\right) \\
\left(\mathrm{T}=50-1000^{\circ} \mathrm{C}\right)\end{array}$ & - & - & - \\
\hline $\mathrm{La}_{0.7} \mathrm{Sr}_{0.3} \mathrm{Cr}_{0.9} \mathrm{Ti}_{0.1} \mathrm{O}_{3-\delta}$ & - & $\sim 0.048$ & - & - & - & - \\
\hline $\mathrm{La}_{0.7} \mathrm{Sr}_{0.3} \mathrm{Cr}_{0.7} \mathrm{Ti}_{0.3} \mathrm{O}_{3-\delta}$ & - & $\sim 0.005$ & - & - & - & - \\
\hline
\end{tabular}


Fig. 1

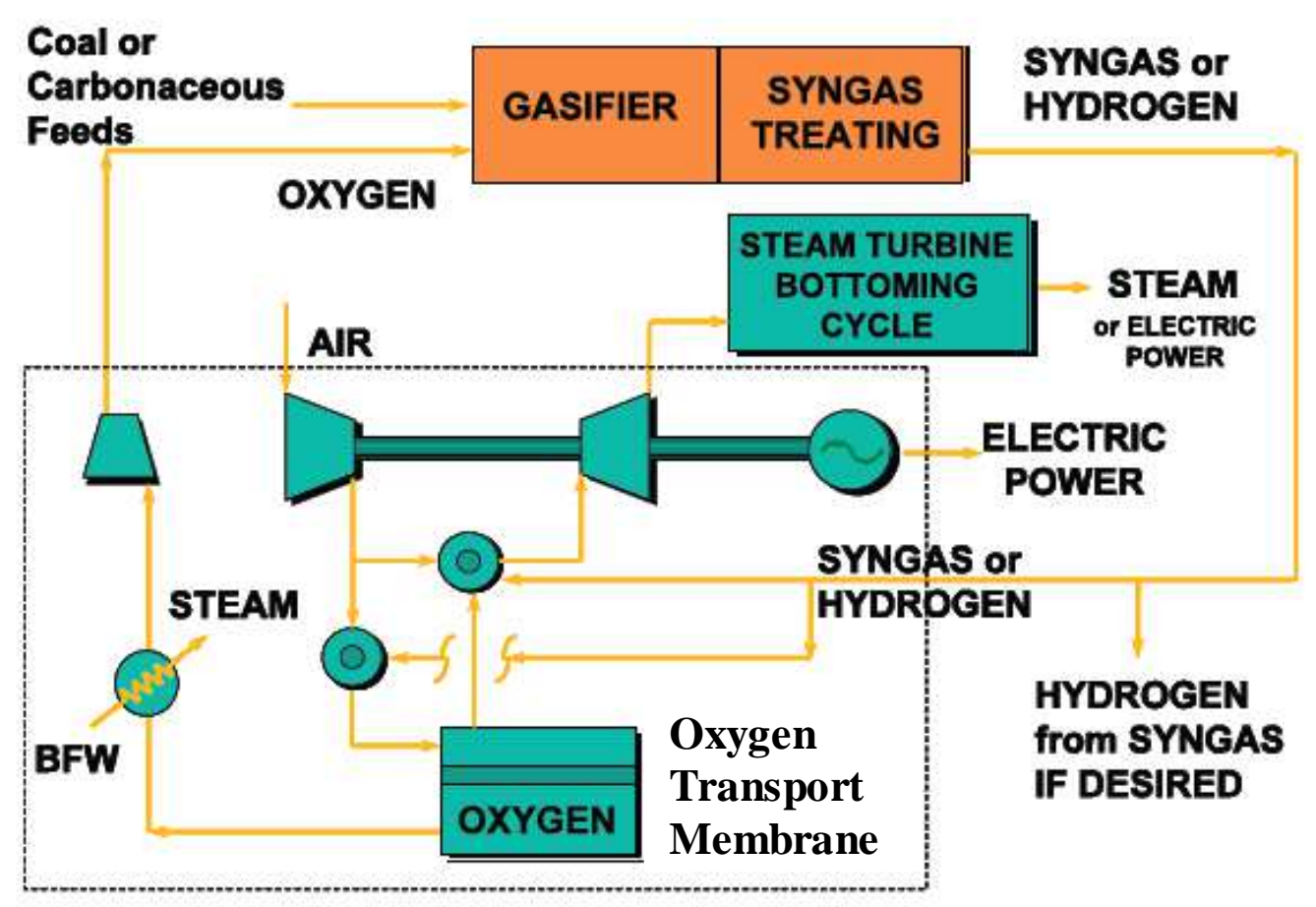

Fig. 1. Simplified process flow diagram of an oxygen transport membrane integrated in IGCC (BFW: Boiler Feed Water) [15]. 
Fig. 2

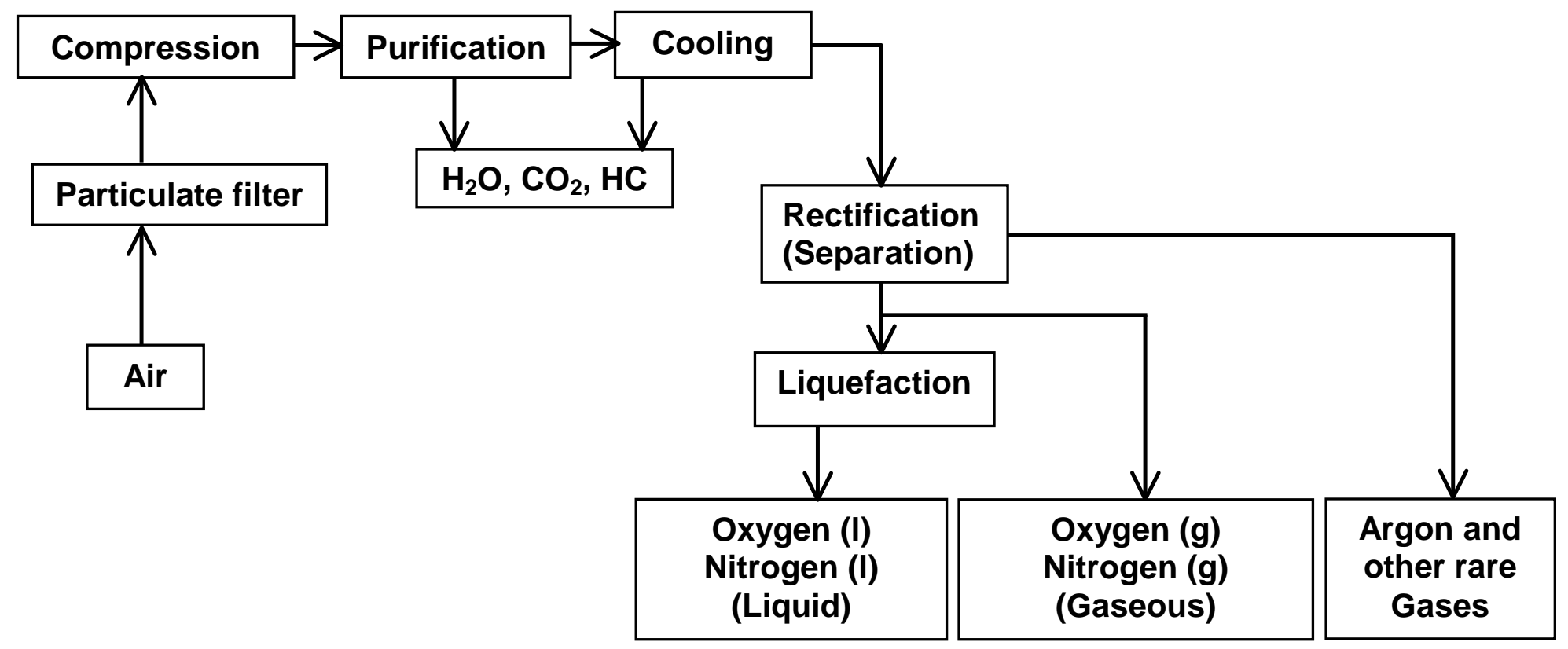

Fig. 2. Flow diagram of cryogenic distillation process [18]. 
Fig. 3

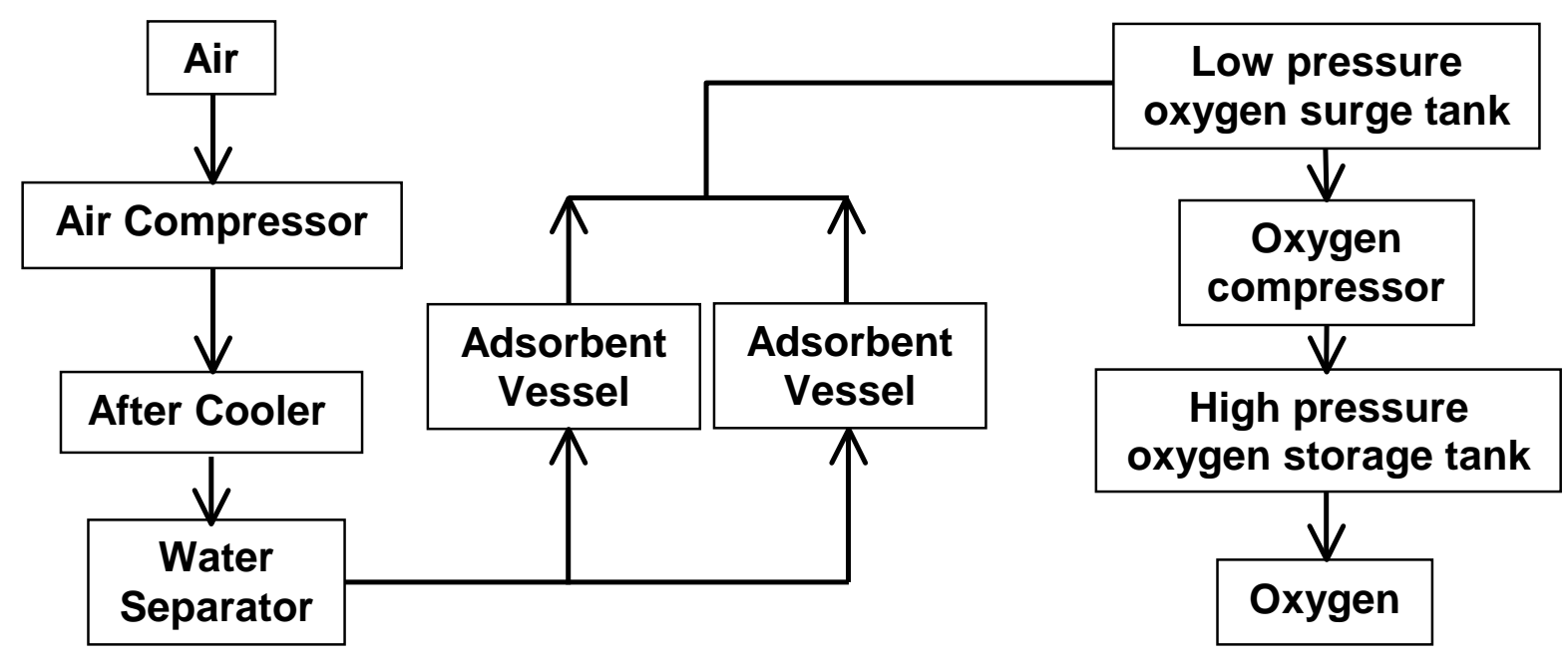

Fig. 3. Flow diagram of pressure adsorption technique for air separation [19]. 
Fig. 4

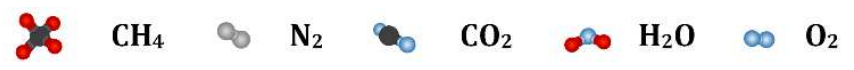

(a)

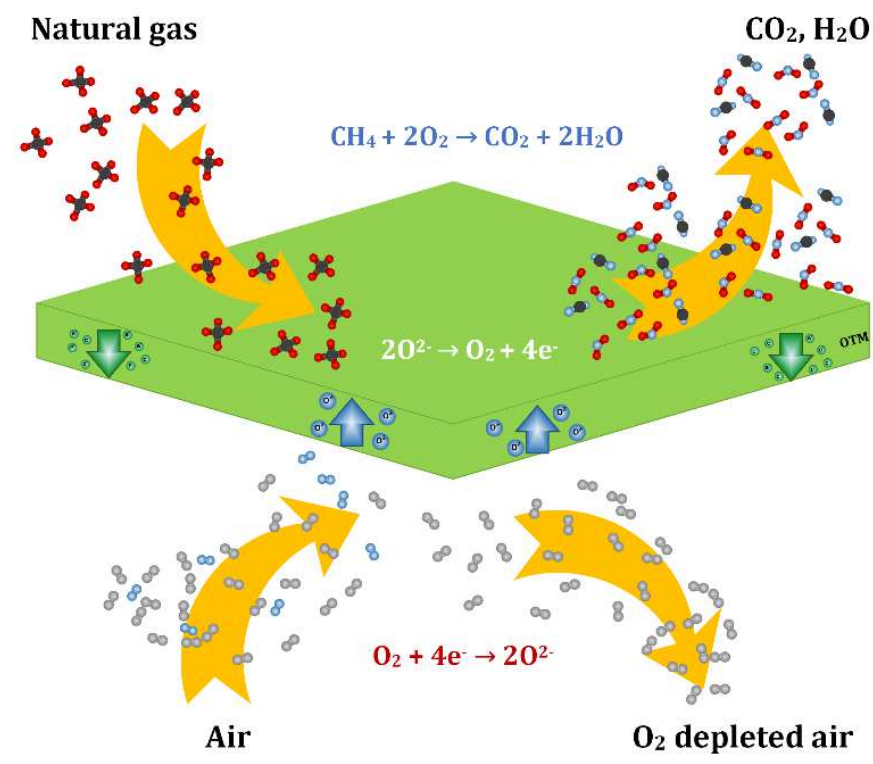

(b)

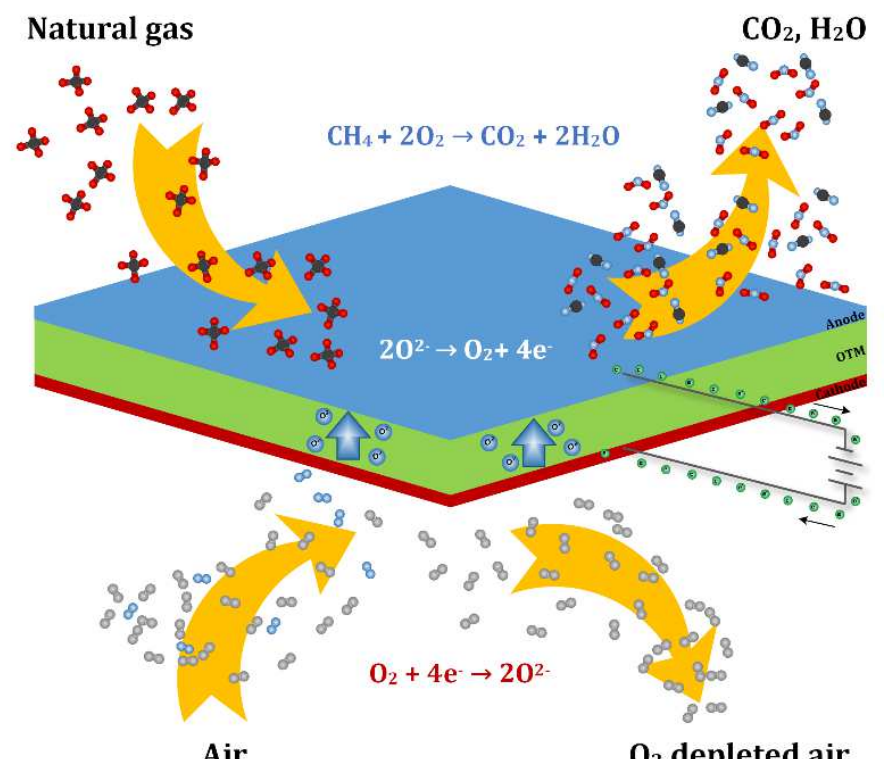

Fig. 4. Schematic of the working principle of oxygen transport membrane (OTM): (a)

Partial pressure driven/Active (Mixed ionic electronic conductor), (b) Electrically driven/Passive (Ionic conductor). 
Fig. 5

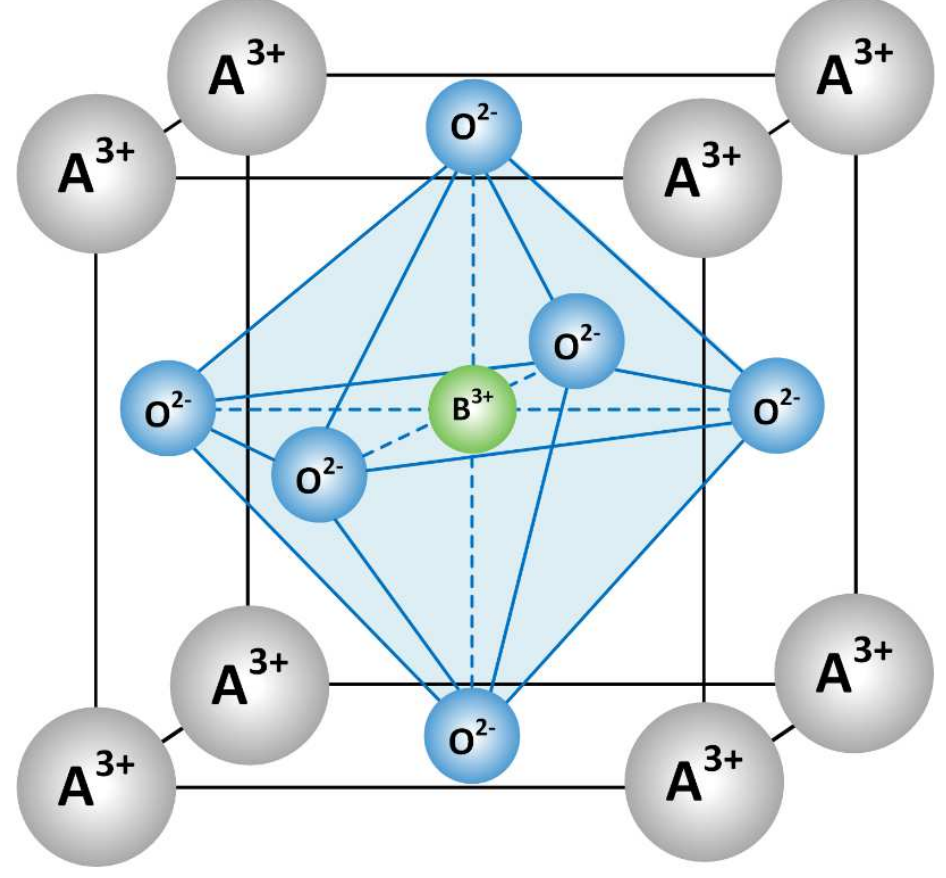

Fig. 5. Ideal perovskite structure of $\mathrm{ABO}_{3}$. 
Fig. 6

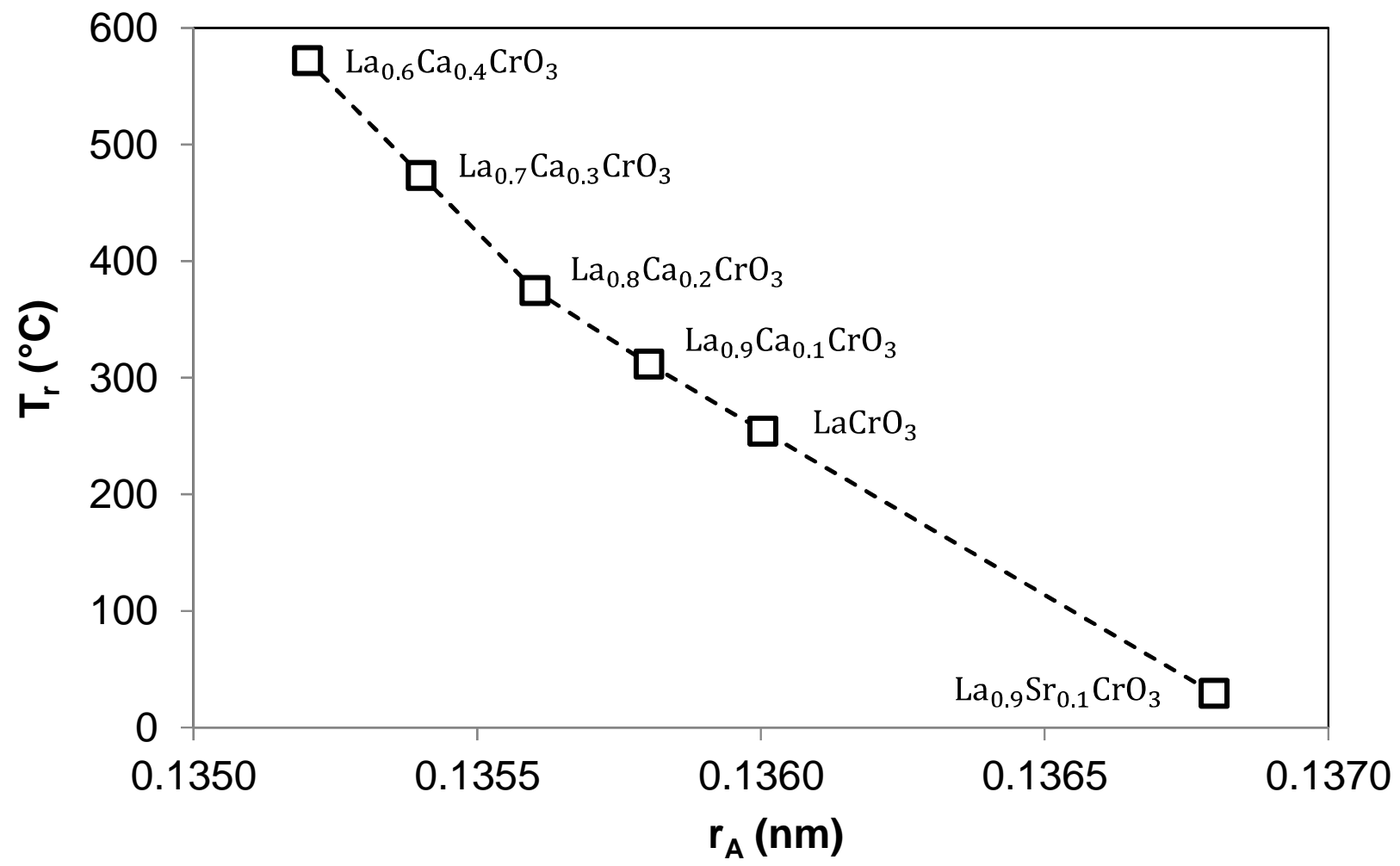

Fig. 6. Orthorhombic to rhombohedral phase transition temperature versus A-site average ionic radii $\left(\mathrm{r}_{\mathrm{A}}\right)$ for $\mathrm{La}_{1-x}(\mathrm{Sr} / \mathrm{Ca})_{x} \mathrm{CrO}_{3}$ (Reproduced from reference 105 with permission). 
Fig. 7

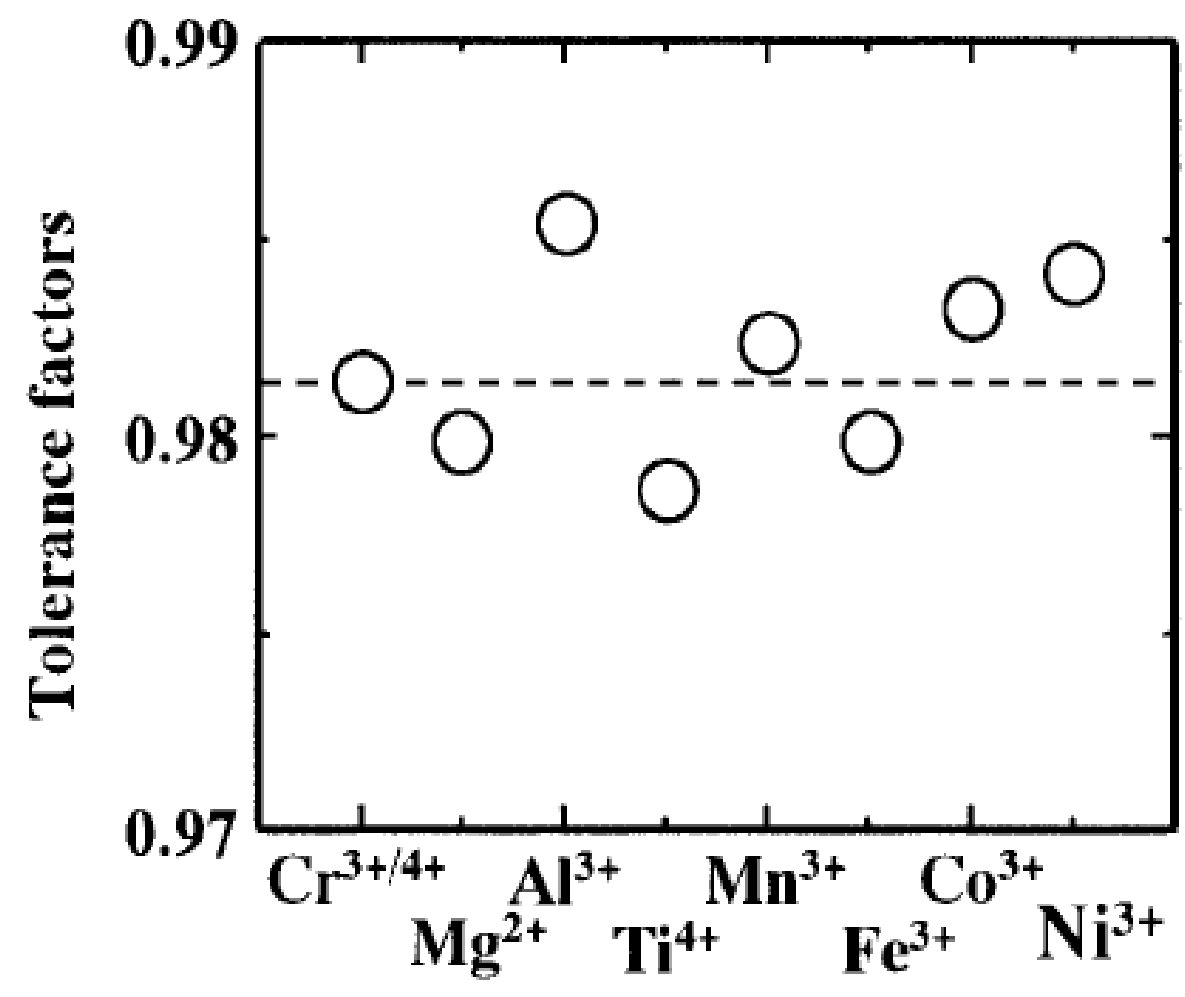

Fig. 7. Tolerance factor (t) of $\left.\mathrm{La}_{0.9} \mathrm{Sr}_{0.1} \mathrm{Cr}_{0.9} \mathrm{M}_{0.1} \mathrm{O}_{3}(\mathrm{M}=\mathrm{Mg}, \mathrm{Al}, \mathrm{Ti}, \mathrm{Mn}, \mathrm{Fe}, \mathrm{Co}, \mathrm{Ni})\right]$. The broken line corresponds to $\mathrm{La}_{0.9} \mathrm{Sr}_{0.1} \mathrm{CrO}_{3}$ tolerance factor [Reprinted from reference [112 with permission]. 
Fig. 8

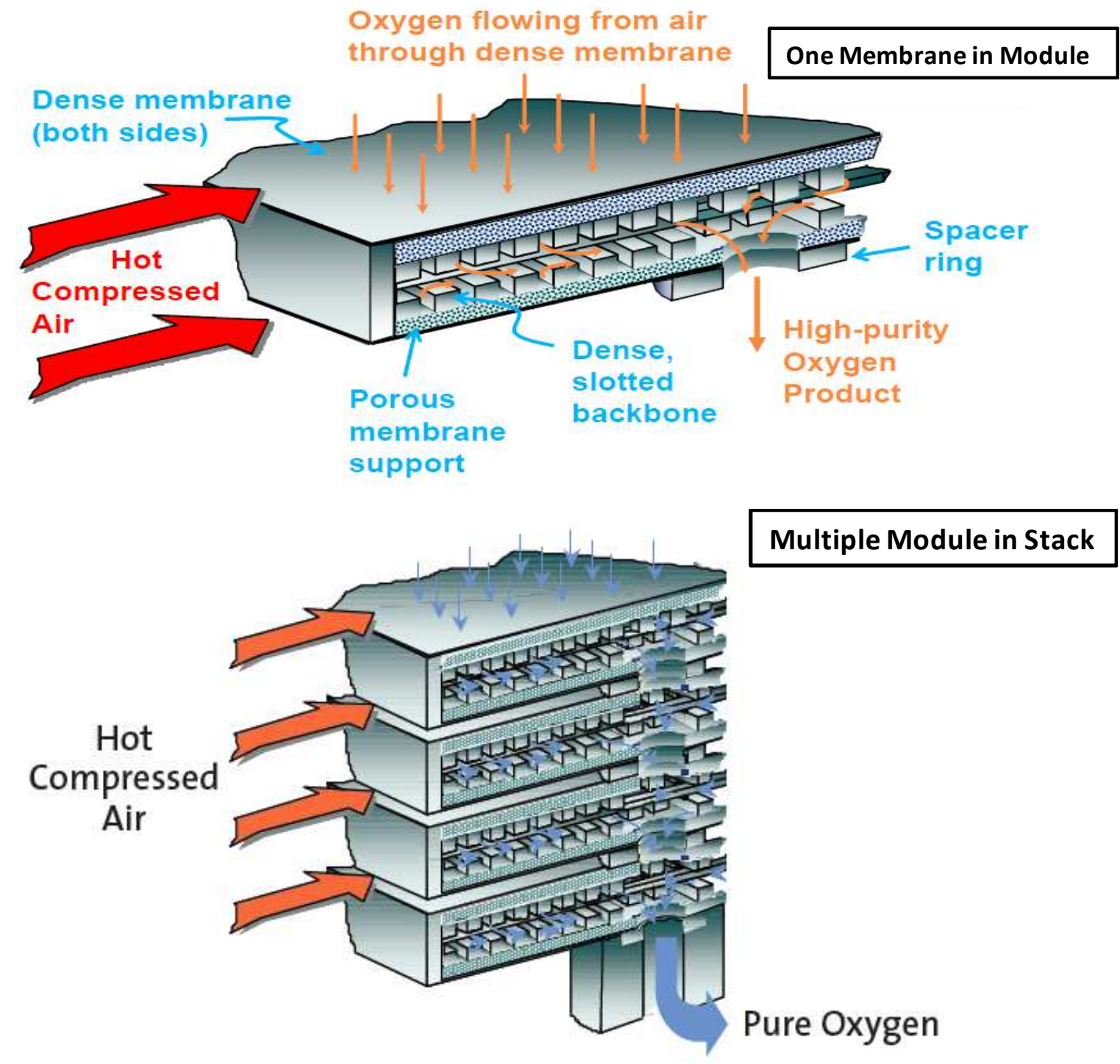

(a) 


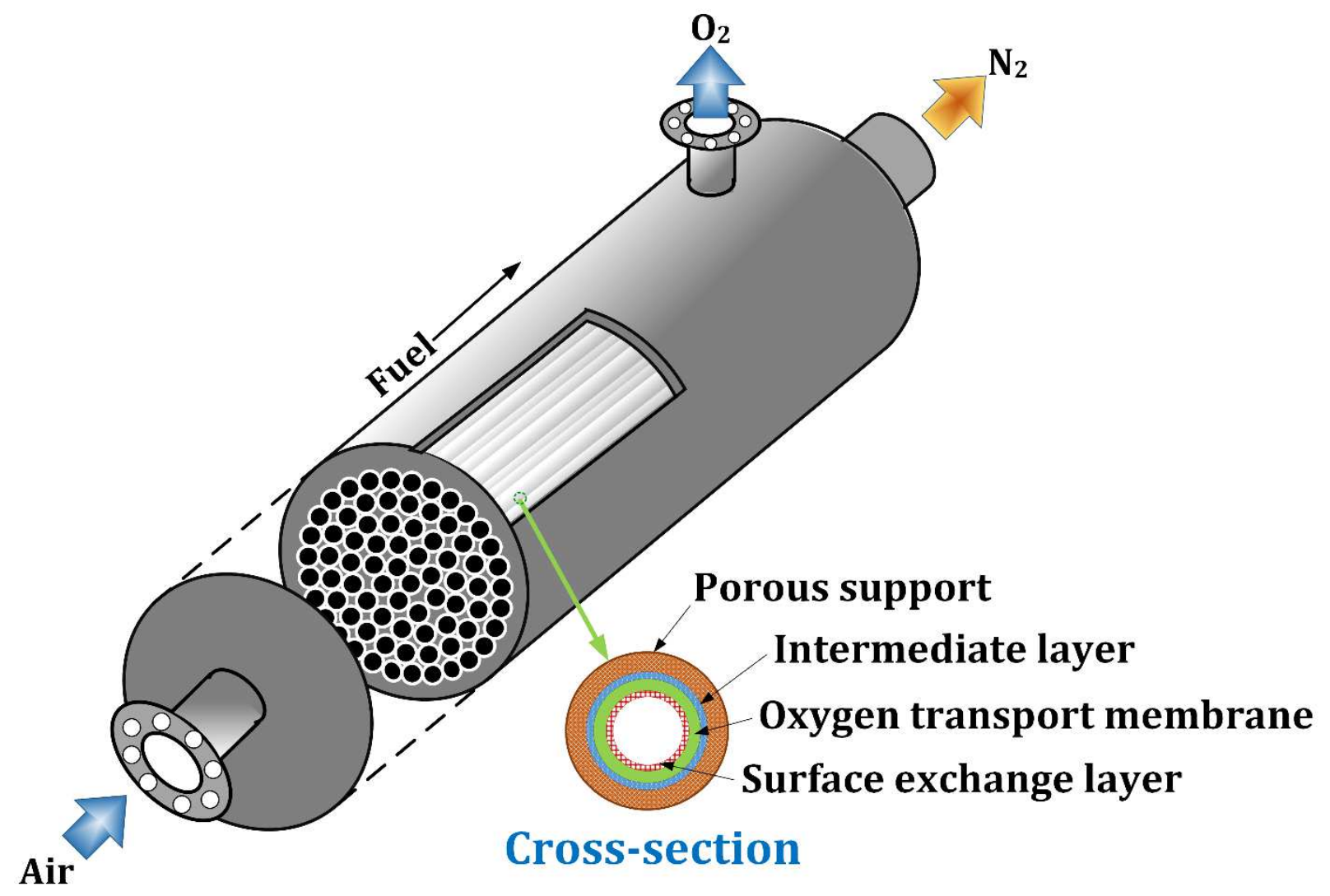

(b)

Fig. 8. Oxygen transport membrane configuration: (a) Planar (single and multiple module) [84], (b) Tubular (with cross-section). 
Fig. 9

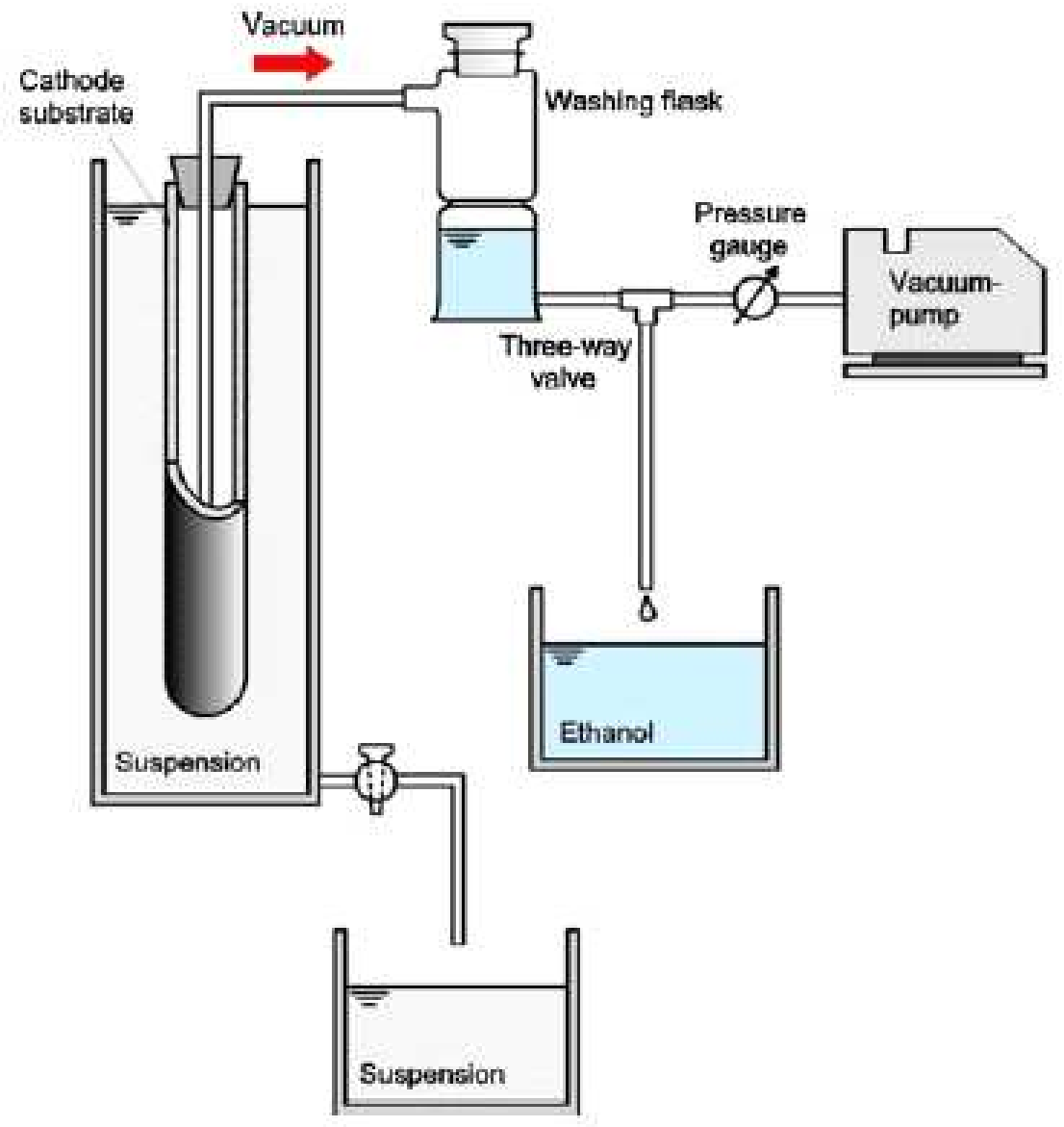

Fig. 9. Schematic of vacuum slip casting for tubular configuration [Reprinted from reference 87 with permission]. 


\section{Fig. 10}

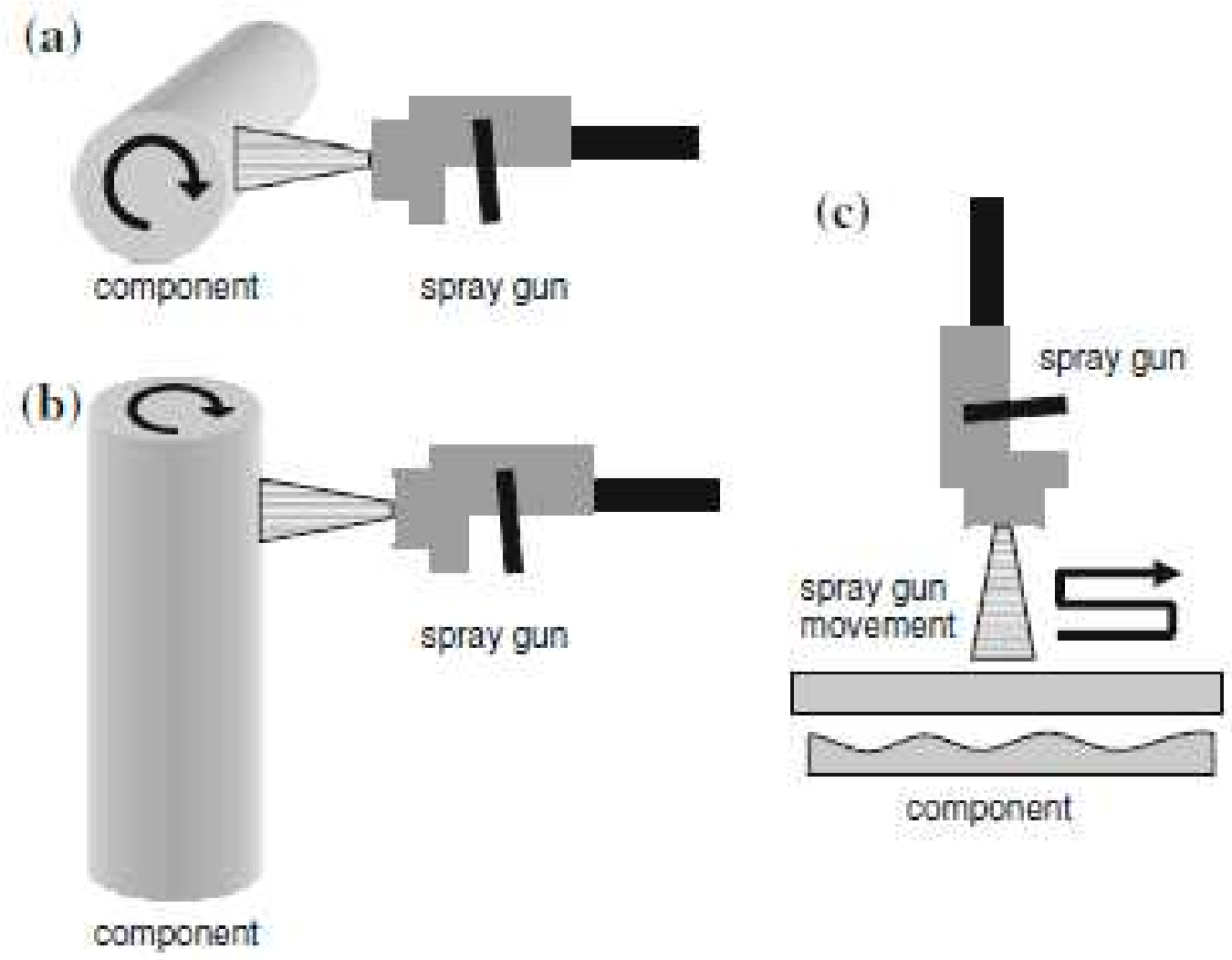

Fig. 10. Positions of spray gun and components to be coated: a) horizontal/horizontal, b) horizontal/vertical, both with tubular design and c) vertical/horizontal with planar design [Reprinted from reference 87 with permission]. 


\section{Fig. 11}
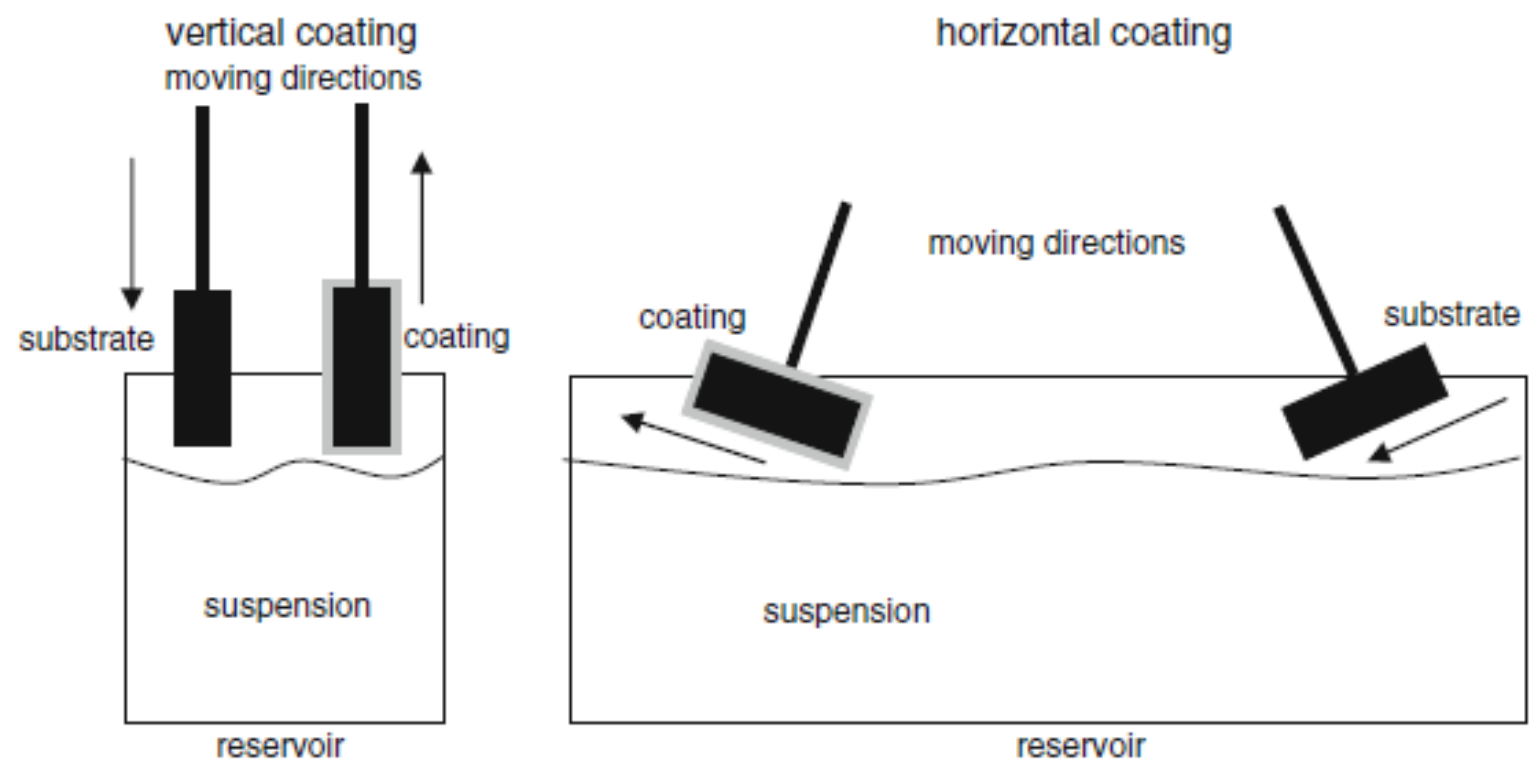

Fig. 11. Sol-gel dip coating technique [Reprinted from reference 87 with permission]. 


\section{Fig. 12}

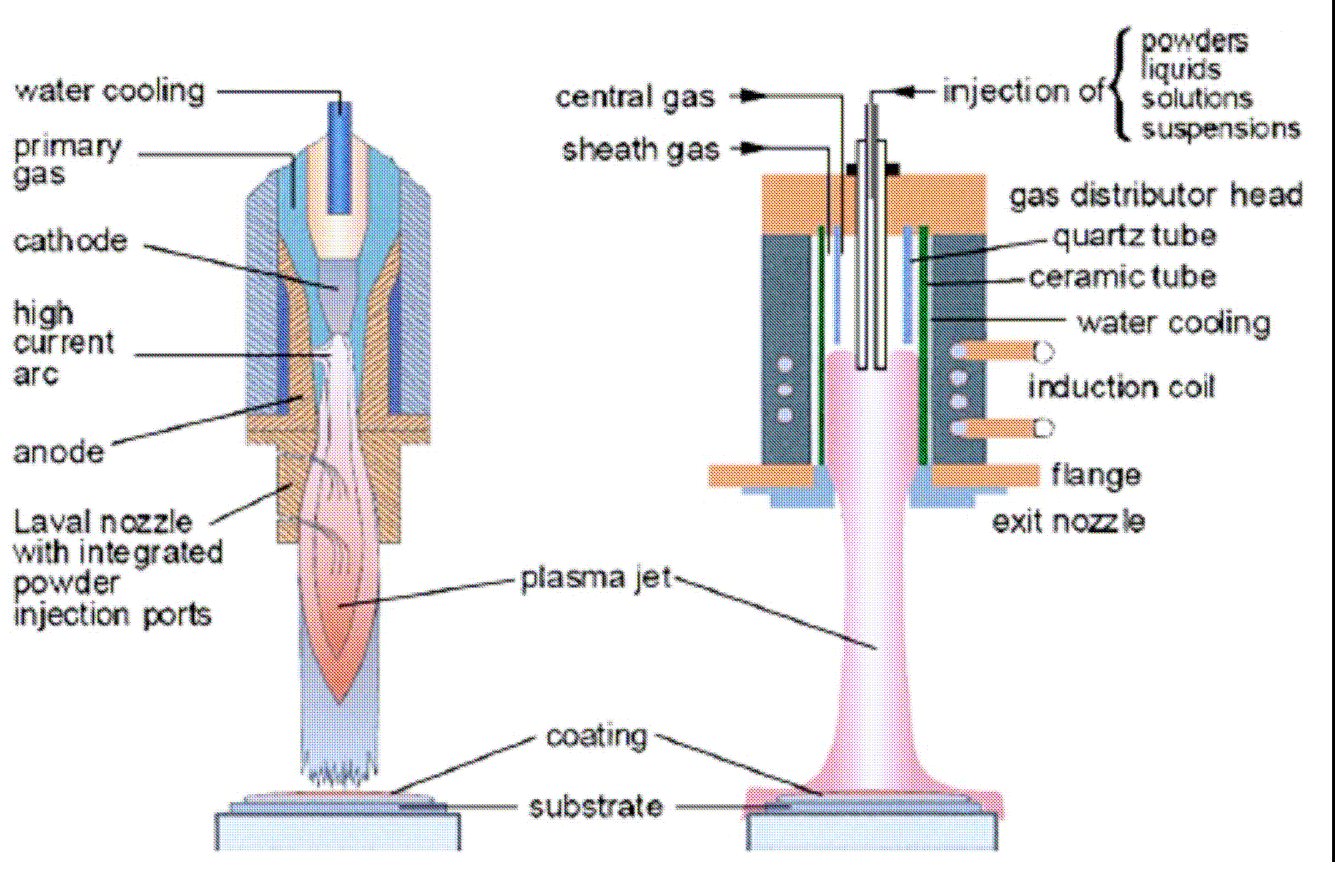

Fig. 12. Schematics of DC and RF plasma spraying apparatus [Reprinted from reference 88 with permission]. 


\section{Fig. 13}

(a)

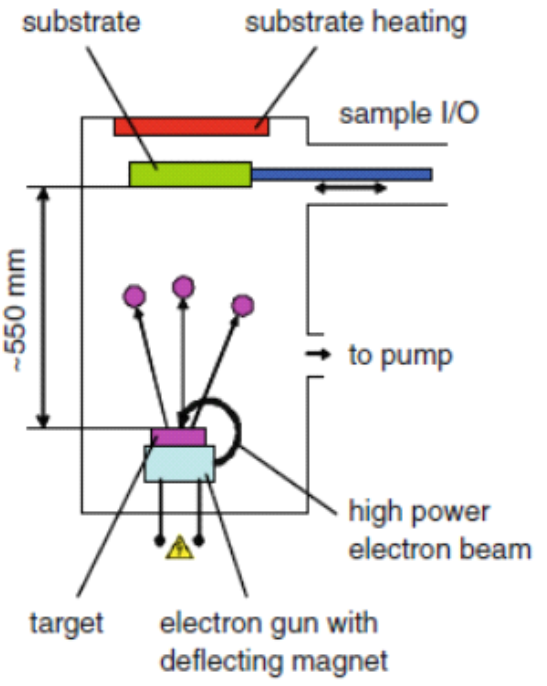

(b)

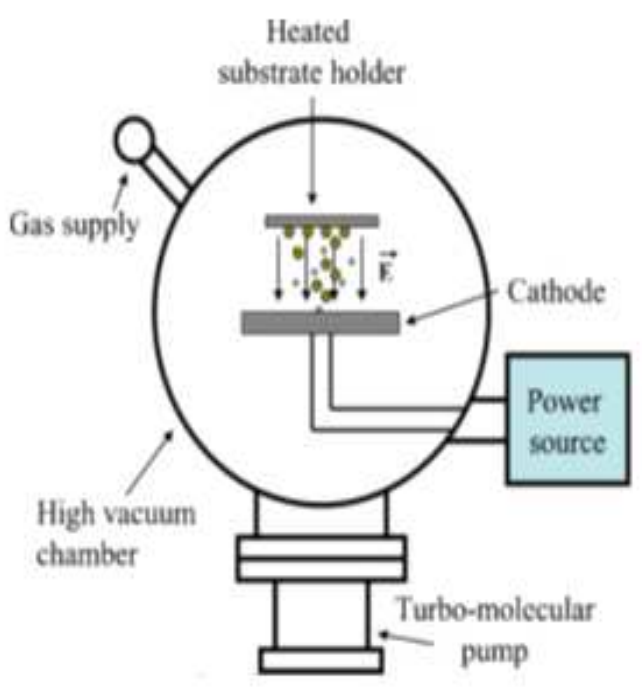

(c)

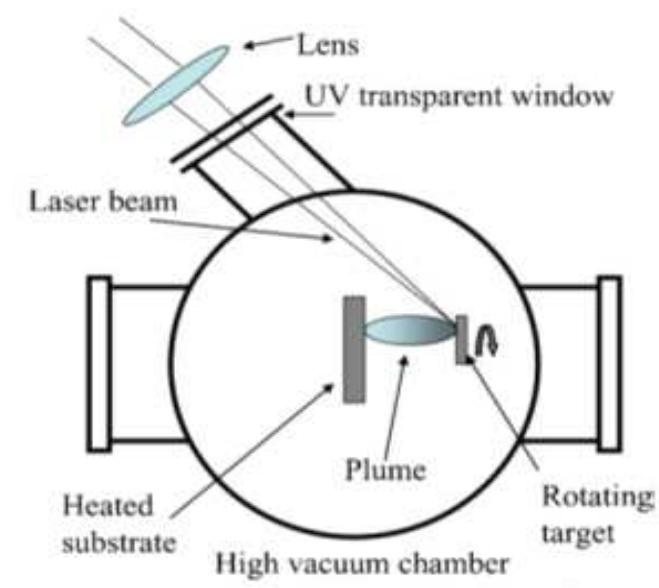


Fig. 13. Schematics of physical vapor deposition techniques: (a) Electron beam (EB) PVD, (b) Sputtering, and (c) Laser ablation [Reprinted from reference 91 with permission].

Fig. 14

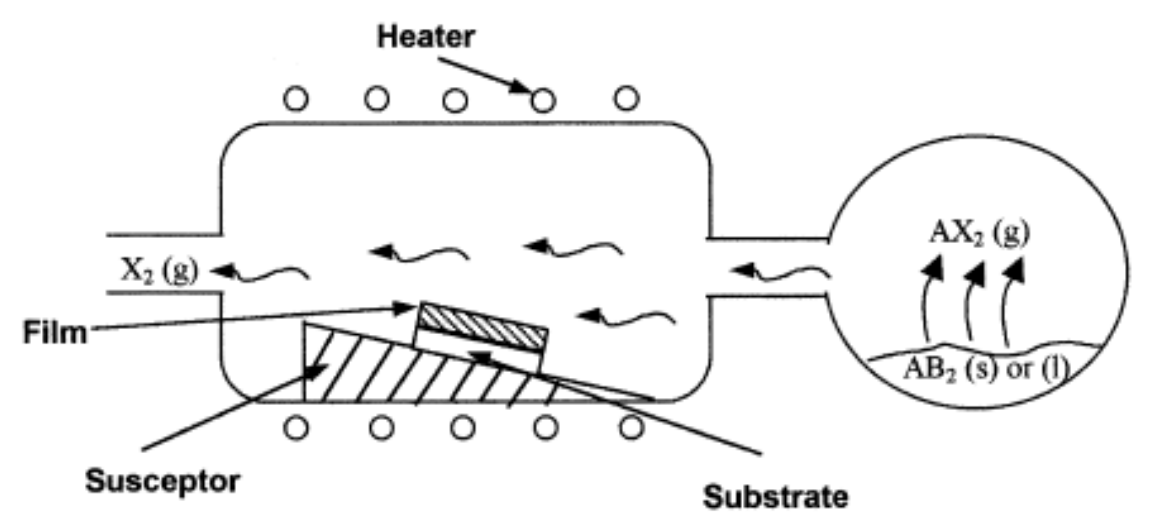

(a)

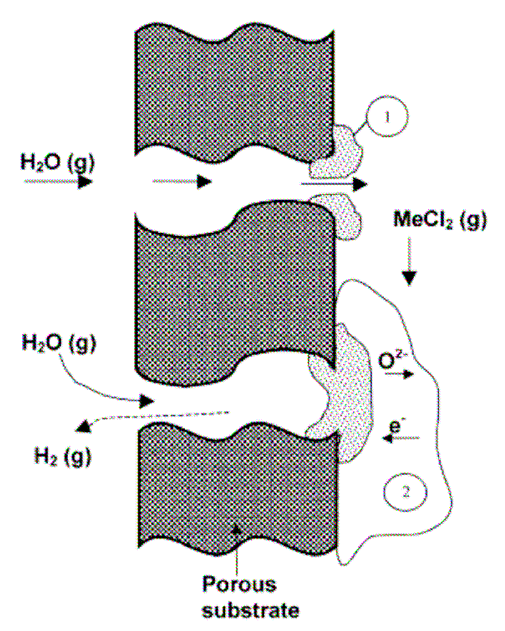

(b)

Stage 1: Pore closure via CVD

$\mathrm{MeCl}_{2}(g)+\mathrm{H}_{2}(g)=\mathrm{MeO}(s)+2 \mathrm{HCl}(g)$ 


\section{Stage 2: Scale growth via EVD}

$$
\begin{aligned}
& \mathrm{H}_{2} \mathrm{O}(g)+2 e \rightarrow \mathrm{H}_{2}(g)+\mathrm{O}^{2-} \\
& \mathrm{MeCl}_{2}(g)+\mathrm{O}^{2-} \rightarrow \mathrm{MeO}(\mathrm{s})+\mathrm{Cl}_{2}(g)+2 e
\end{aligned}
$$

Fig. 14. Schematics of (a) CVD, and (b) EVD techniques [Reprinted from reference 98 with permission]. 
Fig. 15

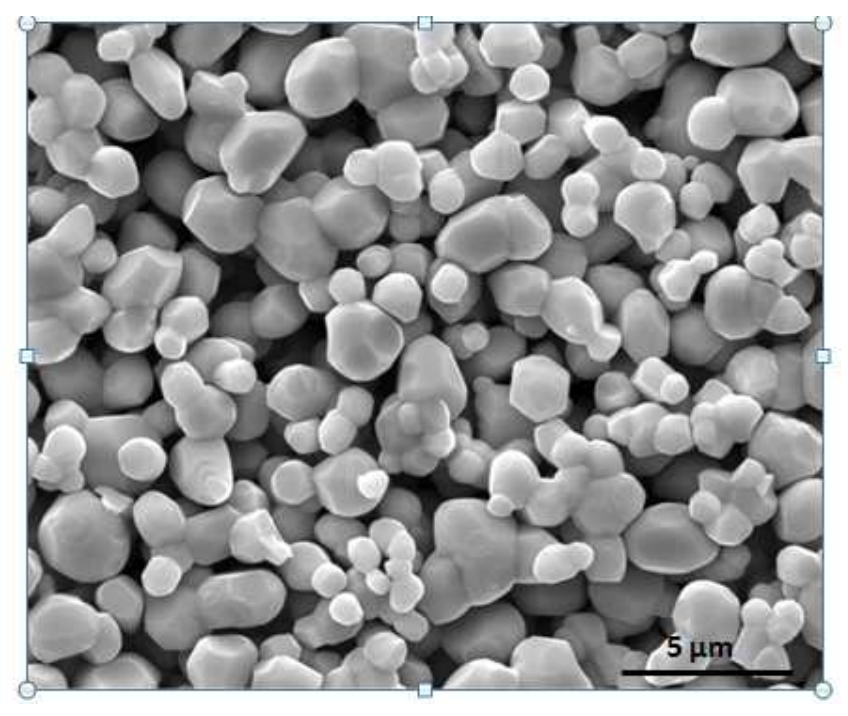

(a)

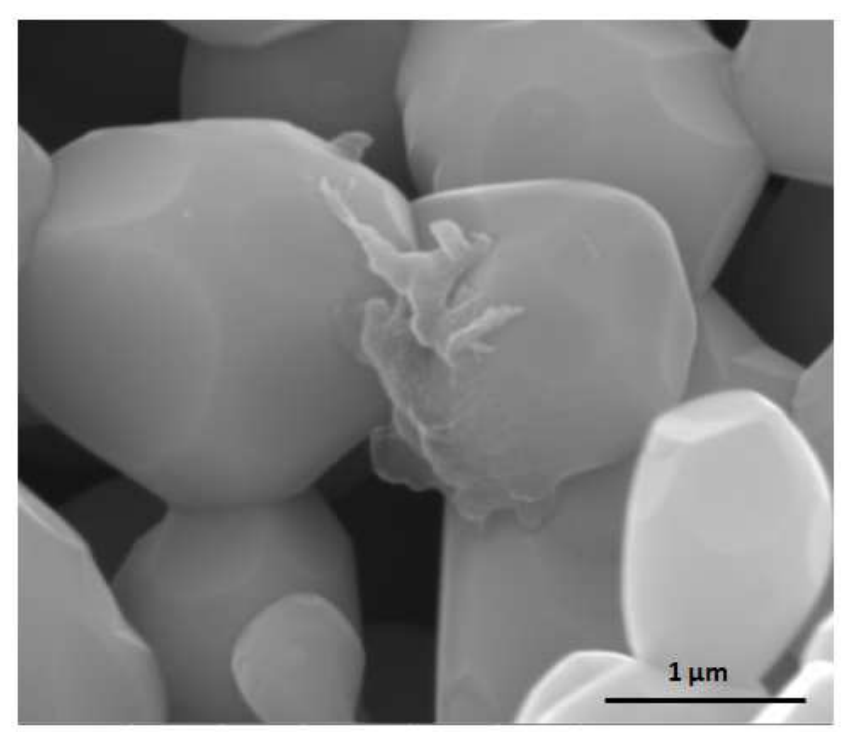

(b) 
Fig. 15. Microstructures of $\mathrm{LaCrO}_{3}$ sintered at $1450^{\circ} \mathrm{C}$ in air for $10 \mathrm{~h}$ : (a) lower magnification to show the porosity, (b) higher magnification with $\mathrm{Cr}_{2} \mathrm{O}_{3}$ deposition at inter-particle neck [113].

Fig. 16

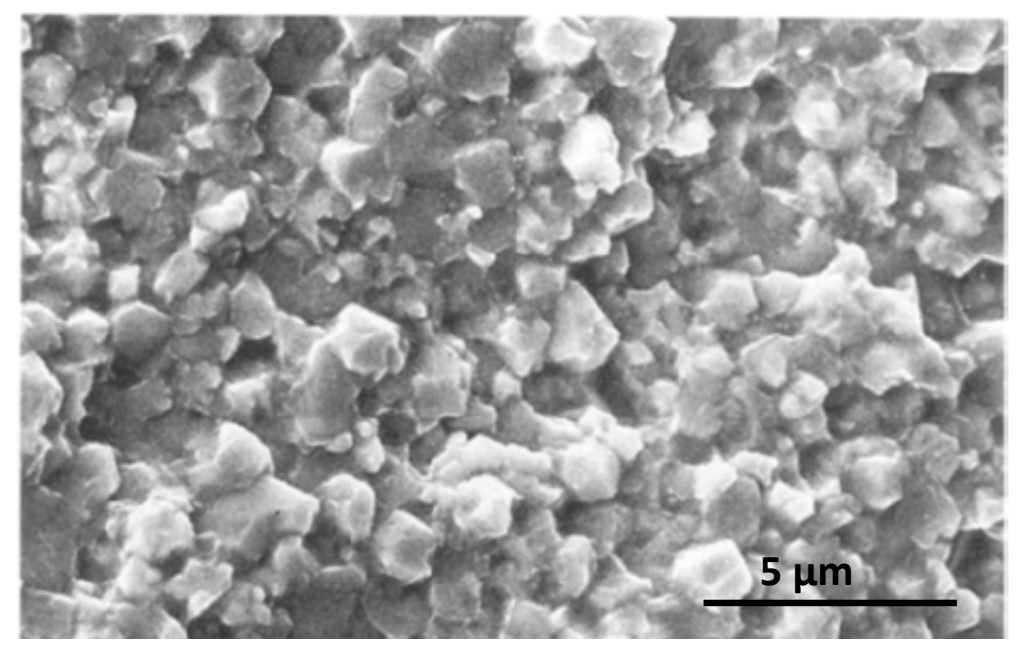

Fig. 16. SE- micrograph for $\left(\mathrm{La}_{0.6} \mathrm{Ca}_{0.4}\right)_{1.02} \mathrm{CrO}_{3}$ heated to $1350^{\circ} \mathrm{C}(2 \mathrm{~h})$ and air quenched to RT [Reprinted from reference 128 with permission]. 
Fig. 17

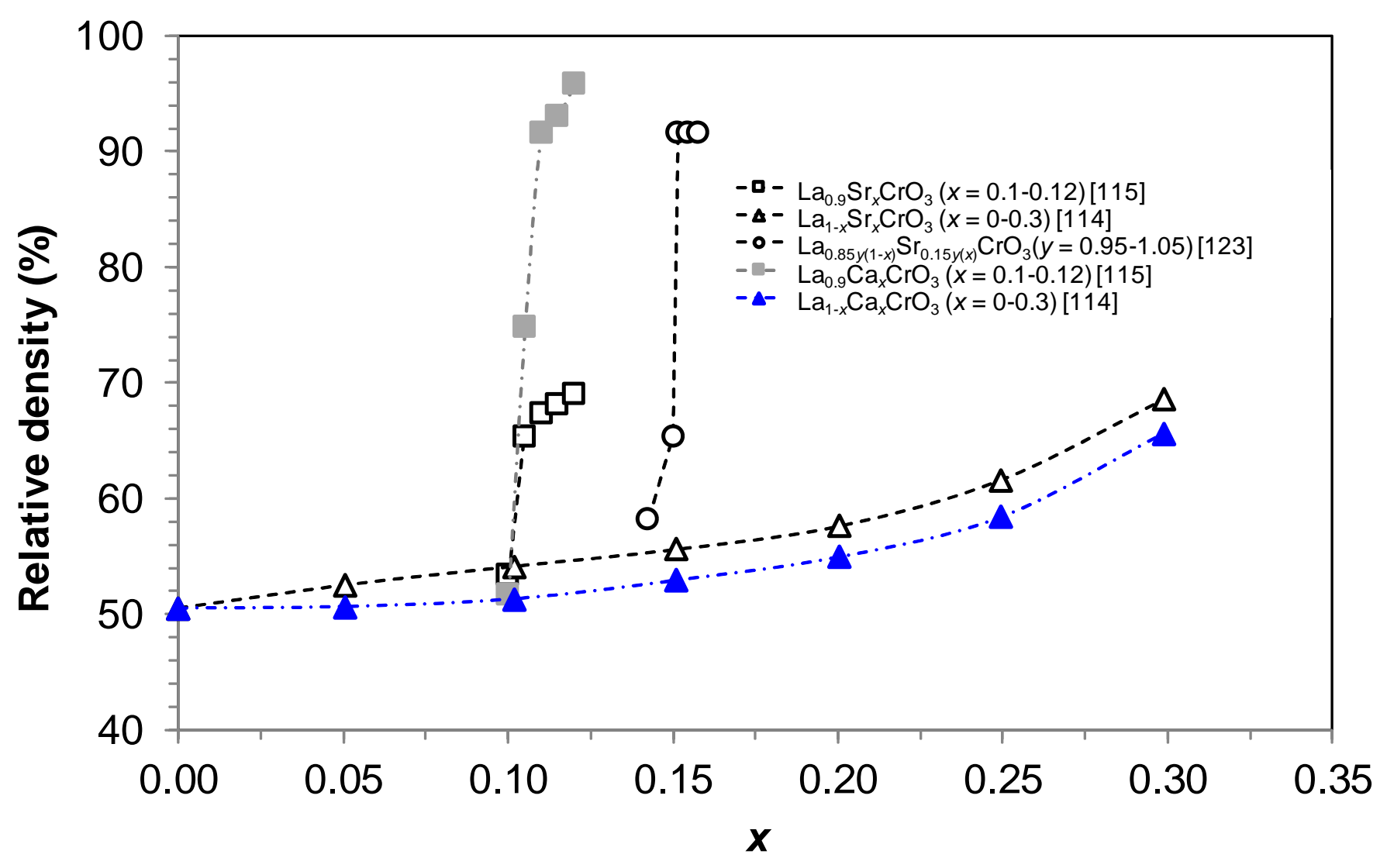

Fig. 17. Relative density of A-site (Sr,Ca) doped $\mathrm{LaCrO}_{3}$ vs $x$ in $\mathrm{La}_{1-x}(\mathrm{Sr} / \mathrm{Ca})_{x} \mathrm{CrO}_{3}$ at $1600^{\circ} \mathrm{C}[114-115,123]$. 


\section{Fig. 18}

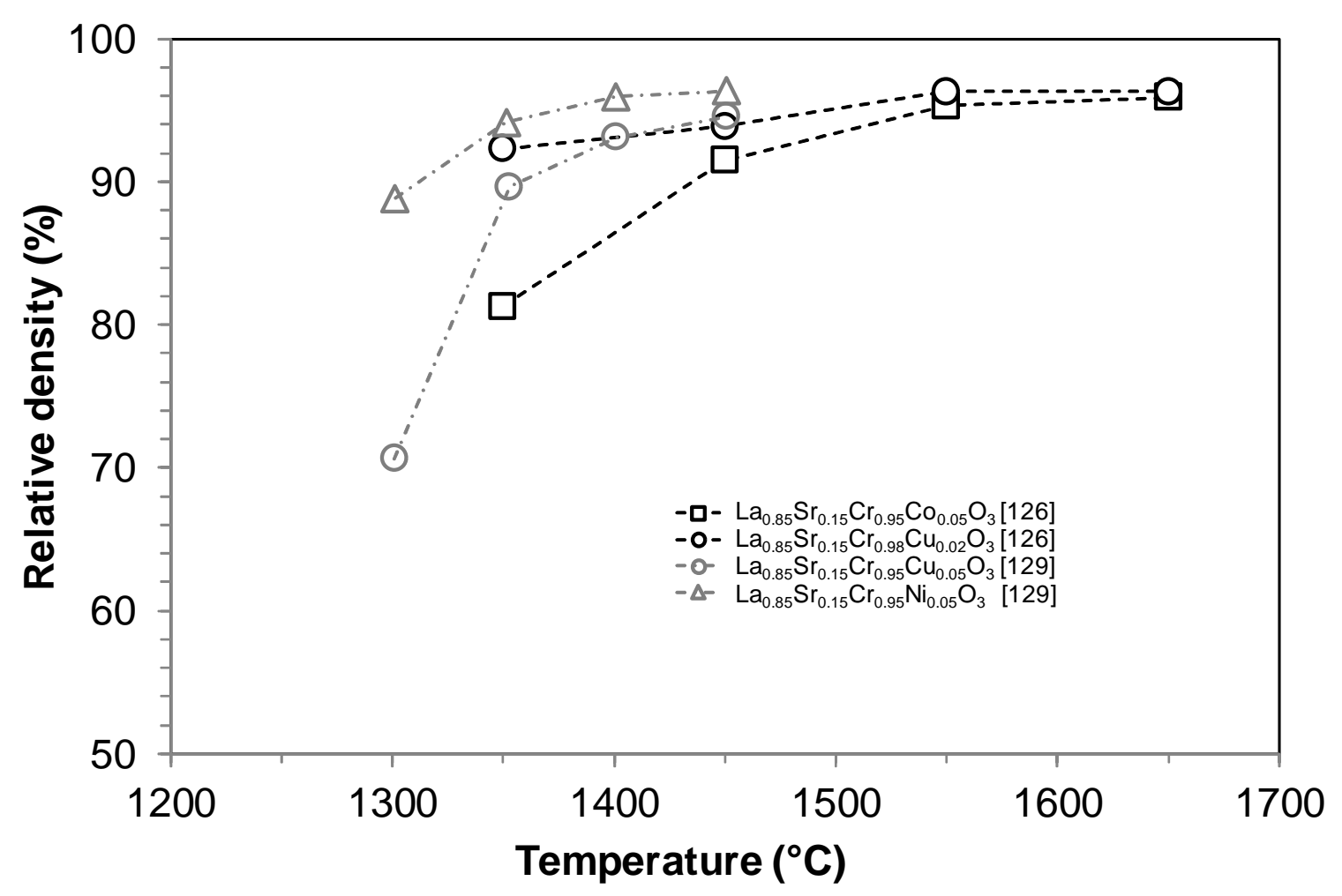

Fig. 18. Relative density of A-site ( $\mathrm{Sr})$ and $\mathrm{B}$-site (Ni, Co and $\mathrm{Ni})$ doped $\mathrm{LaCrO}_{3}$ vs temperature and $x$ in $\mathrm{La}_{0.85} \mathrm{Sr}_{0.15} \mathrm{Cr}_{1-x} \mathrm{M}_{x} \mathrm{O}_{3}(\mathrm{M}=\mathrm{Co}, \mathrm{Cu}, \mathrm{Ni})[126,129]$. 
Fig. 19

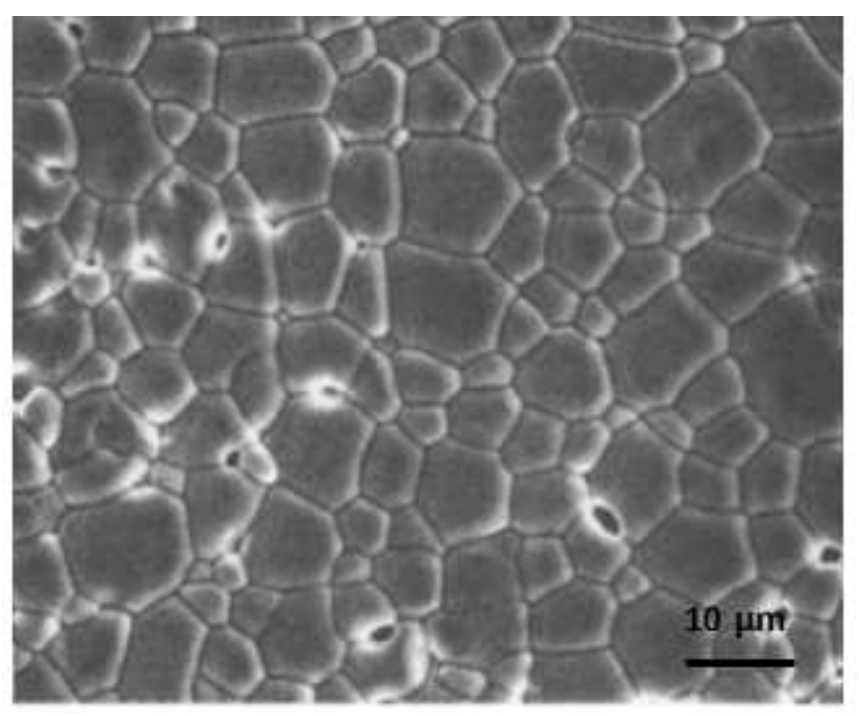

Fig. 19. SE-micrograph of $\mathrm{La}_{0.9} \mathrm{Sr}_{0.1} \mathrm{Cr}_{0.3} \mathrm{Mn}_{0.7} \mathrm{O}_{3}$ sintered at $1475^{\circ} \mathrm{C}$ for $48 \mathrm{~h}$ [Reprinted from reference 133 with permission]. 
Fig. 20

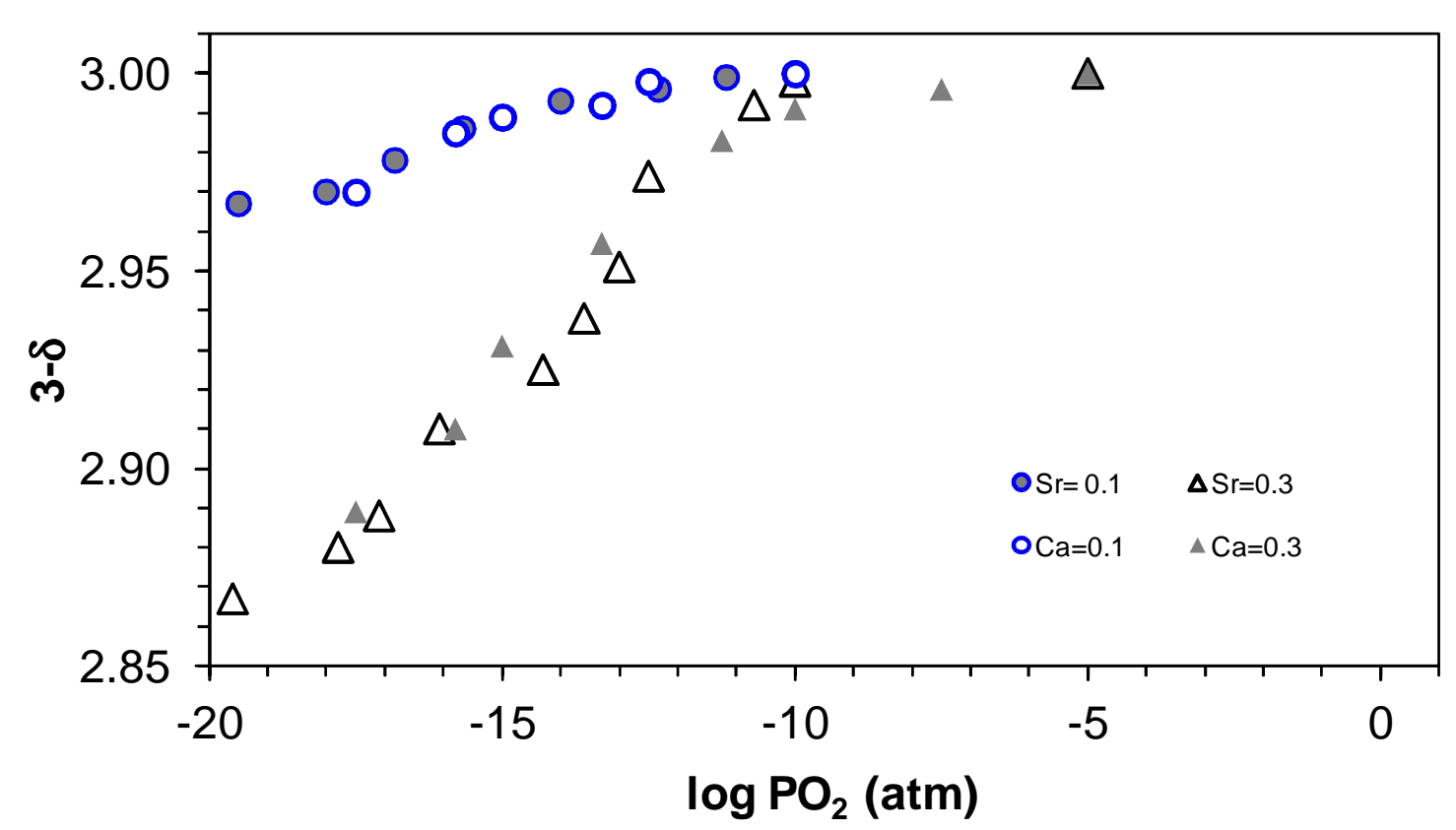

(a)

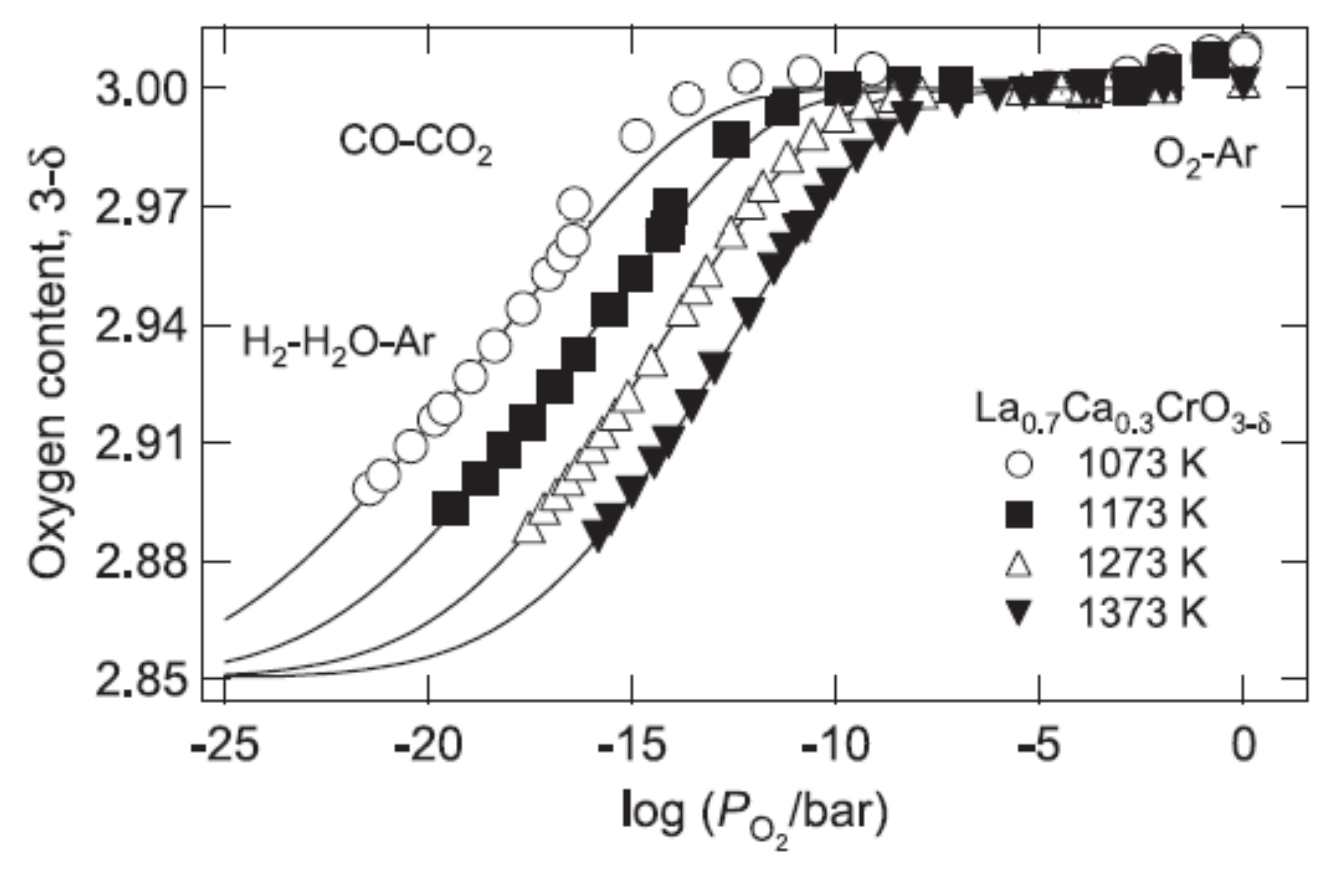


(b)

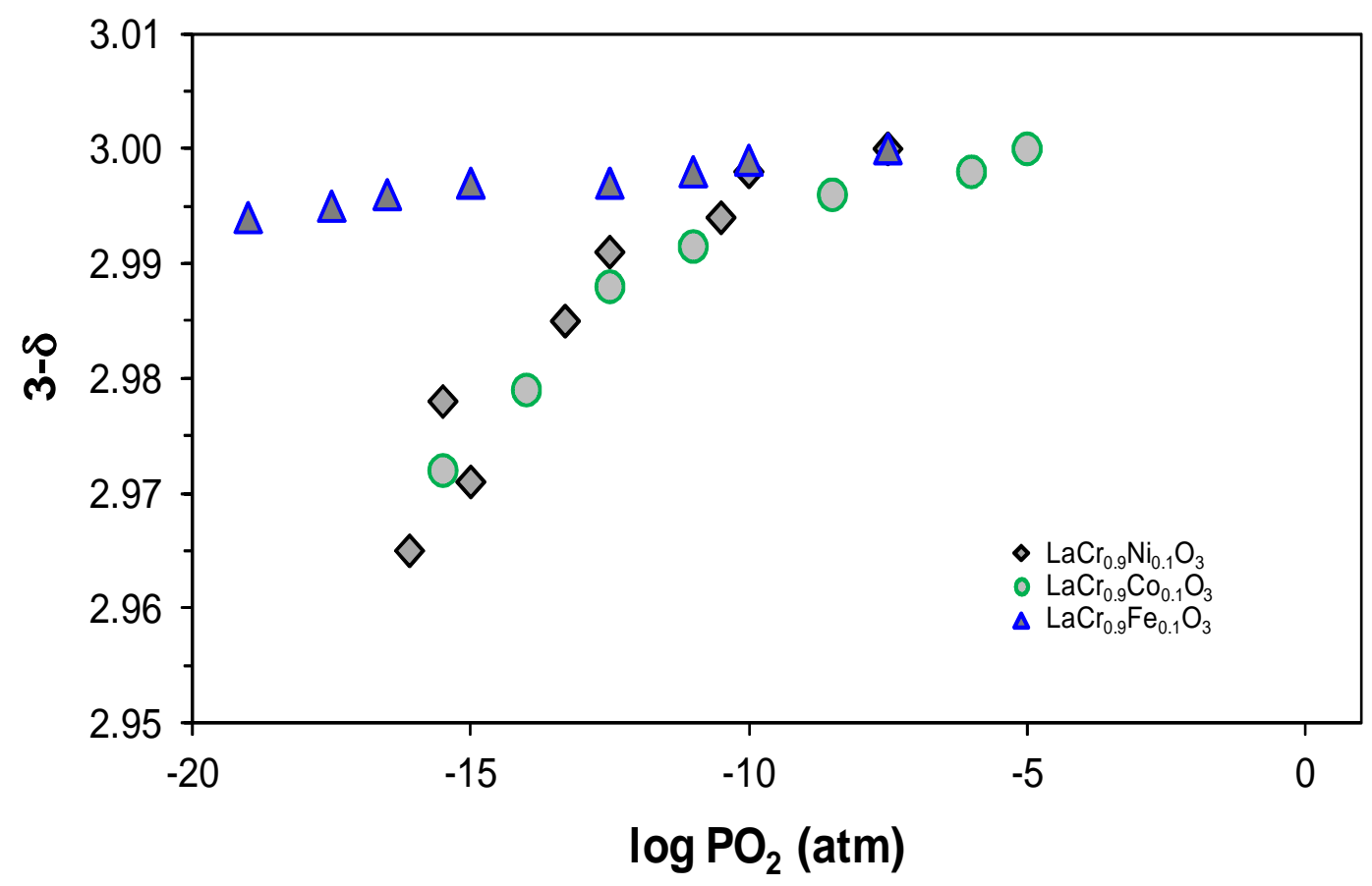

(c)

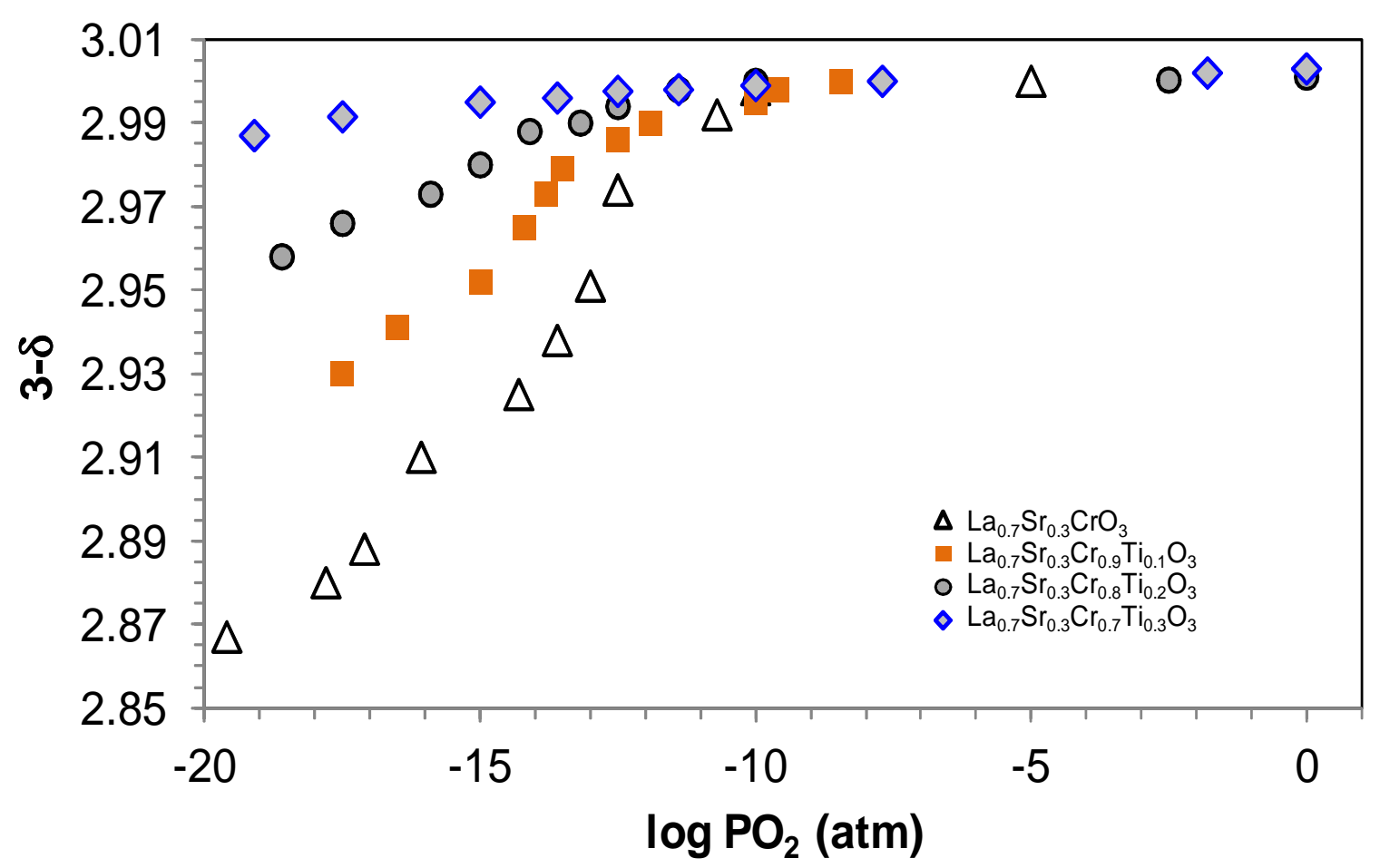


(d)

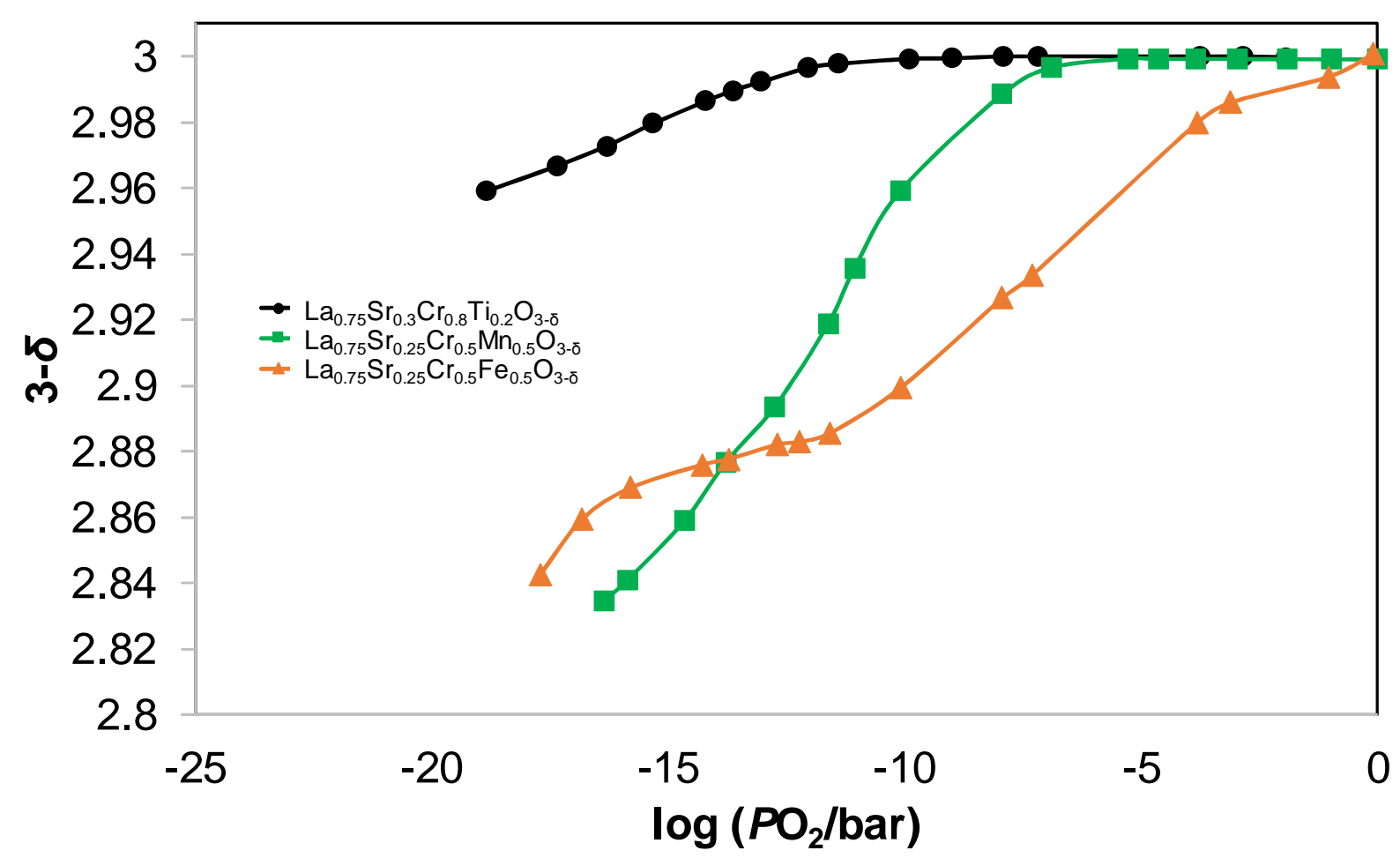

(e)

Fig. 20. Oxygen non-stoichiometry of $\mathrm{La}_{1-x} \mathrm{~A}_{x} \mathrm{Cr}_{1-y} \mathrm{~B}_{y} \mathrm{O}_{3-\delta}$ : a) A-site (Sr/Ca) doping; b) variation with temperature, c) B-site doping (Fe/Ni/Co), and d) Simultaneous A ( $\mathrm{Sr}$ ) and B-site (Ti) doping e) Simultaneous A ( $\mathrm{Sr})$ and B-site (Ti/Mn/Fe) at $1000^{\circ} \mathrm{C}$ [138-142]. 
Fig. 21

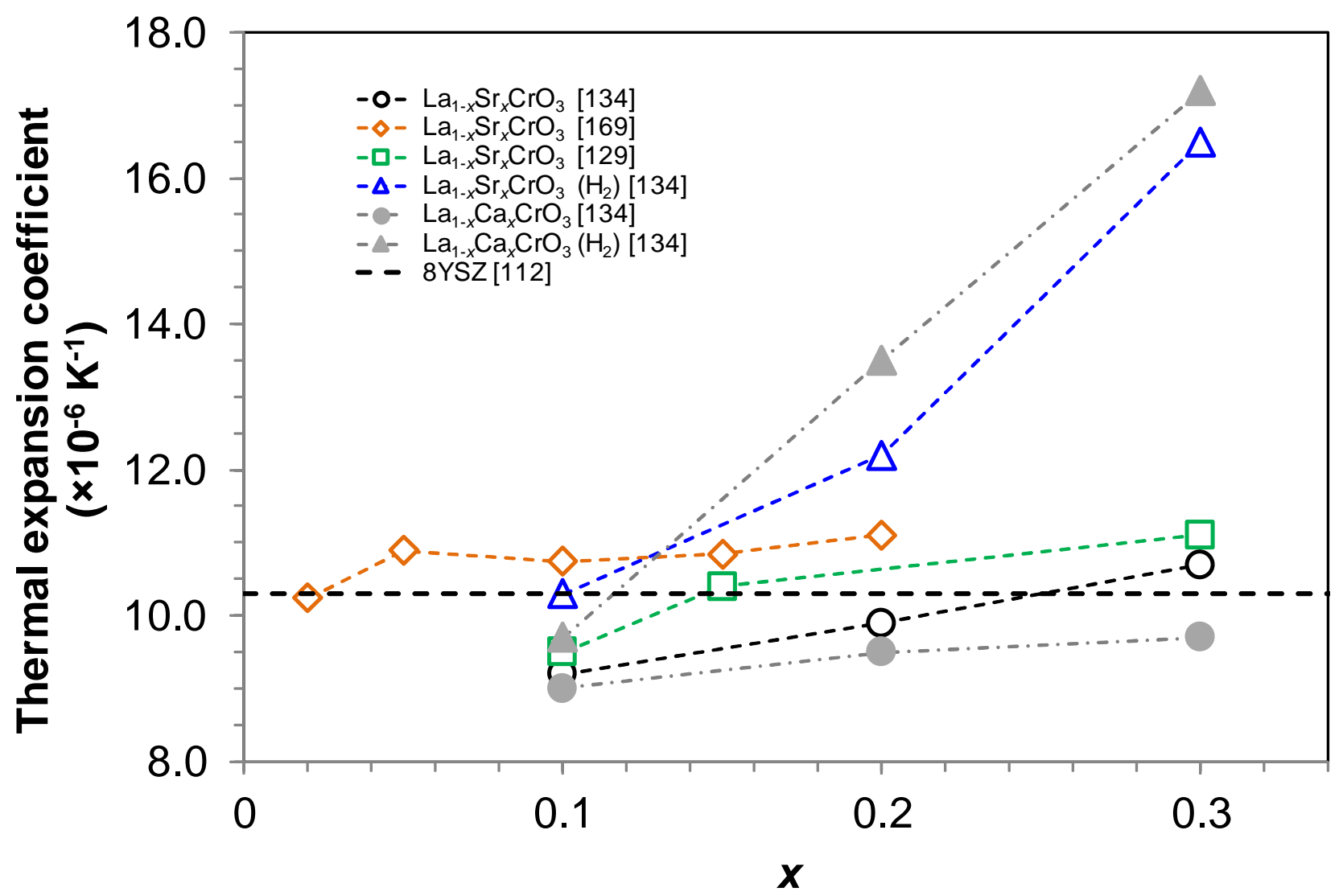

Fig. 21. Thermal expansion coefficient of $\mathrm{La}_{1-x}(\mathrm{Sr} / \mathrm{Ca})_{x} \mathrm{CrO}_{3}$ in air and $\mathrm{H}_{2}$ with $8 \mathrm{YSZ}$ [112,129,134,169] 
Fig. 22
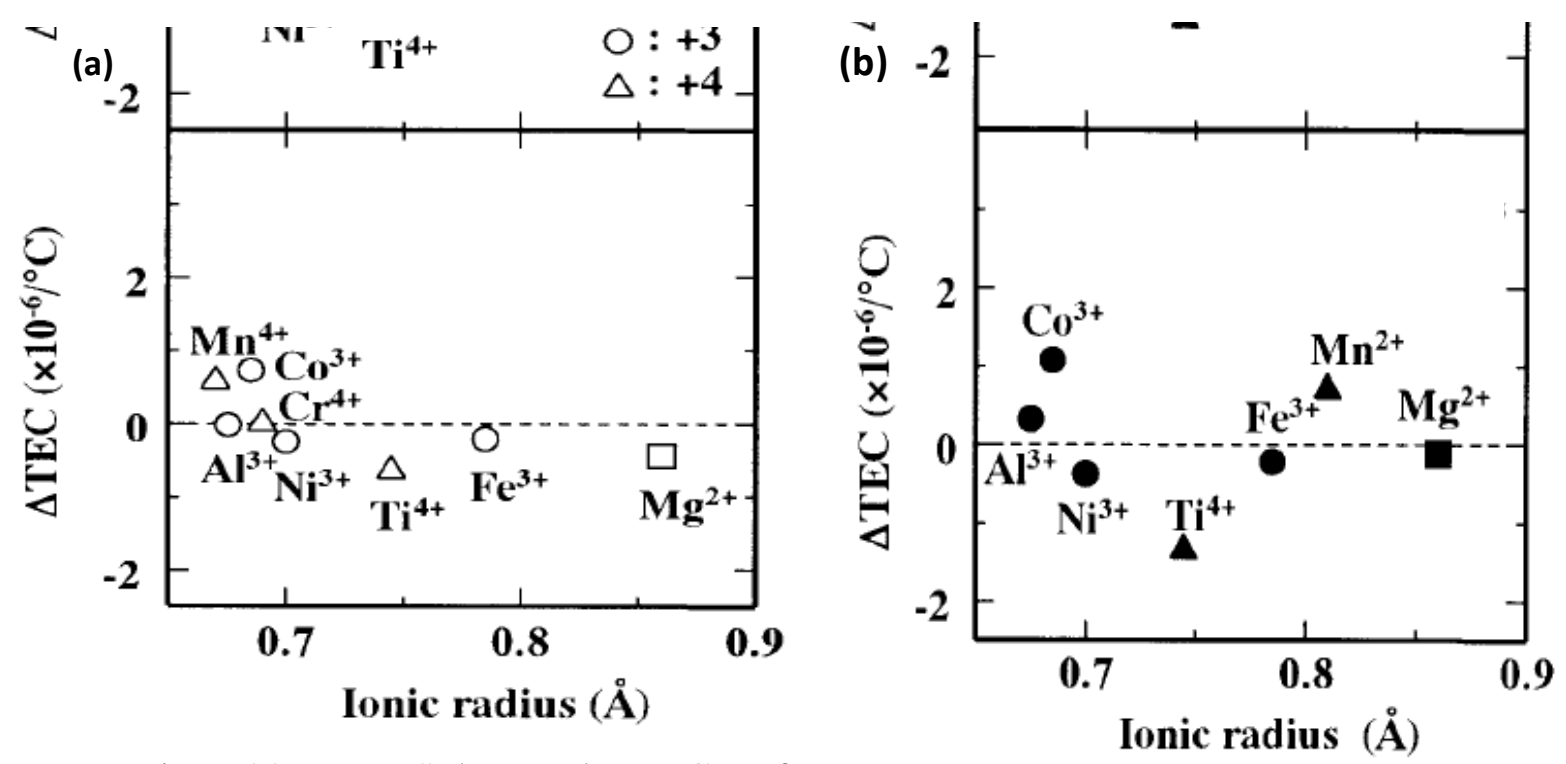

Fig. 22. a) Subtracted TEC of $\mathrm{La}_{0.9} \mathrm{Sr}_{0.1} \mathrm{Cr}_{1-x} \mathrm{M}_{x} \mathrm{O}_{3}(x=0.05 ; \mathrm{M}=\mathrm{Mg}, \mathrm{Al}, \mathrm{Ti}, \mathrm{Mn}, \mathrm{Fe}, \mathrm{Co}, \mathrm{Ni})$ with $\mathrm{La}_{0.9} \mathrm{Sr}_{0.1} \mathrm{CrO}_{3}$ versus ionic radii of B-site dopant in air and b) $\mathrm{H}_{2}$ atmosphere. The subtracted zero TEC values correspond to the broken line [Reprinted from reference 112 with permission]. 
Fig. 23

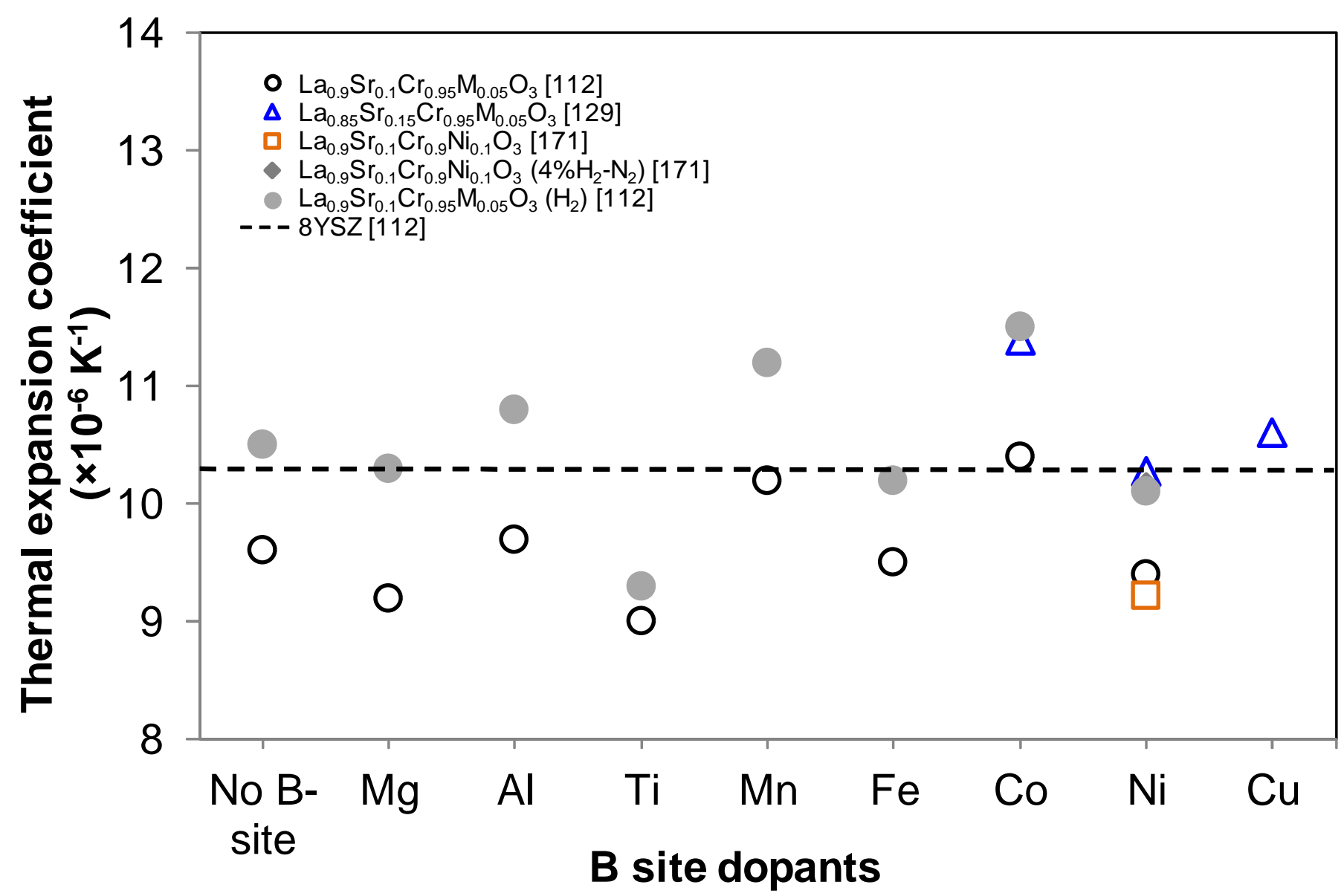

Fig. 23. Comparison of thermal expansion coefficient of A-site ( $\mathrm{Sr})$ and B-site $(\mathrm{M}=\mathrm{Mg}$, $\mathrm{Al}, \mathrm{Ti}, \mathrm{Mn}, \mathrm{Fe}, \mathrm{Co}, \mathrm{Ni}, \mathrm{Cu})$ doped $\mathrm{LaCrO}_{3}$ with (----) $8 \mathrm{YSZ}$ in air and $\mathrm{H}_{2}\left(\sim 50-1000^{\circ} \mathrm{C}\right)$ $[112,129,171]$. 
Fig. 24

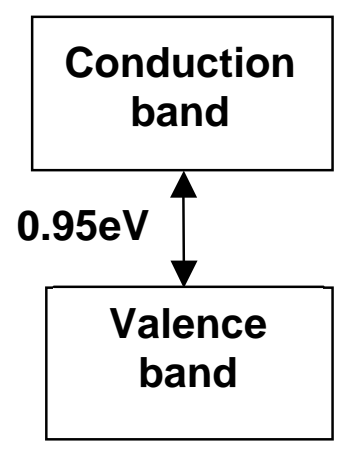

a) $\mathrm{LaCrO}_{3}$

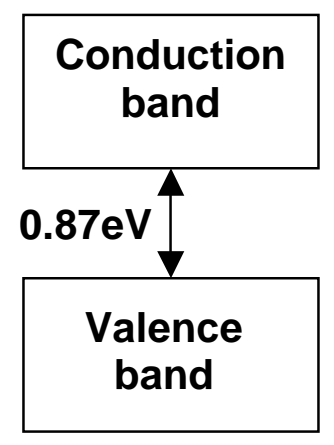

b) $\mathrm{La}_{1-x} \mathrm{Ba}_{x} \mathrm{CrO}_{3-x / 2}$
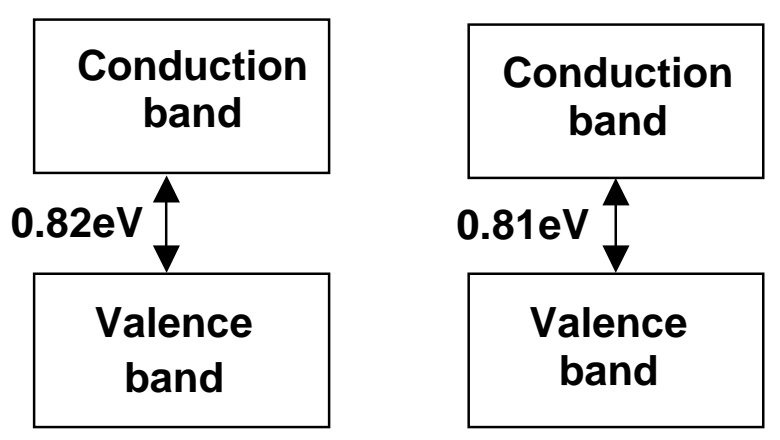
c) $\mathrm{La}_{1-x} \mathrm{Sr}_{x} \mathrm{CrO}_{3-x / 2}$
d) $\mathrm{La}_{1-x} \mathrm{Ca}_{x} \mathrm{CrO}_{3-x / 2}$

Fig. 24. Electronic band structure of $\mathrm{LaCrO}_{3}$ and $\mathrm{La}_{1-x} \mathrm{M}_{x} \mathrm{CrO}_{3-x / 2}(\mathrm{M}=\mathrm{Ba}, \mathrm{Ca}$ and $\mathrm{Sr})$. 
Fig. 25

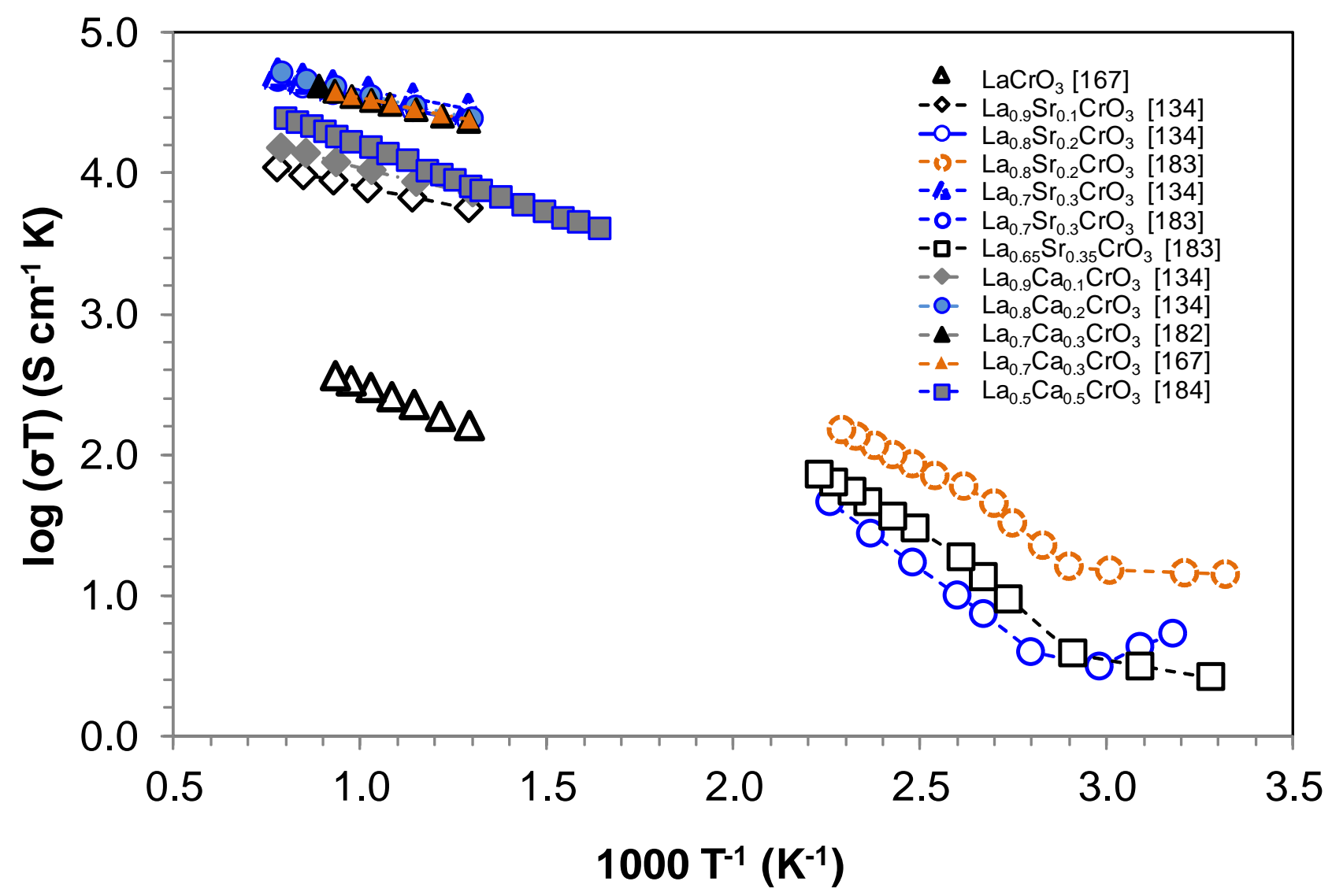

(a) 


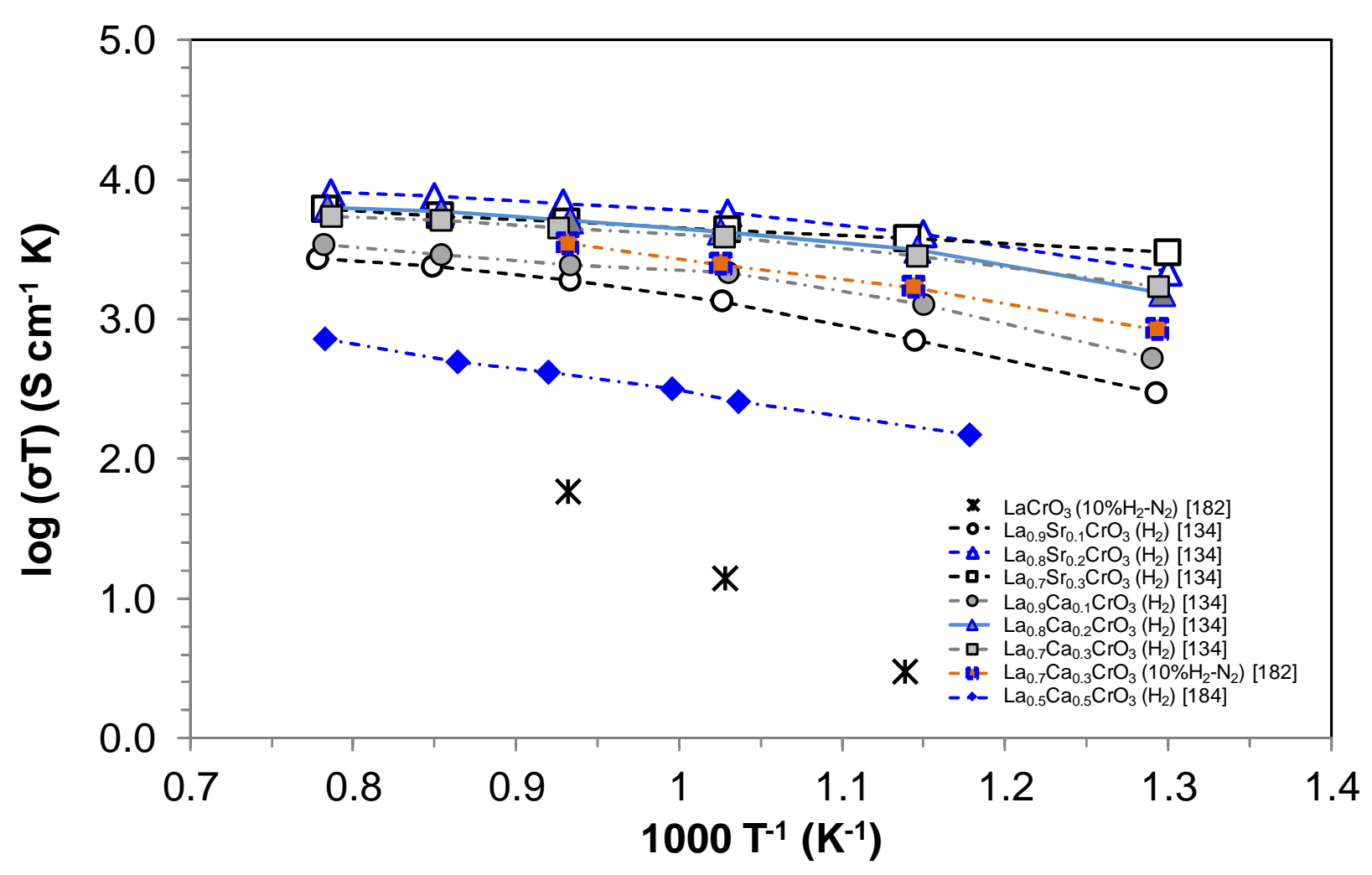

(b)

Fig. 25. Electrical conductivity of A-site ( $\mathrm{Sr}, \mathrm{Ca}$ ) doped $\mathrm{LaCrO}_{3}$ as a function of temperature with various dopant levels: (a) air, (b) $\mathrm{H}_{2}$ atmosphere [134,167,182-184]. 
Fig. 26

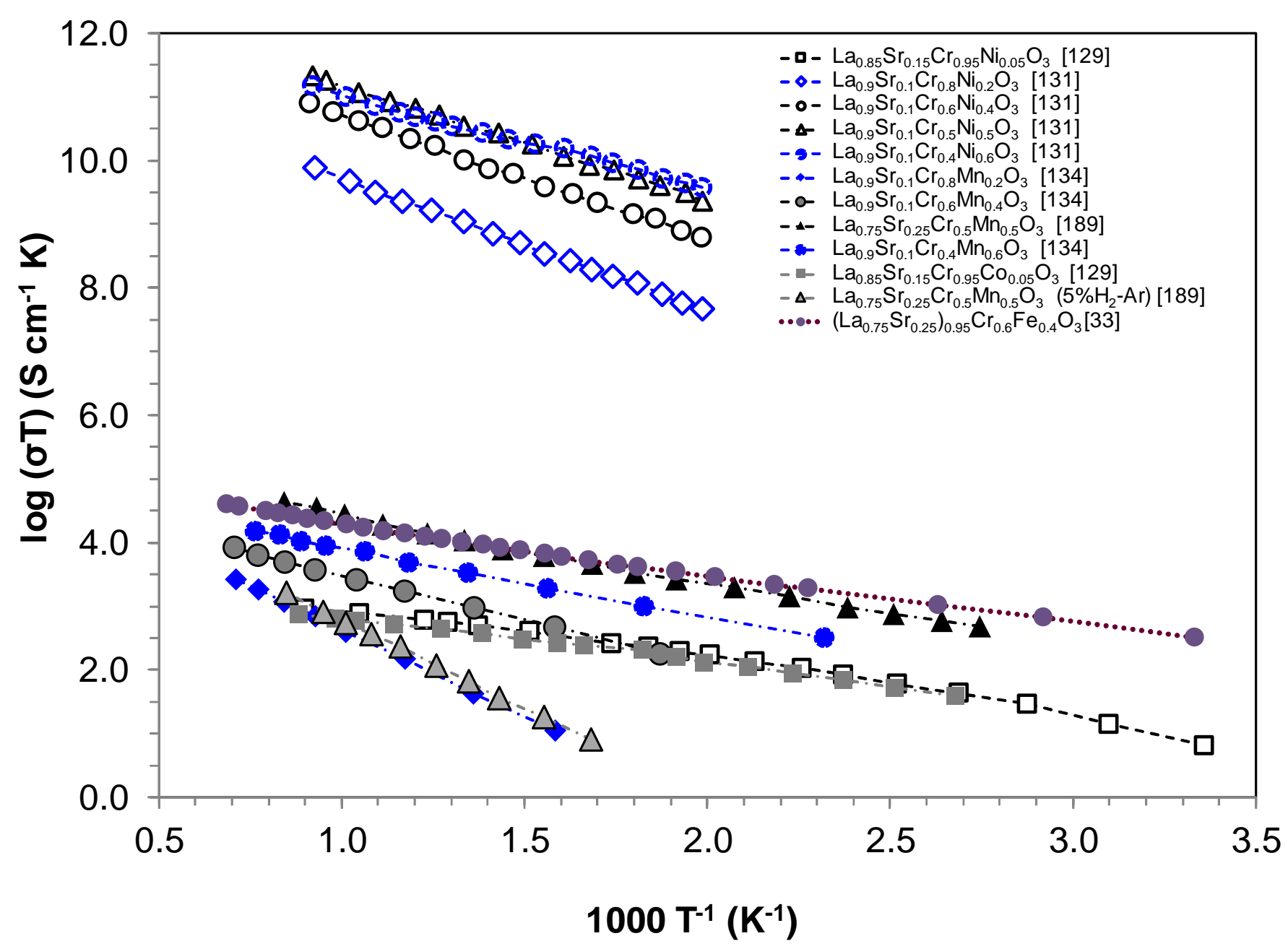

Fig. 26. Electrical conductivity of A-site ( $\mathrm{Sr})$ and $\mathrm{B}$-site $(\mathrm{Ni}, \mathrm{Mn}, \mathrm{Co}, \mathrm{Fe})$ doped $\mathrm{LaCrO}_{3}$ as a function of temperature with various dopant levels $[33,129,131,134,189]$. 
Fig. 27

(a)

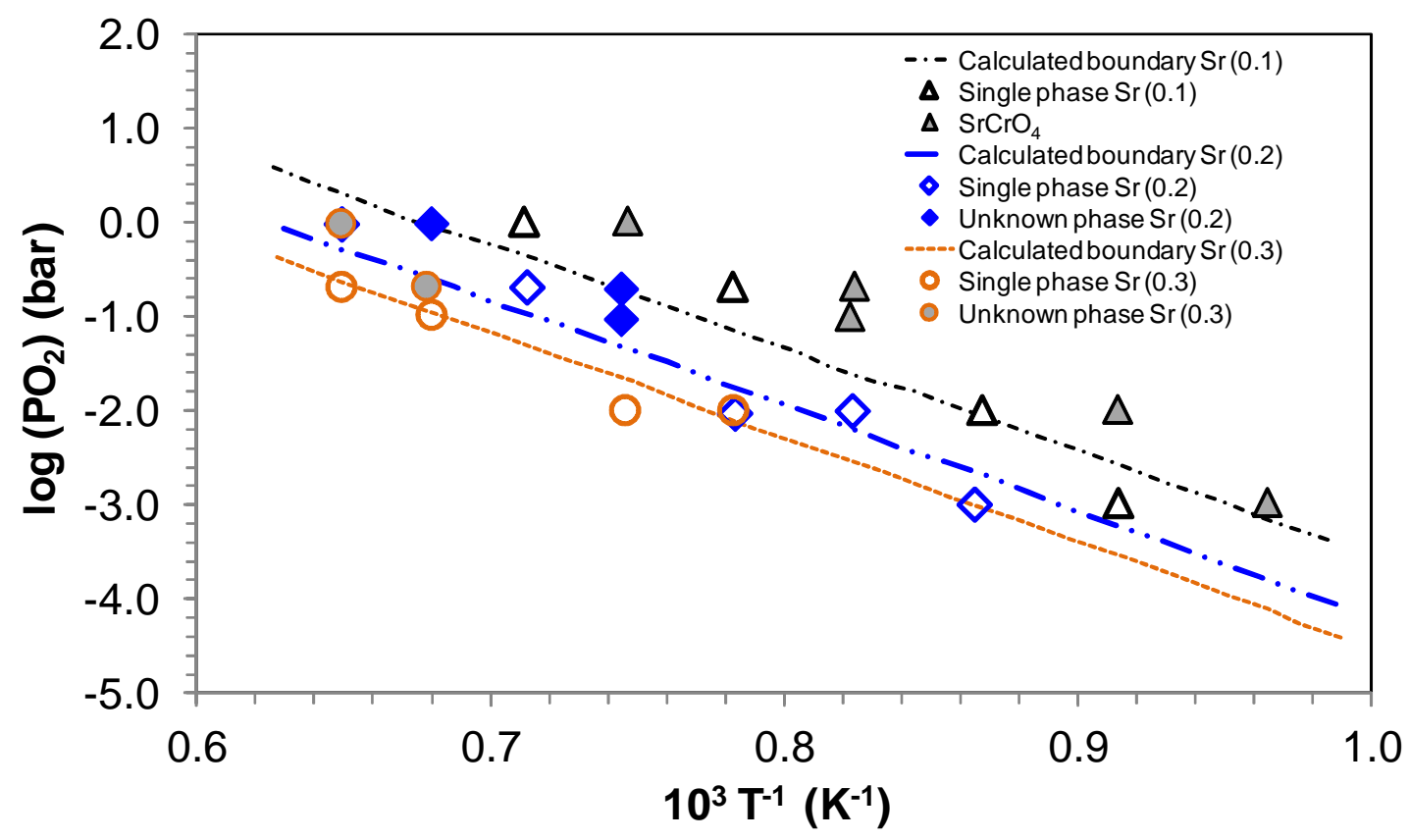

(b)

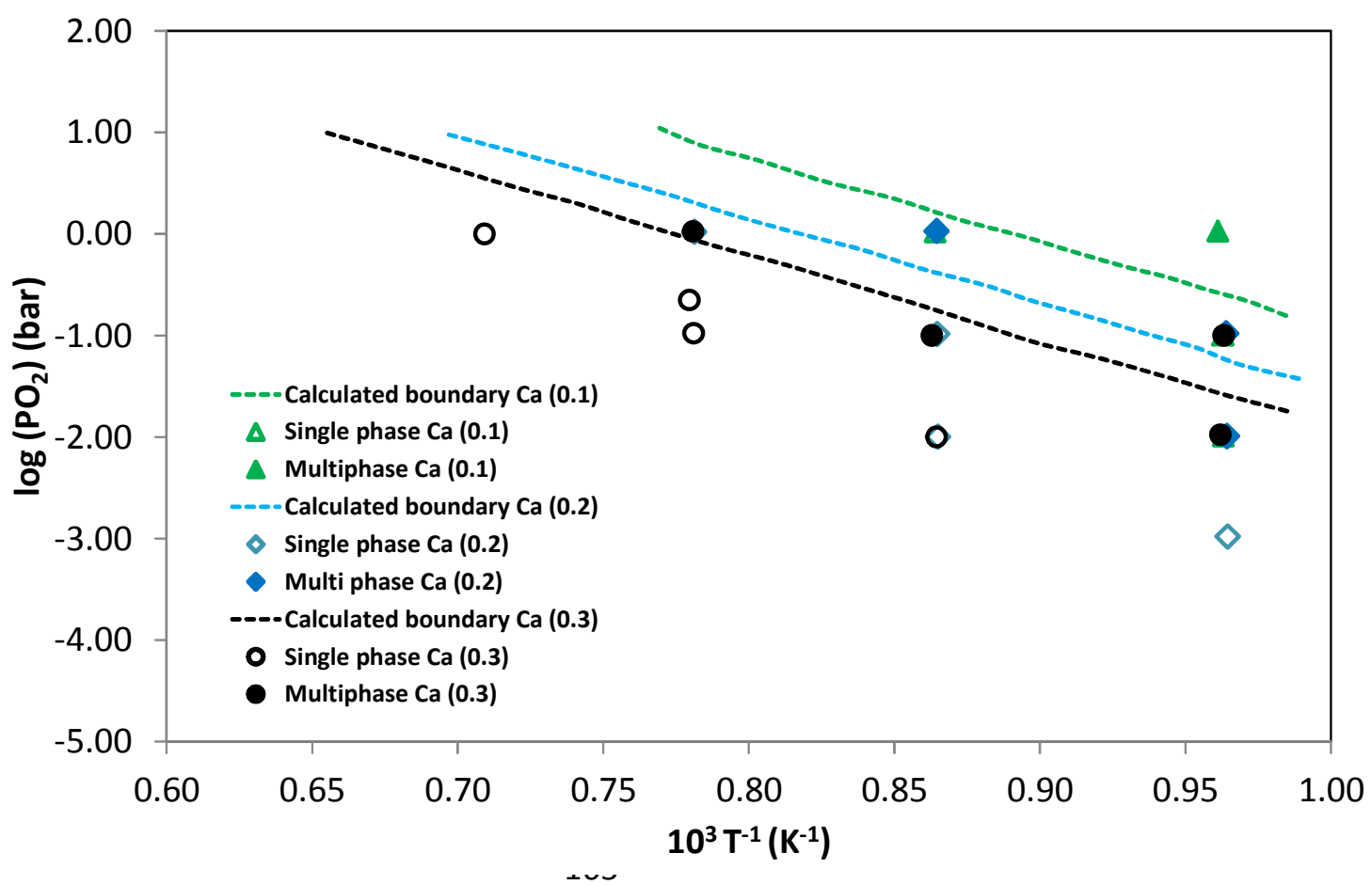


Fig. 27. Solid solubility limit of A-site ( $\mathrm{Sr}, \mathrm{Ca})$ dopants in $\mathrm{LaCrO}_{3}$ with $\mathrm{PO}_{2}$ and temperature: a) Sr-dopant level, (b) Ca-dopant level [Reproduced from references 231,234 with permission]. 
Fig. 28

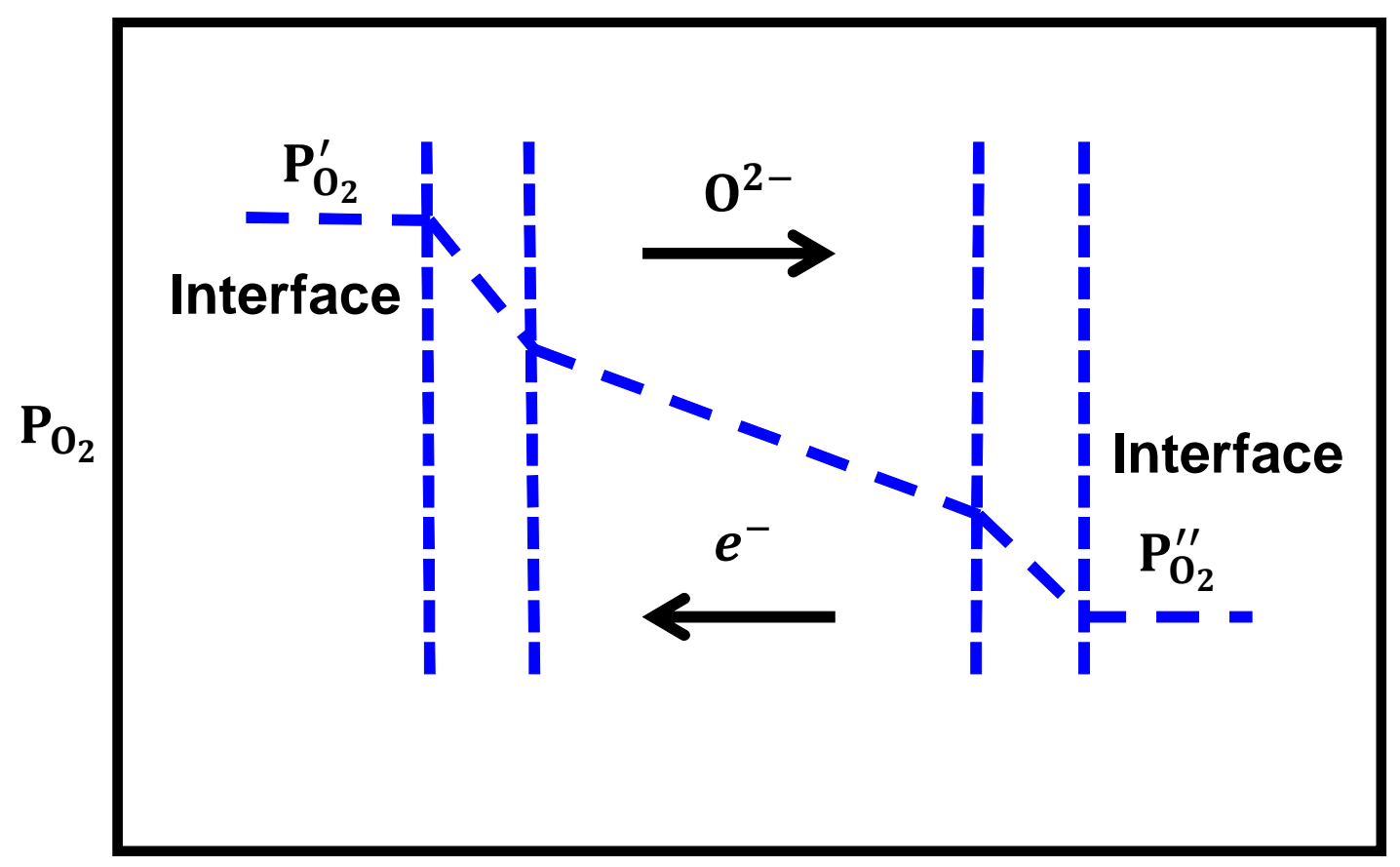

Fig. 28. Oxygen transport steps during oxygen permeation through a dense MIEC [204]. 
Fig. 29

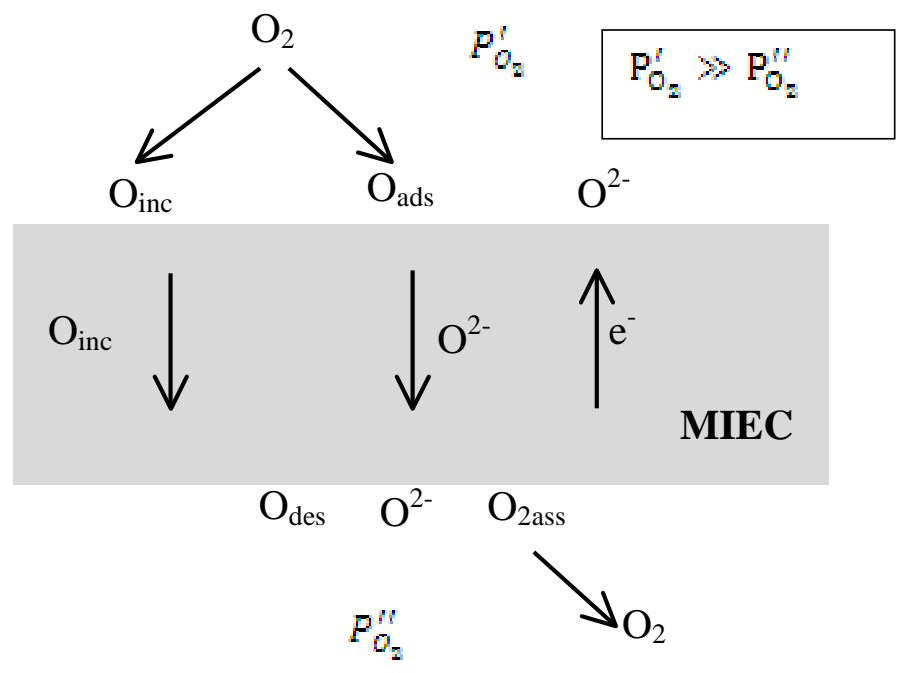

Fig. 29. Schematic of different steps involved in surface exchange for oxygen reduction and its diffusion in OTM. 
Fig. 30

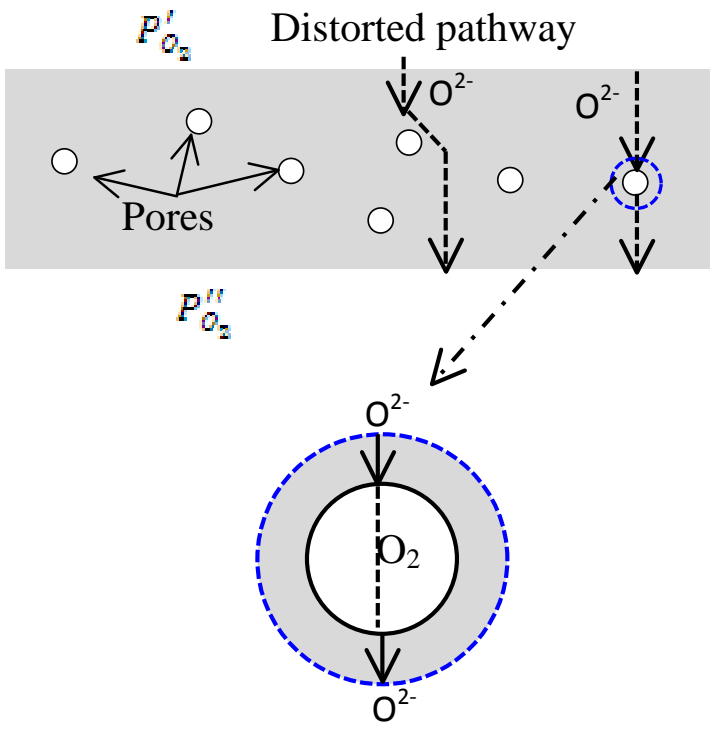

Fig. 30. Schematic of bulk diffusion path for OTM with closed pores. [206] 
Fig. 31

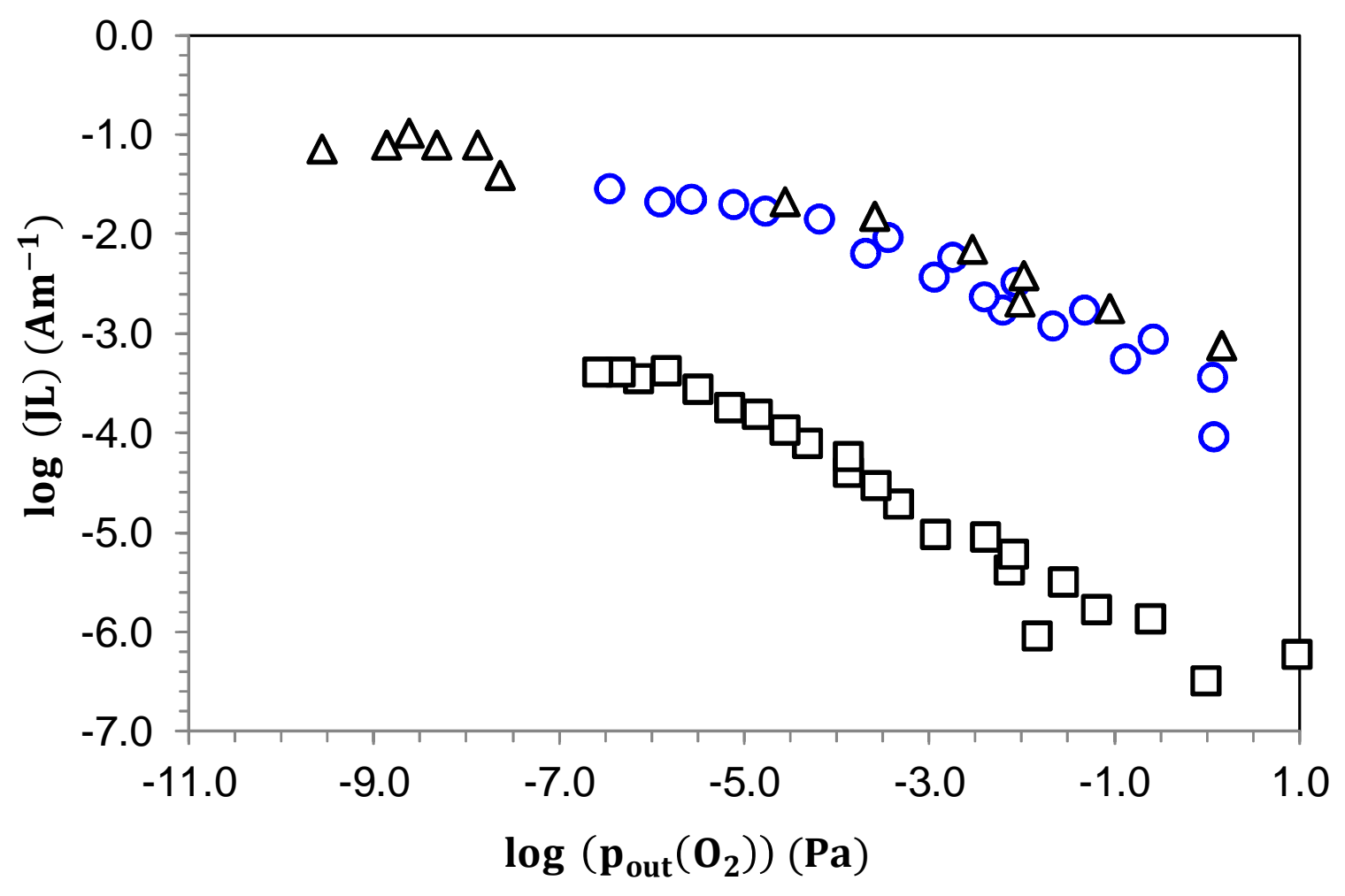

Fig. 31. Effect of calcium content on normalized permeation flux (JL), $(0, \Delta) \mathrm{La}_{0.75} \mathrm{Ca}_{0.25} \mathrm{CrO}_{3-\delta},(\square) \mathrm{La}_{0.9} \mathrm{Ca}_{0.1} \mathrm{CrO}_{3-\delta}, \mathrm{T}=1000^{\circ} \mathrm{C}$ (Reproduced from reference 212 with permission). 
Fig. 32

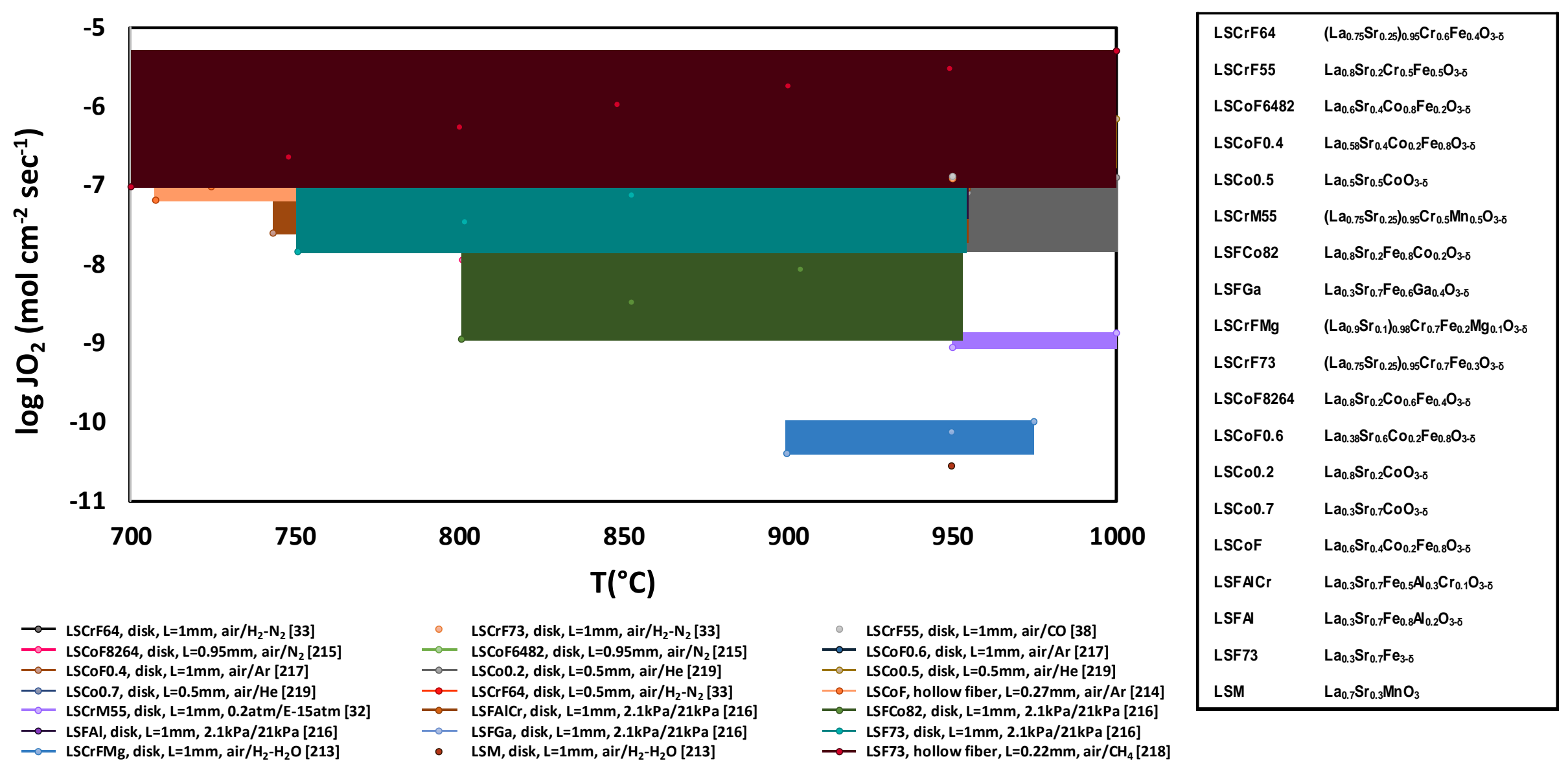

Fig. 32. Oxygen flux of various perovskite phase OTM (lanthanum chromites/manganites/ferrites/cobaltites) as a function of

temperature $\left(700-1000^{\circ} \mathrm{C}\right)[32-33,38,213-219]$. 
Fig. 33

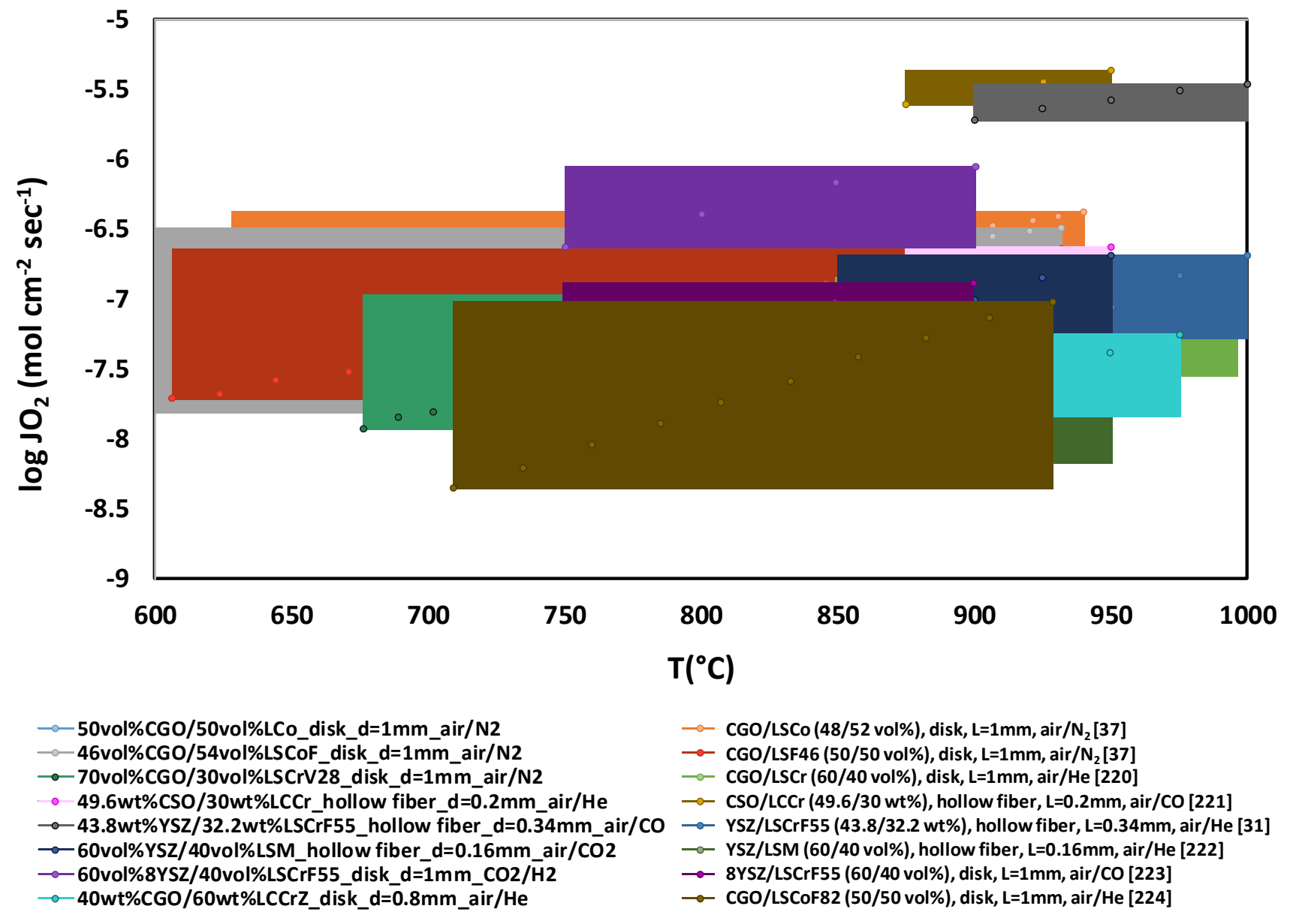

\begin{tabular}{|ll|}
\hline CGO7 & $\mathrm{Ce}_{0.9} \mathrm{Gd}_{0.1} \mathrm{O}_{1.95}$ \\
YSZ & $\mathrm{Zr}_{0.84} \mathrm{Y}_{0.16} \mathrm{O}_{1.92}$ \\
CSSZ & $\mathrm{Zr}_{0.8} \mathrm{Y}_{0.2} \mathrm{O}_{2-\delta}$ \\
LCo & $\mathrm{Ce}_{0.8} \mathrm{Sm}_{0.2} \mathrm{O}_{2-\delta}$ \\
LSCo & $\mathrm{LaCoO}_{3}$ \\
LSCoF & $\mathrm{La}_{0.6} \mathrm{Sr}_{0.4} \mathrm{CoO}_{3-\delta}$ \\
LSCrV28 & $\left.\mathrm{La}_{0.6} \mathrm{Sr}_{0.4}\right)_{0.99} \mathrm{Co}_{0.2} \mathrm{Fe}_{0.8} \mathrm{O}_{3-\delta}$ \\
LCCr & $\mathrm{La}_{0.75} \mathrm{Sr}_{0.25} \mathrm{Cr}_{0.97} \mathrm{~V}_{0.03} \mathrm{O}_{3-\delta}$ \\
LSM & $\mathrm{La}_{0.7} \mathrm{Ca}_{0.3} \mathrm{Cr}_{0.4} \mathrm{O}_{3-\delta}$ \\
LSCrF55 & $\mathrm{La}_{0.8} \mathrm{Sr}_{0.2} \mathrm{MnO}_{3}$ \\
LCCrZ & $\mathrm{La}_{0.8} \mathrm{Sr}_{0.2} \mathrm{Cr}_{0.5} \mathrm{Fe}_{0.5} \mathrm{O}_{3-\delta}$ \\
LSF46 & $\mathrm{La}_{0.7} \mathrm{Ca}_{0.3} \mathrm{Cr}_{0.95} \mathrm{Zn}_{0.05} \mathrm{O}_{3-\delta}$ \\
LSCr & $\mathrm{La}_{0.6} \mathrm{Sr}_{0.4} \mathrm{Fe}_{0.8} \mathrm{O}_{3-\delta}$ \\
LSCF50 & $\mathrm{La}_{0.8} \mathrm{Sr}_{0.2} \mathrm{CrO}_{3-\delta}$ \\
\hline
\end{tabular}

Fig. 33. Oxygen flux of

various dual phase (perovskite-fluorite) OTM (lanthanum chromites/manganites/ferrites/cobaltites and YSZ/CGO/CSO) as a

function of temperature $\left(600-1000^{\circ} \mathrm{C}\right)[31,37,220-225]$. 